\title{
Exploring Teachers' Approaches to Science Practical Work in Lower Secondary Schools in Malaysia
}

By

Siti Shamsiah Binti Sani

A thesis submitted to Victoria University of Wellington in fulfilment of the requirements for the degree of Doctor of Philosophy

Victoria University of Wellington 2014 



\begin{abstract}
Practical work in science is a teaching approach that aims to enable students to develop procedural and conceptual understanding and an understanding about the nature of science. Practical work is required by the Malaysian Science Curriculum at all school levels. The purpose of this research was to gain an understanding of teachers' views and practices in conducting practical work in lower secondary schools. This research, which adopted a case study approach, was underpinned by constructivist views of learning and investigated the phenomenon of practical work in three co-educational schools in the state of Melaka. The participants were three science teachers and their classes of about 35 students each. Data were collected through teacher interviews, classroom observations, document analysis and focus group interviews with students. Findings suggest that teachers' understanding about practical work were aligned with their purposes for conducting practical work. Practical work that teachers offered promoted low levels of inquiry and at best students were developing a view that in science we follow a set of procedures to arrive at a well-known conclusion. Teachers' practices were constrained by limited resources, prescribed texts, the amount of content to be taught, and their science content knowledge. Student learning was constrained by the limited exposure to authentic science investigation, low teacher expectation, a focus on hands-on rather than minds-on learning, and the language of instruction. The findings have implications for teacher practice and science education policy for lower secondary schools in Malaysia.
\end{abstract}




\section{Acknowledgment}

All praises are due to Allah swt the most beneficent and merciful, blessing and salutation upon Prophet Muhammad pbuh. May Allah swt bless the ummah around the world in the dunya and the akhirah.

I would like to thank the Ministry of Education, Malaysia who provided a Doctoral Scholarship that enabled me to pursue my studies at Victoria University of Wellington, New Zealand. I acknowledged Victoria University of Wellington for awarding me the University's Submission Scholarship and Education Faculty Grant. I extend my gratitude to Universiti Pendidikan Sultan Idris for granting me the study leave. Special thanks to Malaysian Students Department in Wellington for their assistance.

My deepest appreciation goes to both of my supervisors, Associate Professor Dr Joanna Higgins and Dr Azra Moeed. They offered guidance in completing this thesis by allowing me to explore the data, making mistakes and learn from those mistakes, and helping me to see things from different perspectives. I also really appreciate their advice and the many hours and energies they have given to see this thesis complete.

My special thanks also go to my participants who were willing to take part in my study. Without them, this thesis would not have been possible. I feel so honoured to be in the classrooms.

Thank you to Kak Azizah and her family who has treated me as her own sister. Your support and love help me to adapt in a new environment and go through ups and downs in completing this journey for all these years. My special thanks to my fellow Malaysian friends and families in Wellington especially Sya, Yana, Nurul, Farha, Naj, Syerina, Kak Sai, Kak Shidah, Kak Bell, Kak lia, and Kak Haniem for encouragement, stories, and laughs that we have shared together. Thank you for memories that we have experienced for the past few years.

To my postgraduate friends from all three houses especially residents at Room 10431 Campbell St.; Abdul, Thuy, Phoung, Kerese, and Jane who shared a similar journey, I thank you for being such a good listener and encouraging me to go through the hard time.

My dear friends Anoor, Dila, Ina, Iza, and Uza thanks for the updates while I am away from home.

Finally, this thesis is dedicated to my beloved mother Puan Hajjah Fatimah binti Md Derus, family members; Halizah, Aisha, Fauzi, Halima, Anuar, Mislin, Bahayah, Arriff, Afiq, Hazim, Adam, Aiman, Fateh, Fazlin, Fazlah, Najihah, Aqilah, Najwa, Irdina, Humairah, Amalina, 
Husna, Zulaikha, and Fairuz; and my dear Rohaizal who always be by my side and believe that I can complete this journey. To my late father En. Sani bin Kasim, may Allah swt grant you a paradise. Abah, I am proud to carry your name wherever I go. 


\section{Contents}

Abstract i

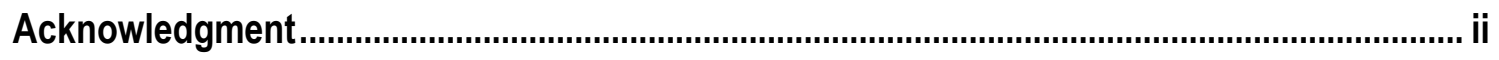

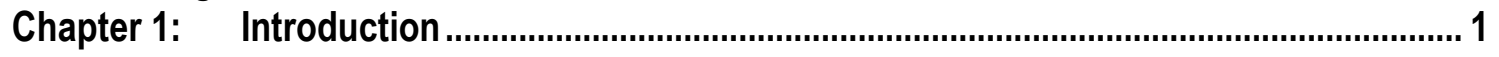

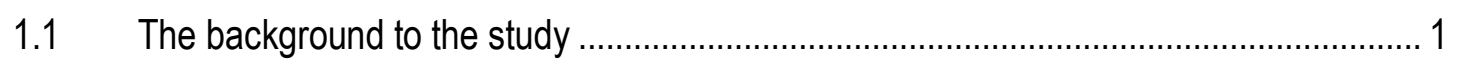

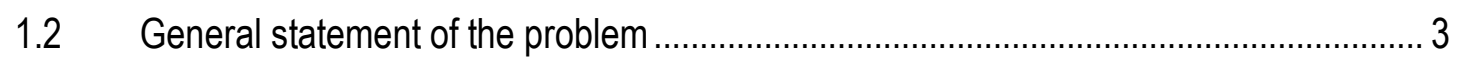

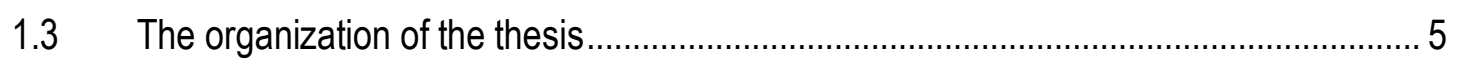



2.1 The landscape of the Malaysian education system ......................................................... 6

2.2 The development of science education in Malaysia ...................................................... 8

2.3 The Integrated Curriculum for Secondary Schools (Science) ..................................... 11

2.3.1 The organisation of the content ........................................................................ 13

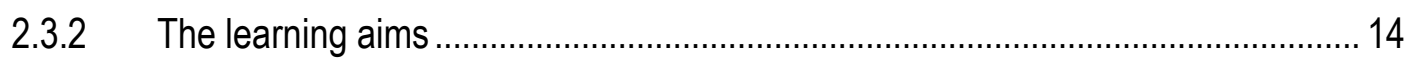

2.3.3 The science investigation/experiment in the integrated curriculum for

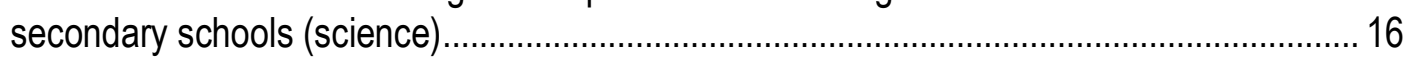

2.3.4 Practical assessment (Penilaian Kerja Amali-PEKA) .......................................... 17

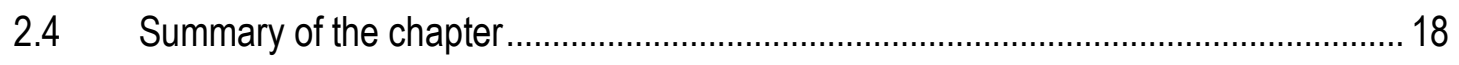

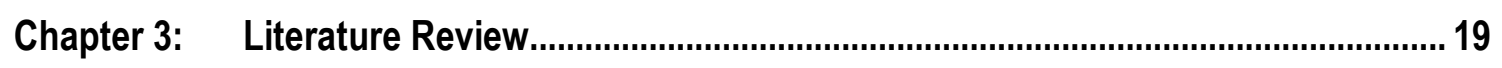

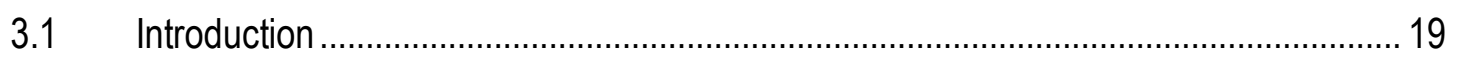

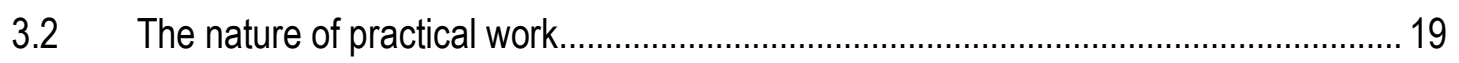

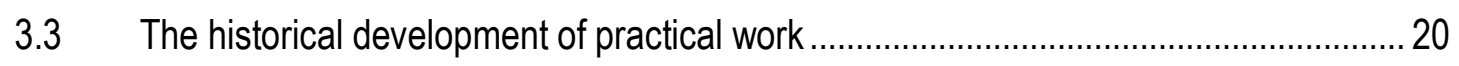

3.3.1 Teachers' views of practical work ....................................................................... 22

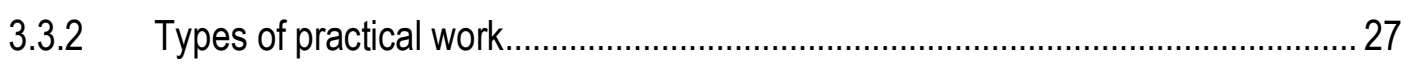

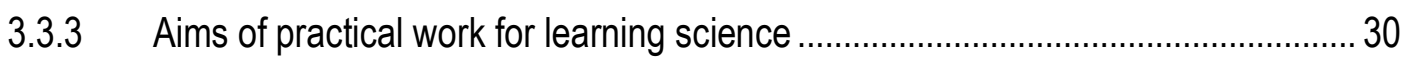

3.3.4 The relationship between aims in conducting practical work and their practices.. 33

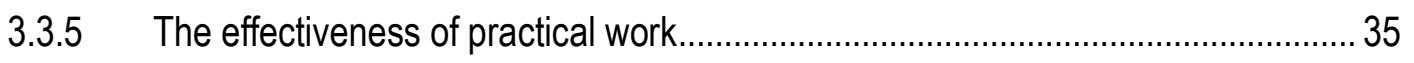

3.4 Studies of practical work in the Malaysian context ................................................... 41

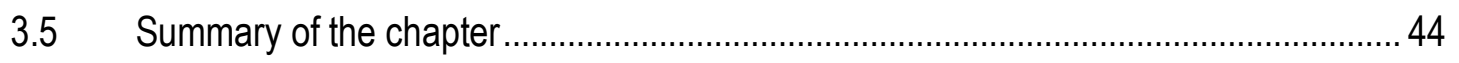

Chapter 4: The Theoretical Framework ........................................................................ 46

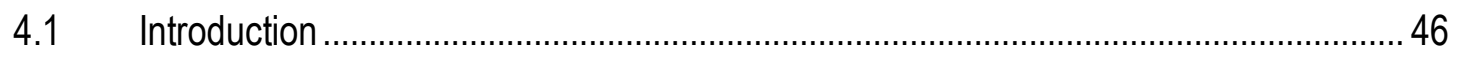

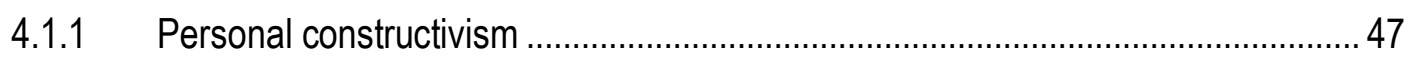



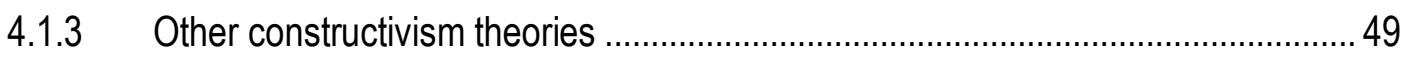

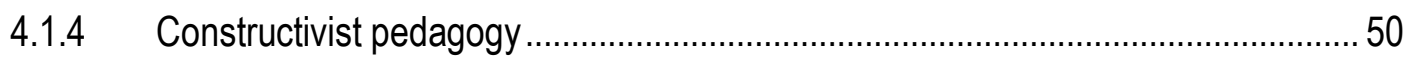

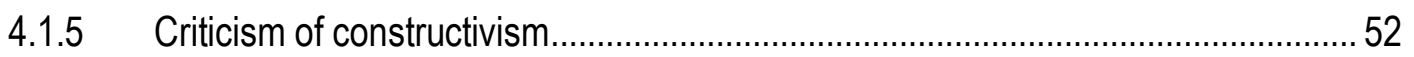


4.2 The difference between traditional and social constructivism classroom interaction... 53

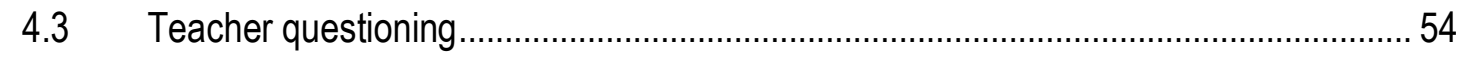

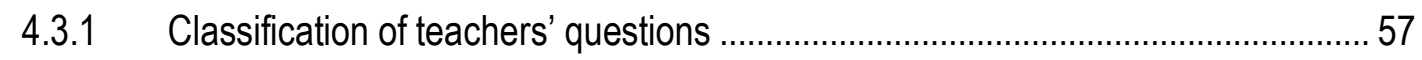

4.3.2 The framework for classroom interaction ........................................................... 58

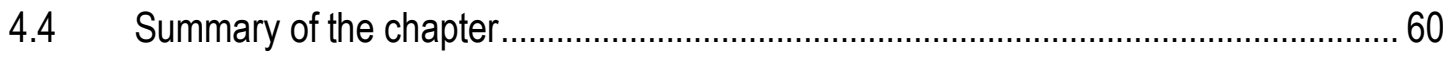

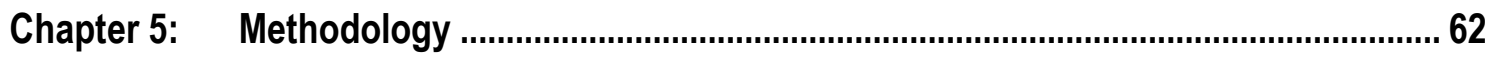

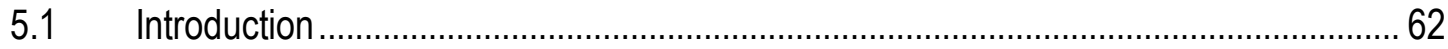

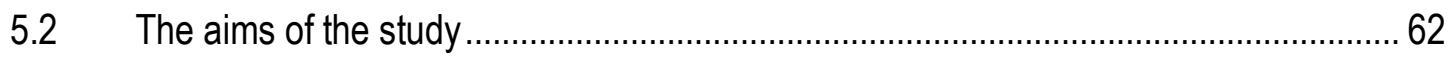

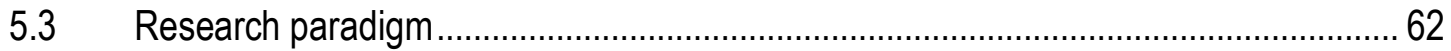

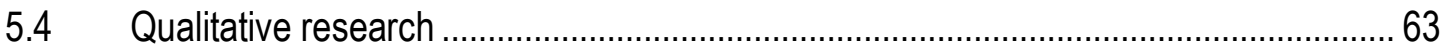

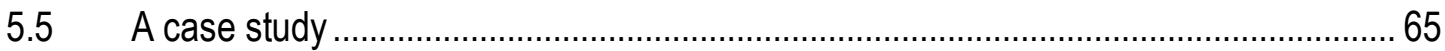

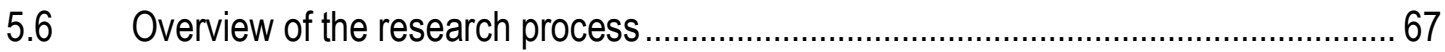

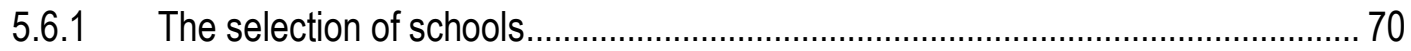

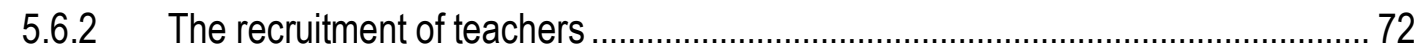

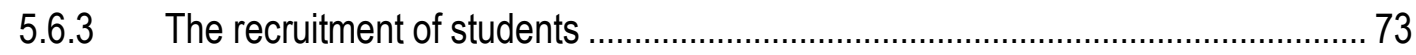

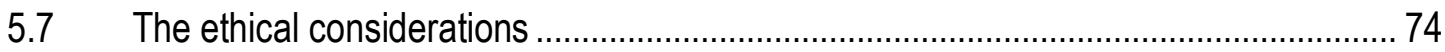

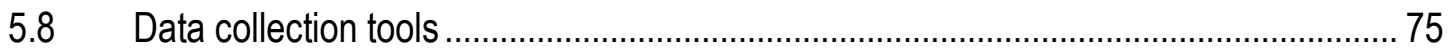

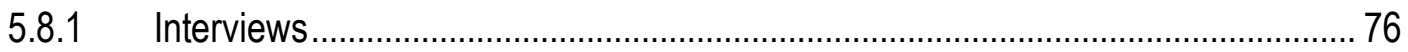

5.8.2 Semi-structured interviews with teacher participants............................................ 76

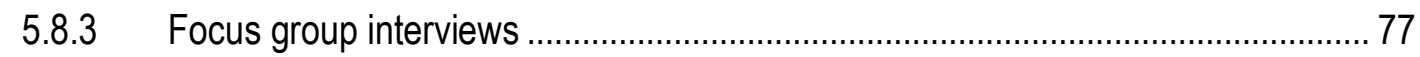

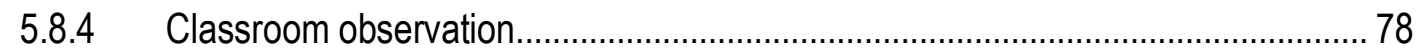

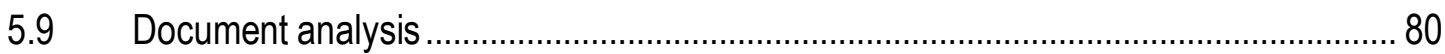

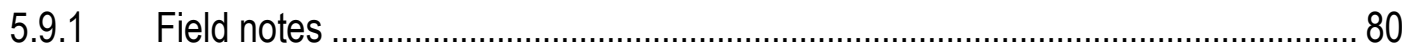

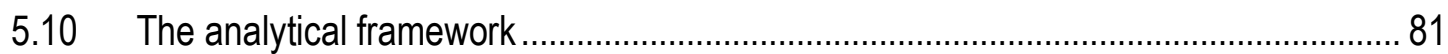

5.11 An analytical framework for investigating the effectiveness of practical tasks ............. 81

5.11.1 Framework A: Two domains of knowledge ........................................................ 82

5.11.2 Framework B: Two levels of effectiveness of practical work .................................. 82

5.11.3 Framework C: A 2x2 effectiveness matrix .......................................................... 84

5.11.4 Analysing the practical work task

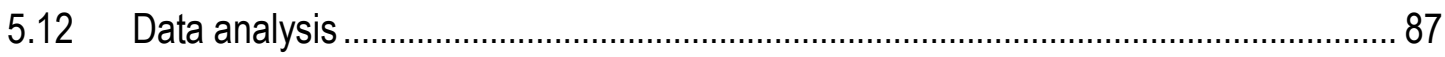

5.12.1 The approach to developing the categories and coding participants' views of

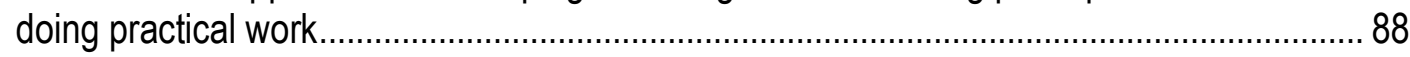

5.12.2 The approaches to developing the categories and coding of types of practical work

5.12.3 The discourse analytical framework .............................................................. 92






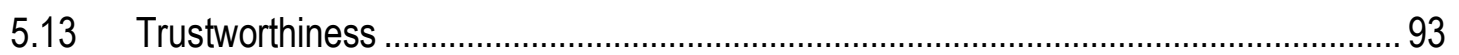

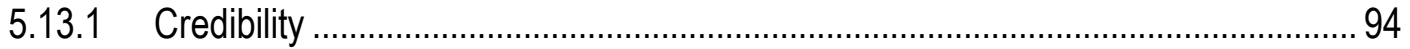

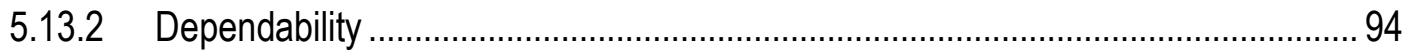

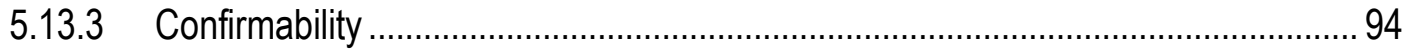

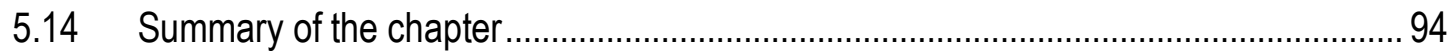

Chapter 6: Teachers' Opinions on Conducting Practical Work: Aims, Practices, and Considerations............................................................................................................................ 96

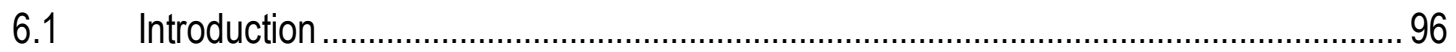

6.2 Stage One: Teachers' aims when conducting practical work...................................... 96

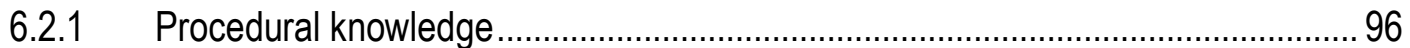

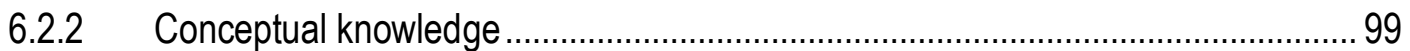

6.2.3 Essential skills (noble values) …..................................................................... 100

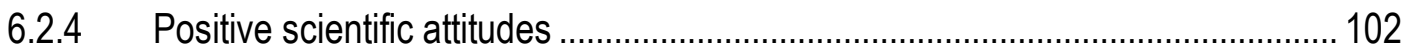

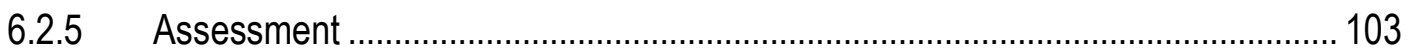

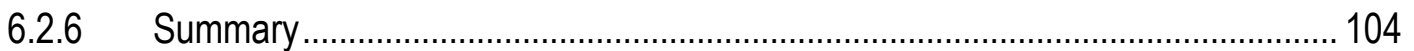

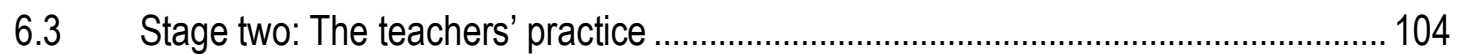

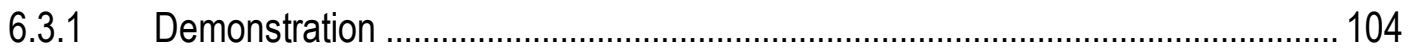

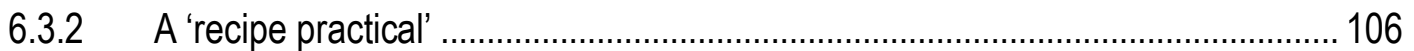

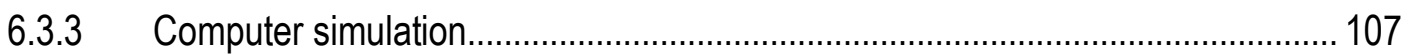

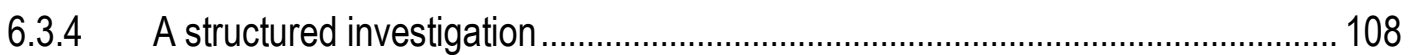

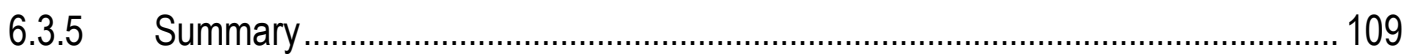

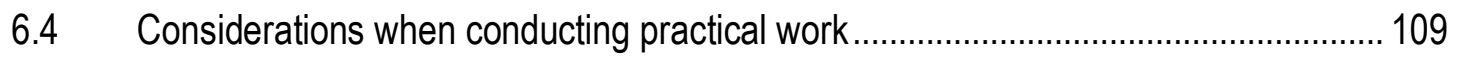

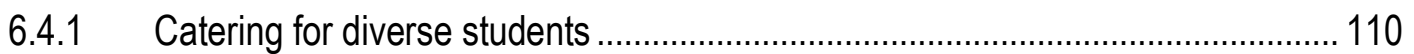

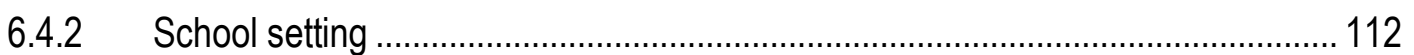

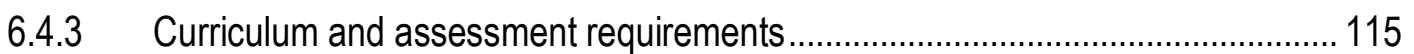

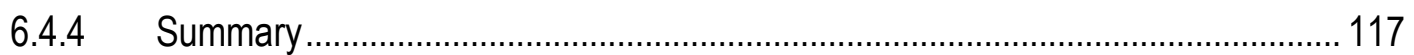

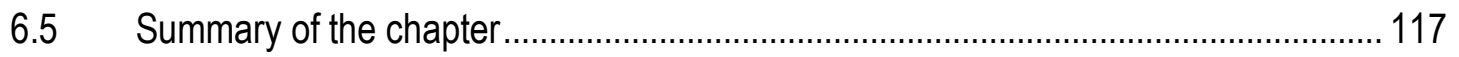

Chapter 7: Results of a Common Lesson Taught by all Three Case Study Teachers .. 119

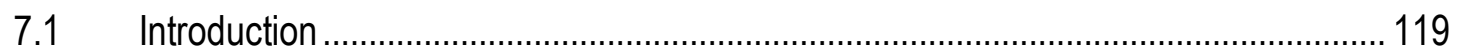

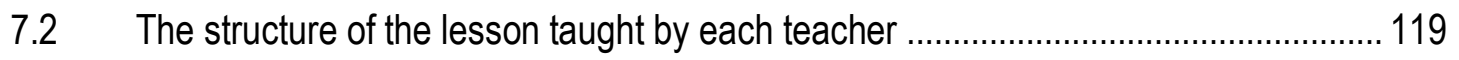

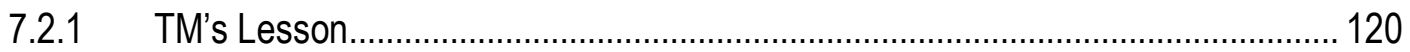

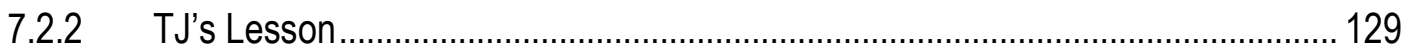

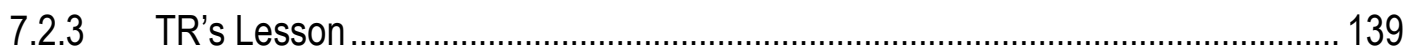

7.3 Similarities and differences in the teaching of the three lessons ................................ 148

7.3.1 Learning outcomes and teaching approaches .................................................... 148 
7.3.2 Types of practical work. 150

7.3.3 The effectiveness of practical work ............................................................. 153

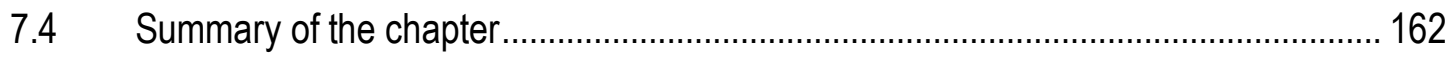

Chapter 8: $\quad$ The Teachers' Questions in Practical Lessons ........................................... 164

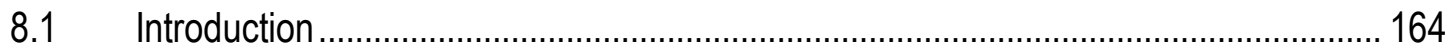

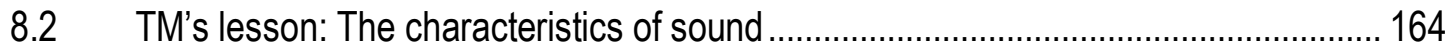

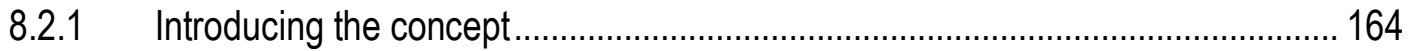

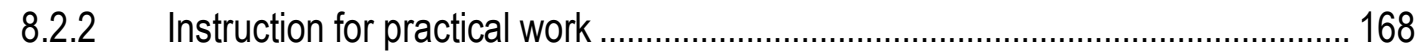

8.2.3 Making sense of the concept through practical work ........................................... 172

8.3 TJ's lesson: The responses of plants to different stimuli.......................................... 175

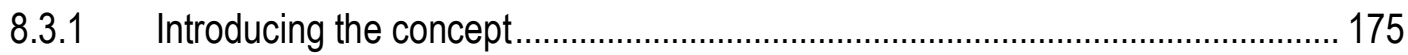

8.3.2 Instruction for practical work …......................................................................... 179

8.3.3 Making sense of the concept through practical work .......................................... 182

8.4 TR's Lesson: The absorption of glucose through the Visking tube............................ 184

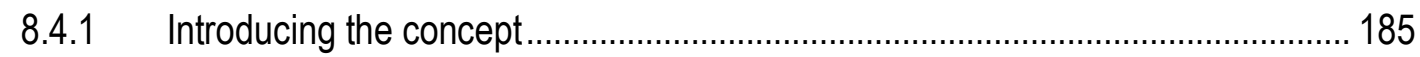

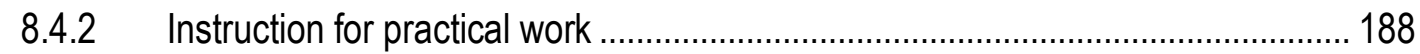

8.4.3 Making sense of the concept through practical work.......................................... 190

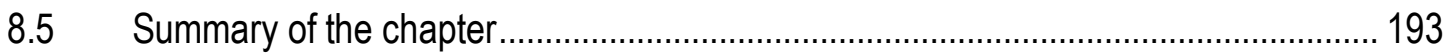

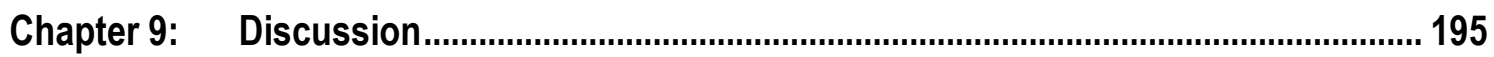



9.2 Theme one: Teachers focused on doing science rather than science investigations 195

9.3 Theme two: Influences on the implementation of practical work ................................ 197

9.4 Theme three: Teacher questioning promoted 'traditional' teaching and learning

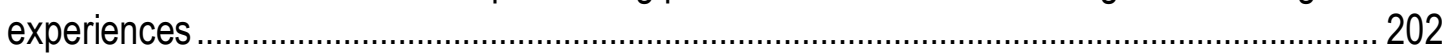

9.5 Theme four: Limited student opportunities to construct understanding ...................... 205

9.6 Theme five: Limited constructivist practice among teachers .................................... 208

9.7 Theme Six: Students showed a lack of procedural knowledge ................................. 210

9.8 Theme Seven: Students showed a lack of conceptual knowledge ........................... 212



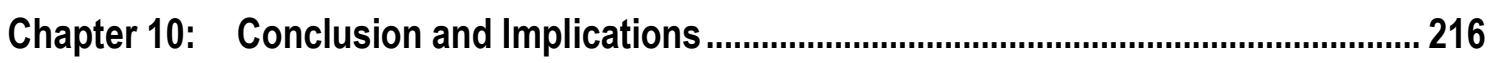

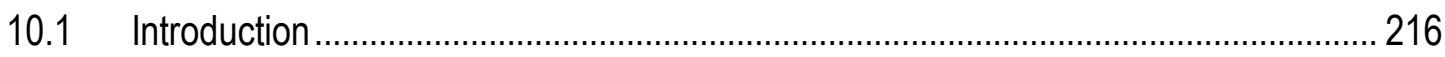

10.2 Research Question 1: How did form two science teachers understand practical work at the lower secondary school level in different types of schools in Melaka? ................. 216

10.2.1 How did form two science teachers understand practical work? ........................ 216

10.2.2 How did form two science teachers practise practical work? .............................. 217 
10.3 Research Question 2: How did teacher talk especially questioning, facilitate classroom interactions in conducting practical work?

10.4 Research Question 3: To what extent were practical work tasks effective in helping students to do what the science teacher intended?

10.5 Research Question 4: To what extent were practical work tasks effective in helping students to learn what the science teachers intended?



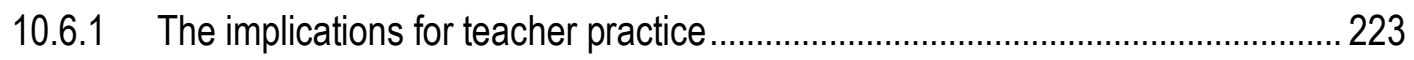

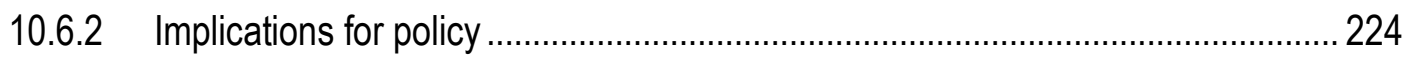

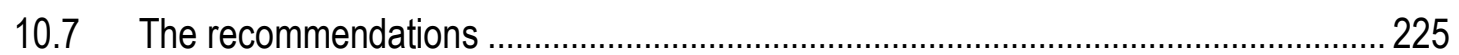

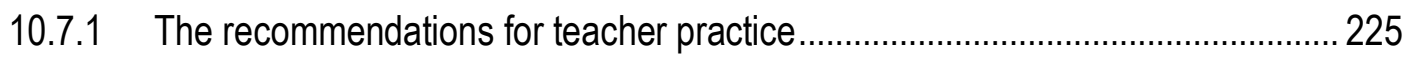

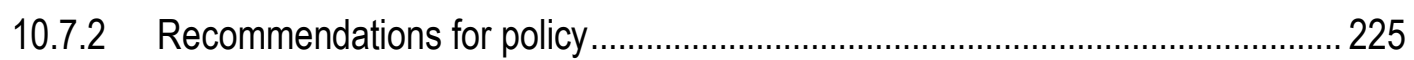

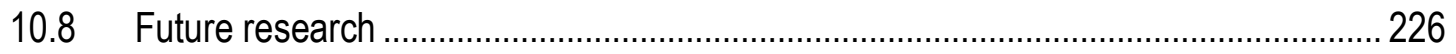

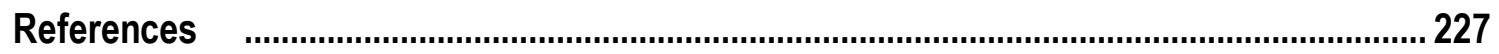

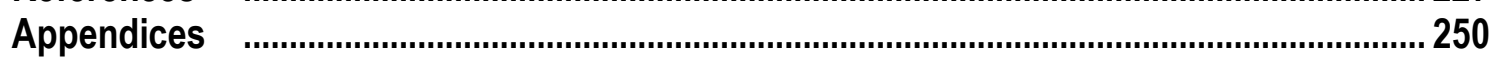

Appendix 5-1: The information sheet for school principal. ................................................ 250

Appendix 5-2: The information sheet for the science teachers and consent form ................... 253

Appendix 5-3: The information sheet for students and consent form..................................... 255

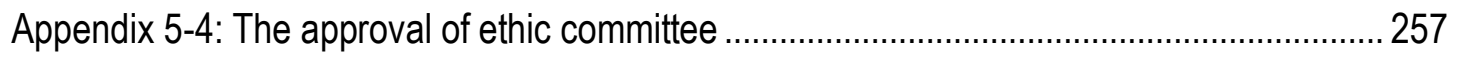

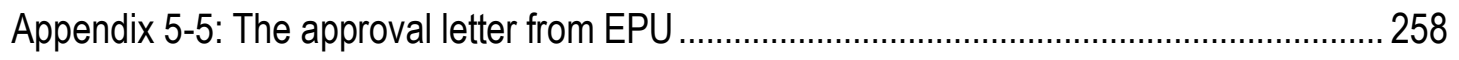

Appendix 5-6: The approval letter from the State Education Department. .............................. 260

Appendix 5-7: Information sheet and consent form for parents.......................................... 261

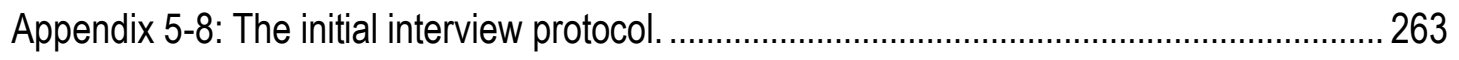

Appendix 5-9: Post-lesson follow-up interview (Teacher) ....................................................... 263

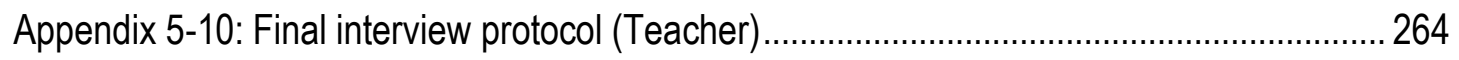



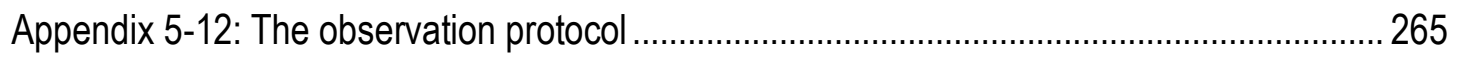

Appendix 5-13: Practical Activity Analysis Inventory (Millar et al., 2002) ................................. 268

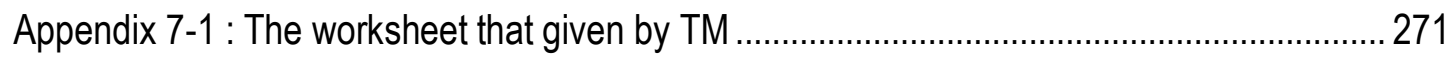

Appendix 7-2: Experiment on the absorption of glucose through the Visking tube (Tong \&

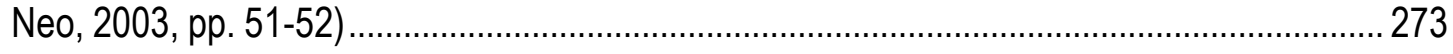




\section{Table}

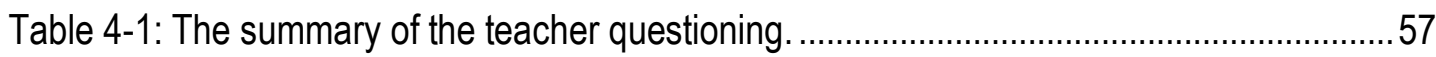

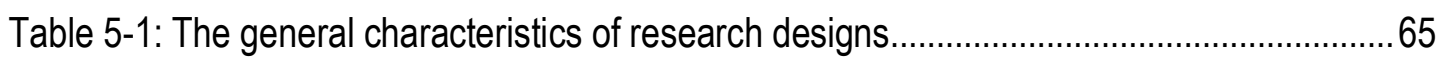

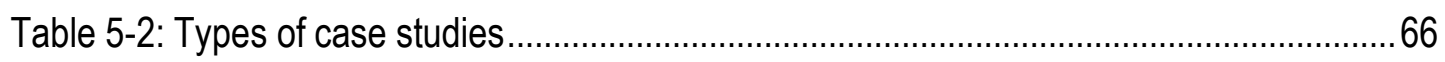

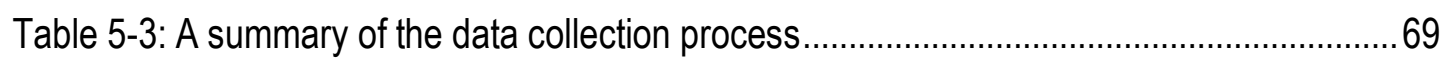

Table 5-4: The teachers who participated in the research ................................................... 73

Table 5-5: The student profiles according to academic achievement...................................... 74

Table 5-6: The number of practical lessons observed........................................................... 79

Table 5-7: The documents that were collected this study .................................................... 80

Table 5-8: The summary of notes organization based on Richardson (2003a) ....................... 81

Table 5-9: The framework to examine the effectiveness of practical work............................... 82

Table 5-10: An analytical framework for considering the effectiveness of the practical work

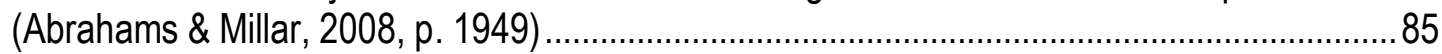

Table 5-11: The process to construct coding and categories for the views of conducting

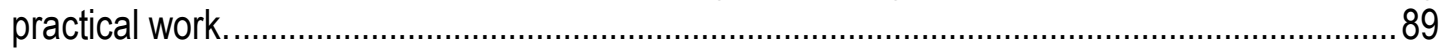

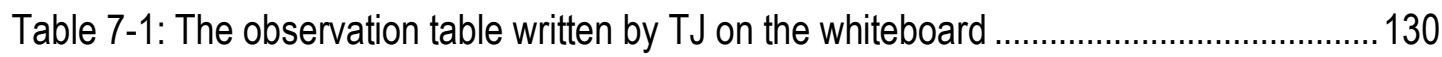

Table 7-2: The observation table suggested by the textbook (Tong \& Neo, 2003, p. 52) ......130

Table 7-3: The observation table for the experiment from the textbook (Tong \& Neo, 2003, p. 52).

Table 7-4: The methods used and time taken to deliver the instructions. 148

Table 7-5: The effectiveness matrix to investigate the absorption of glucose through the Visking tube 154

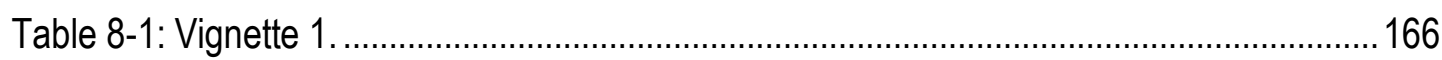

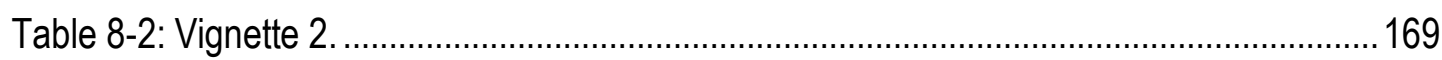

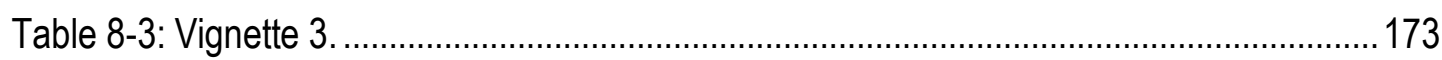

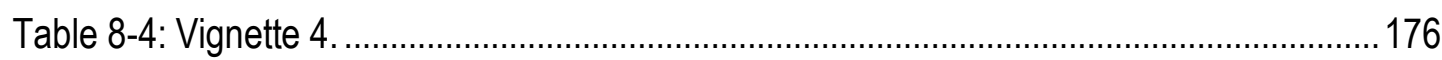

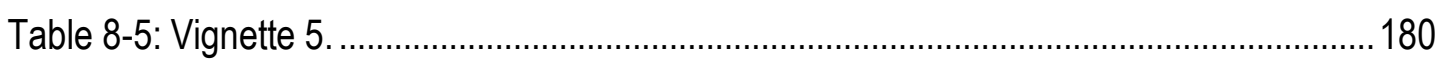

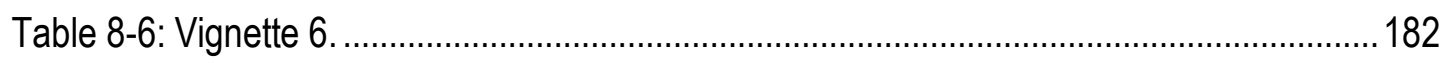

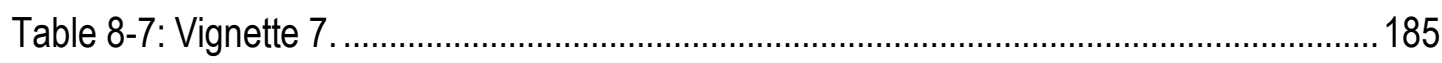

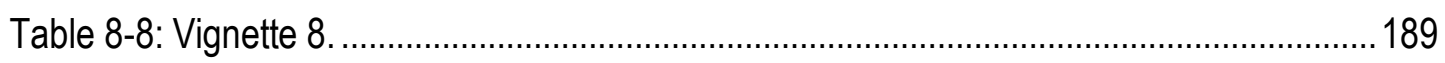

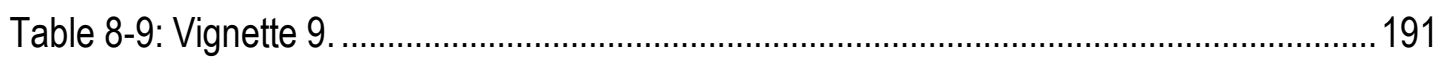




\section{Figure}

Figure 2-1: Details of the curriculum specification for Form Two Science Curriculum 13

Figure 2-2: Science investigation process suggested in the curriculum (MOE, 2002b, p. 12) .16

Figure 3-1: Practical work: linking two domains of knowledge (Millar, 2004, p. 9) .....................31

Figure 5-1 The fundamental purpose of practical work (Tiberghien, 2000, p. 29) ....................82

Figure 5-2: A model of two levels of the effectiveness of practical work (Millar et al., 2002, p. 12) .83

Figure 5-3: The framework for data analysis, based on Creswell $(2009$, p. 185).....................88

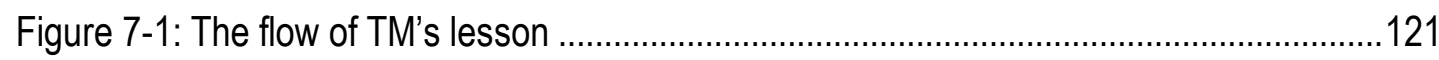

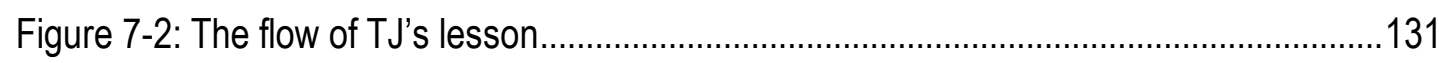

Figure 7-3: The schematic diagram that TJ drew on the whiteboard....................................137

Figure 7-4: The report written by J4 after the practical task .................................................139

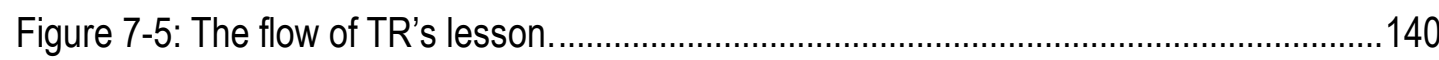

Figure 7-6: The schematic diagrams that TR drew on the whiteboard to compare the structure

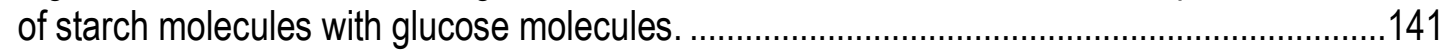

Figure 7-7: The set-up of apparatus to investigate the process of absorption through the

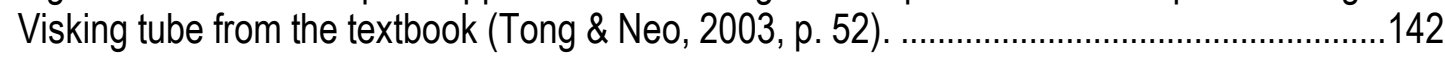

Figure 7-8: The hand-out that TR distributed to the students. .............................................147

Figure 8-1: TM's notes about the production of sound energy on the whiteboard...................165

Figure 8-2: A schematic diagram drawn by TJ on the whiteboard to show the plants' response to light. .184

Figure 8-3: The diagram of the absorption process in the small intestine from the textbook (Tong \& Neo, 2003, p. 51). .187

Figure 8-4: The schematic diagram that TR drew on the whiteboard to show the size differences between the glucose and starch molecules. .187

Figure 8-5: The schematic diagram that TR drew on the whiteboard to show small pores that allow small molecules to diffuse. 188

Figure 8-6: TR's hand-out on the absorption of glucose through a Visking tube. 193 


\title{
Chapter 1: Introduction
}

\subsection{The background to the study}

In the $21^{\text {st }}$ Century, the education system has been the main approach used in Malaysia to achieve Vision $2020^{1}$ that was inspired by its former Prime Minister of Malaysia, Tun Dr. Mahathir Mohammad on $28^{\text {th }}$ February, 1991. One of the aims is to achieve the status of a developed country in all aspects, such as economic, social, spiritual, psychological, and cultural. In order to achieve these aims, one of the challenges is for the country to establish a progressive and scientific society, which can contribute to science and technology advances for civilization in the future. The National Science Education Philosophy stated that:

\begin{abstract}
In consonance with the National Education Philosophy, science education in Malaysia nurtures a Science and Technology Culture by focusing on the development of individuals who are competitive, dynamic, robust and resilient and able to master scientific knowledge and technological competency (MOE, 2002b, p. ix).
\end{abstract}

In realizing the importance of science education in establishing a progressive and scientific society, the Ministry of Education (MOE) has revised the science curriculum. The current curriculum aimed to produce a workforce that was knowledgeable, skifful, and thoughtful (MOE, 2002a). As the curriculum implementers, the teachers have a huge responsibility to meet the needs of the country in accordance with Vision 2020, where the students can grasp scientific knowledge in different situations and approaches. In order to prepare the students to face these challenges, they must be literate in science.

Scientifically competent citizens can be produced if the students have the chance to cultivate science in their lives. Subjects related to science and technology have been introduced in schools to provide a motivation for students to choose science-related careers in the future. Through the Malaysia Education Blueprint 2006-2010, MOE emphasises the implementation of student-centred teaching and learning strategies that allow students to involve more in conducting practical work, carrying out discussion, and problem solving (MOE, 2006a). These teaching strategies may provide opportunities for students to "acquire knowledge, master skills

\footnotetext{
${ }^{1}$ Vision 2020 was an aspiration to be a fully developed country by year 2020 and was introduced by the former Prime Minister, Tun Dr. Mahathir Mohammad, in 1991. One of the approaches to achieve the aim was through education where science and technology was given a high priority (Mohammad, 1997).
} 
and develop scientific attitudes and noble values ${ }^{2}$ in an integrated manner" (MOE, 2002a, p. 12).

In an effective teaching approach, the students should be actively involved in the teaching and learning activities because they do not learn passively (Woolnough, 1994). Learning can take place once the students are ready to learn and when they are involved in teaching and learning activities. Thus the students must be trained to learn the concepts, principles, facts, skills, and values through hands-on activities (Daud \& Noordin, 2008). The hands-on activities refer to a process where the students are involved in observing, measuring, analysing, recording, and interpreting information systematically. The students have the opportunity to develop the skills through practical work.

According to Berg (2003), students can learn effectively if they are actively involved in conducting their own investigation to gather the information. Practical work may provide positive impacts on the development of scientific knowledge, scientific skills, and positive scientific attitudes (MOE, 2003b). Students develop scientific skills as they are involved in planning, carrying out activities, analysing data, and handling laboratory apparatus and chemical substances (Berg, 2009). Practical work can foster positive scientific attitudes, such as honesty, recording data accurately, being systematic, and performing with teamwork, as students normally carry out practical work in groups (Christensen \& McRobbie, 1994).

Hodson (2014) argues that the best way to learn to do science is by doing science. He argues that through practice under the guidance of the teacher students get better at doing science. Whereas Lederman, Antink, and Bartos (2014) prioritise learning about the nature of science and science investigation, Hodson (2014) asserts that the aim of science education should be to develop: conceptual understanding; procedural understanding; understandings about the nature of science; as well as developing the ability to make informed decisions on socioscientific issues. Roberts, Gott, and Glaesser (2009) believes that practical work is more than doing science, it should require students to think about their data to draw conclusions and use evidence when presenting their arguments.

\footnotetext{
${ }^{2}$ Noble values are referred to positive values such as "being kind-hearted and caring, being cooperative, and being diligent and persevering" (MOE, 2002a, p. 10).
} 


\subsection{General statement of the problem}

Internationally, and in Malaysia, science education aims to help students gain an understanding of scientific knowledge and help students to develop an understanding of scientific methods from which scientific knowledge is constructed (Hassard \& Dias, 2009; Millar, 2004). In order to develop students' understanding of scientific knowledge and methods, students need to be actively involved in learning activities to construct new knowledge by seeing, handling, and manipulating real objects and materials around them. The new knowledge students learn in science at the school level is knowledge that is already known by science teachers or scientists (Millar, 2004).

The new knowledge that students acquire is both conceptual and procedural knowledge (Millar, 2004). Conceptual knowledge includes "factual knowledge, concepts, laws, and theories" (Glaesser, Gott, Roberts, \& Cooper, 2009, p. 5) whereas, procedural knowledge includes skills that students need in handling laboratory apparatus and skills to gather, analyse, interpret, and communicate their results (Wellington, 2006). Science educators propose different models of teaching to assist students to acquire the new knowledge in science classrooms (Hassard \& Dias, 2009).

Teaching science in secondary school can be carried out through different models of teaching. A model of teaching is an instructional design that includes a plan or pattern of a lesson (Hassard, 2005). Hassard and Dias (2009) suggested different models of teaching, which included conceptual change, a social-cultural model, inquiry teaching, and the direct or interactive model. Interestingly, all the teaching models at some point involve students in observing and manipulating real objects to construct new knowledge to test against old ideas (Hassard \& Dias, 2009). One teaching and learning approach that allows students to actively construct new knowledge is practical work.

Practical work commonly used as a teaching strategy in science lesson (MOE, 2002a). It is important for science teachers to understand the nature of practical work; not only why (aims of practical work) practical work is conducted in science lessons, but also what (different types of practical work), and how (ways by which practical work is conducted) (Wellington, 2006). Practical work is conducted to maximize student learning (Pekmez, Johnson, \& Gott, 2005; Wellington \& Ireson, 2008). Implementation of practical work as a teaching strategy puts a huge demand on teachers in terms of time and resources (Millar, 2004). Sometimes, practical work involves the use of expensive apparatus that students may not have access to outside 
the science laboratory. Schools need to employ laboratory assistants to maintain the apparatus and materials in the laboratory (Wellington \& Ireson, 2008).

Although practical work is widely accepted by many countries, science educators express their concern about student learning in terms of the acquisition of conceptual and procedural knowledge as a result of engaging students with practical work (Millar, 2001). There is evidence to suggest that students failed to learn the conceptual knowledge that science teachers had planned for them to learn from practical work tasks (Abrahams \& Millar, 2008). Additionally, the mismatch between the students' interpretation of the tasks with what science teachers intended students to learn, reduced the opportunities for students to achieve the intended learning objectives (Berry, Mulhall, Gunstone, \& Loughran, 1999). Students failed to understand the intended phenomenon that they should observe in order to appreciate the patterns, trends, and explanations (Millar, 2001). Consequently, the mismatch reduced the cognitive value of the tasks and students' goals were to complete the tasks rather than learned from them (Berry et al., 1999).

According to Thulstrup (1999), secondary school science teachers in Malaysia devote more than $50 \%$ of their time in science lessons to practical work. It shows that science teachers frequently used practical work as a teaching approach. However, a recent study shows that practical work has become an unpopular teaching approach among teachers (Zainudin, 2008). Teachers do not like to conduct practical work. Despite that, little attempt has been made to understand the implementation of practical work and its effect on student learning in the Malaysian context especially at the lower secondary school level. This study intends to investigate the following research questions:

i. How did form two science teachers understand practical work at the lower secondary school level in different types of schools in Melaka ${ }^{3}$;

a. How did form two science teachers understand practical work?

b. How did form two science teachers practise practical work?

ii. How did teacher talk, especially questioning, facilitate classroom interactions in conducting practical work?

iii. To what extent were practical work tasks effective in helping students to do what the science teacher intended?

\footnotetext{
${ }^{3}$ Melaka is a state located at the southern part of Peninsular Malaysia and it is among the smallest states in Malaysia. Melaka is a multiracial state with a total population of approximately 180,000.
} 
iv. To what extent were practical work tasks effective in helping students to learn what the science teachers intended?

\subsection{The organization of the thesis}

This thesis is made up of 10 chapters. Chapter one has introduced the background and the rationale of the study. The researcher also highlights research questions that will be addressed in this thesis. In chapter two, the researcher provides an overview of the Malaysian education system and particularly science education. In this chapter, the researcher highlights the uniqueness of Malaysian education system starting from the British colonial era until now. It provides an overview of how science is taught in school, the development of the science curriculum, the challenges in implementing the science curriculum, the organization of the current curriculum, and assessment, particularly related to science practical work. In chapter three, a review of the literature related to science teaching and learning, particularly regarding practical work, at the secondary school level is presented. The theoretical framework of the study is explained in chapter four. Chapter five presents the methodology framework for data gathering and data analysing. In chapter six, seven, and eight the findings related to the aims of conducting practical work from teachers' perspectives, teachers' practices in conducting practical work, and teacher questioning in practical lessons respectively are presented. Key themes emerging from this study are highlighted in chapter nine. Lastly, in chapter ten the pedagogical implications and recommendations to strengthen the implementation of practical work in lower secondary schools along with suggestion for future research to enhance teaching and learning in science are discussed. 


\title{
Chapter 2: The Curriculum Context of the Study
}

\subsection{The landscape of the Malaysian education system}

The goal of the national education system in Malaysia is to develop the potential of each individual and fulfil the aspiration of the nation, as outlined in the National Philosophy of Education:

\begin{abstract}
Education in Malaysia is an on-going effort towards further developing the potential of individuals in a holistic and integrated manner, to produce individuals who are intellectually, spiritually, emotionally, and physically balanced and harmonised, based on a firm belief in and devotion to God. Such effort is designed to produce Malaysian citizens who are knowledgeable and competent, who possess high moral standards and who are responsible and capable of achieving high levels of personal wellbeing, as well as being able to contribute to the harmony and betterment of the family, the society and the nation at large (MOE, 2002a, p. v).
\end{abstract}

In Malaysia, all children must undergo at least nine years of schooling, which consists of six years of primary school (age 7 to 12-years-old) and three years of lower secondary school (age 13 to 15-years-old). Then, there are two years of upper secondary (age 16 to 17-yearsold) and a further two years of post-secondary school education (age 18 to 19-years-old), before they can embark on education at the tertiary level.

The education system in Malaysia is unique in comparison with other multicultural countries, as it is the only country in the world to organize a primary education based on three major races, Malay, Chinese, and Indian and it has three types of race-based schools, which are the national schools, the national-type Chinese schools, and the national-type Tamil schools. Each of these schools uses their mother tongue as the medium of instruction. This vernacular school system began during the British colonial period in the 1800 s and continues today.

At primary school (age 7 to 12-years-old), students move to the next level despite their academic performance. After six years of primary education, the students sit the standard test, known as Primary School Evaluation Test (Ujian Pencapaian Sekolah Rendah - UPSR). The examination includes Bahasa Malaysia (comprehension and writing), mathematics, science, and English (comprehension and writing) (Lembaga Peperiksaan Malaysia, 2011). However, it is not compulsory for students in the national-type Chinese and Tamil schools to sit the comprehension and writing tests in Chinese and Tamil languages, respectively. 
The students then move to the lower secondary school level (age 13 to 16 or 14 to 16 -yearsold), which is divided into core and additional subjects. The core subjects are compulsory for all students and are aligned with the aspiration to provide general education for everyone. The core subjects are: Bahasa Malaysia, English, Islamic education (for Muslim students), moral education (for non-Muslim students), mathematics, science, history, geography, living skills, physical education and health care, and arts education. The Ministry also offers additional subjects, such as Mandarin, Tamil, and Arabic for communication, which are not compulsory. After three years of schooling, students sit another examination, the Lower Secondary Assessment (Penilaian Menengah Rendah - PMR ${ }^{4}$ ). Again, regardless of the students' academic performance they continue their studies to the upper secondary school.

At upper secondary school level, from age 16 to 17-years-old, the Ministry provides students with different study streams, academic, technical, vocational, and Islamic. At this level, students also choose which field of study they want to pursue in tertiary education. There are two academic streams, arts (humanities) and science. Students can also choose to continue their studies in either a technical, or a vocational stream. The core subjects at upper secondary school level are similar to core subjects at the lower secondary school level. Science is one of the core subjects at this level for students in art, vocational, and Islamic studies streams. Before they graduate from upper secondary school, they sit Malaysian Certificate of Education (Sijil Pelajaran Malaysia - SPM), which is equivalent to The British General Certificate of Secondary Education (GCSE).

At the post-upper secondary school level, students have the opportunity to pursue their studies at tertiary level or join the workforce. If they choose to continue their studies in school, after two years they have to sit another examination - Malaysian Higher School Certificate (Sijil Tinggi Pelajaran Malaysia - STPM) equivalent to General Certificate of Secondary Education (GCSE 'A' Level). At this level, students can choose to study any five subjects on offer at this level, and General Studies. Most schools stream their students into science, arts (humanities), or Islamic studies. The subjects can be categorized into three fields, language and literature, social studies and Islamic studies, sciences and mathematics (MOE, 2011). Students can also pursue their studies at the tertiary level where they choose to enter the matriculation or join certificate/diploma programmes offered by polytechnics and private or public universities.

${ }_{4}^{4}$ Penilaian Menengah Rendah (Lower Secondary Assessment) is a Malaysian national examination taken by Form Three students. 
Science is a compulsory subject from primary school upwards. It has a long history in the Malaysian education system, since independence from Britain. Changes to the curriculum and in teaching approaches have grown steadily to meet demands to create a critical mass of science and technology labour for a knowledge-based economy. The Malaysian government is committed to producing citizens who are competent in science and technology, with good scientific skills, attitudes, and who are able to cope with the rapid advances in science and technology. The development of science education in Malaysia is presented in the following section.

\subsection{The development of science education in Malaysia}

The importance of science education in improving the standard of living is highlighted in the Higher Education Planning Committee Report 1966 (clause 100):

\footnotetext{
The importance of science and technology in developing both resources (human and natural) cannot be denied. A strong foundation in science subjects with sufficient human capacity to specialise in various fields of science is important, not only for research, but also for development (Meerah, 1999, p. 10).
}

Science education in Malaysia has changed gradually since its introduction during the British colonial era from 1786 until 1957 (Lee, 1992). In 1939, the government of Straits Settlement (Penang, Malacca, and Singapore) and Malay States established a committee to change science education and the science curriculum. Initially, the government introduced general science for only four years in secondary schools. In 1948, there was only one school in the Malay States that offered science, and during the Second World War (WW2), science education was terminated. After the war, science education based on the British curriculum was reintroduced in all schools in the Malay States and Straits Settlement.

After Malaysia gained independence from Britain in 1957, science was taught as nature studies, hygiene, and agriculture. However, as science and technology was considered important for boosting the economy and for social development, science education was expanded and strengthened to cope with the demands. The importance of science education was emphasised through several policies, such as: The Second Malaysia Plan, Razak Education Committee (1956), and Cabinet Committee of Education (1979).

In the late 1960s, the Ministry of Education implemented a number of strategies to improve the quality of science education. One strategy reformed the science curriculum through a number of projects. Strategies included: the Special Science Project for Primary Schools (Projek Khas 
Sekolah Rendah); an Integrated Science Syllabus for Lower Secondary Schools (Kurikulum Sains Paduan Sekolah Menengah Rendah); the Modern Science Curriculum for Secondary Schools (biology, physics, chemistry, and science); Kurikulum Sains Tulen Moden (Biologi, Fizik, Kimia, dan Rampaian Sains); the New Primary School Curriculum (Kurikulum Baru Sekolah Rendah-KBSR); and the Integrated Curriculum for Secondary Schools (Kurikulum Bersepadu Sekolah Menengah - KBSM) (Lee, 1999).

The Special Science Project for Primary Schools aimed to overcome the weaknesses in science learning among students, especially at primary school level. The two main objectives of this project were to ensure that all students learned science and mathematics appropriate to their age through experiencing it, conducting investigations, and developing their own conceptions by the use of logic. The second objective was to ensure that all students were able to memorise scientific facts and acquire basic science skills. The Ministry introduced a new syllabus that emphasised suitable science content (facts, terms, and concepts) and planned appropriate teaching and learning activities that were suitable for the achievement of the learning objectives (Meerah, 1999).

Traditionally, since the 1950s, the science curriculum for secondary schools has emphasised scientific facts and concepts, which changed in the 1960s to vague curriculum goals that only listed topics and gave instructions for laboratory work (Meerah, 1999). Students who experienced this science curriculum had to memorise scientific facts rather than understand the concepts of science itself. The involvement of students in laboratory work focused on fostering their manipulative skills, rather than improving their scientific skills. This curriculum was also unable to provide actual science practice, because the main concern of science education was to prepare students for examination (Meerah, 1999).

In 1969, the ministry took progressive action and reformed the curriculum. In 1969, the Integrated Science Syllabus (adapted from the Scottish Integrated Science) for lower secondary schools was implemented with the Ministry introducing the syllabus at the lower secondary school level. In 1972, the Ministry introduced modern chemistry, modern physics, and modern biology for science students at the upper secondary school level, using a syllabus from the British Nuffield Science O-Level project. In 1974, the Ministry adapted and implemented the General Modern Science Curriculum from the British Nuffield General Science project at the upper secondary school level for students who studied in the arts stream. The aims of introducing the new curricula were to upgrade the science content by using suitable local materials, implementing inquiry discovery approaches as teaching and 
learning activities, and broadening the understanding of scientific concepts and their application in real life situations. There were three main reasons for adapting and implementing the new curricula. Firstly, the objective of the science curriculum was to be relevant to current development and daily activities. The approach was consistent with the philosophy of a modern lifestyle. Secondly, the education system in Malaysia was influenced by the British education system; therefore, the Ministry relied on British expertise to provide support, training, and preparation in implementing the curricula. Thirdly, the Ministry believed that adapting the existing curricula was sufficient rather than inventing a new one, as Malaysia did not have enough expertise at the time to develop a new science curriculum (Lee, 1992). It was decided that the language of instruction would be English.

In 1983, the Ministry implemented a new primary school curriculum (KBSR), nationally. The major concern of this curriculum was to ensure that all students could grasp the basic skills of literacy and numeracy. It also focused on the development of students' intellectual, physical, spiritual, and emotional talents, and on their attitudes and aesthetic values by using a holistic approach. The Ministry combined science with other subjects, such as, history, geography, health, and civic studies to form a new subject called 'Man and His Environment' (Alam dan Manusia). In 1982, the Ministry introduced this subject to students in primary school (age 10 to 12-years-old). The students were taught about abiotic components (energy, water, air, shape, and electricity), the environment, types of diseases, the respiratory system, the reproductive system, and a healthy diet. The purpose of introducing this subject was to expand students' knowledge and understanding regarding the interactions of humans with their environment. The teachers used the national language (Bahasa Malaysia), to instruct the students, which aimed to create a Malaysian identity and unity (Daniel, 2005).

However, in 1994 this subject was switched to science because the Ministry encountered a lot of problems at the implementation stage (Meerah, 1999). Teachers and students experienced problems, with teachers claiming that the in-service training programme was insufficient and they were unprepared to teach the new subject. They claimed that the subject itself was tough and only suitable for high achievers (Seth \& Ismail, 1993).

In 1994, the Ministry introduced science to year four (age 10-years-old) to replace the 'Man and His Environment' subject. Science provides opportunities for students to learn about themselves and their environment through everyday experiences and scientific investigations and the Ministry believed that its aims were to prepare students with sufficient background knowledge and skills to continue with their studies at the lower secondary school level (MOE, 
2003a), where their knowledge and skills would continue to be nurtured and strengthened. The MOE hoped that through KBSR, students would develop positive attitudes towards science, levels of achievement would be enhanced, and enrolments would increase.

The Ministry introduced the Integrated Curriculum for Secondary Schools (science) after seven years of the implementation of KBSR. In agreement with the National Philosophy of Education, the aim of science in KBSM was to foster scientific skills and knowledge and also to nurture scientific thinking and promote noble values, so the students would appreciate and understand the application of science in real life. The new curriculum focused, not only on knowledge and skills, but also on the abilities of the students to solve everyday problems in order to become responsible citizens (Meerah, 1999).

In summary, the science curriculum in Malaysia has undergone several changes since independence. There have been significant changes in term of aims, contents, and teaching approaches, influenced by views regarding science and science learning. Rapid technological changes and the demand to produce a mass of science knowledge and technology labour for the knowledge-based economy have influenced the development of the curriculum and changed the policy in terms of teaching approaches and language of instruction. A description of The Integrated Science Curriculum for Secondary Schools in Malaysia follows.

\subsection{The Integrated Curriculum for Secondary Schools (Science)}

The Integrated Curriculum for Secondary Schools (Science) offers three core and four elective science subjects (MOE, 2002a). The science subjects are science at the primary school level, science at the lower secondary school level, and science at the upper secondary school level. The elective science subjects are physics, chemistry, biology, with additional science offered to students at the upper secondary school level. The aims of introducing core science subjects for primary and lower secondary school are to "...provide students with basic science knowledge, prepare students to be literate in science, and enable students to continue their science education at the upper secondary level..." (MOE, 2002a, p. 1).

The aims of core science subjects at the upper secondary level are to "...produce students who are literate in science, innovative, and able to apply scientific knowledge in decision making and problem solving in everyday life..." (MOE, 2002a, p. 1). The Ministry offers the elective science subjects to "...prepare students who are more scientifically inclined to pursue the study of science at the post-secondary level..." (MOE, 2002a, p. 1). At the upper 
secondary school level, practical work becomes more common, especially in elective science subjects (MOE, 2002a).

As well as the aims, the Ministry has developed detailed science curriculum specifications for each science course. The curriculum specifications used at the lower secondary school level are, Integrated Curriculum for Secondary Schools Curriculum Specifications Science Form One (MOE, 2002b), Integrated Curriculum for Secondary Schools Curriculum Specifications Science Form Two (MOE, 2002a), and Integrated Curriculum for Secondary Schools Curriculum Specifications Science Form Three (MOE, 2002c). These are formal documents used by science teachers to teach science.

In 2003, the fourth Prime Minister, Tun Dr. Mahathir Mohammad, introduced a new policy: English for Teaching Mathematics and Science (ETeMS). The policy began in year one at primary school level, at form one at secondary school level, and in lower sixth classes (preuniversity). The Ministry acknowledged that science and mathematics were important to the development and modernisation of a country, and they gave science a high priority because of the increasing and rapid development in both fields. Thus, it was important to keep citizens abreast of rapid changes in order to fulfil the 2020 vision through education (Mohammad, 1997). English became the language of instruction for both subjects to allow students to tap into knowledge from a wider range of sources. They can obtain information about science and mathematics in English in different contexts, which helps them to understand more about the developments in science and technology, giving them access to knowledge beyond the confines of their classrooms. In addition, they have more opportunity to use English to communicate, which increases their proficiency in the language (MOE, 2002a).

Over the past decade, MOE has developed strategies to implement the new policy. In order to produce science teachers who are competent to teach science in English, in-service teachers are provided with support, especially in upgrading their proficiency in the English language. The language of instruction in pre-service teacher programmes is now English. The textbooks and other teaching resources have been translated into English. MOE has encouraged teachers to utilise Information Communication Technology (ICT) by providing a teaching course as one of the teaching aids to help teachers integrate ICT in their lessons. They have translated and upgraded the curriculum in English.

The science curriculum is organised around several themes and each theme comprises several learning areas. Each learning area has a number of learning objectives and each 
learning objective has one or two measurable learning outcomes. The Ministry has based the outcomes on the cognitive and affective domains of knowledge, understanding, application, analysis, synthesis, and evaluation. The affective domains includes "to be in awe, to be aware of, to be appreciative, to be thankful, to love, to practise, and to internalise" (MOE, 2003b, p. 3). The Ministry has integrated the teaching of positive scientific attitudes and noble values into teaching and learning activities. Teachers can modify the suggested learning to suit student ability, learning style and availability of equipment. Teachers are also encouraged to design teaching and learning activities that can achieve the learning outcomes. Teachers are provided with notes to remind them of the learning objectives and check the meaning of scientific terms.

The Curriculum Development Centre has planned the science curriculum in detail to ensure achievement of learning outcomes. For example, Figure 2-1 shows the details of the form Two Science Curriculum Specification (MOE, 2002c, p. 16).

THEME: MANAGEMENT AND CONTINUITY OF LIFE

LEARNING AREA: 1. THE WORLD THROUGH OUR SENSES

\begin{tabular}{|c|c|c|c|c|}
\hline $\begin{array}{l}\text { Learning } \\
\text { Objectives }\end{array}$ & Suggested Learning Activities & Learning Outcomes & Notes & Vocabulary \\
\hline $\begin{array}{l}1.1 \\
\text { Understanding } \\
\text { the sensory } \\
\text { organs and } \\
\text { their functions. }\end{array}$ & $\begin{array}{l}\text { Carry out activities to make } \\
\text { connection between the five } \\
\text { senses, the sensory organs and } \\
\text { the stimuli. } \\
\text { Discuss what happens in our body } \\
\text { after a stimulus is detected. }\end{array}$ & $\begin{array}{l}\text { A student is able to: } \\
\text { - identify and relate a sensory } \\
\text { organ to its stimulus, } \\
\text { - state the pathway from stimulus } \\
\text { to response: } \\
\text { Stimulus } \rightarrow \text { Sensory organs } \rightarrow \\
\text { Nerves } \rightarrow \text { Brain } \rightarrow \text { Nerves } \rightarrow \\
\text { Response }\end{array}$ & $\begin{array}{l}\text { The five sensory } \\
\text { organs have been } \\
\text { introduced in } \\
\text { Primary Science. }\end{array}$ & $\begin{array}{l}\text { brain - otak } \\
\text { nerve - saraf } \\
\text { response - gerakbalas } \\
\text { stimuli - rangsangan } \\
\text { sensory organ - organ } \\
\text { deria }\end{array}$ \\
\hline $\begin{array}{l}1.2 \\
\text { Understanding } \\
\text { the sense of } \\
\text { touch. }\end{array}$ & $\begin{array}{l}\text { Carry out activities to study the } \\
\text { following: } \\
\text { a) structure of the human skin } \\
\text { involved in stimuli detection, } \\
\text { b) sensitivity of the skin at } \\
\text { different parts of the body } \\
\text { towards stimuli. } \\
\text { Discuss the sensitivity of the skin } \\
\text { in connection to the following } \\
\text { situations: } \\
\text { a) receiving an injection, } \\
\text { b) using Braille. }\end{array}$ & $\begin{array}{l}\text { A student is able to: } \\
\text { - identify the structure of the } \\
\text { human skin involved in stimuli } \\
\text { detection, } \\
\text { - state the function of different } \\
\text { receptors - pressure, heat, pain, } \\
\text { - draw conclusion on the } \\
\text { sensitivity of the skin at different } \\
\text { parts of the body towards stimuli. }\end{array}$ & $\begin{array}{l}\text { The structures of the } \\
\text { receptors are not } \\
\text { required. }\end{array}$ & $\begin{array}{l}\text { cold - kesejukan } \\
\text { heat - kepanasan } \\
\text { pain - kesakitan } \\
\text { pressure - tekanan } \\
\text { receptor - hujung saraf } \\
\text { sensitivity - kepekaan } \\
\text { skin - kulit } \\
\text { touch - sentuhan }\end{array}$ \\
\hline
\end{tabular}

Figure 2-1: Details of the curriculum specification for Form Two Science Curriculum (MOE, 2002a, p. 16)

\subsubsection{The organisation of the content}

The science content is organised into the different areas of science, biology, physics, chemistry, and astronomy. The themes are: 

i. Introducing science
ii. Man and the variety of living things
iii. Matter in nature
iv. Maintenance and continuity of life
v. Force and motion
vi. Energy in life
vii. Balance and management of the environment
viii. Technological and industrial development in society
ix. Astronomy and space exploration (MOE, 2003b, p. 5).

The number of themes for each form-level is different. In form one, there are four themes; Introducing Science, Man and the Variety of Living Things, Matter in Nature, and Energy. Form two has five themes out of nine themes from the integrated science curriculum at lower secondary school level. These are; Management and Continuity of Life, Man and the Variety of Living Things, Matter in Nature, Force and Motion, and Technological and Industrial Development in Society (MOE, 2002a, p. iii). In form three, there are five themes; Management and Continuity of Life, Matter in Nature, Energy in Life, and Astronomy and Space Exploration (MOE, 2002c, p. iii).

Students learn similar themes in each area of science. The learning areas in each theme are organised according to the complexity of the theme. For example, in form one; students cover the first learning area, which is The Cell as a Unit of Life in Man and the Variety of Living Things (MOE, 2003b). Then in a similar theme, students learn about The Variety of Living Things and their Classification in form two, where they learn about cells as building blocks of an organism and, in the next learning area, about the diversity of organisms that includes animals and plants. The themes aim to provide an understanding of human beings and biological entity.

\subsubsection{The learning aims}

The aim of the Malaysian science curriculum is to develop active learners. The Ministry expects students to participate in teaching and learning activities that will help them to develop science concepts, gain scientific skills, and that foster positive scientific attitudes and noble values. In addition, the activities should be "geared towards activating students' critical and creative thinking skills and not be confined to routine or rote learning" (MOE, 2003b, p. 3). Firstly, students acquire scientific knowledge so that they can make decisions in their daily 
lives and improve wellbeing and prepare students to pursue science related disciplines in future. Secondly, the aim of science teaching is to provide students with scientific skills. These skills are categorized into two components: science process and manipulative skills. The curriculum lists twelve skills, "observing, classifying, measuring and using numbers, inferring, predicting, communicating, using space-time relationships, interpreting data, defining operationally, controlling variables, hypothesising, and experimenting" (MOE, 2002a, p. 3). Manipulative skills refers to psychomotor skills in scientific investigation which enable students to "use and handle science apparatus and laboratory substances correctly, store science apparatus correctly and safely, clean science apparatus correctly, handle specimens correctly and carefully, and observe, record, and measure accurately" (MOE, 2002a, p. 4).

Thirdly, the science curriculum promotes thinking skills and thinking strategies, which can be categorised into critical and creative thinking skills. Students are to use critical thinking in evaluating ideas in a systematic manner. Creative thinking skills include the generation of original ideas or the modification of ideas and products. Some thinking skills relate to the science process skills, for example, the students may be involved in creative thinking when making hypotheses (MOE, 2002a).

The curriculum aims to foster positive scientific attitudes and noble values, which it can implicitly inculcate through teaching and learning activities. The development of positive scientific attitudes and noble values cuts across all themes. The suggested learning activities in the curriculum specification provide guidance for teachers to plan lessons to achieve these attitudes and values. The Ministry outlines scientific attitudes and noble values, such as "having an interest in, and curiosity towards, the environment, honesty and accuracy when recording and validating data, and perseverance and diligence" (MOE, 2002c, p. 10).

To achieve the aims of the science curriculum, teachers are expected to plan teaching and learning activities that provide opportunities for students to engage. The Ministry suggests using different teaching and learning strategies to maximise students' participation. All suggested teaching and learning activities have the potential to produce active learners through the involvement of students in science investigations, experimentation, and hands-on activities. The teachers can emphasise the inquiry approach that incorporates thinking skills and thinking strategies throughout the teaching and learning process. Another factor in promoting active participation from students is relevant content and contexts, which can enhance students' interest in the subject. 


\subsubsection{The science investigation/experiment in the integrated curriculum for secondary schools (science)}

The Ministry encourages science teachers to implement different teaching approaches in planning lessons that achieve the aims of science education at the lower secondary school level. Science investigations or experiments are teaching approaches promoted by the curriculum. The scientific investigation is introduced in form one, in the first theme, Introducing Science. There is only one learning area in this theme, which is an Introduction to Science, where students learn about scientific investigation as a scientific method of acquiring scientific knowledge. "Students are trained to conduct investigations systematically in order to understand natural phenomena and test its truth and validity" (MOE, 2003b, p. 6).

There are some learning outcomes that students are expected to achieve from the learning objective understanding scientific investigation. They should be able to state the steps in conducting a scientific investigation or experiment and carry out the scientific investigation as a fair test. It is conducted by using a linear process, where the students or teachers do not revisit or reflect on the steps they have performed. The process begins with defining the problem and ends with producing a report. Figure 2-2 shows the flow of the scientific investigation as stated in the curriculum specification.

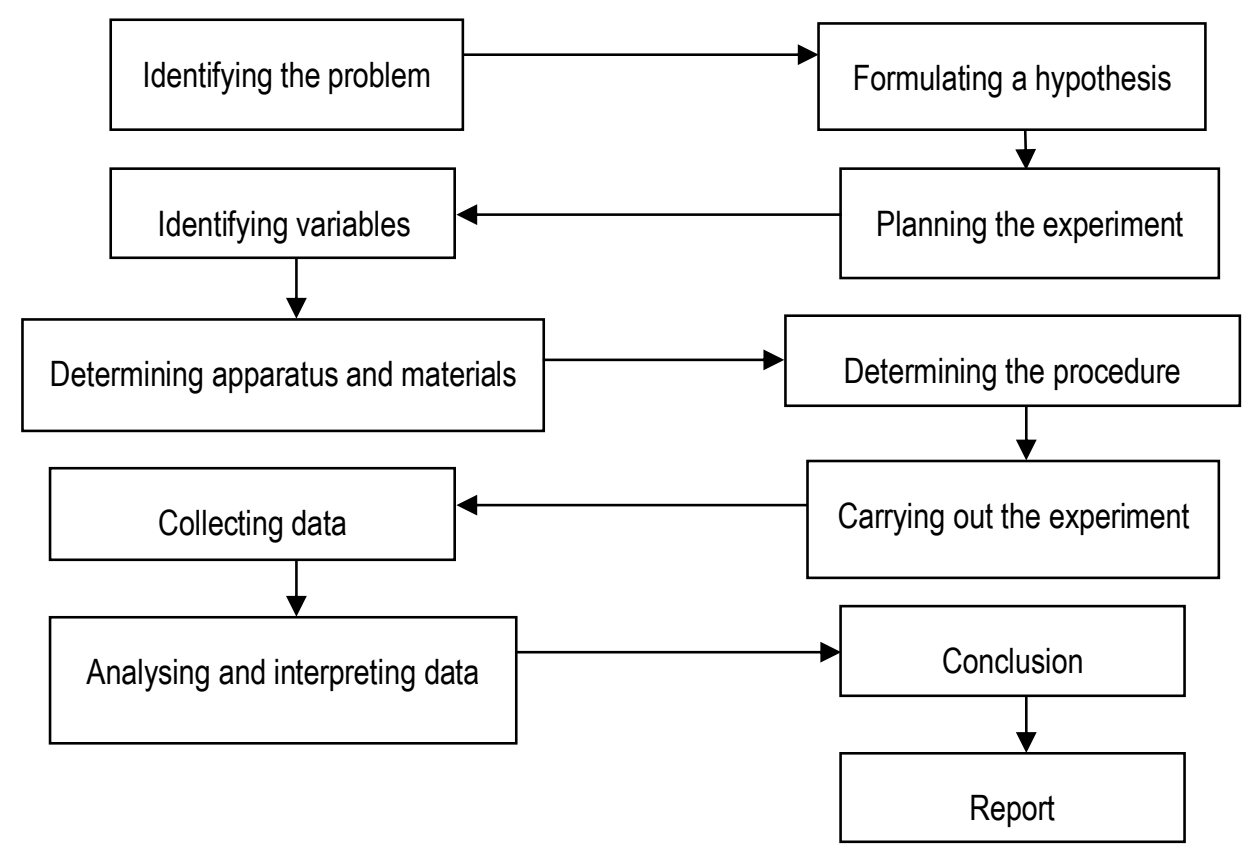

Figure 2-2: Science investigation process suggested in the curriculum (MOE, 2002b, p. 12) 
Although the Ministry introduces the science investigation in form one as one of the learning areas, science investigation is suggested as a learning activity in other themes. For example, in the learning area The World through Our Senses, eight of the nine learning objectives can be achieved through the science investigation. One of the learning objectives in this learning area is Understanding the Stimuli and Responses in Plants (MOE, 2002a, p. 21). The curriculum specification suggests an investigation as an approach to achieving the learning objectives. For example, students can state the stimuli that cause response in plants and identify the parts of plants sensitive to specific stimulus (MOE, 2002a, p. 21). Likewise, in the learning area Nutrition, the curriculum suggests three scientific investigations as teaching and learning activities to achieve the learning outcomes. For example, in the learning objective Understanding the Process of Absorption the students are required to carry out an investigation to differentiate types of foods that can or cannot be absorbed through the wall of small intestine. They are required to build a model from materials and apparatus that are available in the laboratory to show the absorption process (MOE, 2002a). Later, the students use the results from the scientific investigation to develop their understanding about the concept of absorption in the human digestive system.

In addition to the scientific investigations, the curriculum suggests experiments that require students to conduct laboratory activities by following a set of procedures to produce the stated phenomenon. It is suggested that experiments provide hands-on experience which helps to develop manipulative skills (Tong \& Neo, 2003). It is not necessary for students to conduct experiments to test hypotheses. For example, the learning objective, Understanding Sound and Hearing suggests learning activities that teachers can carry out with students that have the potential to engage the students in examining the conditions needed for sound to travel.

\subsubsection{Practical assessment (Penilaian Kerja Amali-PEKA)}

Penilaian Kerja Amali (PEKA) or the practical assessment is a school-based assessment (Lembaga Peperiksaan Malaysia, 2004b). The students are assessed in biology, physics, chemistry, additional science and science for Lower Secondary Assessment (Penilaian Sekolah Rendah - PMR) and Science for the Malaysian Certificate of Education (Sijil Pelajaran Malaysia - SPM). It was introduced in 1999 to assess different elements, including: science process skills, experimenting and manipulative skills, scientific attitudes, and noble values (Kheng, 2013). These elements are assessed whilst the students are involved in science activities, which include experiments, investigations or fieldwork. For this internal 
assessment, teachers collect the evidence to evaluate the students' achievements in the elements.

Muhammad (1990) suggested that practical work is not only aimed at fulfilling the assessment requirement, but also provides the experience for students to do experiments in the laboratory, in the hope that the students can learn more from the results. PEKA is aimed at improving the effectiveness of teaching and learning in science and is complementary to the science curriculum in schools. The scientific skills are referred to as science process and manipulative skills. Through science process skills, the students are involved in critical, creative, analytical and systematic thinking. The manipulative skills are referred to as psychomotor skills in science investigation. Scientific attitudes include the emotional, physical and mental aspects of conducting scientific activities (Lembaga Peperiksaan Malaysia, 2004b).

However, it seems that some students do not grasp these skills and find stating the aims of the investigation, making the links between the concepts and practical work problematic. Although the students have been exposed to assessment since at the lower secondary school level, some cannot perform in the examination in form five. They cannot answer the questions that require them to plan an investigation (Lembaga Peperiksaan Malaysia, 2004a).

\subsection{Summary of the chapter}

In the British colonial era, the Malaysian education system was highly influenced by the British education system. However, Malaysia's science curriculum has gradually changed in terms of content, teaching resources, assessment, and teaching approaches since the $19^{\text {th }}$ Century until now. It shows a continuous commitment of the Malaysian government to develop scientifically literate citizens that are suitable in the Malaysian context. One of the major changes is related to the teaching approaches in that the suggested activities in the science curriculum have the characteristics of practical work. Although the Ministry implements practical work widely in the Malaysian curriculum, the nature and effectiveness of that implementation in achieving the aims at lower secondary school level, especially in the second year of secondary students aged about 14 to 15-years-old, is unknown. The issues related to practical work will be discussed in the following chapter. The review focuses on the findings of survey studies that have studied the purpose of practical work in England, Australia, Spain, and Finland. Particular attention is on how students carry out practical work and different models in evaluating the effectiveness of practical work. 


\section{Chapter 3: Literature Review}

\subsection{Introduction}

The review examines the science curriculum specification in Malaysia and the different types of practical work, and various ways of conducting it. The review discusses the research findings from previous studies in the literature, in particular the views of science teachers and students concerning practical work in science and its effectiveness in promoting student learning are identified. In order to understand the role of practical work in teaching and learning science, the review includes teachers' views about practical work, how the teachers carried out practical work, and what students can learn from it.

\subsection{The nature of practical work}

Internationally, practical work is a common teaching and learning approach in science (Hodson, 2014; Hofstein \& Lunetta, 2004; Lunetta, Hofstein, \& Clough, 2007; Millar, 2010; Woolnough, 1991). Hodson (1990) offers a broad definition of practical work as "activities that require active students' involvement" (p. 36). Woolnough (1991) suggests that practical work refers to the "doing of experiments or practical exercises with scientific apparatus, usually in a science laboratory" (p. 3). Millar (1999) refines Hodson's definition of practical work as all those kinds of learning activities in science which involve students handling or observing real objects or materials; he also includes simulation or video recording. More recently Hodson (2014) has suggested that practical work is about "using methods and procedures of science to investigate phenomena, test and develop understanding, solve problems and follow interests" (p. 13). Lunetta et al. (2007) provided the following definition of practical work: "learning experiences in which students interact with materials or with the secondary resource data to observe and understand the natural world" (p. 394). Recently Millar (2010) has revised his definition, to "any science teaching and learning activity in which the students, working individually or in small groups, observe and/or manipulate the objects or materials they are studying" (p. 109). This is a much tighter definition than Lunetta et al. (2007), who considered students' work with secondary data sources as practical work.

The meaning of practical work in this study is closest to Millar's (2010) definition, although not restricted to activities carried out by students in the laboratory, as it also refers to activities at home or in other places. This research includes activities that students carry out in the laboratory and activities that utilise scientific skills (manipulative skills and science process 
skills) and other attributes, such as scientific attitudes and essential skills, that help to develop higher-order learning skills, such as observing, formulating hypotheses, identifying variables, predicting, and planning scientific investigations (Bybee, 2000).

\subsection{The historical development of practical work}

The term 'practical work' is widely used in the United Kingdom (UK) whereas 'laboratory experiment' is more commonly used in United States (US) (Lu, 2006). Even though different terminology is used globally, practical work or laboratory experiments are prominent teaching approaches in science education in many countries, including Malaysia.

There is a long history of practical work in science education, beginning in the mid-1850s. Practical work was first introduced in schools in the Nineteenth Century in Britain (Atkin \& Black, 2007). From the mid-Nineteenth Century until the late Twentieth Century, the method of practical work gradually developed into three major approaches. Hodson (1996) classified these approaches as the discovery, the process, and investigation approaches. All three approaches have influenced the development of the science curriculum in Malaysia, particularly the teaching methods.

In the mid-Nineteenth Century, practical work was driven by a teacher-centred approach and science teachers perceived practical work as a means to disseminate scientific concepts. Teachers dominated teaching and learning activities, performing demonstrations to teach students about scientific phenomena, rather than getting students involved in practical activities (Hodson, 1990). Malaysia implemented this approach in the early 1950s in the Traditional Science Curriculum for Secondary Schools and this was criticised, as students schooled under this curriculum learnt the scientific content without fully understanding it (Meerah, 1999).

However, in the early 1960s, the 'discovery approach', originating in the US, for the new Biological Sciences Curriculum Study, was developed in the UK in a number of courses, such as Physical Science Study Committee and Nuffield courses. According to Wellington (1998), science educators of the time believed that students should be involved in hands-on activities and discover scientific knowledge. In the late 1960s, Malaysia adopted the science curricula developed in the UK (Nuffield courses), which were used for 16 years and students were expected to discover concepts for themselves. A number of researchers have criticised this approach (Gott \& Duggan, 1995; Millar \& Driver, 1987; Wellington, 1998), claiming it to be theory-laden (Millar \& Driver, 1987; Wellington, 1998) as the teachers expected students to 
learn concepts based on observation. Hodson (1996) argued that this approach was naive inductivism, due to the assumption that science begins with observations, and generalisations which can be made, based on results or data. Hodson (1996) concluded that "the discovery approach was philosophically unsound and pedagogically unworkable" (p. 18).

In the US, the implementation of practical work then moved from the discovery approach to the process approach in the late 1960s and this happened a decade later in the UK. Various types of process course curricula were introduced including: A Process Approach in the US and Warwick Process Science in the UK (Woolnough, 1991). The underlying assumption of the process approach was that students could construct science knowledge by engaging in the scientific process (observing, inferring, hypothesising etc.). The process approach was part of student-centred learning activities where the students were expected to act and think as a scientist. The following assumptions led to the development of view that the scientific concepts were not content free and less important than the process. A further belief was that the students could imitate the work of scientists and transfer skills from one context to another. Students could also develop the scientific concepts from engagement with the process. Hodson (1996) contested those assumptions, arguing that not all students were able to transfer skills from one context to another.

In the late 1980s there was a change in thinking and a move towards a holistic view of practical work taking an investigation approach (Woolnough, 1991). It was introduced in England and Wales, and was included in the English National Curriculum. Through the investigation approach; students used, considered, and made judgements before proposing ways of answering the questions or solving problems, which was different from the discovery and process approaches, as students were required to justify their actions rather than following a set of instructions as discrete steps without understanding them. It was hoped that using this approach, students could develop procedural and conceptual understanding in science. However, the investigation work that schools carried out was distorted. As with the other approaches, what was implemented was not what was being promoted; as Roberts and Gott (2004) argued, "...the investigation has become synonymous with practical work in science and in some textbooks any activity that uses apparatus seems to be called an investigation" (p. 113). 


\subsubsection{Teachers' views of practical work}

This section reviews several quantitative and qualitative studies to gain insight into teachers' aims for doing practical work.

Teaching science by doing science has become a key element of science education internationally (Hipkins et al., 2002). As a pedagogical approach, doing science does not always refer to a scientific investigation but also to hands-on activities (Millar, 1998). Hodson (1996) argued that if the aim of a teaching and learning activity was to ensure students understand the role of scientific investigation, then it was necessary for teachers to plan lessons that link learning science with doing science. Minstrell and van Zee (2000) explained that science investigation provided authentic experience to students. The students were not only active in doing practical work, but also involved in the thinking behind doing science (Gott \& Duggan, 1995). For example, Gott and Duggan (1995) explained that in a scientific investigation, the students were involved in judging the quality of data.

A number of researchers have conducted quantitative research to investigate science teachers and students' views regarding learning from practical work (for example, Hodson, 1990; Abrahams \& Millar, 2008). In the UK, Kerr (1963) examined the aims of implementing practical work from the perspectives of secondary school science teachers. Kerr (1963) was the first researcher to investigate the aims of practical work from the perspective of science teachers at different levels of the school system in England and Wales. In his study, he proposed ten aims of practical work, as follows:

i. To encourage accurate observation and careful recording;

ii. To promote simple, common-sense, scientific methods of thought;

iii. To develop manipulative skills;

iv. To give training in problem-solving;

v. To meet the requirements of practical examination regulations;

vi. To elucidate the theoretical work so as to aid comprehension;

vii. To verify facts and principles already taught;

viii. To be an integral part of the process of finding facts by investigation and arriving at principles;

ix. To arouse and maintain interest in the subject, and

x. To make biological, chemical and physical phenomena more real through actual experience (Kerr, 1963, p. 21). 
The survey found that teachers who taught science at different levels had different aims. For example, the teachers who taught at Key Stage 3 (age 11 to 14-years-old) ranked the aim of arousing and maintaining interest in the subject as the main priorities in conducting practical work. At Key Stage 4 and $6^{\text {th }}$ form, the teachers had changed their aims of conducting practical work. They did not perceive the aim of arousing and maintaining interest in the subject as their main concern. The teachers who taught Key Stage 4 ranked the aim of ensuring the students to be an integral part of the process of finding facts by investigation and arriving at principles. However, the teachers in the $6^{\text {th }}$ form related the aim of conducting practical work with data gathering. They perceived that practical work was important in encouraging students to make accurate observations and careful recording. It seemed that, the aim of conducting practical work changed significantly across the full secondary age range. Kerr concluded that, although the teachers strongly emphasised conducting practical work individually, however, this situation had caused issues:

\begin{abstract}
Inflexible, repetitive, outmoded, and often inadequate to integrate with the theory...in all science subjects, there was plenty of practical work being done but it was not well integrated with the theory and it was unlikely to achieve the unique educational value often claimed [by educational theorists] for it (Kerr, 1963, pp. 95-96).
\end{abstract}

In spite of changes that have taken place over the last 50 years, there are limited studies that have been carried out to investigate the teachers' views about the aims for conducting practical work. There were two studies conducted by Domin (1999) and Beatty and Woolnough (1982) which sought to understand teachers' and students' views in Key Stage 5 (age 17 to 18-years-old) of the aims of practical work. A study conducted by Thompson (1975), focused on the teachers' views about practical work. Beatty and Woolnough (1982) were concerned about Key Stage 3 (age 11 to 13-years-old) teachers' views about practical work. Thompson (1975) developed 20 aims for practical work and the participants were required to rank the aims accordingly. He extended the initial lists of aims developed by Kerr, based on the implementation of the Nuffield Science curriculum.

The results of Beatty and Woolnough (1982) showed that there were no drastic changes in aims of conducting practical work in comparison with Kerr's survey study, in spite of the implementation the curriculum (Nuffield curriculum) at that time. They found that the teachers'

\footnotetext{
${ }^{5}$ Key Stage is the term used in the UK that refers to a level. Key Stage 4 (age 15 to 16-year-olds) relates to the fourth and fifth years of secondary school education. Key Stage 5 (age 17 to 18-year-olds) refers to the two years of post-compulsory secondary school education.
} 
aims in conducting practical work could be divided into two categories which were as "an aid to theory and developing practical skills" (Beatty \& Woolnough, 1982, p. 28). It seemed that the teachers were concerned with developing scientific skills, such as making correct observations and recording the results accordingly. They also wanted to foster positive attitudes towards science and provided opportunities for students to manipulate the objects to make sense of the phenomena that they produced through practical work. However, the teachers believed that practical work was less effective in strengthening scientific knowledge or understanding it, which is contradicted by Hodson's (2014) more recent views that carefully crafted practical work can be used to illustrate science concepts.

Lynch and Ndyetabura (1983) and Wilkinson and Ward (1997) were researchers who studied the aim of conducting practical work from students' and teachers' perspectives. Both studies were conducted in Australia through questionnaires. Lynch and Ndyetabura (1983) attempted to compare students' and teachers' aims of conducting practical work at different levels: "grade 7/8 (age 12 to 13-years-old); school certificate (age 15 to 16-years-old), and matriculation (age 16-years-old and above)" (p. 664). The study was conducted with 257 science teachers and 724 students. Both teachers and students completed the same set of questionaires. There were 10 possible aims, as listed by the researchers, and the participants were required to rank the aims of practical work based on their own experiences. The findings of the study showed that the teachers' priorities in conducting practical work at grade $7 / 8$ were significantly different when compared to certificate and matriculation levels. At grade $7 / 8$, the teachers perceived that the development of scientific skills was important in conducting practical work. They ranked the aims such as "give training in skills and techniques" and "careful observation" as the main priorities, as opposed to reasoning skills, such as "interpret observation logically". However, the teachers' views about aim of conducting practical work at certificate and matriculation levels were similar. They aimed to "prepare students for enrolling in science-related fields in the future". Thus the aim of encouraging "students to study science further" was significantly higher for conducting practical work at the higher level (p. 666).

Lynch and Ndyetabura (1983) found that the students' aims in conducting practical work were totally different from the teachers. The students at grade $7 / 8$ did not perceive practical work as a teaching approach to "develop skills and technique". They ranked the aim of "making careful observation" as their main priority. They also did not perceive the aim of "developing understanding towards scientific concept" (p. 668). In contrast, students at the higher level ranked the aim of "training in skills and techniques" in conducting practical work as their main 
priority. It seemed that different responses from the different groups of students were due to type of practical work that they had experienced.

In summary Lynch and Ndyetabura (1983) found the mismatches in teachers' and students' views of the priorities in conducting practical work; the teachers misjudged the benefits that the students might get from practical work. Despite that, the teachers and students shared some common views about the aims of conducting practical work. Both teachers and students did not consider the aim of "preparing students for final examination" as the main priority in conducting practical work. Practical examinations were not inclusive at any level of the education system in Tasmania where the study took place.

Fourteen years later, Wilkinson and Ward (1997) replicated the Lynch and Ndyetabura's (1983) study, with a smaller sample size. The study was conducted in six different schools in Victoria, Australia. The total number of students was 139 (59 male and 80 female) in six classes at Year 10 level of secondary school and six science teachers participated in this study. The sample size represented $20 \%$ of the total population at Year 10 level in this region. The findings showed that there were similarities between students' and teachers' responses regarding the aims in conducting practical work. Both teachers and students ranked the aim to "prepare students for examination" as the least important aim of practical work. They (students and teachers) also ranked the aim to "make science more interesting and enjoyable through actual experience" as the main priority in conducting practical work (p. 608). The results of the study supported the findings of Lynch and Ndyetabura's study in 1983. The survey also showed that both teachers and students believed practical work could perhaps develop understanding of the theory. Although Wilkinson and Ward (1997) reported that both teachers and students shared a similar view in conducting practical work, none of the schools provided a written policy to support the development of theory through practical work. It seemed that the aim might be difficult to achieve due to the educational settings that did not support the development of conceptual knowledge.

However, there was another disagreement or mismatch between students' and teachers' views about practical work. The teachers perceived that practical work was useful in everyday life but the students did not share the same thought. This situation might have occurred, as the students did not see the relevance of laboratory work in their everyday experiences. They would have had difficulty with more than just the instructions, as it was not apparently related to their daily life. The teachers' perceptions might be influenced by their personal experiences. 
Wilkinson and Ward (1997) inferred that the students may not have understood the instructions and the objectives of the practical work.

Swain, Monk, and Johnson (1999) did an interesting comparative study about the aims in conducting practical work from the teachers' perspective in three different countries; Egypt, Korea, and the UK. There were 155 science teachers (35 Korean teachers, 54 Egyptian teachers, and 66 UK teachers) who participated in this study. The teachers were required to rank the aims for conducting practical work according to their practices. The questionnaire was based on studies conducted by Kerr (1963) and Beatty and Woolnough (1982). Swain et al. (1999) found that teachers from different countries ranked the aims of practical work differently. The Korean teachers perceived practical work as an approach to developing conceptual knowledge. Their views might have been influenced by their teaching approaches. They emphasised aspects that may lead to rote learning, such as "findings facts, verifying facts, and remembering facts" (p. 1315). In contrast, UK teachers perceived practical work as an approach for developing skills in conducting a scientific investigation. They were keen on developing creativity among students to solve problems, and produce critical and logical thinking that focused on creating new knowledge rather than confirming existing knowledge. The Egyptian teachers ranked "to develop creativity", "to develop self-reliance", and "to give experience in standard technique" highly (p. 1316). It seemed that the combinations that were ranked by the Egyptian teachers had no connection between each aim that they ranked.

All the participating teachers perceived the aim of conducting practical work as: "to practise seeing problems and seeking ways to solve them, to arouse and maintain interest, to make phenomena more real, for finding facts and arriving at new principles" (p. 1318). It seemed that the teachers' aims could be grouped into categories, which were: making new knowledge (e.g., to practise seeing problems and seeking ways to solve them, for finding facts and arriving at new principles), and helping students to learn science (e.g., to arouse and maintain interest, and to make phenomena more real). The differences in teachers' responses might have been influenced by different factors, which were: the curriculum that was implemented in those countries, and the epistemological standpoints. This appears to show that the aims for conducting practical work reflected the teachers' pedagogical approaches and the educational settings of the countries.

Then, after 47 years, Abrahams and Saglam (2010) replicated Kerr's (1963) work. They examined whether there had been any changes in teachers' aims for conducting practical work since the first large survey, conducted by Kerr. As opposed to studies conducted by 
Beatty and Woolnough (1982), Abrahams and Saglam used the original questionnaire that had been developed by Kerr. Their study included four different school systems in the UK, which were: comprehensive schools, grammar schools, independent schools, and specialist schools. However, the sample size of Abrahams and Saglam's study was smaller (363 participants), compared with the sample size of Kerr's study (701 participants). The findings showed that the teachers' views about the aims of practical work at Key Stage 3 remained unchanged in comparison with the findings of studies conducted by Kerr (1963) and Beatty and Woolnough (1982). Over these decades, the teachers' priorities in conducting practical continued to be to foster positive attitudes towards science. In addition, at Key Stage 3, the students did not have to sit a practical examination, which reduced the pressure of preparing students for the assessment.

However, there was a significant change in the teachers' view of the aims in conducting experiments, especially at Key Stages 4 and 5. Abrahams and Saglam (2010) perceived the aim "to prepare students for assessed practical work - including Sc1 investigation (practical assessment of public examination)" as the main priority (p. 762). It seemed that the teachers' priorities were to develop procedural knowledge, such as "to encourage accurate observation and careful recording", "to promote common sense and scientific method of thought", or "to develop manipulative" skills decreased significantly (p. 762). The implementation of practical assessment played an important role in changing the science teachers' views about the aims of practical work. The educational environment that focused on preparing students for the examination had influenced the teachers to meet the assessment demands.

The findings of previous studies portray the teachers' and students' perceptions about practical work rather than the real practice in the classrooms. The researchers conducted most of their research through surveys, which provided a general view of practical work but did not present the nature of practical work as conducted in classes. They also ranked practical work generally without considering different types of practical work that the teachers carried out with students in science lessons. They also overlooked the effectiveness of different types of practical work in promoting students' learning. Thus, the results of the studies portrayed the rhetoric, rather than reality of practical work (Abrahams \& Millar, 2008).

\subsubsection{Types of practical work}

In order to assess the effectiveness of practical work, it is important to understand the different types of practical work. Some researchers categorised practical work according to the degree 
of openness of the task (Fradd, Lee, Sutman, \& Saxton, 2001; Herron, 1971; Schwab, 1962). "Open" refers to the experiments conducted by students and "closed" to those performed entirely by teachers (e.g., a demonstration or a computer simulation). Baillie and Hazel (2003) classified practical work according to different levels of enquiry. At the highest level of enquiry, teachers give less guidance when conducting practical work and the teachers did not know the answers. Others (Hassard \& Dias, 2009) classified practical work in terms of students' autonomy in conducting it, that is, whether it was highly controlled by teachers or students.

A controlled exercise is one with the least student autonomy and is sometimes called "a recipe practical" or a "cookbook approach" (Woolnough, 1991). Domin (1999) called it "an exploratory activity", and it was considered a popular teaching approach. Gott and Duggan (1996) considered it to be the lowest enquiry level of practical work. In controlled exercises, science teachers designed tasks that required students to verify the scientific theory (Baillie \& Hazel, 2003). They provided detailed information regarding the aims of the task, materials, and procedures, including written materials and verbal instructions. The outcomes were already known and students compared their results with the expected results (Domin, 1999).

Research conducted by Kamarudin, Halim, Osman, and Meerah (2009) in Malaysia shows that the teachers played a dominant role in ensuring that the practical work runs smoothly. They closely monitored students work in groups and gave instructions to make sure they completed the practical task. This approach may be easy for teachers as they can use the prescribed activities from year to year without too much work. It is also cost effective and can be completed in a short time (Domin, 1999). However, this approach can be tedious with little cognitive value, and may lower students' interest in science (Baillie \& Hazel, 2003; Hodson, 1990). In contrast to controlled exercises, an investigation provides more opportunities for students to engage with real scientific investigation. Wellington (2006) suggests that investigations vary in the degree of structure. Students may have full autonomy in conducting their own investigation or science teachers may control the investigation (Wellington, 2006). An investigation can be highly structured or unstructured in terms of its aims, the materials, the procedure, and the length of the investigation (Hazel \& Baillie, 1998). A scientific investigation may take a few minutes to complete or weeks, to get the results.

In structured investigations, sometimes the science teachers provide the aims and materials required by students, and students have autonomy to plan how to find the answers to their query (Baillie \& Hazel, 2003). However, in the unstructured investigation (also known as openended), the aim is sometimes provided, but the students plan other components of the 
scientific enquiry. By engaging students in unstructured investigation, they have more opportunities to experience scientific enquiry, which may motivate them to learn science (Hazel \& Baillie, 1998). The limitations of unstructured investigation are that they require too much time and resources, they may be risky in terms of safety, the teachers may face management issues with large numbers of students involved in their own investigations, and teachers may be uncomfortable, not knowing the outcome (Baillie \& Hazel, 2003).

Watson, Goldsworthy, and Wood-Robinson (2002) suggested that investigations can be conducted in different ways and gave six types of investigations, which were: "classifying and identifying; fair testing; pattern seeking; exploring; investigating models; and making things or developing systems" (p.62). These types of investigation are called approaches to investigation and are promoted as aims in The New Zealand Curriculum (Ministry of Education, 2007). Despite many types of scientific investigations, "the fair testing" approach seems to be preferred by teachers (Tytler, 2007). Tytler asserted that scientific investigations that control variables are not sufficient to portray actual scientific endeavour.

Projects are interdisciplinary and long term. It is another main approach in scientific enquiry, which allow students to evaluate real-life problems, plan the possible solutions before implement the chosen solution to solve problems. Science teachers believe that students are more motivated to learn because they have greater autonomy (Hassard \& Dias, 2009). However, the project teaching approach becomes a hindrance when students expect science teachers to provide them with the correct answers (Hassard, 2005). Teachers can implement the project teaching approach by making models and developing systems, which are also types of investigations (Watson et al., 2002). Students may use their conceptual and procedural knowledge to make models or develop systems to understand concepts or to explain phenomena that they are interested in investigating. Through project work, students may have more autonomy in defining aims, identifying resources, and selecting procedures, with more opportunities to develop oral and written communication skills when they report and present their findings (Baillie \& Hazel, 2003). Projects can sometimes raise safety issues for teachers, and students may need guidance to ensure the projects they carry out are worthwhile (Baillie \& Hazel, 2003).

To conclude, there is a difference between how scientists conduct scientific investigation and what might happen in a school science laboratory. Scientists conduct science investigation in different ways and do not rely on a single method to solve problems. The selection of the method depends on the nature of the investigation Knorr-Cetina (1999). The investigations 
implemented in schools are mostly predetermined by teachers, which might reduce students' opportunities to learn scientific investigation from different perspectives. Millar (2004) suggested that there are significant differences between research laboratories and the school science laboratory and that "scientists explore the boundaries of the known and believe that they are capable of doing so" whereas students are only trying to come to terms with already accepted knowledge (p. 15). This distinction has relevance to this study which investigated the types of practical investigations implemented by Malaysian teachers and their reasons for doing so.

\subsubsection{Aims of practical work for learning science}

There is some agreement amongst science education researchers about the aim of science education, which includes developing conceptual knowledge, procedural knowledge and an understanding of the nature of science (Hodson, 1998; Hodson, 2014; Lederman et al., 2014; Monk, 2006). In essence, this also means that the aims for learning through practical work in science depends on the relative emphasis researchers and teachers place on the aforementioned aims for science education. Various aims for learning through practical work have been articulated by researchers, internationally (Hofstein \& Lunetta, 2004; Lunetta et al., 2007; Millar, 1998; Woolnough \& Allsop, 1985). According to Woolnough and Allsop (1985) the aim of practical work is for students to: develop scientific skills, be a problem-solving scientist, and experience the phenomenon.

Hodson (1990) described the aims for practical work offered by teachers. These aims go beyond the development of conceptual and procedural knowledge and include skills and attitudes. Hodson found the following reasons were given by teachers for using practical work in their classes:

i. To motivate pupils, by stimulating interest and enjoyment;

ii. To teach laboratory skills;

iii. To enhance the learning of scientific knowledge;

iv. To provide insight into scientific methods and develop expertise in using them;

v. To develop certain scientific attitudes such as open-mindedness, objectivity, and willingness to suspend judgement (p. 34).

Lazarowitz and Tamir (1994) considered that understanding scientific concepts was the main aim of practical work. They suggested that practical work could provide real experience and 
the opportunity for teachers to identify student misconceptions and help students to extend or modify their understanding of concepts. Lazarowitz and Tamir recommended different approaches to accessing students' prior knowledge, such as observation, listening, and questioning while they were engaged with the experiment, and allowing students to reveal their thinking and understanding.

Wellington (1998) stated that the advantages of including practical work in science lessons were to promote the development of cognitive and affective skills. Students could improve their understanding of science and confirm what theories they have learnt. He referred to the development of the affective domain among students and claimed that practical work provided excitement for the students. He stated that they might find practical work interesting, which "...helps to promote positive attitudes towards science" (p. 7). He explained that students could develop manipulative skills through the handling of objects, for example, by taking measurements. Wellington explained that students could develop processing skills, such as making predictions, inferring and making conclusions and "...learning to work with others and develop an understanding of scientific enquiry" (p. 7).

Millar (1998) discussed the general aims of conducting practical work and focused on the development of conceptual knowledge and knowledge about science. However, he argued that the development of conceptual knowledge could take place during discussions as students engaged in practical experiments. He stated that students' practical sessions and discussions should be simultaneous as they are both related. Millar's idea is supported by Hodson (2014) adding that practical work may help students to make links between the materials they have manipulated and the scientific concepts, which is illustrated in Figure 3.1.

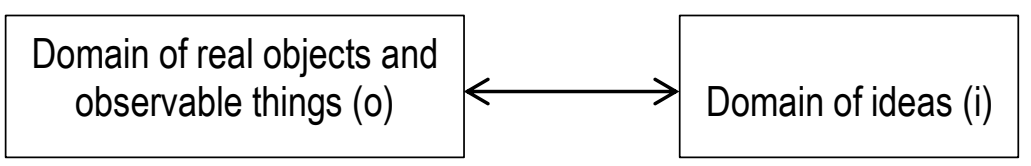

Figure 3-1: Practical work: linking two domains of knowledge (Millar, 2004, p. 9)

Millar suggested that teachers play an important role in providing scaffolding for the students to make the links between the domains of objects and ideas. Similarly, Wellington (2005) highlighted the teachers' role in bridging knowledge and experience. He argued that the development of student understanding about the 'world' of experiences (the phenomena that students observe) and the 'world' of explanation (the concepts and theory) does not simply happen by engaging in practical work. He claimed that "the gap between 'knowledge that' 
(phenomenon that students observe) and 'knowledge why' (understanding the reasons why the phenomenon occur) is not filled by unguided 'discovery' or unsupported activities" (p. 107). Pekmez et al. (2005) examined English science teachers' understanding regarding the nature and purpose of practical work, particularly scientific investigation. This study was conducted with twenty-four science teachers from different types of schools in England and Wales through semi-structured interviews. This study differed from the research that was conducted by Kerr (1963), as the aims of conducting the practical work were elicited from the science teachers' viewpoints, rather than pooled from the presented purposes. The science teachers' responses were generated through interviews to gain an insight into their actual practice in science practical work. The findings of the Pekmez et al. study revealed that the science teachers' aims for practical work could be classified into four major categories, including; development of the students' scientific knowledge and procedural skills, motivating students towards science and sharpening students' communication skills.

Hofstein and Lunetta (2004) and Hodson (1996), shared similar ideas in classifying the aims of practical work. Hofstein and Lunetta (2004) added 'scientific habits of mind' and 'understanding the nature of science' to the list of aims proposed by Hodson. They believed that the principle aims of conducting practical work were to enhance students':

i. Understanding of scientific concepts;

ii. Interest and motivation;

iii. Scientific practical skills and problem solving abilities;

iv. Scientific habits of mind;

v. Understanding of the nature of science (p. 38).

In a recent study, Lunetta et al. (2007) provided a similar list, but added a new category of 'argumentation from data'.

Hodson (2014) argues that the most effective way to learn to do science is by doing science and recommends that the best way to achieve this is by working alongside experienced practitioner who can provide guidance, advice, criticism and support on the spot. Hodson asserts that "by doing science, students will learn to do it better" (p. 14). He suggests a threephase approach: 
i. Modelling (Teacher makes explicit, justifies, explains, and demonstrates and approach appropriate to the focus of inquiry).

ii. Guided practice (students perform specified tasks and selected aspects of the inquiry with the help and support of the teacher).

iii. Application (students perform independently of the teacher) (p. 14).

Hodson (2014) argues that by following successive cycles of observing an expert, practicing, and applying what they have learnt, students can become intellectually independent to take on the responsibility of planning, conducting and reporting their inquiry. This would be a useful aim to aspire students to learn from practical work.

There are similarities in the researchers' classification of the aims of conducting practical work. All of them include the development of conceptual understanding (facts, laws, and principles) in their lists, some include the development of scientific skills (manipulative and science process skills) and some say the conditions that allow the development of conceptual knowledge can take place in practical lessons. Another aim is to foster positive attitudes and motivation to learn science. I use this classification of aims to examine teachers' aims in conducting practical work in Malaysia alongside examining the implementation of practical work in terms of conceptual understanding, development of scientific skills, and linking both domains as required by the curriculum.

\subsubsection{The relationship between aims in conducting practical work and their practices}

There are a number of quantitative research studies that have attempted to illustrate the connection between teachers' aims and their practice, when conducting practical work in schools (Abrahams \& Millar, 2008; Kang \& Wallace, 2004; Pekmez et al., 2005). In these studies the researchers were involved in collecting data through classroom observations, interviews with the participants, and document analysis.

Kang and Wallace's (2004) research sought to establish the relationship between science teachers' epistemological beliefs, goals and practice in laboratory activity. Their study used multiple case studies in North America with three experienced science teachers (science teachers who each had 16 to 17 years of teaching experience). The data was collected using semi-structured interviews, classroom observations and document analysis of the teaching materials used by the science teachers. The findings of this study reported that some science teachers had naive epistemology about science and the scientific method. They views the aim 
of science laboratory work was merely to seek the right answers, rather than developing students' scientific skills or knowledge. Kang and Wallace concluded that the teachers' beliefs about science and the scientific process had strong influence on their teaching practice, especially through practical work.

Ottander and Grelsson (2006) investigated experienced biology teachers' views regarding the role of laboratory work, as required by the Swedish national syllabus. Four experienced biology teachers (who each had more than 15 years of teaching experience) from two upper secondary schools were involved in this study. The data was collected through student and teacher questionnaires, informal observations and semi-structured interviews. They found that the biology teachers realized that science laboratory work made a significant contribution to helping the students in making meaningful connections between theory and practical experiments. Further they concluded that laboratory work stimulated student enjoyment and interest, taught them laboratory skills and helped the students to challenge their own alternative conceptions. However, not all the biology teachers in this study emphasised the process of scientific investigation as an important outcome of practical work, although it was stated in the curriculum document (Ottander \& Grelsson, 2006).

Abrahams and Millar (2008) investigated the effectiveness of practical work as a teaching and learning method in science. The researchers examined twenty-five typical science lessons in eight different schools in England and Wales (three urban schools and five rural schools) at Key Stages 3-4 (age 11 to 16 years-old). The findings of this study reported that some teachers, especially those working outside their specialist subject, conducted the practical work by following the guidelines provided by the schools. Consequently, activities that the teachers had planned provided fewer opportunities for unexpected questions or events that arose during the practical work. Furthermore, the students were able to do what the teachers intended them to do but were unable to make connections between the intended scientific ideas or the concepts that the teachers wanted the students to learn.

The above review has presented a summary of literature findings of qualitative research about the relationship between teachers' espoused aims and actual practice of practical work. Even though these issues have been intensively investigated in developed countries like the UK, Canada, the US and Australia, at all levels of the education system, (primary, secondary, and tertiary), the nature of practical work in the Malaysian lower secondary schools has not been explored extensively. The next section looks at research into the effectiveness of practical work. 


\subsubsection{The effectiveness of practical work}

A number of studies have investigated the effectiveness of practical work in relation to:

i. Developing conceptual knowledge;

ii. Developing procedural knowledge;

iii. Developing positive scientific attitudes and values.

\section{Practical work for enhancing the learning of scientific knowledge}

Researchers have examined the effectiveness of practical work in developing conceptual understanding through quantitative and qualitative approaches. For example, Watson, Prieto, and Dillon (1995) conducted a study to investigate the development of scientific knowledge on a specific topic through engagement with practical work, by using an experimental design. They compared students' understanding about the concept of combustion in the two different countries (Spain and England). Both countries required similar learning objectives to be met for the topic of combustion for 14 to 15 -years-old students. The total number of participants in each country was 150 students who attended mixed-ability, co-educational, comprehensive schools. Students' understanding about combustion was explored through a set of questionnaires. The results of the study showed that there were significant differences in the teaching approaches, in terms of the expressions used and the substances that the students manipulated during practical work, but not in student understanding of combustion. It seemed that the differences in teaching approaches might be the factors that caused the differences in students' responses. The researchers concluded that, although practical work was practised intensively in England, it "had only a marginal effect on their understanding of combustion" (p. 487).

A study conducted by Thompson and Soyibo (2002) examined the differences in student understanding about the concept of electrolysis through experimental design. One hundred and thirty-eight, grade 10 students (14 to 16-years-old), from two different schools (traditional and technical schools) in rural Jamaica participated in this study. Each school had one control group and one experimental group. In the experimental group, the teachers taught through the lecture method, by teacher demonstration, classroom discussion and practical work in small groups (three to four students). In the control group, the teachers taught through similar teaching approaches but without practical work. Nine lessons were observed in both groups for four weeks. The students' understanding about electrolysis was measured through the students' performance in a pre- and post-test of Understanding of Electrolysis Test (UET). The 
results of the study showed that the experimental group performed better in the UET, compared to the control group who were not involved in practical work. Although the study had a small sample, the inclusion of practical work as one of the teaching approaches provided the insight that practical work potentially influenced student performance in the understanding of the concept of electrolysis.

Thijs and Bosch (1995) made a comparison between two different teaching approaches, which were teacher demonstrations and students' practical work, to understand the concept of forces on objects at rest. The study was carried out with 160 students (15-years-old) in two schools in the Netherlands. Three classes were taught using demonstrations and the other three classes were taught through practical work. The teachers taught similar content and used similar instructions. Students' understanding of the concepts was measured through written probes of conceptual understanding, analysis of students' work and observation notes by researchers. From the study, they found that "overall cognitive effects of small-group practical's and demonstrations do not differ" (Thijs \& Bosch, 1995, p. 34). However, they found that male students could perform better in practical work, as opposed to female students.

Similarly, Freedman (1997) examined the impact of practical work on student achievement in examinations. The study was conducted with $9^{\text {th }}$ grade students (14 to 15-years-old) in the US. There were 270 students from a large, urban, high school involved in this study. The study adopted an experimental design, where the participants were selected from twenty physical science classes randomly. Six out of the twenty classes had immigrant students with Limited English Proficiency (LEP). The study showed that the students who were involved in the laboratory programme were influenced positively in their examination performances, compared with the students who did not have a laboratory programme. The students in the experimental groups scored significantly higher $(p<0.01)$ on achievement in scientific knowledge.

Tsai (1999) conducted a study with twenty-five, $8^{\text {th }}$ grade students (13 to 14 -years-old) in Taiwan. The study showed that students preferred to do open-ended investigations. Other students said that guided practical work helped to make scientific concepts clear. The students added that participation in practical work might act as an aid in remembering scientific concepts. They suggested that practical work helped them to confirm the facts presented in the textbook or by the teachers. 
Hart, Mulhall, Berry, Loughran, and Gunstone (2000) conducted a case study in Australia to understand the implementation of practical work in their schools. The participants said that practical work was not the best teaching strategy to construct abstract conceptual knowledge. However, the researchers found that practical work might provide concrete evidence of the phenomenon leading to a basic understanding of the concepts. Furthermore, practical work helped students to develop procedural knowledge, such as designing an investigation, verifying the procedure and results and communicating their findings.

Similarly, Abrahams and Millar (2008) conducted twenty-five case studies in eight schools in England. They conducted one or more classroom observations of science lessons in Key Stage 3 or Stage 4 (age 11 to 14-years-old and 15 to 16-years-old respectively) to understand how practical work is carried out in schools. The results showed that teachers focused on teaching substantive knowledge, rather than the procedural knowledge of scientific inquiry. There is little evidence that the teachers required students to connect the data that they had collected with the concepts that they should learn.

To conclude, the empirical studies show limited evidence to support the theory that practical work had a different impact on the development of conceptual knowledge, when compared to teacher demonstration or other non-practical, teaching approaches. It seems that an overwhelming endorsement of the importance of practical work by the teachers and stakeholders is not supported by the results of the studies.

\section{Practical work for developing scientific skills}

A number of empirical studies have examined the effectiveness of practical work for the development of scientific skills (Abrahams \& Millar, 2008; Atan \& Noordin, 2008; Gott \& Duggan, 1995). Some researchers are in agreement with the view of Roberts and Gott (2004) about the development of procedural understanding and student ability to put together a solution to a practical problem using their own understanding of concepts and skills, rather than following a recipe provided by the teacher.

Gott and Duggan (1995), investigated the students who performed science investigations. They found that the students' performance in designing the investigation was good. However, the students showed some weaknesses in identifying the variables. Students paid less attention to verifying the results, although they had already identified that there was a defect in their experimental design. It seemed that the students overlooked the importance of evaluating their results before they could make a claim or a conclusion. 
Similarly, Fairbrother and Hackling (1997) found that students lacked scientific skills, especially in designing an investigation and analysing the data. Very few students planned how they would control or measure variables or record the data before they conducted the investigation. It appeared that the practical work in which they were engaged was unable to assist the students in recognising the weaknesses of the methodology of their experiments.

In relation to scientific skills, Abrahams and Millar (2008) found that practical work was effective in getting the students to do what was intended with the objects and materials. The use of recipe practicals in most of the practical lessons had a significant effect in assisting the students to complete the task. However, it seemed that recipe practicals sessions were less effective in getting the students to reflect upon their actions or observations with scientific ideas. The researchers in this case attributed this recipe practicals sessions approach to limited time for the teachers to engage with the students' scientific ideas.

Atan and Noordin (2008) investigated the relationship between students' achievement and experimenting on the topic of Force in Johor, Malaysia. The study involved 134 form four students (age 16 to17-years-old) from five different schools, who were taking physics as an elective subject. Student achievement in planning the investigation was measured through a paper and pencil test. The students were required to design their experiment by formulating the hypothesis, writing the steps they would follow how they would record the data and analyse it. The findings showed that the students could not formulate the hypothesis correctly; they had problems in designing the experiment, especially in identifying the manipulative and responding variables and stating the steps they would follow, correctly. The students also showed a lack of skill in verifying the results and analysing the data, identifying the variables and graphing the results. Despite the students showing some weaknesses in handling the data, they managed to draw the setup of the experiment and state the aims of the practical. Overall, the results of the study showed that the majority of students were unable to plan the experiment successfully. Atan and Noordin (2008), pointed out that practical work the students experienced in science lessons was less effective in preparing students to be involved in planning investigation.

The research cited above shows that engagement in practical work does not always lead to the development of procedural knowledge or understanding. Through engaging in practical work most students can follow a recipe to complete a task, however, only a small number are able to plan an investigation. Students also had limited skills in writing hypotheses, measuring and controlling variables and most were unable to make the link between the science concept 
and the practical work they had carried out. Of particular interest to the present research is the finding that comparatively few Malaysian students were able to plan an investigation compared to their counterparts in the UK.

\section{Practical work in developing attitudes and values}

Recent studies have shown that students' positive attitudes towards science decline as they move from primary to secondary school and that this decline is more significant for females (Osborne \& Dillon, 2010; Osborne, Shirley, \& Collins, 2010). Students are expected to learn scientific and procedural knowledge while they are engaged in scientific investigation. They are also expected to learn other skills and develop positive attitudes and values whilst engaging with the task (Abrahams, 2009). Several studies have explored the effectiveness of a different teaching approach in fostering a positive attitude in students towards science in general (Dawson, 2000; Francis \& Greer, 1999; Gardner, 1975; Osman, Iksan, \& Halim, 2007; Solomon \& Harrison, 1991). Some studies have been conducted to understand the development of a student affective domain through practical work (Abrahams, 2009; Chin \& Kayalvizhi, 2005; Palmer, 2009). Chin and Kayalvizhi (2005) suggested that there was limited research examining the effectiveness of practical work in fostering attitudes, especially during open-ended investigations. Freedman (1997) suggested that a hand-out of the laboratory instructions might promote students' positive attitudes towards science. Another study by Parkinson, Hendley, Tanner, and Stables (1998) investigated the attitudes of students (13 to 14-years-old) towards science in South Wales, four years after the National Science Curriculum was implemented in schools. The researchers surveyed over 1000 students, and interviewed a representative sample (72 students). The study showed that practical work was a significant factor that contributed towards positive attitudes to science. In the interviews, the students explained that they enjoyed observing the phenomena and communicating with other students, whilst engaging the task at hand.

A study by Piburn and Baker (1993) revealed that practical work provided opportunities for students to work with others and it could motivate students. The researchers interviewed 149 primary and secondary school students. The findings showed that students perceived practical work in primary schools as an interesting learning activity because they had the opportunity to explore the materials without feeling worried about making mistakes or not getting the correct answers. However, students' perceptions changed as they progressed to junior high schools. The researchers found that the students did not feel comfortable with practical work any longer as the activities offered by teachers were based on worksheets and workbooks. The 
experiments were convergent and less exploratory, and the students were concerned about getting the correct answers or results.

Morrow (1999) conducted a attitudinal survey of students who studied biology in schools. The findings showed that more than fifty-three per cent of the respondents preferred an openinvestigation, compared to a recipe practical. They preferred to do the open-investigation because they said it was more fun, challenging, and like real science. They had the opportunity to design their own experiment. More than $70 \%$ of the students suggested that the chance to plan their own investigation helped them to understand the concept better, compared to a structured investigation. However, some students, who preferred the structured investigation, found that it was easier to perform the investigation without making too many mistakes.

Several researchers claim that practical work, which is conducted in groups, is able to foster students' social skills of communication, interaction and co-operation. However, a study conducted by Wellington (1998) showed that "group work often reveals domination by forceful members, competition, lack of engagement for some and division of tasks which may leave one pupil simply recording results or drawing out neat table without even seeing, let alone touching, any apparatus" (p. 8). Jimenez-Aleixandre and Diaz de Bustamante's (1997) case study conducted with high school biology students in Spain, observed specimens using microscopes and showed that some of the group members were dominating all of the activities, whereas the other students did not get involved in the activities at all.

Zin (2003) claimed that group work is one of the factors that restricts a student's active involvement in learning through practical work. She argued that when students work in groups, rather than individually or in pairs, a few students in a group get involved in manipulating the objects, while other members become passive observers. The students are expected to do practical work in a large group, particularly in urban schools. A large number of students in one class may not provide equal opportunities for all students to engage due to limited materials and equipment in the laboratory. It is, therefore, difficult for teachers to plan practical work that allows students to work in pairs or individually.

Wellington (1998) stated that practical work may also bring confusion to some students. He argued that sometimes the students may not produce the desired results because "...the practical goes wrong, leaving students with mixed messages" (p. 7). Some students may see practical work as a social activity, not requiring learning. Wellington also argued that there was 
little evidence to support the notion that scientific skills learnt during practical work can be transferred to other contexts, as practical work can be context-specific.

Evidence from the above study suggests that just because students are involved in practical work, it does not necessarily follow that they will develop positive attitudes and values. Participation in group work with the intention that students would learn to interact, cooperate, and communicate does not always take place. At times dominant students may take over while others have limited input in the task. Perhaps if the teachers' expectation is the development of conceptual and procedural knowledge and development of positive attitudes, the teacher has to clearly articulate what is it that the students are expected to do and learn. In the following section, the current studies about the implementation of practical work in the Malaysian context will be examined to understand how the lower secondary school teachers carry out practical work with their students, and what they want their students to learn. It also includes the students' perspectives about learning science in general.

\subsection{Studies of practical work in the Malaysian context}

A number of studies have attempted to illustrate the implementation of practical work by science teachers and the effect on student learning in Malaysia. The purpose of studies conducted by Edinin (2005), Marimuthu (2005), and Taridi (2007) was to investigate the implementation of practical work in secondary schools in Malaysia. The above studies were conducted mainly through qualitative approaches. Daniel (2005), compared the implementation of practical work in rural and urban areas. Then, the most recent studies were related to student performance in developing procedural knowledge and conceptual knowledge (Nik Kar \& Saleh, 2012; Surif, Arshad, \& Ibrahim, 2008).

The study conducted by Edinin (2005) investigated different types of practical work frequently used in secondary school science lessons. The findings of this study revealed that science teachers preferred to engage students in structured investigation and controlled activities. Additionally, science teachers were dependent on textbooks in designing teaching and learning activities. The teachers rarely engaged students with unstructured investigation. Similarly, Marimuthu (2005) conducted a study to investigate how pre-service science teachers implemented practical work at the upper secondary school level. The findings of the study showed that pre-service science teachers preferred to engage students with controlled activities to confirm scientific theories or concepts, rather than engaging students in unstructured investigations or projects. Neither study examined the reasons why science 
teachers, or pre-service science teachers, preferred structured investigation and controlled activities rather than other types of practical work. Both of the studies looked at the teachers' pedagogical approaches in conducting practical work, without considering what students actually did and learned from structured investigation and controlled activities.

Taridi (2007) investigated the implementation of practical work in biology at the upper secondary school level. The findings of Taridi's study showed that biology teachers lacked experience in implementing the experiments that were specified in the curriculum. Consequently, students were not prepared to conduct the experiment as planned by their teachers. Students' opportunities to learn from planned activities may be minimal because of mismatches between a science teacher's intentions and the students' actions in completing the tasks (Millar, 2004).

Studies conducted by Edinin (2005), Marimuthu (2005), and Taridi (2007) revealed that science teachers preferred to engage students in controlled activities and structured investigation in science lessons. It seemed that the studies showed that science teachers played a dominant role in guiding them in completing the activities. Marimuthu (2005) explained that the teachers were in a position of power to take control of the lesson in the traditional lesson. The teachers' approaches might suppress student creativity because students received the information from the teachers. Taridi (2007) added that structured practical work made students less interested to be involved in science lessons as they might perceive the activities to be irrelevant to them and their environment.

Daniel (2005) conducted a case study at the primary school level to examine the implementation of science lessons, in particular in conducting practical work in urban and rural areas. She interviewed and conducted classroom observation with six teachers from six different primary schools. It included three teachers from each area. The study revealed that all teachers rarely conducted practical work. They did not intend to conduct the suggested practical work from the textbook or the experiment book. They preferred to run the lesson through a lecture-based approach. She outlined three factors that included environmental factors, the curriculum, and teaching approaches that might affect teachers' practices. Firstly, the facilities that were available in schools were insufficient to meet the needs of students to conduct practical work. Secondly, the teachers aimed to complete the science syllabus and prepare students for examination. Thirdly, she pointed out that the teachers were not prepared to conduct practical work because they lacked procedural or conceptual knowledge. All the factors influenced student achievement in science as opposed to other subjects in both areas. 
She concluded that teachers could improve student achievement by increasing student participation in teaching and learning activities.

Surif et al. (2008) conducted a comparative study to examine the development of scientific skills of students between the ages of 9 and 15-years-old in the UK and Malaysia. More than 600 students from each country participated in this study. The participants undertook a modified test, based on the National Curriculum, to test student ability in designing an investigation. The results showed that students at Key Stage 3 in the UK could perform better in planning the investigation compared to students at the same stage in Malaysia. Of the students in the UK, $63.02 \%$ could identify the variables and state the procedure correctly, as opposed to only $9.09 \%$ of the students in Malaysia. Surif et al. (2008) concluded that the failure of Malaysian students in planning the science investigation might be influenced by types of practical work that they experienced in science lessons.

Nik Kar and Saleh (2012) conducted an experimental study to examine the effect of different teaching approaches on student achievement in the concept of atomic structure. Two groups of students (16 to 17-years-old) participated in the study and had experienced different teaching approaches. The experimental group was taught the concept of atomic structure through practical work and the control group learned the concept of atomic structure through a lecture-based approach. The student understanding about the concept was measured through a paper and pencil test. The results of the study showed that the experimental group performed better in the test as opposed to the control group. The experimental group was actively involved in exploring the nature phenomenon by themselves, as opposed to the control group that were not involved in making sense of the concept through the lecture-based approach. They concluded that the difference in student achievement was due to the learning processes that the experimental group had experienced through practical work, which might help the students in developing their conceptual understanding.

Razali et al. (1996) examined the teaching and learning approach in Malaysia. They conducted a survey with 16-years-old students. In the study, the researchers looked at the students' perceptions about the teachers' teaching approaches that included the teachers' questions, the teachers' feedback on students' work, the teachers' teaching strategies, and the students' motivation to learn science. The results of the study showed that $47 \%$ of the respondents suggested that the teachers used the lecture-based approach frequently in teaching science. Students felt that teachers were not interested in listening to their suggestions or opnions. The respondents $(47 \%)$ believed that the teachers provided 
opportunities for students to share thoughts and ideas during the lesson which means that perhaps more than half of the respondents did not have an equal opportunity to join in constructing knowledge in the lessons. The researchers also found that almost half of the respondents $(47 \%)$ stated that the teacher gave feedback on their work. Although the percentage was quite high in scoring on teacher feedback, their responses were inconsistent with their responses on the teacher evaluation of their work. It seemed that only $38 \%$ of the respondents stated that the teachers were interested in considering their answers. Razali et al. (1996) concluded that these results may be reflected in the assessment system in Malaysia. They claimed that the demand of the public examination had become the priority, not only for the students, but also other stakeholders, such as teachers and parents. The demand has affected the teacher pedagogical approaches for the past 30 years despite efforts to change the assessment approaches so that they are more school-based.

\subsection{Summary of the chapter}

International research shows that learning from practical work is limited. Further that although leading science educators and researchers (for example studies conducted by Hodson (2014) and Lederman et al. (2014) argue that learning science include learning about science, doing science, and learning to address socio-scientific issues, little is known about what students experience when they are doing science or what the teachers' learning intentions are when they conduct practical work. Taridi (2007) has researched implementation of the science curriculum at secondary school level in Malaysia. Daniel's (2005) case studies showed that, due to a lack of procedural and conceptual knowledge, primary school teachers in his study did not do the practical work suggested in the textbooks. They mostly used the lecture-based approach to teach and prioritised preparing students for examination. The findings of Daniel's study suggest that even though teachers thought that they prepared the students for examination, the students did not perform well in the examination. Nik Kar and Saleh's (2012) study investigated the development of conceptual understanding and compared two groups of students at the upper secondary school level in Malaysia. One group was only taught the theory and the experimental group experienced practical work. The assessment in this study was done as a pen and paper test. Razali's (1996) study at the upper secondary school level had found that the demands of examination had impacted on teachers' pedagogical approaches, and that teaching was teacher driven and in a lecture-based approach. Even though students said that they had the opportunity to put forth their ideas and were given feedback, the research did not report what impact this had on student learning. 
Seeing that the aforementioned Malaysian studies were either conducted at the upper secondary school or primary school levels, it is important to investigate what practical work is conducted in the lower secondary school level. Students at the lower secondary school are very important because at the end of the lower secondary level, they make decisions about their future science learning. It is crucial to know what teachers in lower secondary schools want their students to learn. How did they decide what practical work to do? What were their aims for student learning when they conducted practical work? How is the curriculum, that is underpinned by constructivist philosophy of learning and gives priority to student centred pedagogies, being implemented in the lower secondary school in Malaysia? Due to a paucity of studies that have investigated the effectiveness of practical work tasks and the nature of practical work from the perspective of science teachers in the Malaysian context, this study will explore the nature of practical work at the lower secondary school level from teachers' perspectives. Their views about why they want their students to do practical work, how they practise practical work with their class, and what they want their students to learn will be examined. Specifically, this study will research practical work tasks and their effectiveness at the lower secondary school level in promoting student learning. 


\section{Chapter 4: The Theoretical Framework}

\subsection{Introduction}

The Malaysian science curriculum mandates practical work as a preferred pedagogical approach for school science teaching (MOE, 2002a). The theoretical frame underpinning this thesis is social constructivism and it is accepted that knowledge is personally constructed and socially mediated. From this position the teacher has a significant role in providing the tools and the opportunities for students to construct their understanding, in this case through participation in practical work. This section reviews the literature about constructivist perspectives.

At the Malaysian lower secondary school level, teachers teach classes of between 25 to 35 students. Under these circumstances, the idea of allowing students to work in groups of two, or individually, is impractical (Zin, 2003). A study conducted by Kamarudin et al. (2009) in Malaysia showed that teachers planned structured practical work and discussed their findings after the students performed the task. It seems that the teachers planned practical work in this way to ensure that students conducted the investigation as planned, however, this raises the problem that they "have little possibility for responding to each individual student's cognitive processes over a sustained period of time" (Leach \& Scott, 2003, p. 95). It is very important to understand, on the one hand, how teachers teach in the laboratory in a social setting and, on the other, how students procure knowledge, and later apply this knowledge to a different context individually.

Driver, Asoko, Leach, Scott, and Mortimer (1994a) suggested that knowledge cannot be transmitted, and that learning is an active, rather than a passive, process and students construct their own understanding. The fundamental constructivist belief is that students construct their understanding by making meaningful connections to their prior knowledge. "Personal constructivism does not acknowledge the role of social setting in the meaningmaking process" (O'Loughlin, 1992, p. 791). Knowing which pedagogical approaches develop students' understanding about concepts, scientific skills, and how to foster an affective domain helps teachers to improve student learning through planning (Driver, Squires, Rushworth, \& Wood-Robinson, 1994b). 
According to Geelan (1997), there are several types of constructivism, a classification which is based on the individual learner, social and cultural environment, role of language, and the balance of power. Geelan attributes the five constructivist theories to five scholars:

i. Personal constructivism: Driver and Easley (1978);

ii. Social constructivism: Solomon (1987);

iii. Radical constructivism: (von Glaserfeld, 2007);

iv. Critical constructivism: Taylor (1996);

v. Contextual constructivism: (Cobern, 1993).

These learning theories are briefly discussed in the following section.

\subsubsection{Personal constructivism}

Personal constructivism stems from the Piaget's cognitive theory (O'Loughlin, 1992). The theory states that students develop their own understanding about the phenomenon, and that they should be active in constructing their knowledge. The social and cultural aspects are not considered in personal constructivism (O'Loughlin, 1992).

Osborne and Wittrock (1983) provided the following characteristics of personal constructivism:

i. The learner's existing ideas influence what use is made of the senses and in this way the brain can be said to actively select sensory input.

ii. The learner's existing ideas will influence what sensory input is attended to and what is ignored.

iii. The input selected or attended to by the learner, of itself, has no inherent meaning.

iv. The learner generates links between the input selected and attended to and parts of the memory store.

v. The learner uses the links generated and the sensory input to actively construct meaning.

vi. The learner may test the constructed meanings against other aspects of the memory store and against meanings constructed as a result of other sensory input.

vii. The learner may subsume constructions into the memory store. 
viii. The need to generate links and to actively construct, test out, and subsume meanings requires individuals to accept responsibility for their prior own learning (p. 65).

Although personal constructivists do not acknowledge the role of the social or the cultural setting, they take into consideration the students' 'prior knowledge' and 'alternative concept' and the importance of diagnostic assessment. They emphasize the need to consider what the students already know. This theory suggests that the teachers should begin the lessons with what the students already know. Driver and Easley (1978), suggested that observation is theory laden, and that the students' knowledge is important to cognitive development that determines the understanding derived from an experimental situation.

Solomon (1987) highlighted the importance of teachers considering the ideas that students bring to schools. Osborne (1985) discussed the reasons why students' scientific ideas (children's science) are different from scientists' scientific ideas (scientists' science). This situation happens as the teachers make the assumption that their students would link concepts they had learned in the previous lesson with those of the current lesson. According to Osborne (1985), students perceived each lesson as a separate entity. Moreover, the students showed a lack of interest in conducting practical work. The students' understanding of the concepts that they developed through the practical work was different to the teacher's intended learning outcome. Bell (2005) stated that one of the reasons that the students were unable to grasp the ideas as intended by the teacher was possibly that "the students were not engaging with the ideas of science, that is, minds-on science was not occurring" (p. 21).

To conclude, it seems that personal constructivism goes against the reality of classroom interaction. It does not acknowledge social interactions in the classroom that occur between the students and the teacher, and amongst the students themselves. The details of how social interaction has a significant impact on student learning are discussed in the following section.

\subsubsection{Social constructivism}

Tobin, Tippins, and Gallard (1994) stated "learning is a social process of making sense of experience in terms of extant knowledge" (p. 47). In nature, a person is born into the environment and interacts with objects through his/her senses. Solomon (1987) explained the importance of social settings in the meaning-making process. She argued that the social setting "makes an essential difference to the learning situation, to how the task is perceived 
and even to the tools for thought that will be used" (p. 63). She further suggested that learning processes take place in social contexts where the students interact with peers and teachers to construct meaning. Solomon also highlighted that the students may not understand the concepts until they can talk about or discuss them with their teachers or their fellow students.

As opposed to the personal constructivist perspectives, the social constructivist acknowledges the importance of social interaction in the social setting and the learners' contributions to developing their conceptual understanding. Solomon (1987) made the following remark in her research on the influence of the social interaction on shaping student learning:

"As students interact with one another, with the teacher...they develop ideas that, because they are held in common, create a universal discourse, a common frame of reference in which communication can take place" ( $p$. $68)$.

Social constructivism has been criticized by various scholars, such as von Glasersfeld (1993) and Bell (2005). von Glasersfeld (1991) explained that neither Piaget, nor other constructivists, have provided a specific model of how social interaction influences students' learning. He emphasised that knowledge cannot be separated from knowing. Human connection to knowledge is through experience. It is through experience that we come to know the real world. The students, for example, might construct meaning according to their own experience. Bell (2005) also argued that the social constructivist view of learning as proposed by Solomon is "under developed" and "vague" (p. 41).

\subsubsection{Other constructivism theories}

Other constructivism theories include radical, critical and contextual constructivism. Ernst von Glasersfeld (1993) proposed the radical constructivist view of learning at the NARST Meeting in Atlanta in 1991. He stated that there are two principles of learning: 'Trivial' constructivism and 'Radical' constructivism. 'Trivial' constructivism dictates that "knowledge is always the result of a constructive activity and, therefore, it cannot be transferred to a passive receiver" (von Glasersfeld, 1993, p. 3). In other words, the learners themselves develop knowledge, but the teachers can assist the learners through general instructions. According to 'Radical' constructivism, however, "the function of cognition is adaptive and serves the organization of the experimental world, not the discovery of ontological reality" (von Glasersfeld, 1989, p. 162). Thus, the learners construct all knowledge through meaning making experiences in order to survive (Geelan, 1997). However, some scholars have criticized von Glasersfeld's 
view of radical constructivism. Matthews (1995), for example, argued that von Glasersfeld had ignored the role of the social setting and the view of reality in the meaning-making process.

Critical constructivism is another form of constructivism that emphasized the social-cultural context in the meaning making process and acts as "a referent for cultural reform" (Taylor, 1996, p. 9). Thus, the purpose of learning is to ensure that students are aware of their personal and social identity. The teachers' roles are to guide students to "enable students to become the architects of their own education so that they can invent themselves during the course of their lives" (Eisner, 2003, p. 652). Tobin (1992) suggests that critical constructivism includes "self-regulation that reveals the psychological, ethical, moral, and political beliefs intertwined with the construction of knowledge" (p. 20).Tobin posits that knowledge construction goes beyond personal and social factors.

Cobern (1993) coined the term contextual constructivism. This view stemmed from the social constructivist theory as proposed by Solomon (1987). Cobern suggested that the development of knowledge among students is not influenced by social interaction per se, but rather by various factors related to the culture of the students. The learning process occurs when the culture of the learner of science is explored and understood. The inclusion of context in the teaching and learning of science is based on this view. The Malaysian science curriculum (MOE, 2002a) proposes the contextual learning approach that associates learning with the "daily experience of students" (p. 13). Finding a context that relates to the lives of the students can help the students to appreciate science.

\subsubsection{Constructivist pedagogy}

The theory of constructivist learning emerged in the 1980s, but constructivism as a theory of teaching, began to receive attention a decade later (Richardson, 2003b). Researchers in the 1990s conducted various studies to identify subject specific teaching practices in the classroom. For example, Tobin (1993) researched teaching practices in science lessons, while Cobb et al. (1991) examined teaching practices in mathematics lessons. Nie, Tan, Liau, Lau, and Chua (2013) argue that knowledge construction takes place when students engage in socially negotiated interactions in real life situations. Baviskar, Hartle, and Whitney (2009) listed the following criteria of the constructivist pedagogy: "eliciting prior knowledge, creating cognitive dissonance, application of new knowledge with feedback, and reflection on learning" (p. 541). 
The first criterion of constructivist pedagogy was "eliciting prior knowledge" (Baviskar et al., 2009 , p. 543). Baviskar et al. proposed several ways of eliciting this prior knowledge. These included pre-tests, setting up an informal interview and concept mapping. They highlighted that the teacher must ensure that the activities that they have planned for the students are suitable for the concepts that they want to teach. The second criterion is related to the selection of the task. Wheatley (1991) suggested that teachers select activities that were "problematic" for students, thus creating "cognitive dissonance" (p. 544). In the study conducted by Baviskar et al. (2009), for example, the teacher used a concept map to determine the students' initial ideas about a topic. The students added new links to the initial ideas after the lessons, or changed previous links if necessary. It seemed that by eliciting and organizing the students' thoughts through concept mapping, the teacher was able to understand the students' cognitive structure. It also helped the teacher to identify the students' alternative conceptions (Driver et al., 1994a).

Baviskar et al. (2009, p. 546) proposed the "application of knowledge with feedback" as the third feature of constructivist pedagogy. They suggested a few activities that the teacher could plan to allow students to apply the new knowledge that they developed during the lesson. The teacher could try a quiz, presentations, or other activities that enable students to compare their knowledge with other students. Validating 'new' knowledge is important as it allows students to connect 'new' knowledge to a wider context. This feature of the constructivist pedagogical approach may help students to explore concepts and restructure their prior knowledge, and in some cases improve their understanding. On the other hand, some students may explore other aspects of learning, such as developing skills. These aspects may lead to different learning outcomes for students (Smart \& Marshall, 2013).

The constructivist pedagogical approach is suggested in the Malaysian science curriculum where: "students learn about something when they construct their own understanding" (MOE, 2002a, p. 12). Through this approach, the teachers begin the lesson by eliciting students' prior knowledge. Then teachers plan teaching and learning activities that allow the students to relate the new ideas to their prior knowledge for themselves. Lastly, the students should also have the opportunity to explore, share and reflect their ideas through teaching and learning activities. 


\subsubsection{Criticism of constructivism}

Fensham (1992) claimed "the most conspicuous psychological influence on curriculum thinking in science since 1980 has been the constructivist view of learning" (p. 801). This view of constructivism has since been extended to other aspects of science education since the 1980s. It has been promoted as "a theory of teaching, a theory of education, a theory of the origin of ideas and a theory of both personal, and scientific knowledge" (Matthews, 2002, p. 121).

According to Matthews (2002), constructivism has had a significant influence on curriculum reform in science and mathematics education in Western countries. However, he argued that being a constructivist does not mean that the teacher has to embrace every aspect of the above-mentioned aspects of constructivism. In practice, it seems that teachers gave attention to students' prior knowledge and encouraged students to engage in the lesson. Matthews also argued that constructivism appears to raise the awareness of the "human dimension of science and its fallibility, its connection to culture and interests, the place of convention in science theory, the historicity of concepts and complex procedures of theory appraisal" ( $p$. 132). Constructivism has also influenced the Malaysian science curriculum (MOE, 2002a), as the constructivist teaching approaches are suggested as preferred pedagogical approaches in the curriculum.

In summary, constructivism as a theory of learning, has been explored in science education since the 1980s, and expanded to other areas in education more recently. The underlying idea is that knowledge is constructed by the learner in relation to their prior knowledge. Various strands of constructivism as theories of learning have emerged and there appears to be a continuum of views. At one end are the radical constructivists, who focus on the individual constructing their knowledge through subjective interpretation of their active experiences. At the other end of the continuum are the social constructivists, who believe that social interactions have an important place in the construction of knowledge. Social constructivists emphasize the input of teachers and peers in learning. In classroom, students interact with teachers or peer to make sense of what they have seen or heard. Brooks and Brooks (1999) explained that in the constructivist classroom, teachers are mediators for students. They are not information givers or behaviour managers for students as usually happened within traditional classroom setting. The classroom interaction from social constructivism lessons in comparison with traditional classroom will be discussed in the following section. 


\subsection{The difference between traditional and social constructivism classroom interaction}

According to Palincsar (1998) discourse is a mediating tool in a social constructivism. Through discourse, the students construct meanings and develop understanding when they learn science (Duit \& Treagust, 1998). Some researchers agree that classroom interaction has a significant effect on student learning (Cazden, 1988; Edwards \& Westgate, 1994; Edwards \& Mercer, 1987; Hofstein \& Kind, 2012). However, there are significant differences in terms of the classroom interaction in the traditional and constructivism classroom.

In the traditional classroom, the students and teacher engage in evaluative activities (Palincsar, 1998). Sinclair and Coulthard (1975) described the classic example of the structure of classroom interaction as 'IRF' exchanged, this means initiation [I] (normally initiated by teachers), student response [R], and teacher feedback [F]. With a similar view, Mehan (1979) changed the third part of the structure to teacher evaluation [E]. Lemke (1990) described this exchange as a 'triadic dialogue' that consists of three-parts of exchange structures. Crawford (2005) explained that the pattern of interaction would minimize the student-to-student interaction in the classroom.

Crawford (2005) suggested that in the traditional classroom, interaction is dominated by teacher talk. The teachers initiated the discourse by asking questions (Sinclair \& Coulthard, 1975). According to Chin (2006), in the traditional teaching approach, teachers tended to ask a closed question to seek information or recall facts. It seems that the questions also minimized the students' roles in the meaning making process. Lemke (1990) supported the view that the triadic dialogue in the traditional classroom interaction limited students' opportunities to think critically and that the closed questions promoted lower-order thinking skills that required students to recall the facts. In this approach, the students attempted to give short answers without further elaborations. Normally, the teachers already knew the answers for the questions that they asked. This was followed by giving positive remarks if the students gave the correct answers or they corrected students' answers if wrong (Chin, 2006). In other cases, the teachers' feedback was not necessarily to evaluate students' answers (Sinclair \& Coulthard, 1975). It had the potential to encourage students to generate ideas, hypotheses, and test students understanding. Although the discourse structure was criticized (Lemke, 1990), some researchers found that the triadic dialogue has a significant effect on classroom interactions. Newman, Griffin, and Cole (1989) suggested that the three-exchange method had "a built in repair structure in the teacher's last turn so that the incorrect information can be 
replaced with the right answers" (p. 127). As a result of the interaction, the students might learn the facts effectively but it seemed that it was less evident that it supported the students involved in higher order thinking skills, such as problem solving (Palincsar, 1998).

Constructivism learning places a great emphasis on student learning in a small group or a whole class (Hand, Treagust, \& Vance, 1997). Students engage in collaborative activities where they interacted with other group members (Cohen, 1994). Thus, they have opportunities to actively engage in constructing scientific conceptual knowledge. The classroom interaction in the constructivism classroom does not follow the classic format of the classroom interaction (IRF/IRE). The teachers and students play different roles in the constructivist classroom, where the teacher is not the intellectual authority and the students have opportunities to communicate with other students during teaching and learning activities (Forman \& Ansell, 2002). They are not merely asked an evaluative question but they are also to co-construct knowledge with students (Palincsar, 1998). They initiate the classroom interaction by asking open-ended questions that may lead to approaches to solving problems (Erdogan \& Campbell, 2008). Then, the students respond by giving the answers, follow by the teachers' comments that encourage the students to evaluate or reflect on their answers. Forman and Ansell (2002, p. 258) describe the classroom interaction in the constructivist classroom as the "discussion orchestration".

\subsection{Teacher questioning}

Wellington and Osborne (2001) suggested that teacher questioning was an element of classroom discourse. Lemke (1990) and Mehan (1979) found that the teachers intended to engage the students in the traditional classroom discourse where the students responded to teachers' questions and the teachers evaluated the students' answers. Dillon (1985) explained that the IRE format of classroom discourse might limit students' active engagement in the teaching and learning activity. Tobin (1987) and Rowe (1986) related the implementation of 'wait time' to improve students' participation in the classroom and suggested that the implementation of 'wait time' might provide time for students to think of the appropriate answers before they provided the answers. van Zee and Minstrell (1997) added that the IRE form of interaction might constrain students' thinking and they were expected to accept the teachers' answers. Unlike in the traditional classroom, the teachers used questioning in the constructivist classroom for different reasons, such as to scaffold students' ideas and thinking (Ahtee, Juuti, Lavonen, \& Suomela, 2011). 
The teachers usually use questions in initiating the classroom interaction (Sinclair \& Coulthard, 1975). In a constructivist classroom, Chin (2006) found that the teacher intended to ask open-ended questions to elicit what the students already knew. Chin explained that the teachers' questions should be flexible in order to promote higher order thinking and they developed questions based on students' responses. Baird and Northfield (1992) explained that the questions that the teachers asked might require the students to give more than a onesentence answer and engage students with higher order thinking. Martin and Hand (2009) suggested that open-ended questions also could increase student participation. They found that more students participated in the lessons, as opposed to when the teacher asked closed questions. McNeill and Pimentel (2010) agreed that:

"Teacher questions provide an avenue to open up classroom discourse beyond the traditional lecture format of teaching by telling. Questions have the potential to bring students into the conversation and increase student talk, but the type of teacher question impacts how it affects student participation" (p. 207).

van Zee, Iwasyk, Kurose, Simpson, and Wild (2001) proposed different ways of eliciting students' ideas. They found that the questions that the teachers asked and the implementation of a 'wait time' could impact on the development of conceptual knowledge. They argued that by eliciting students' ideas, the teachers could know students' prior knowledge and build the lesson based on it. Smith, diSessa, and Roschelle (1994) argued that the teachers could also diagnose and refine students' ideas through questioning. Those questions might help students to clarify students' ideas and monitor their thinking.

Another study showed that the teacher questioning could also lead to "conceptual change" (Yip, 2004, p. 77). The model of conceptual change is aligned with the personal constructivist view of learning. In Yip's view the teachers portrayed characteristics of constructivism by asking questions to elicit, challenge, extend, and apply knowledge. Teachers can practise a constructivist approach through: "probing students' conceptions, challenging students to resolve inconsistent views; guiding students to establish relationships between existing knowledge and a new concept, and helping students apply a newly acquired concept to a different situation" (p. 76).

In the constructivist classroom, the teachers could respond naturally, rather than giving evaluative comments in giving feedback on students' answers (Roth, 1996). They did not look for the correct answers, but they encouraged students to elaborate their answers in developing conceptual knowledge (Chin, 2006). Smart and Marshall (2013) argued that the 
students' opportunities to justify their responses might establish a teaching and learning environment that invited the co-construction of knowledge between students and teachers.

According to Roth (1996), student-centered discussions can be fostered if the teachers designed questions that aimed to 'draw out' students' knowledge and to support students' discursive activities. The teachers did not evaluate the students' answers based on substantive knowledge or standard knowledge. However, the teachers still played dominant roles in the classroom interaction as they implemented the IRE format. Lemke (1990) also supported the view that teacher authority in the classroom was maintained by the IRE format. Table 4-1 shows a summary of the nature of teacher questioning in traditional and constructivist-based teaching. 
Table 4-1: The summary of the teacher questioning.

\begin{tabular}{|c|c|c|}
\hline Criteria & Traditional learning & Constructivist-based learning \\
\hline Purpose of questioning & Evaluate what the students know & $\begin{array}{l}\text { Elicit what students think, } \\
\text { encourage them to elaborate }\end{array}$ \\
\hline $\begin{array}{l}\text { Structure of questioning } \\
\text { sequence }\end{array}$ & IRE (teacher - student - teacher) & IRFRF chain \\
\hline $\begin{array}{l}\text { The nature of teachers' } \\
\text { questions and students' } \\
\text { responses }\end{array}$ & $\begin{array}{l}\text { Closed-ended questions, recall } \\
\text { the facts, promote lower thinking } \\
\text { order, the students give short and } \\
\text { predetermined answers }\end{array}$ & $\begin{array}{l}\text { Open-ended questions, engage } \\
\text { students in taking more } \\
\text { responsibility for thinking that } \\
\text { promotes higher order thinking, the } \\
\text { students give a long response, } \\
\text { they give one- or two-sentence } \\
\text { answers }\end{array}$ \\
\hline The teachers' responses & $\begin{array}{l}\text { Acknowledge right answers and } \\
\text { wrong answers, }\end{array}$ & $\begin{array}{l}\text { Do not judge students' answers } \\
\text { promptly. Accept and acknowledge } \\
\text { students' answers naturally }\end{array}$ \\
\hline $\begin{array}{l}\text { Authority for judging } \\
\text { answers }\end{array}$ & $\begin{array}{l}\text { The teacher is the authority and } \\
\text { asserts knowledge claims that } \\
\text { he/she expects students to accept }\end{array}$ & $\begin{array}{l}\text { The teacher shifts the authority to } \\
\text { evaluate the answers to students. }\end{array}$ \\
\hline
\end{tabular}

Adapted from Chin (2007, p. 819)

\subsubsection{Classification of teachers' questions}

Ulijn and Verweij (2000) suggested that the teachers' questions can be analysed in three levels which are form, content, and intent. They explained that the questions could be asked in a form of a verb-subject format. In science teaching, the teachers can ask questions by using why, how, and what (Wragg, 1996). The what question is where the students are required to describe the phenomenon based on the accepted scientific concepts. The how question required the students to describe the findings of the practical work, or state the observation of the demonstration. Lastly, the teachers may ask the why question for inviting students to provide the reasons. 'Intent' is referred to as the cognitive knowledge that the teachers want to develop through questioning. Dickson and Hargie (2006) classified the questions into several subtypes, which are open and closed questions, leading, recall, multiple, and rhetorical questions.

The questions also can be categorized according to Bloom's taxonomy (Bloom, Engelhart, Furst, Hill, \& Krathwohl, 1956). Bloom proposed a way of classifying the question according to the cognitive domain. The categories are knowledge, comprehension, application, analysis, synthesis, and evaluation. The categories are arranged from simple to complex and from concrete to abstract. Elstgeest (1985), also proposed six types of questions that were 
arranged systematically from a concrete to an abstract question. The categories were attention focusing, measuring and counting, action questions, problem posing, and how and why questions. These questions can promote productive thinking.

Koufetta-Menicou and Scaife (2000) classified the questions that the teachers ask in conducting practical work into nine categories. They classified the questions that the teachers asked into lower-level thinking and higher-level thinking. The questions that promoted lowerlevel thinking were "recalling the facts or events" or "decribing the element of experiment". Questions that demanded a higher order thinking were: "decribing the procedure of (the how question), "seeking for evidence", "recognizing the pattern", "reasoning behind the procedure (the why question), "what-if" question, "giving predictions", and "reaching conclusions" (p. 81). They found that the questions that the teachers asked were not equally distributed throughout the lesson. Teachers asked lower-level thinking questions, especially in describing the elements of the experiment, rather than asking higher-level thinking questions. Despite the different ways of classifying teachers' questions, Wellington and Ireson (2008) highlighted that questions that the teachers asked in the classroom should include all the categories.

\subsubsection{The framework for classroom interaction}

The framework to examine the classroom interaction in this study is based on the approach proposed by Mortimer and Scott (2003). They introduced an analytical framework to examine classroom interaction that encompassed six elements. The analytical framework encompassed: (a) teaching purpose, (b) intended learning goal, (c) the form of utterance in terms of whether it is a description, explanation, or generalization, (d) communicative approach (interactive vs non-interactive, authoritative vs dialogic), (e) the patterns in the flow of the interaction, and (f) teacher interventions. In this study, the classroom interaction focuses on two aspects, which are the pattern of the interaction and the communicative approaches.

The first aspect of classroom interaction is the pattern in the flow of the interaction. Lemke (1990) and Mehan (1979) explained that the pattern of the interaction is an important aspect of the classroom discourse as it defines the structure of participation (teacher or students) in the classroom talk. The pattern of interaction proposed by Mortimer and Scott (2003) and Lemke (1990) will be used to examine the pattern of interaction in the classroom. Mortimer and Scott (2003) suggested three different patterns of interaction. In the traditional classroom, the teacher and students are involved the IRE format of interaction as the teachers always initiates the classroom interaction through questioning. Then the students answer the question 
by giving single answers without a further elaboration. Then the teacher makes an evaluation of students' answers. The second pattern of interaction is known as a closed chain of interaction (IRFRFRF). In this sequence, the teacher still initiates the question and he/she prompts more responses from students by asking questions to generate different responses from students. Then, the teacher ends the interaction by making an evaluation of students' responses. The third pattern of interaction is known as an opened chain of interaction. It is quite similar to a previous pattern of interaction, but the teacher does not end the sequence with evaluative comments. The fourth pattern was introduced by Lemke (1990) which is known as the Question-and-Answer pattern. The questions are asked by the students and then followed by the teacher's answers.

The second aspect of classroom interaction is the communicative approach. Scott (1998) identified two dimensions of classroom discourse. The first classroom discourse dimension is known as: authoritative and dialogic discourse; and the second classroom dimension is interactive or non-interactive talk. Teachers use an authoritative discourse for delivering the information, facts, instruction, and reviews to students. The authoritative discourse focuses on a single point of view that is normally dominated by the teacher without exploring different ideas.

Through a dialogic discourse (Scott, 1998), there are other voices that are involved in the discourse and the intention is to generate new ideas. In this discourse, the teacher gives elaborated feedback instead of evaluating or praising students' responses. The teacher repeats or elaborates the students' answers. There are a few examples of elaborated feedback, such as repeating a student's answers as an encouragement for students to continue, making comments on students' answers, and asking the students to elaborate their responses. This pattern of discourse encourages a dialogic interaction and allows the teacher to explore the students' ideas. Mortimer (1998) suggested that both types of discourse are crucial in developing conceptual knowledge. Scott (1998) named the usage of both discourses in the meaning making process as the "rhythm of the discourse" in the classroom (p. 64). The teaching and learning process may enhance this, as there is a balance between both types of discourse in presenting and exploring ideas. The second dimension of the communicative approach is interactive and non-interactive discourse (Mortimer \& Scott, 2003). It considers to what extent the teacher allowed the students to participate in the classroom talk. The talk can be interactive if the teacher invites more than one student to participate, or non-interactive, in the sense that only one student takes part in the classroom interaction considered. 
Mortimer and Scott (2003) proposed four combinations of communicative approach. In the first combination, teachers used the combination of an interactive/authoritative communicative approach. Through this combination, the teacher interacts with students to elicit responses from students about certain issues. However, he/she is keen to 'correct answers' from students and neglects responses that are not aligned with the scientific concepts. The teacher prefers to invite students into a series of questions that leads students to give the correct answers. The second combination is the interactive/dialogic approach, where the teacher interacts with students to explore and consider students' ideas, although the ideas are different from the scientific concepts. Thirdly, the teacher uses the combination of a noninteractive/authoritative approach for delivering the concepts and instructions. For example, the teacher gives lectures to present the scientific concepts, without involving students in the lessons. Lastly, the teacher uses the combination of a non-interactive/dialogic approach in the lesson where there is no interaction with students but the teacher gives additional information on top of the scientific concepts. For example, the teacher provides a review, a different point of view, or highlights similarities and differences of certain aspects.

The authoritative approach is important as it provides a structure to view the world (Aguiar, Mortimer, \& Scott, 2010). The students cannot make an appropriate scientific reasoning without guidance from teachers or other experts. In learning science, the students learn the canonical knowledge of reasoning in science (Anderson, Holland, \& Palincsar, 1997) and acquiring "normal science" (Kuhn, 1962, p. 5). Although the authoritative approach alone is not enough to encourage students to be involved in meaningful learning, this type of approach is dominant in the high school science classroom (Aguiar et al., 2010). Consequently the students have limited opportunities to use the scientific language in a teaching and learning activity.

\subsection{Summary of the chapter}

This chapter outlines the theoretical framework that was used in the analysis of the findings to conduct this study. Learning to investigate is viewed from personal and social constructivism perspectives. It also involves constructivism pedagogy, which includes eliciting prior knowledge, eliciting students' prior knowledge, providing learning experiences, challenging students' ideas, and giving feedback. The teacher creates opportunities for students to learn by introducing the ideas, guiding the students, and encouraging students to reflect on their 
own learning. Constructivism learning also suggests that the students learn through the interaction with the context, not only with the teacher alone.

As the constructivist learning process takes place in a social setting, this study looks at classroom interaction where the students' ideas are elicited through questioning. The framework develops by Mortimer and Scott (2003) is used to examine the classroom interaction in terms of the communicative approaches and the flow of interaction when the teachers conduct practical work. The classroom interaction would be interpreted based on types of questions that teachers would ask in the lessons. 


\section{Chapter 5: Methodology}

\subsection{Introduction}

The study is an exploration across a group of science teachers and students of the teachers' purposes and practices in conducting practical work. The data are gathered through different approaches. This chapter presents the research aims and questions, the research paradigm, the qualitative research method, the selection of participants, the phases of the research procedures of data collection, the analytical framework for investigating the effectiveness of the practical work, data analysis, and considerations of trustworthiness.

\subsection{The aims of the study}

The study sought to investigate the effectiveness of practical work in a Malaysian context. In particular, it focused on teachers' understanding and practice of practical work and what the students did, and learnt, from practical work through the following questions:

i. How did form two science teachers understand practical work at the lower secondary school level in different types of schools in Melaka?

a. How did form two science teachers understand practical work?

b. How did form two science teachers practise practical work?

ii. How did teacher talk, especially questioning, facilitate classroom interactions in conducting practical work?

iii. To what extent were practical work tasks effective in helping students to do what the science teacher intended?

iv. To what extent were practical work tasks effective in helping students to learn what the science teachers intended?

\subsection{Research paradigm}

Cohen, Manion, and Morrison (2007) suggested that researchers need to understand elements of epistemology ${ }^{6}$, ontology ${ }^{7}$, and methodology 8 in developing a framework for conducting research. The combination of the three elements affects the direction of a study.

\footnotetext{
6 Epistemology or knowledge claim refers to its nature and form, how knowledge is obtained, and how to communicate knowledge to others (Burrell \& Morgan, 1979).

7 Ontology is a nature of social phenomena that are under study. The nature of question that is "how is the social world perceived and understood?" (Hitchcock \& Hughes, 1995, p. 19).

8Methodology is a "theory or analysis of how research should be conducted" (Hitchcock \& Hughes, 1995, p. 20).
} 
Similarly, Hitchcock and Hughes (1995) stressed that ontological assumptions give rise to epistemology assumptions which lead to methodological assumptions. The methodology guides researchers in choosing suitable instruments and data collection methods to address research questions.

According to Guba (1990), a research paradigm is a "basic set of beliefs and feelings that guides action" (p. 17). Research is guided by beliefs and feelings about the world and how it should be understood (Denzin \& Lincoln, 2005). The qualitative research paradigm, not only focuses on how a study should be conducted, but also raises issues about the focus of a study and approaches to interpreting the data (Bryman, 1988). Therefore, the research paradigm is important as a guideline for inquiry.

An interpretive research paradigm seems appropriate as it focuses on the subjective nature of personal experiences and recognized the importance of individual experiences that were attached to the specific event (Devetak, Glažar, \& Vogrinc, 2010). In this study, the researcher attempted to understand the implementation of practical work by the teachers, and the students' learning from the implemented practical work. The researcher interacted with the participants to construct the understanding and the interpretation of practical work in the natural setting (epistemological assumptions). The assumption is that knowledge is constructed within participants' minds and knowledge is "subjective, personal, and unique" (Cohen et al., 2007, p. 7). Each participant is likely to have different interpretations, based on their perspectives and experiences of practical work (ontological assumptions). In this study, participants' collective interpretations created multiple realities that enhanced the researcher's understanding about the implementation of practical work in the Malaysian context. The methodological assumption was concerned with the approach to gain information directly from participants to construct the knowledge about the implementation of practical work in the Malaysian educational context. The researcher did not manipulate or control of the variables related to the implementation of practical work nor introduce a new intervention to promote student learning. For all the above reasons a qualitative research approach was chosen because it allowed the researcher to understand the nature of practical work in three Malaysian schools.

\subsection{Qualitative research}

In qualitative research, researchers are concerned with examining issues in detail and they explore issues that people have little knowledge about (Punch, 2005). In this study open- 
ended questions were asked so as to understand participants' experiences about the phenomenon of practical work.

There are no prescribed instruments to collect qualitative data. Researchers develop protocols as guidelines to record interviews, document analysis, and observations of data (Denzin \& Lincoln, 2005). Researchers develop either an interview protocol that consists of a set of questions to guide interviews, or observation protocols to record participants' actions. The intention in collecting qualitative data is to gather text or images from participants (Creswell, 2009). According to Creswell (2008), questionnaires, or observation checklists, can be used as instruments to gain quantitative data within qualitative research. The quantitative data can be triangulated with the data from interviews, document analysis, and observations to strengthen the findings (Coles \& McGrath, 2010).

In analysing qualitative data, researchers explain contexts and participants' information in detail. Researchers analyse text to develop relevant themes to describe phenomena under study (Cohen et al., 2007; Punch, 2005). From detailed descriptions, researchers may interpret the findings by reflecting on the existing study or personal reflections on lessons learnt from studies (Cohen et al., 2007).

Researchers have more flexibility in reporting qualitative findings, compared with quantitative findings. The structures may be different from one qualitative study to another. Whereas some qualitative reports are written using a long, narrative approach, others are written with a more objective and scientific approach, similar to quantitative reports, (Creswell, 2008). Researchers need to report findings accurately to convince their readers (Cohen et al., 2007).

There are a number of ways of conducting qualitative research. The process of choosing an appropriate research design is based on the purpose of the study. Cohen et al. (2007) supported the notion that "fitness of purpose" is a guide in selecting a research design. There are different types of research designs, such as grounded theory, narrative, ethnography, phenomenology, and case study. Each research design has different purposes. Different research designs and their characteristics are presented in Table 5-1. 
Table 5-1: The general characteristics of research designs

\begin{tabular}{ll}
\hline Research design & Characteristics \\
\hline Ethnography & $\begin{array}{l}\text { Provides details of information about cultures, beliefs, values, and } \\
\text { attitudes that are shared by participants (Denzin \& Lincoln, 2005). }\end{array}$ \\
Phenomenology & $\begin{array}{l}\text { Helps to understand an individual's or a group's experiences of events } \\
\text { or issues. Researchers need to suspend the feeling about the } \\
\text { phenomenon to view the issue as it is (Johnson \& Christensen, 2008). }\end{array}$ \\
Grounded theory & $\begin{array}{l}\text { Develops theory from the data, not from the researcher's interpretation. } \\
\text { The report is written in simple language, and can be generalized } \\
\text { (Glasser \& Strauss, 1999). }\end{array}$ \\
Narrative research & $\begin{array}{l}\text { Tells life-experiences of individuals, rather than describing and } \\
\text { interpreting a culture or behaviour or constructing explanations about } \\
\text { experiences shared by many people (Clandinin \& Connelly, 1990). }\end{array}$ \\
\hline
\end{tabular}

\subsection{A case study}

Stake (1995), Merriam (2001), and Yin (2003) have defined and categorized case studies in different ways. Yin (2003) defined a case study as a research process. Stake (1995) put emphasis on a case or (an object of a study) as a case study and Merriam (2001) focused on the end product. Table 5-2 provides the characteristics of case studies. 
Table 5-2: Types of case studies

\begin{tabular}{|c|c|c|}
\hline Scholar & Definition of a case study & Type of case study \\
\hline \multirow[t]{3}{*}{ Stake (1995) } & \multirow{3}{*}{$\begin{array}{l}\text {... "the study of particularity and } \\
\text { complexity of a single case, } \\
\text { coming to understand its activity } \\
\text { within important circumstances" } \\
\text { (Stake, 1995, p. xi). }\end{array}$} & $\begin{array}{l}\text { Intrinsic case study: to examine a specific } \\
\text { case and attempt to understand a little- } \\
\text { known phenomenon in-depth. }\end{array}$ \\
\hline & & $\begin{array}{l}\text { Instrumental case study: to understand } \\
\text { the general issues, rather than the } \\
\text { particular case and intend to apply the } \\
\text { findings from the specific case study to } \\
\text { other settings. }\end{array}$ \\
\hline & & $\begin{array}{l}\text { Collective case study: to compare } \\
\text { several case studies conducted } \\
\text { concurrently to gain a fuller picture about } \\
\text { the issues. Researchers select a number } \\
\text { of case studies, depending on resources. }\end{array}$ \\
\hline \multirow[t]{3}{*}{ Merriam (2001) } & \multirow[t]{3}{*}{$\begin{array}{l}\text {... "intensive, holistic description } \\
\text { and analysis of a single unit or } \\
\text { bounded system" (Merriam, 2001, } \\
\text { p. 12) }\end{array}$} & $\begin{array}{l}\text { Descriptive case study: to describe a } \\
\text { phenomenon under study in detail. The } \\
\text { findings are presented in narrative } \\
\text { accounts. }\end{array}$ \\
\hline & & $\begin{array}{l}\text { Interpretive case study: to develop } \\
\text { conceptual categories inductively in order } \\
\text { to examine initial assumptions. } \\
\text { Researchers' interest is to understand } \\
\text { the phenomenon, rather than describing } \\
\text { the event in detail. }\end{array}$ \\
\hline & & $\begin{array}{l}\text { Evaluation case study: to describe, } \\
\text { explain, and judge the phenomenon. }\end{array}$ \\
\hline \multirow[t]{3}{*}{ Yin (2003) } & \multirow{3}{*}{$\begin{array}{l}\text {... "an empirical inquiry that } \\
\text { investigates a contemporary } \\
\text { phenomenon within its real-life } \\
\text { context, especially when the } \\
\text { boundaries between phenomenon } \\
\text { and context are not clearly } \\
\text { evident" (Yin, 2003, p. 13) }\end{array}$} & $\begin{array}{l}\text { Exploratory case study: to handle a pilot } \\
\text { study and later develop hypotheses for } \\
\text { further inquiry. }\end{array}$ \\
\hline & & $\begin{array}{l}\text { Descriptive case study: to gain } \\
\text { information on the particular features of } \\
\text { an issue and require a theory to point the } \\
\text { data collection in the right direction. }\end{array}$ \\
\hline & & $\begin{array}{l}\text { Explanatory case study: to answer why } \\
\text { and how something happens or } \\
\text { happened. Therefore, this research } \\
\text { design needs a long-term engagement } \\
\text { on the site. }\end{array}$ \\
\hline
\end{tabular}

Although different authors have defined and categorized a case study differently, they seem to agree on some common advantages. A case study allows researchers to examine cases, or phenomena, in a real context in detail. Data are collected from multiple sources, such as interviews, observations, and document analysis (Merriam, 2001). Thick description is used to 
explain the events, phenomena, settings, and participants in detail (Geertz, 2001). It allows readers to compare and apply the findings in their own contexts. Additionally, researchers use everyday language to disseminate the findings for wider audiences (includes non-academic). Consequently, readers can apply the findings to their own situations and contexts.

Despite their advantages, a case study also has some disadvantages. The findings of a case study cannot be generalized to a population because a case study involves a small number of participants. Additionally, researchers have limited control on the variables that may affect the findings because the study is conducted in the natural setting. Therefore, researchers may face difficulty in drawing cause-and-effect conclusions (Yin, 2009). Lastly, researchers have to be aware of bias in reporting findings because only the researchers know the criteria used for selecting the information to be reported (Cohen et al., 2007).

In conducting a case study, researchers need to distinguish between a case and a case study. A case is defined as "a thing, a single entity, a unit around which there are boundaries" and it can be a school, a student, a teacher, or a program (Merriam, 2001, p. 27). The case in this study is defined as practical work. Practical work was studied through a group of students and several science teachers who were involved in practical work at the lower secondary school level in three schools. Case study as defined by Merriam (2001) was used to guide the study. Specifically, an interpretive case study, as suggested by Merriam (2001), was employed to understand the practical work tasks designed by science teachers and to evaluate the effectiveness of practical work tasks on student learning.

The case was investigated through three case studies in three different schools in Melaka, Malaysia a cross-case analysis about how the teachers conducted practical work tasks and how it affected students' actions and learning. Merriam (2001) suggested that by investigating more than one case, researchers could gain variation across the cases and strengthen the interpretation of the findings.

\subsection{Overview of the research process}

Creswell (2008) stated that the qualitative research process is emergent because it is conducted in a natural setting. Data collection was conducted from January 2011 until May 2011. Unexpected events arose throughout the data collection, such as difficulties in recruiting the participants and schools, changes in the classroom timetables, and the withdrawal of the participants from the study, which somewhat affected the flow of the data collection process. 
The data collection process was divided into three phases. The first phase of the study was the pilot study. It was conducted before the researcher embarked on the actual data collection. The researcher conducted the initial interview with two science teachers who had had three years of teaching experience. The aim in conducting the initial interviews was to check the use of language.

Phase I of the data collection was focused on getting access to the research sites and permission from the school principals to conduct the research in their schools. Sampling techniques are important in selecting participants to ensure researchers can gain sufficient information to answer research questions (Coles \& McGrath, 2010). In this study, purposive sampling had been employed to select participants, or sites, to understand the implementation of practical work. Although the researcher had approached nine schools in total, the researcher received permission to conduct the study in eight schools, of which three were urban schools and five were outskirt schools. One school, which was located in the urban area, refused to participate in the study. The permission from the school principals allowed the researcher to recruit the science teachers who taught science at the lower secondary school level. Although the researcher received permission from the school principals, the teachers from one urban and two outskirt schools also refused to participate in the study.

Phase II of the data collection was divided into two sections. In the first section, the researcher conducted on-going classroom observations and spontaneous conversations with the focus group students while they participated in practical work. Then, the researcher conducted postlesson follow-up interviews with the case study teachers after practical lessons to gain the teachers' reflections on the practical teaching and learning activities. The first focus group interview was conducted with the focus group students, a few days after they conducted the practical work. In the second part of Phase II, the researcher conducted the final interview with the case study teachers to check the consistency of their responses on the implementation of practical work and the teaching and learning activities. The researcher also conducted the final focus group interviews with students and collected their work, such as laboratory reports, notebooks, and worksheets. Table 5-3 is a summary of the data collection process. 
Table 5-3: A summary of the data collection process

\begin{tabular}{|c|c|}
\hline Date & Data collection activities \\
\hline $26^{\text {th }}$ December 2010 & - Carry out the pilot study with the two science teachers \\
\hline $\begin{array}{l}10^{\text {th }} \text { January 2011- } \\
4^{\text {th }} \text { March } 2011\end{array}$ & $\begin{array}{l}\text { Phase I: } \\
\text { - Approach nine schools in Melaka. } \\
\text { - Get permission from eight out of nine school principals. Two } \\
\text { - Appron schools and three outskirts schools. } \\
\text { science teachers who teach science at the lower secondary } \\
\text { school level. } \\
\text { - Invite science teachers to participate in this study. Six } \\
\text { - teachers agreed to participate in the study. } \\
\text { - Planduct initial interviews with science teachers. } \\
\text { - practical work sessions. } \\
\text { - } \text { Ask science teachers to nominate four to five students in their } \\
\text { - Get consent from parents/guardians. }\end{array}$ \\
\hline $\begin{array}{l}9^{\text {th }} \text { February- } \\
22^{\text {nd }} \text { April } 2011\end{array}$ & $\begin{array}{l}\text { Phase II } \\
\text { - On-going classroom observations. } \\
\text { - Conduct post-lesson follow-up interviews with science } \\
\text { teachers. } \\
\text { - Conduct spontaneous conversations with students during } \\
\text { practical work. } \\
\text { - Conduct the first focus group interviews with students. }\end{array}$ \\
\hline $\begin{array}{l}4^{\text {th }} \text { March- } \\
5^{\text {th }} \text { May } 2011\end{array}$ & $\begin{array}{l}\text { Phase II } \\
\text { - Final formal interviews with case study teachers. } \\
\text { - Conduct the second focus group interview with students. } \\
\text { - Collect students' artefacts. }\end{array}$ \\
\hline
\end{tabular}




\subsubsection{The selection of schools}

The total number of schools in Melaka Tengah District is 35 and of those, 27 schools are coeducational schools that are organized by the government. With the overwhelming majority of students in this area being educated within the co-educational school, the researcher decided to restrict the study to co-educational schools only. Despite restricting this study to the specific type of school, the researcher considered the details of the schools in terms of the size of the school, location, and academic performance to have a better understanding about the context of the schools.

The schools were chosen based on students' achievement in science in PMR. The research of Daniel and Idris (2007) found that there was no significant difference in overall students' performance in science between urban and outskirts schools. However, the number of students in outskirt schools who scored grade A was lower compared with students in urban schools, although the number of candidates in the outskirt area schools was significantly higher compared with urban schools (Daniel \& Idris, 2007). Additionally, the Bumiputra ${ }^{9}$ students' achievement in science was lower compared with non-Bumiputra ${ }^{10}$ students. Taking account of this information a purposive sampling method was used in selecting schools from both areas (urban and outskirts areas) with an average performance in science in PMR. The characteristics of schools were:

i. Urban schools with an average rating in PMR results for science in Melaka.

ii. Outskirt schools with an average rating in PMR results for science in Melaka.

The researcher visited five urban schools and four outskirt schools that met the criteria. The researcher met the school principals and explained the purpose of the study. Each of the school principals received a copy of the information sheet to have a better understanding about the research and a consent form to get the approval to conduct the research with his/her staff (Appendix 5-1). The researcher managed to get the permission to conduct the research from five school out of nine schools that the researcher approached.

\footnotetext{
9 Bumiputra means "native of the soil". This term refers to Malays and other indigenous tribes such as Kadazandusuns, Muruts, Bajaus and other tribes in Sabah; Dayaks, Ibans, Penans, and others in Sarawak (Ministry of Finance, 1986).

10 Non-Bumiputra refers to other ethnic such as Chinese, Indian, Sri Lankan, Eurasian, and other communities (Ministry of Finance, 1986).
} 


\subsubsection{Pseudonyms for the case study schools}

Meranti or Shorea spp. is also known as Philippine Mahogany. This species was commonly found in the rain forest of Malaysia. The group of Meranti are Light Red Meranti, Dark Red Meranti, White Meranti, Yellow Meranti, and Balau. The height of the tree ranges from $1 \mathrm{~m}$ up to $60 \mathrm{~m}$, which depends on the species ("The Wood Database," 2010). The common uses of Meranti include interior furniture, construction, boatbuilding, and concrete forms.

Resak or scientific name Vatica spp. is widely spread in Malaysia. Some of the species grow in hilly areas, such as Vatica nitens and some of the species, such as Vatica pauciflora, grow in fresh water swamps. Resak is considered as a small tree because is only 1 to $1.5 \mathrm{~m}$ tall. It is mainly used for heavy construction, flooring, and window frames.

Jati or Tectona spp. Is another tropical hardwood tree in Malaysia. It is a tall evergreen tree that has a hard, heavy, durable yellowish-brown wood. The average height of the tree is $30 \mathrm{~m}$. The texture of Jati wood is hard and durable that is mainly used for interior furniture and boatbuilding because it is highly resistant to infection of pests, such as fungi, rot, and mildew.

Keruing or Dipterocarpus spp. is widely found in peninsular Malaysia and Borneo. The tree can grow up to $60 \mathrm{~m}$ tall. It can be found on sandy and sandy clay soils on coastal hills and inland ridges, up to $1000 \mathrm{~m}$ altitude. The texture of Keruing varies between species. It ranges from fine to coarse. The colour also varies between species but is commonly red-brown (Department of Agriculture Fisheries and Forestry, 2012).

Chengal, or Balanocarpus spp. is a straight large hardwood. It can grow in peninsular Malaysia in a wide range of areas from swamp flats to hilly areas. Chengal has different colours that range from pale yellow, heartwood, or dark brown. It is used for heavy duty purposes, such as constructing bridges, railway sleepers, and wharves due to its high density (Department of Agriculture Fisheries and Forestry, 2012).

Each case study school was given a pseudonym to protect the identity of the school. The schools were named after the native timber species that grow in the rain forest in Malaysia. The species are: Meranti, Resak, Jati, Keruing, and Chengal. The description of each school is described in the following section.

\subsubsection{Case study schools}

Case study schools are located in Melaka Tengah District. Two schools are located in the urban areas and three in the outskirts. The total number of students in the case study schools 
ranged between 800 to 1600 students. The facilities such as libraries, canteens, prayer halls, workshops for the vocational and technical streams, and science laboratories are well maintained and in good condition. All schools implement the national policy of using Bahasa Malaysia as a medium of instruction for all subjects other than English, science and mathematics that are taught in English as per the Teaching of Mathematics and Science (ETeMS) policy. The researcher found that although the policy of teaching science in English was to change to Bahasa Malaysia the year following data gathering the case study teachers already used Bahasa Malaysia as a medium of instruction to teach both subjects.

\subsubsection{The recruitment of teachers}

Phase 1 of research entailed recruiting teachers. After receiving permission from the school principals and having been introduced to the heads of department from the schools, the researcher managed to reach the science teachers who taught science at the lower secondary school level. Before the researcher could recruit the teachers to participate in the study, the researcher talked to each teacher who taught science at the lower secondary schools level. Each school has two or three science teachers who taught science at this level. After the briefing session in which they were invited to participate, all of them received an information sheet and a consent form (Appendix 5-2). The information sheet provided information about the aims of this study, research procedures, and the participants' roles. The consent form contained information for the participants' attention to ensure that they were aware that they had the right to participate or withdraw from the study at any stage of the research. The researcher gave a few days for the teachers to consider the invitation. As a result, six teachers from five schools gave consent to participate in Phase I of the study. Out of six teachers who were willing to participate in Phase I, only three teachers from three different schools agreed to embark to Phase II of the study. A pseudonym was used to represent the teachers to protect the teacher's identity. The teachers are named after the school. For example, Teacher Jati taught at Jati School and Teacher Resak taught at Resak School. The profiles of the teachers will be discussed in the following paragraph. Table 5-4 shows the teachers who were willing to participate in the study. 
Table 5-4: The teachers who participated in the research

\begin{tabular}{|c|c|c|c|c|}
\hline School & $\begin{array}{c}\text { Number of science } \\
\text { teachers who } \\
\text { teach science } \\
\text { Form Two }\end{array}$ & $\begin{array}{c}\text { Number of } \\
\text { science teachers } \\
\text { who participated } \\
\text { in Phase I }\end{array}$ & $\begin{array}{c}\text { Number of } \\
\text { science teachers } \\
\text { who participated } \\
\text { in Phase II }\end{array}$ & The participant \\
\hline $\begin{array}{l}\text { Jati } \\
\text { School }\end{array}$ & 4 & 1 & 1 & Teacher Jati (TJ) \\
\hline $\begin{array}{l}\text { Meranti } \\
\text { School }\end{array}$ & 2 & 1 & 1 & Teacher Meranti (TM) \\
\hline $\begin{array}{l}\text { Resak } \\
\text { School }\end{array}$ & 2 & 1 & 1 & Teacher Resak (TR) \\
\hline $\begin{array}{l}\text { Keruing } \\
\text { School }\end{array}$ & 4 & 1 & 0 & Teacher Keruing (TK) \\
\hline \multirow[t]{2}{*}{$\begin{array}{l}\text { Chengal } \\
\text { School }\end{array}$} & 3 & 2 & 0 & $\begin{array}{c}\text { Teacher Chengal } 1 \\
\text { (TC1) }\end{array}$ \\
\hline & & & & $\begin{array}{c}\text { Teacher Chengal } 2 \\
\text { (TC2) }\end{array}$ \\
\hline
\end{tabular}

In selecting science teachers, a number of parameters were considered. The parameters were years of teaching experience and their teaching philosophy. However, it is more likely that science teachers' participation was dependent on the recommendations of head of science departments and science teachers' willingness to be involved in the study.

All the participating teachers are graduates with Bachelor of Science or Bachelor of Science Education and some are diploma holders in science education from teacher training institutions. They have taught science at the lower secondary school level for more than seven years. These teachers also teach different subjects for example mathematics, biology, or chemistry at the upper secondary school level.

\subsubsection{The recruitment of students}

The researcher recruited students to take part as focus group students in Phase I of the research. In each case, the researcher involved five form two students in each school. It is a norm that students work together in groups of four to five to conduct practical work (JimenezAleixandre \& Diaz de Bustamante, 1997). These students participated in focus group interviews.

There are a number of reasons for selecting form two students rather than other grades. Form one students may be inexperienced in practical work because they are in the first year in secondary school. Form three students are involved in the national examination and it would 
be difficult to get consent to participate in any research (MOE, 2006b). Due to these limitations of recruiting form one or form three students, form two students seem a better option for the study.

The students were recruited based on the science teachers' recommendations. In general, the researcher asked the teachers to nominate five students to participate in the study. The criteria included students who were low to high achievers, based on their science results in the final term in form one. The researcher approached the students and explained the aims and their roles in Bahasa Malaysia. The students were given the opportunity to ask questions about the study before they received the information sheets and consent forms after the briefing sessions (Appendix 5-3). Each student was given a week to make the decision whether he/she wanted to participate in this study. Table 5-5 shows the student profiles.

Table 5-5: The student profiles according to academic achievement.

\begin{tabular}{lllll}
\hline School & Class & Low achievers & $\begin{array}{l}\text { Moderate } \\
\text { achievers }\end{array}$ & High achievers \\
\hline Jati School & 2 Blue & J4, J5 & J2 & J1, J3 \\
Meranti School & 2 Red & M1,M3 & M2, M4 & M5 \\
Resak School & 2 Yellow & R5, R4 & R3 & R1, R2 \\
\hline
\end{tabular}

The students conducted practical work, mainly through small groups. All the case study teachers permitted the students to form their own group, based on friendships. There was not a single practical lesson where teachers formed the groups for students. They formed the group according to students who sat at the same bench. The size of the group was from five to seven students in one group.

\subsection{The ethical considerations}

Victoria University of Wellington places high priority on conducting ethical research. The researcher lodged an application with the Faculty of Education Ethics Committee that addressed the key ethical and legal issues to protect the researcher's and the participants' rights. After gaining the ethical approval (Appendix 5-4) from the Ethics Committee, the researcher embarked on the study. 
The researcher also applied for approval from various government sectors to conduct the research in the government schools. Firstly, the researcher lodged the application at the Economic Planning Unit (EPU), Prime Minister's Department in Malaysia and the State Education Department. The researcher lodged the online application with the EPU in November 2010. However, the researcher got the approval to conduct the study from the EPU in early January 2011 (Appendix 5-5). Secondly, the researcher applied for permission from the State Education Department (Appendix 5-6). Without the approvals from the government sectors, a researcher could not get access to the schools.

Each participant (students and science teachers) received an information sheet and a consent form. The information sheet provided information about the aims of this study, research procedures, and the participants' roles. The researchers explained to participants regarding the research in Bahasa Malaysia. They were allowed to ask questions for clarification about the research. The consent form contained information for the participants' attention before they participated in this study. The researcher also sought consents from the parents/guardians to enable the involvement of under-age students in the study.

The researcher had to maintain the security, privacy, and confidentiality of the participants' details. Pseudonyms were used to ensure the participants' confidentiality. The protection also applied to the schools where this study was conducted. The consent from the guardians was important, as all the students were under-age. Each guardian also got a copy of the information sheets to inform them about the intention of the research and consent forms to ask for the permission to do research with their dependents (Appendix 5-7). The researcher sought permission to record the interviews and classroom observations. The students who participated in the study were promised confidentiality. It was necessary to change all the names. The researcher created a system in which it was easy to identify which schools the students belonged to. They were identified as a capital letter of the school. For example, the students from Jati School were represented by the alphabet letter ' $J$ ', followed by a number 1 , 2, and etc. (e.g.: J1, J2 etc.). Whereas students in the class were identified as small letter 'j' followed by number 1,2 and etc. (e.g.: j1, j2 etc.).

\subsection{Data collection tools}

To understand the nature of practical work, different tools are employed to collect the data, such as semi-structured interviews, focus group interviews, classroom observations, document analysis, and field notes. Each tool will be discussed in turn. 


\subsubsection{Interviews}

An interview is a valuable tool for "assessing people's perceptions, meanings, definitions of situations and constructions of reality" (Punch, 2005, p. 168). Several approaches can be taken in carrying out interviews. These include structured interviews, semi-structured and group interviews, and unstructured interviews (Punch, 2005). The researcher conducted semistructured interviews with teachers and focus group interviews with focus group students.

\subsubsection{Semi-structured interviews with teacher participants}

In conducting semi-structured interviews, participants "received the same questions in the same order, and these were delivered in a standardized manner" (Punch, 2005, p. 170). The semi-structured interviews were conducted at the beginning of the study to obtain teachers' views of practical work and post-lessons to clarify any issues that arose during observations.

A survey study carried out by Abrahams and Saglam (2010), based on Kerr (1963), revealed a wide variety of purposes of conducting practical work, as perceived by teacher participants. However, a survey study cannot help researchers to investigate how teachers implement practical work as a teaching and learning activity. Therefore, interviews may provide better chances to gain deeper understanding into the teachers' views about the nature of practical work (Pekmez et al., 2005).

The initial formal interview protocol was divided into two sections (Section A and Section B). In Section A, teacher participants were asked questions about their background (teaching experience, subject specialism, etc.) and their opinions regarding the purpose of conducting practical work. In Section B, the interview questions were focussed on the teachers' understanding about different types of practical work and the reasons why they implemented practical work rather than other teaching approaches (Appendix 5-8). All the interview sessions were recorded and later transcribed.

Post-lesson follow-up interviews were conducted to gain teacher participants' reflections on practical work sessions, the setting, and learning objectives for the next practical work session (Appendix 5-9). The post-lesson follow-up interviews were conducted for approximately 15-20 minutes during teacher participants' non-contact period or after the school session. Final formal interviews were carried out with teacher participants after all observation sessions had been conducted. The final formal interviews helped the researcher to clarify and refine data from the initial interviews and observations (Appendix 5-10). Most questions were focussed on 
the teachers participants' aims for conducting practical work and their justification in selecting particular types of practical work.

Interviews were conducted in Bahasa Malaysia. At the end of interviews, the participants were provided with transcriptions to check for accuracy. Then, the researcher translated these into English. Two English language lecturers who have good command of English and Bahasa Malaysia were approached to check the translations for accuracy. The researcher used pseudonyms for participants before sending the document to the two English Language lecturers to check the translations to maintain confidentiality of participants.

\subsubsection{Focus group interviews}

Focus group interviews are "...the process of collecting data through interviews with a group of people, typically four or six" (Creswell, 2008, p. 226). Focus group interviews are another way of gaining understanding about the shared experiences of a group of people (Creswell, 2008). Each focus group interview was held for approximately 45 minutes. Through the focus group interviews, the researcher could collect the data from a group of students at the same time and help them reduce their anxieties that they may have had in individual interviews.

The limitation of focus group interviews is that the researcher may have some difficulties in taking notes because a considerable amount of information is generated through such interviews. The researcher may be unable to discriminate between the voices of the participants in the group. Therefore, the researcher had to listen to the recorded conversation more than once to help distinguish between the different student participant voices in transcribing the conversations. Later, the student participants received the focus group transcripts to check for accuracy.

In this study, three focus group interviews were conducted after all the practical work was completed. The first focus group interview was an ice breaker session. It was conducted to develop a good relationship with the student participants and set up ground rules during the focus group interviews. In the ice breaker session and at the start of the interviews, the researcher reminded the focus group students not to share or discuss anything from the interviews with anyone else to maintain the confidentiality of the information shared by focus group students. The session took about 45 minutes during their non-contact period or after the school session. The other two focus group interviews were conducted after the teacher participants had covered two learning areas. The learning areas were: The World Through our Senses and Nutrition in the theme of Management and Continuity of Life (MOE, 2002, p. 16). 
The questions were focussed on practical work tasks that the student participant had done and to examine what the student participant had learnt (Appendix 5-11). The interview with students provided an insight into the effectiveness level of practical work tasks from student participant perspectives and to gauge whether it was at the Effectiveness level 2 (0) or Effectiveness level 2 (i) (Abrahams \& Millar, 2008).

\subsubsection{Classroom observation}

Observation is a tool to record participants' actions that cannot be captured through interviews or questionnaires. Creswell (2008) highlighted an observation is opened-ended process in gathering data by making observation on people or events at the particular place. In the study, the researcher conducted classroom observation sessions in a double period of approximately 90 minutes. In Malaysia, practical work is usually carried out in a double-period lesson and a single period is about 45 minutes. Each classroom observation session was recorded. Through classroom observation, the researcher could observe ways teachers engage students at the beginning of the lesson, how they assist students throughout the lesson, and ways in which they conclude the lesson. The teachers' actions in practical work were recorded through the observation protocol (Appendix 5-12).

A pilot study was conducted at the beginning of the classroom observation phase in each participating school. The researcher wrote field notes under broad categories of student actions, teacher actions, and nature of the task on observation protocol. She indicated the context of the student actions - by individuals (i), in a group (g), or as a class (c) on the observation protocol, the classroom settings and the seating plan. Each practical lesson was audio-recorded and later transcribed as an additional check.

Although observations allow researchers to observe participants' actions in the research site it is impossible to gain insights into student participants' thinking on tasks not observed. In order to clarify incidents during observations, the researcher conducted spontaneous conversations with students during practical work. Spontaneous conversations allowed the researcher to gain evidence as to whether or not the students made links between concepts and ideas that teachers intended them to use in conducting practical work tasks. Examples of questions were: 'Why do you test starch solution with iodine solution?' and 'Why do you use anhydrous calcium chloride in this experiment?' The researcher observed 10 practical lessons conducted by teacher participants; more in the second learning area, compared to the first learning area. 
Table 5-6 shows the scientific concepts that the case study teacher taught through practical work.

Table 5-6: The number of practical lessons observed

\begin{tabular}{|c|c|c|c|c|}
\hline \multirow{2}{*}{ School } & \multirow{2}{*}{ Participants } & \multicolumn{2}{|c|}{ Learning area } & \multirow{2}{*}{ Aim of practical work } \\
\hline & & 1 & 2 & \\
\hline \multirow{3}{*}{$\begin{array}{l}\text { Jati } \\
\text { School }\end{array}$} & \multirow{3}{*}{ TJ } & $\sqrt{ }$ & & $\begin{array}{l}\text { To investigate and identify the parts of plants } \\
\text { that are sensitive }\end{array}$ \\
\hline & & & $\sqrt{ }$ & To test for starch, glucose, protein, and fats \\
\hline & & & $\sqrt{ }$ & $\begin{array}{l}\text { To show the absorption of glucose through a } \\
\text { Visking tube }\end{array}$ \\
\hline \multirow{6}{*}{$\begin{array}{l}\text { Meranti } \\
\text { School }\end{array}$} & \multirow{6}{*}{ TM } & $\sqrt{ }$ & & The sound travels through vibration \\
\hline & & $\sqrt{ }$ & & $\begin{array}{l}\text { The sound needs a medium to travel and } \\
\text { sound is reflected and absorbed }\end{array}$ \\
\hline & & $\sqrt{ }$ & & $\begin{array}{l}\text { To investigate and identify the parts of plants } \\
\text { that are sensitive }\end{array}$ \\
\hline & & & $\sqrt{ }$ & To test for starch, glucose, protein, and fats \\
\hline & & & $\sqrt{ }$ & The action of salivary amylase on starch \\
\hline & & & $\sqrt{ }$ & $\begin{array}{l}\text { The absorption of glucose through a Visking } \\
\text { tube }\end{array}$ \\
\hline $\begin{array}{l}\text { Resak } \\
\text { School }\end{array}$ & TR & & $\sqrt{ }$ & $\begin{array}{l}\text { The absorption of glucose through a Visking } \\
\text { tube }\end{array}$ \\
\hline
\end{tabular}

As shown on Table 5-6, the number of lessons that the researcher observed was different among the participants. Three practical lessons were observed from TJ's lessons. He conducted one practical work from learning area one, followed by two practical lessons from learning area two. TM conducted more practical work as opposed to TJ. She conducted three practical lessons from each learning area one. TR conducted almost all the suggested practical work and appeared to conduct practical work on a regular basis following the suggestion in the science textbook. The students' reports confirmed that they had conducted practical tasks on both learning areas, however, due to some unforeseen circumstances, the researcher only had a chance to observe his lesson once. The researcher had difficulties 
arranging the classroom observation with TR as Resak School changed the school timetable regularly. This teacher also cancelled some of the appointments, as he was involved with other administration work that he had to handle outside the school. Although the researcher did not have the opportunities to observe an equal number of lessons with all the participants, the researcher found that the participants shared quite similar approaches in conducting the task with their students.

\subsection{Document analysis}

By examining relevant documents, researchers can cross-check information collected from other sources (Punch, 2005) which may help researchers to triangulate the data from interviews, classroom observations, or checklists. Table 5-7 shows a summary of documents that were collected by the researcher in this study.

Table 5-7: The documents that were collected this study

\begin{tabular}{ll}
\hline Document & Purpose \\
\hline $\begin{array}{l}\text { The science curriculum } \\
\text { specification for form two (MOE, } \\
\text { 2002a) }\end{array}$ & $\begin{array}{l}\text { To examine the learning objectives that teachers want to } \\
\text { achieve. }\end{array}$ \\
$\begin{array}{l}\text { Science form two textbook (Tong } \\
\text { \& Neo, 2003) }\end{array}$ & $\begin{array}{l}\text { To examine the suggested activities that the teachers } \\
\text { implemented to achieve the learning objectives. }\end{array}$ \\
Worksheets for practical book & $\begin{array}{l}\text { To examine the suggested activities that the teachers used } \\
\text { to achieve the learning objectives. }\end{array}$ \\
Students' practical work reports & $\begin{array}{l}\text { To examine any evidence that student participants tried to } \\
\text { establish the relationship between theory and the tasks. }\end{array}$ \\
\hline
\end{tabular}

\subsubsection{Field notes}

Throughout this study the researcher kept journals to enhance the credibility of the data. By taking field notes, the researcher explored how teacher participants conducted practical work and explored student participants' actions in completing the task. Additionally, the researcher also recorded her own reflections and reactions on interviews, observations, and her ongoing document analysis. The notes were organized into four categories based on Richardson (2003a). Keeping detailed notes added to the trustworthiness of the research (Richardson, 2003a). Table 5-8 summarizes the characteristics of note organization. 
Table 5-8: The summary of notes organization based on Richardson (2003a).

\begin{tabular}{ll}
\hline Category & Description \\
\hline Observation notes (ON) & $\begin{array}{l}\text { Researchers' records about events that they collect through } \\
\text { senses - fairly accurate (e.g.: see, hear, taste and so on). }\end{array}$ \\
$\begin{array}{l}\text { Methodological notes } \\
\text { (MN) }\end{array}$ & $\begin{array}{l}\text { Researchers' notes to themselves on how to collect data. } \\
\text { Theoretical notes (TK) }\end{array}$ \\
$\begin{array}{l}\text { Researchers' hunches, critiques, and hypotheses based on } \\
\text { actions, thinking, and observations. Researchers explore other } \\
\text { interpretations and engage with multiple realities. }\end{array}$ \\
$\begin{array}{l}\text { Personal notes (PN) } \\
\text { Researchers' feelings towards studies, the interviewees, the } \\
\text { setting, the doubts, the anxieties, and the pleasures. Personal } \\
\text { notes are also important, as they will affect what/who } \\
\text { researchers claim to know. }\end{array}$ \\
\hline
\end{tabular}

\subsection{The analytical framework}

It is important to analyse the specific tasks to assess the effectiveness of practical work. Tiberghien, Veillard, Maréchal, Buty, and Millar (2001) proposed a way of analyzing practical work systemically to provide clear descriptions of features of practical work. The framework provided a checklist for analyzing practical work tasks.

\subsection{An analytical framework for investigating the effectiveness of practical tasks}

Three frameworks were proposed by scholars to examine the effectiveness of practical work. Tiberghien proposed the initial framework in 2000. Millar, Tiberghien, and Marechal (2002) used this as the basis for a more complex framework that incorporated two levels of effectiveness. In 2008, Abrahams and Millar further developed the framework. Each framework will be explained in the following section. Table 5-9 shows a summary of the frameworks. 
Table 5-9: The framework to examine the effectiveness of practical work.

\begin{tabular}{cll}
\hline Framework & \multicolumn{1}{c}{ Purpose of framework } & \multicolumn{1}{c}{ Author(s) } \\
\hline A & $\begin{array}{l}\text { Effectiveness of practical work based on } \\
\text { linking the domain of objects with the } \\
\text { domain of ideas }\end{array}$ & Tiberghien (2000) \\
& $\begin{array}{l}\text { Effectiveness of practical work based on a } \\
\text { model of two levels of effectiveness of } \\
\text { practical work }\end{array}$ & Millar et al. (2002) \\
B & $\begin{array}{l}\text { Effectiveness of practical work based on a } \\
\text { model of two levels of effectiveness of } \\
\text { practical work and two domains of } \\
\text { knowledge }\end{array}$ & \\
\hline
\end{tabular}

\subsubsection{Framework A: Two domains of knowledge}

The first framework of practical work by Tiberghien (2000) focused on the relationship between real objects and ideas. The domain of real objects and observable things requires students to engage with real objects and materials to produce the desired phenomena, whereas the domain of ideas deals with the concepts, laws, and theory that teachers want students to learn (Abrahams \& Millar, 2008). The framework was useful to examining connection between the domain of real objects (o) and observable things and domain of ideas (i). A limitation of this initial framework was that it did not highlight the teacher's role in practical work in making a meaningful connection between these two domains as illustrated in Figure 5-1.

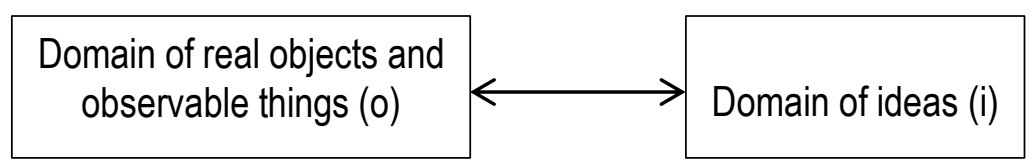

Figure 5-1 The fundamental purpose of practical work (Tiberghien, 2000, p. 29)

\subsubsection{Framework B: Two levels of effectiveness of practical work}

In 2002, Millar, Tiberghien, and Marechal developed a framework by incorporating two levels of effectiveness to show the importance of the teacher's intentions of doing practical work. This was useful to examining how the effectiveness of practical work relates to the actions of teachers and students before and after the lesson. Each of the teaching and learning activities 
(see Figure 5-2, Boxes A, B, C, and D) has a strong connection with students' and teachers' views of science, teaching, and the context (see Figure 5-2, Circles on the right-hand side).

In this model, it is assumed that teaching and learning activities begin with teachers stating the learning objectives that they intend students to learn beforehand (Box A in Figure 5-2) which link to what the students actually learn (Box D in Figure 5-2). The objective could be the scientific knowledge or specific aspects of scientific enquiry, such as collecting, analyzing, or interpreting the data, after which, teachers design appropriate tasks to achieve the intended learning outcomes (Box B in Figure 5-2). These two stages are influenced by teachers' views about science and learning. They are also influenced by the practical and institutional contexts, such as resources, mode of assessment, and curriculum requirement (Circles on the right-hand side).

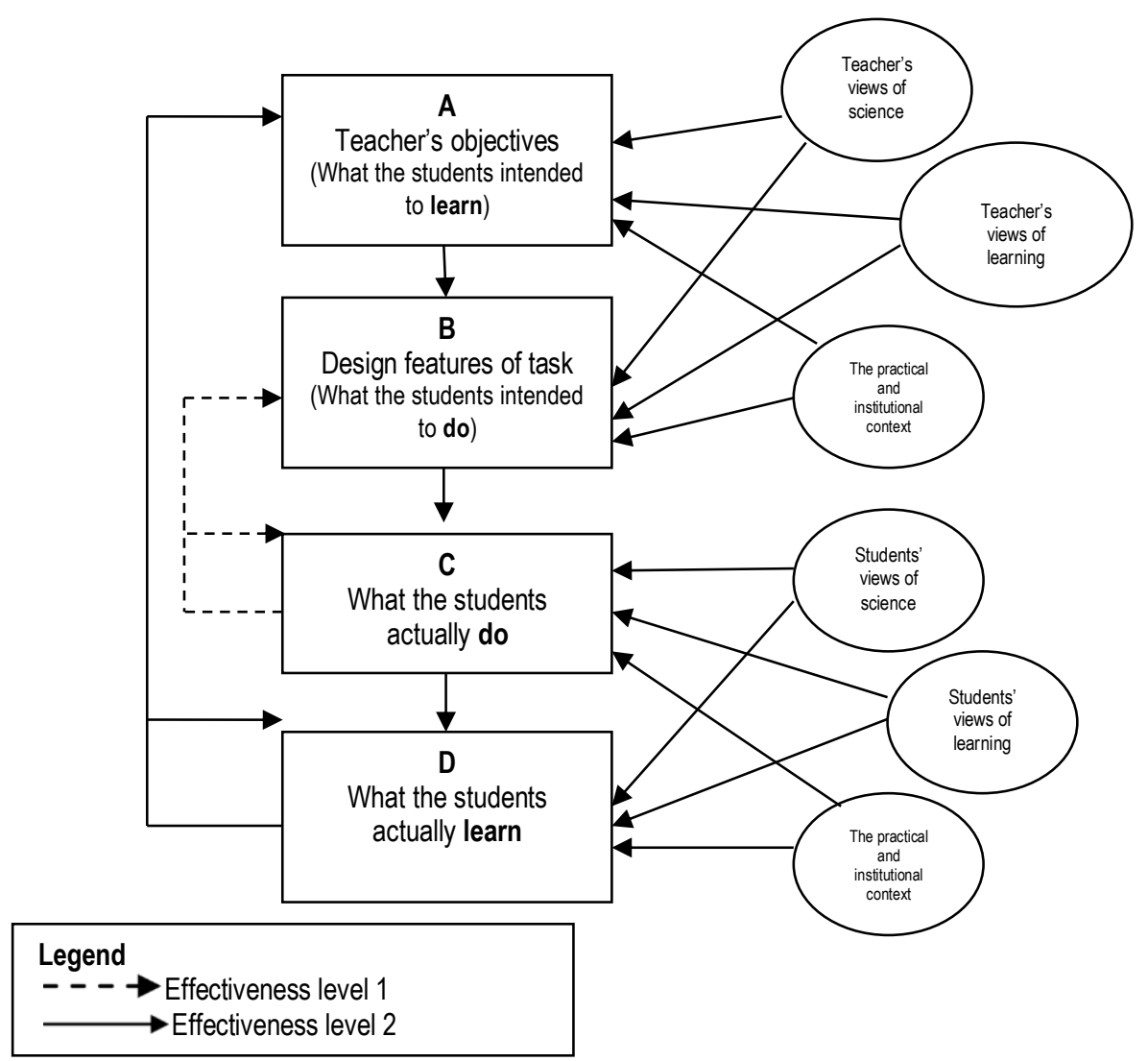

Figure 5-2: A model of two levels of the effectiveness of practical work (Millar et al., 2002, p. 12)

As practical work is implemented, teachers can observe what students actually do (Box C). Box $D$ is concerned with what students actually learn from the tasks. 
In some cases, there is a mismatch between teachers' and students' intended learning outcomes from the task that the students were engaged with (Millar et al., 2002). For instance, teachers designed tasks for students to engage in scientific enquiry, but students expected to be told the correct answers (Millar et al., 2002; Tiberghien et al., 2001). Therefore, students' actions may not lead to achievement of the intended learning outcomes (Millar et al., 2002). This may be because students' actions and learning through practical work are influenced by students' views about science, learning, and the educational settings (Millar et al., 2002). Therefore, the success of student learning to achieve the intended learning outcomes is dependent upon what they do with the tasks.

The strength of this model is that it distinguishes two levels of effectiveness in practical work. The basic level of effectiveness (Effectiveness level 1) is the match between what teachers want students to do and what students actually do. Then, the second level of effectiveness (Effectiveness level 2) is the match between what students learn and what teachers intended students to learn. Therefore, the Effectiveness level 1 is the relationship between Boxes $B$ and $C$, whereas the Effectiveness level 2 is the relationship between Boxes $A$ and $D$ in Figure 5-2 (Millar et al., 2002).

In 2008, Abrahams and Millar observed that students were unable to produce phenomena as planned by teachers for various reasons. Students might not understand the instructions; the equipment and materials were not enough for everyone; or students were unable to grasp what teachers had planned. Although students could produce the intended activity, there was no certainty students could use the ideas that teachers intended students to use (Abrahams \& Millar, 2008). Earlier, Lunetta (1998) had reported that students were involved in manipulating objects and materials in conducting practical work but did not manipulate the ideas to understand the tasks. This led Abrahams and Millar to think about a more complex framework.

\subsubsection{Framework C: A 2x2 effectiveness matrix}

The third framework used a $2 \times 2$ effectiveness matrix based on a combination of the model of two domains of knowledge (Tiberghien, 2000) and the model of two levels of effectiveness of practical work (Millar et al., 2002). The $2 \times 2$ effectiveness matrix provides a detailed analytical framework to measure the effectiveness of practical work tasks. The analytical framework measures students' conceptual and procedural knowledge. Additionally, the analytical framework focuses on what students do physically and mentally in completing practical work 
tasks. Table 5-10 summarizes the combination of the model's two levels of effectiveness and the model of two domains of knowledge to analyse the effectiveness of the practical task.

Table 5-10: An analytical framework for considering the effectiveness of the practical work (Abrahams \& Millar, 2008, p. 1949)

\begin{tabular}{|c|c|c|}
\hline Effectiveness & Domain of observable (o) & Domain of idea (i) \\
\hline $\begin{array}{l}\text { Practical work is } \\
\text { effective in level } 1 \\
\text { (doing level) }\end{array}$ & $\begin{array}{l}\text { Students engage with manipulating } \\
\text { the objects and materials provided by } \\
\text { a teacher participant to produce the } \\
\text { intended data or phenomenon the } \\
\text { teacher participant intended. }\end{array}$ & $\begin{array}{l}\text { Students think about their actions } \\
\text { and observations using the ideas that } \\
\text { the teacher participant intended them } \\
\text { to use. }\end{array}$ \\
\hline $\begin{array}{l}\text { Practical work is } \\
\text { effective in level } 2 \\
\text { (learning level) }\end{array}$ & $\begin{array}{l}\text { Students can later recall things they } \\
\text { did with objects or materials, or that } \\
\text { they observed when carrying out the } \\
\text { task, and key features of the data } \\
\text { they collected. }\end{array}$ & $\begin{array}{l}\text { Students can later show } \\
\text { understanding of the ideas the task } \\
\text { was designed to help them learn. }\end{array}$ \\
\hline
\end{tabular}

The Effectiveness level 1 can be analysed during practical work by analyzing the actual students' actions in completing practical work tasks compared with the intended activities that teachers had planned for the students to do (Niedderer et al., 2002). The notion of what the students do with objects and observables (Effectiveness level 1(0)) is assessed through observation of how the tasks are carried out by teachers to engage students with the objects and materials to produce the intended phenomenon (Abrahams \& Millar, 2008).

The notion of the Effectiveness level 1(i) or what the students do with ideas is the mental process or thinking process that students engage in when completing the task in hand. The main assumption of the thinking process which occurs during practical work is that students talk explicitly about the objects and materials to complete the task in terms of "theoretical entities or constructs that are not directly observable" (Abrahams \& Millar, 2008, p. 1955).

Next, the Effectiveness level 2(0) or what the students learn about objects and observable aspects is assessed through the focus group interviews after practical work. Researchers can gain detailed information about what students have done with the objects and materials and observed phenomena (Abrahams \& Millar, 2008). If students are unable to recall what they have done during practical work, it is doubtful to claim that students have learned anything from the practical work. 
Lastly, the Effectiveness level 2(i), or what the students learn about the ideas, is assessed through post-lesson interviews to find evidence that students are able to retain the idea (Abrahams \& Millar, 2008). However, one has to be aware that the Effectiveness level 2 (i) in Table $5-10$ is hard to acquire in a single practical work experience (Millar, 2009). The acquisition of scientific ideas and concepts needs a series of lessons that incorporate a number of teaching and learning activities. Therefore, it is difficult to measure the Effectiveness level 2 (i) (Abrahams \& Millar, 2008).

To conclude, the analytical framework in Table 5-10 will be used for this study. The analytical framework is useful to analyse the acquisition of students' ideas about the scientific concepts or the scientific methods. This framework analyses the effectiveness of practical work by analyzing what students do and what students learn from practical work. Additionally, the four cells of Table 5-10 are dependent on each other. For instance, a task can be effective in level 2 (i) if students can show their understanding at level 1 (i). Then, if students are able to achieve level 2 (o), the students should be able to perform successfully at level 1 (0).

\subsubsection{Analysing the practical work task}

Practical work tasks can be analysed by different approaches; one is by using the inventory such as that developed by Millar et al. (2002). It provides opportunities for researchers to examine features of practical work tasks in terms of the design of practical work. Consequently, researchers may have information for considering the effectiveness of practical work tasks. The information recorded from the framework helps the researcher to consider ways of improving the effectiveness of practical work to maximize student learning.

Millar et al. (2002, p. 13) divided each category in the inventory into a set of more specific features. Each feature consisted of a set of codes. Then, one or more codes were allocated to provide detailed descriptions of practical work tasks. Appendix 5-13 shows the categories and features in the framework. A summary of components of the inventory is presented as follows:

i. $\quad$ Aspect A: The intended learning outcomes (or learning objectives)

ii. Aspect B: Key elements of the task design including:

a. Aspect B1: The cognitive structure of the task

b. Aspect B2: the level and nature of students' involvement

c. Aspect B3: the practical context of the task. 


\subsection{Data analysis}

The interpretation of the implementation of practical work is gained through the combination of detailed descriptions of students' actions, thinking, and reflections; teachers' actions and views in conducting practical work; and the researcher's thinking and reflections on practical work. In analysing the data, the researcher identified categories and themes across the data sources (the interviews, the classroom observations, and the documents analysis). Then, the data were coded based on the categories. Themes were identified as a pattern emerged from the data. Theories and generalizations were compared with the existing literature. Creswell's (2009) flow chart (Figure 5-3) was followed as a framework in analysing the data.

In this study, the researcher analysed each case study separately to highlight and distinguish their characteristics. Cross case analysis between case studies was employed to examine differences and similarities in answering the research questions (Yin, 2009). Such a process helps researchers to describe in detail complex real-life situations that cannot be captured through a survey study (Yin, 2009). Based on detailed descriptions of case studies, explanations of phenomena were generated. 


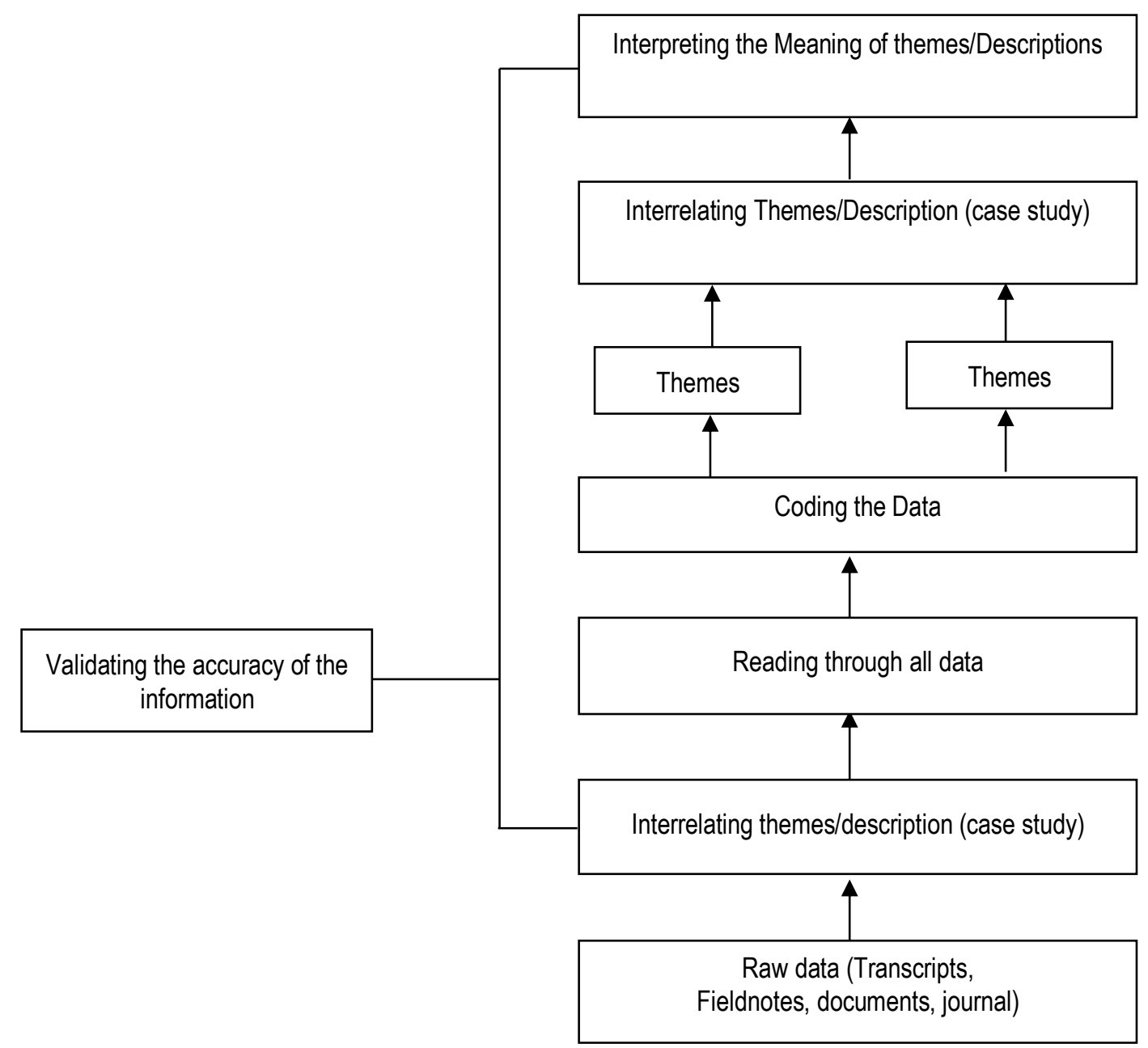

Figure 5-3: The framework for data analysis, based on Creswell (2009, p. 185)

\subsubsection{The approach to developing the categories and coding participants' views of doing practical work}

In developing the categories and coding regarding the purposes and aims of doing practical work, long interviews and conversations were recorded and transcribed verbatim. Later, long statements from the initial interviews were reduced into phrases that contained a few words that the researcher called 'coding'. For example, in the first interview question, teachers were asked to explain the reasons why they did practical work. Examples of phrases such as use the laboratory equipment or know the names of apparatus were given. Those answers were grouped together as a coding and later grouped into similar categories. Table 5-11 shows the process of how the coding related to teachers' views in conducting practical work that emerged from the interviews. 
Table 5-11: The process to construct coding and categories for the views of conducting practical work.

\begin{tabular}{|c|c|c|c|}
\hline Theme & Category & Coding & Phrases \\
\hline \multirow{10}{*}{$\begin{array}{l}\text { Aim of } \\
\text { conducting } \\
\text { practical work. } \\
\text { Category that } \\
\text { emerged from } \\
\text { the interviews. }\end{array}$} & & $\begin{array}{l}\text { Developing manipulative } \\
\text { skills }\end{array}$ & $\begin{array}{l}\text {-use the laboratory apparatus. } \\
\text {-know the name of laboratory } \\
\text { apparatus. }\end{array}$ \\
\hline & $\begin{array}{l}\text { Developing } \\
\text { procedural } \\
\text { knowledge }\end{array}$ & $\begin{array}{l}\text { Developing science } \\
\text { process skills }\end{array}$ & $\begin{array}{l}\text { Science process skill (SPS): } \\
\text { Basic science process skills } \\
\text {-a skill to record data } \\
\text {-analysing data } \\
\text { SPS: Integrated science } \\
\text { process skills } \\
\text {-making the hypothesis } \\
\text {-identify the variables. }\end{array}$ \\
\hline & \multirow{2}{*}{$\begin{array}{l}\text { Developing } \\
\text { conceptual } \\
\text { knowledge }\end{array}$} & $\begin{array}{l}\text { Developing conceptual } \\
\text { knowledge }\end{array}$ & $\begin{array}{l}\text {-understand the concepts } \\
\text {-memorize the facts } \\
\text {-strengthen their understanding } \\
\text { of what they have learned in the } \\
\text { theory lesson }\end{array}$ \\
\hline & & $\begin{array}{l}\text { Memorizing the } \\
\text { concepts and the } \\
\text { expected results }\end{array}$ & $\begin{array}{l}\text {-memorize the concepts if the } \\
\text { students are involved in } \\
\text { teaching and learning activities. } \\
\text {-they could remember the } \\
\text { results. }\end{array}$ \\
\hline & \multirow{2}{*}{$\begin{array}{l}\text { Preparing for the } \\
\text { examination }\end{array}$} & $\begin{array}{l}\text { Preparing students for } \\
\text { assessment }\end{array}$ & $\begin{array}{l}\text {-complete the practical work } \\
\text { assessment (PEKA). } \\
\text {-choose practical work that was } \\
\text { frequently asked for in the } \\
\text { exam. }\end{array}$ \\
\hline & & $\begin{array}{l}\text { Observing real } \\
\text { phenomena }\end{array}$ & $\begin{array}{l}\text {-could not imagine the events } \\
\text { from the lecture. } \\
\text {-easy to remember the concept } \\
\text { where the students could see } \\
\text { the actual event. }\end{array}$ \\
\hline & \multirow{2}{*}{$\begin{array}{c}\text { Fostering } \\
\text { Essential skills }\end{array}$} & Developing confidence & $\begin{array}{l}\text {-confident to speak to group } \\
\text { members. } \\
\text {-being confident to use the } \\
\text { laboratory apparatus. }\end{array}$ \\
\hline & & Developing teamwork & $\begin{array}{l}\text {-work cooperatively. } \\
\text {-work together. }\end{array}$ \\
\hline & \multirow[t]{2}{*}{$\begin{array}{c}\text { Fostering } \\
\text { A positive scientific } \\
\text { attitude }\end{array}$} & $\begin{array}{l}\text { Fostering students' } \\
\text { interest in science }\end{array}$ & $\begin{array}{l}\text {-make lesson more fun. } \\
\text {-avoid boredom among } \\
\text { students. } \\
\text {-different from normal teaching } \\
\text { approach (taking notes and } \\
\text { listening to lectures). }\end{array}$ \\
\hline & & $\begin{array}{l}\text { Developing honesty in } \\
\text { recording data }\end{array}$ & $\begin{array}{l}\text {-foster honesty among his } \\
\text { students in recording the data. }\end{array}$ \\
\hline
\end{tabular}




\subsubsection{The approaches to developing the categories and coding of types of practical}

work

The second part of the interview was focused on teachers' practices in doing practical work. To probe teachers' responses regarding different types of practical work, they were asked to talk about how they conducted practical work and the reasons why they chose to organize the practical lesson in that way. For example, in the interviews the teachers gave the responses 'I prefer to tell the procedure first' when they answered the questions about how they organized the practical lessons. The teachers' responses were grouped together based on the structure of practical work that they used in organizing the lessons. Table 5-13 shows the process of categorizing different types of practical work conducted by the teachers.

Table 5 13: The process to construct coding and categories of the type of practical work

\begin{tabular}{|c|c|c|c|}
\hline Theme & Category & Coding & Phrases/Evidence \\
\hline & \multirow{4}{*}{ A recipe practical. } & Aim & $\begin{array}{l}\text { Aim is given } \\
\text {-Teachers stated the aims } \\
\text { verbally. }\end{array}$ \\
\hline & & Material & $\begin{array}{l}\text { Materials are given } \\
\text {-materials are prepared by } \\
\text { our laboratory assistant. } \\
\text {-I check whether the } \\
\text { equipment is available in } \\
\text { planning the lessons. }\end{array}$ \\
\hline & & Method & $\begin{array}{l}\text { Method is given } \\
\text {-I prefer to tell the } \\
\text { procedure first. } \\
\text {-I have to guide them step } \\
\text { by step. } \\
\text {-I provide worksheets to } \\
\text { guide students }\end{array}$ \\
\hline & & Answer & $\begin{array}{l}\text { Answer is given } \\
\text { - We discussed the } \\
\text { answers after or before the } \\
\text { students did the task. } \\
\text { - I discussed the answers } \\
\text { with the students. }\end{array}$ \\
\hline & \multirow{3}{*}{ Demonstration } & Aim & $\begin{array}{l}\text { Aim is given } \\
\text { The teachers explained the } \\
\text { aims of practical work. }\end{array}$ \\
\hline & & Material & $\begin{array}{l}\text { Material is decided by } \\
\text { teachers } \\
\text {-I prepared the materials } \\
\text { and equipment. }\end{array}$ \\
\hline $\begin{array}{l}\text { The teachers' } \\
\text { practices in }\end{array}$ & & Method & $\begin{array}{l}\text { Method is decided by } \\
\text { teachers } \\
\text {-I showed them how to use }\end{array}$ \\
\hline
\end{tabular}


conducting

practical work the equipment.

-I showed them the steps

of how to complete the

task before I allowed the

students to do it in groups.

-I performed the first step,

and then the students also

performed the first step.

The answer is given by

teachers

-I conducted the

demonstration and wrote

the findings on the

whiteboard.

\begin{tabular}{cll}
\hline & Aim & $\begin{array}{l}\text { Aim is decided by } \\
\text { teachers } \\
\text {-no evidence. }\end{array}$ \\
\cline { 2 - 3 } A computer simulation & Material & $\begin{array}{l}\text { Material is decided by } \\
\text { teacher }\end{array}$ \\
& & $\begin{array}{l}\text {-The school has limited } \\
\text { resources. }\end{array}$ \\
\cline { 2 - 3 } & & $\begin{array}{l}\text { Method is performed by } \\
\text { teachers. }\end{array}$
\end{tabular}

-I used graphics and

simulation for the

courseware.

-So I used the simulation to demonstrate the procedure.

Answer is discovered by students

-The students saw the results.

\begin{tabular}{|c|c|c|}
\hline \multirow{4}{*}{$\begin{array}{l}\text { Structured } \\
\text { investigation }\end{array}$} & Aim & $\begin{array}{l}\text { Aim is given } \\
\text {-No evidence. }\end{array}$ \\
\hline & Materials & $\begin{array}{l}\text { Materials is given all or } \\
\text { part by the teachers } \\
\text {-prepared by the teachers. }\end{array}$ \\
\hline & Method & $\begin{array}{l}\text { Method is given (all or } \\
\text { part) by teachers } \\
\text { - I asked the students to } \\
\text { decide the variable that } \\
\text { they wanted to change. }\end{array}$ \\
\hline & Answer & $\begin{array}{l}\text { Answer discovered by } \\
\text { students } \\
\text {-the students wrote the } \\
\text { conclusion, and analysed } \\
\text { the data. }\end{array}$ \\
\hline
\end{tabular}




\subsubsection{The discourse analytical framework}

Sinclair and Coulthard (1975) used 'a unit of analysis' to analyse classroom discourse. The analytical framework included four aspects of classroom discourse (speakers, content, types of utterance, and cognitive process). The content referred to conceptual knowledge (scientific ideas and concept) and procedural knowledge (procedural and materials) that teachers wanted the students to learn. In the triadic dialogue IRF (Initiation-Response-Feedback), the utterance refers to questions, statements, answers, or comments. Finally, the cognitive process refers to the thinking process associated with students' responses.

Sinclair and Coulthard (1975) suggested that 'The Initiation Move' (I) refers to statement (S) or question $(Q)$ or a combination of both elements in engaging students in the classroom discourse. Questions or statements could aim to develop scientific concepts or introduce the task (e.g., procedure) to students. However, the context (when and how the speaker asked or delivered questions or statements, accordingly) might affect the nature of responses.

'The Response move' $(R)$ referred to the students' or teachers' responses to the questions or statements that were made on the previous move (Initiation or Feedback moves). The utterance could be in the form of an answer $(A)$, question $(Q)$, statement $(S)$, or no response at all. Each of the utterances served different purposes, which were elicitation, acceptance, information, reply, directive, clue, check, acknowledgement, evaluation, or silence. The responses resulted from the questions or statements by the speakers that could determine the level of cognitive process that they engaged with. It was impossible to gain direct information about the students' thinking so the speakers' responses were used to support the arguments about the thinking process that had taken place in the lesson. For example, if the teacher asked the following question what is the initial result of the task? before the students observed the findings, the students might engage at a different cognitive level than that which was required for students to think beyond the materials that they had observed. If the teachers had asked the same questions after the students conducted the task, they might engage with the lower cognitive process.

The typical 'Feedback Moves' (F) were in the form of comments on students' answers, statements, questions, the combination of those three feedback types, or no responses. The comments $(C)$ could be in the form of acknowledgement and praises on students' answers. The statement (S) refers to the content-related (scientific ideas) that the teachers stated in 'the Initiation Move' or she/he made a statement based on students' responses or the teachers 
stated the procedure of the task. Lastly, the questions asked could be related to students' responses or questions could extend students' thinking on other aspects of the concepts or the procedure. However, in some instances, the feedback could be the combination of 'comment and question' (C-Q) or 'statement and question' (S-Q). The questions and statements could overlap with the 'Initiation Move' on the next IRF cycle. The other combination includes a form of 'comment and statement' (C-S).

The transcripts of the student-teacher interactions in practical lessons were analysed to identify different patterns of IRF cycles. The interaction included teachers or students who initiated the discourse, the responses from students and teachers on questions or statements, and feedback in response to questions or statements.

\subsubsection{Initial stages of analysis}

The first stage of the analysis involved the preparation of the raw data, transcription of audiotapes made during practical lessons, post-lesson follow-up interviews with the teachers, and focus group interviews. The transcripts were prepared with information from the field notes that was relevant, and non-audible, such as students' gestures, teachers' actions, and the classroom settings.

The implementation of practical work by each teacher was reported individually as case study reports. Each case study report used the same format that separated out the chronological record of the classroom lessons and the effectiveness of the practical work. To achieve the aim of each case study report, the practical lessons were presented in the following three elementary sections as proposed by Domin (2007):

i. Pre-practical activity: How the teacher presented the task to the students.

ii. Students' practical activity: What the students did, thought, and talked about when they conducted the task.

iii. Post-practical activity: How the teacher summarised the task.

\subsection{Trustworthiness}

Trustworthiness refers to the quality of the research process. It raises the issues on credibility (internal validity), dependability (reliability), and confirmability (objectivity). All the issues related to trustworthiness will be discussed in the next section. 


\subsubsection{Credibility}

The credibility, or internal validity, is a match between researchers' interpretations with participants' interpretation who provide the data. There are different ways to produce a credible and an accurate study. Cohen et al. (2007) suggested triangulation, participants' validation, and a prolonged engagement with participants as approaches to enhance the credibility of qualitative research. Participants' validation is gained through member checking to ensure the researcher transcribes, analyses, and interprets the data faithfully. Therefore, researchers may gain new information to enhance the interpretation of the data. Triangulation is conducted by mixing data and methods to obtain diverse viewpoints about a topic and to avoid misinterpretations of the findings (Stake, 2006). Besides, each data source has strengths and drawbacks. By collecting data from different sources, researchers can minimize the weaknesses of a single data source (Patton, 2002).

\subsubsection{Dependability}

Dependability is the consistency of the interpretation of the data (Cohen et al., 2007). The focus of dependability is to ensure that the process of inquiry is "logical, traceable, and documented" (Schwandt, 2007, p. 299). Therefore, the researcher reported the participants' background, the context of the study, and the research procedure in detail. The information helped readers to retrieve the evidence written in the report.

\subsubsection{Confirmability}

Confirmability is "fidelity to real-life, context and situation-specificity, authenticity, comprehensiveness, detail, honesty, depth of response and meaningfulness to participants" (Cohen et al., 2007, p. 149). This is a norm where researchers spend sufficient time in natural settings to gain significant data that represents actual events. Unpredicted things may happen and affect an initial plan as researchers embark on sites (Creswell, 2008). Therefore, the researcher applied an audit trail procedure to track and record the changes that occurred throughout the research process and the rationale for the changes.

\subsection{Summary of the chapter}

The study explored the implementation of practical work at the lower secondary schools in the Malaysian context and addressed the following questions: 
i. How did form two science teachers understand practical work at the lower secondary school level in different types of schools in Melaka?;

a. How did form two science teachers understand practical work?

b. How did form two science teachers practise practical work?

ii. How did the teacher talk, especially questioning, facilitate the classroom interaction in conducting practical work?

iii. To what extent were practical work tasks effective in helping students to do what the science teacher intended?

iv. To what extent were practical work tasks effective in helping students to learn what the science teacher intended?

To answer the first research question, the researcher conducted six case studies with science teachers from five schools who taught science in form two. The data were collected through the initial interviews. Then to answer research questions 2, 3, and 4 three case studies, were conducted with TJ, TM, and TR. The instruments to collect the information were through classroom observations, field notes, focus group interviews, students' artefacts, and postlesson follow-up interviews. The findings are presented in Chapters 6, 7, and 8. 


\section{Chapter 6: Teachers' Opinions on Conducting Practical Work: Aims, Practices, and Considerations}

\subsection{Introduction}

The results of the investigation into teachers' aims and practices when conducting practical work are presented in two sections that correspond to the two stages of questioning. There was some variation in the responses from teachers when asked about both aspects. The first stage of questioning focused on the teachers' aims when conducting practical work. Their responses can be grouped into five categories; conceptual understanding, procedural understanding, essential skills, positive attitudes towards science, and preparation of students for assessment. The second stage of questioning focused on their practices. The teachers described their practical work as demonstrations, 'recipe practicals', computer simulations, and structured investigations. The two stages of questioning focused on factors that might influence their practice. The results presented in this chapter of the responses from teachers participating in this study show some similarities with the categories cited in the literature. The following section draws on data from teacher interviews and presents their aims, practices, and considerations when conducting practical work.

\subsection{Stage One: Teachers' aims when conducting practical work}

All the teachers believed that practical work is crucial in teaching and learning science, but for different reasons. All teachers $(n=6)$ considered the aim of learning through practical work as the development of procedural knowledge. Five teachers said that practical work could develop conceptual knowledge, and some $(n=3)$, believed that practical work could foster essential skills. Two teachers suggested that practical work could encourage positive attitudes towards science, and two teachers did practical work to prepare students for assessment. The teachers' responses fell into more than one category, and are presented in the following section.

\subsubsection{Procedural knowledge}

The teachers considered that procedural knowledge includes the development of manipulative skills and science process skills. In their view, manipulative skills include students learning to handle laboratory equipment safely, observing, and making accurate measurements. All 
teachers talked about focusing on science process skills when conducting practical work and their responses covered both basic and integrated science process skills.

Four teachers (TC1, TC2, TR, and TK) said their aim in conducting practical work was to improve students' skills in handling laboratory equipment and chemical substances, because the students were handling materials that they rarely used. Therefore, students should be taught how to use them correctly, to minimise the chance of being injured while in the laboratory and because teachers placed a high value on student safety. For example, TC2 said that some of the laboratory equipment and chemical substances could be quite dangerous and corrosive, and explained the consequences of unsafe practice:

...The students might get burnt if they do not have the skills to use the Bunsen burner correctly.

(TC2, 23.2.2011)

TM believed that a lack of skills when using laboratory equipment might affect their ability to take measurements and explained that some students did not know how to use basic laboratory equipment correctly. For example, she found that some students did not know how to determine the meniscus level when they took readings, and some students knew nothing about the meniscus level. TM believed that inaccurate measurements might affect the accuracy of the students' results, and in order to overcome the challenges of taking measurements accurately, she worked with students to help them develop these skills. She said:

...I supervise the students while they take the measurements. I ask the students to show me the steps they follow to use the measuring cylinder or the thermometer to measure the volume of fluid or the temperature. Then they show the meniscus level

(TM, 14.2.2011).

Three teachers, (TM, TJ, and TK), suggested that through practical work, they could strengthen the students' capabilities when using laboratory equipment. They argued that practical work offered teaching and learning experiences, and opportunities for students to use the laboratory equipment. For example, TR said that providing practical opportunities helped students to improve their manipulative skills. 
They can strengthen their skills using laboratory equipment correctly if they use it regularly. They have the chance to use the equipment if they are actively involved in the experiment.

(TR, 10.3.2011)

All four teachers (TR, TJ, TM, and TC1) said that one aim of conducting practical work was to develop science process skills, and they wanted students to grasp basic and integrated science process skills. TR and TJ emphasised the need to develop integrated science process skills when they talked about procedural knowledge and believed that some of the integrated science process skills were related to each other. If students failed to grasp the first skill, then they were likely to make mistakes with the others. They used the examples of how to identify variables and how to formulate a hypothesis in their responses:

...identifying the variables and formulating a hypothesis are related to each other. If students have problems identifying the variables, they may also face the same problem writing the correct hypothesis.

(TJ, 31.2.2011)

TM claimed that students could complete an investigation without realising they had successfully performed basic science process skills, and said that sometimes while conducting an investigation they were able to draw on the skills they had learnt without being aware that they even had those skills. The following quote demonstrates that the teacher did not believe it was necessary to interrupt students when carrying out an investigation just to check if they knew they were applying the skills they had learned earlier:

...some of the students can record the data very well, but they do not realise they are using a particular skill. I think it is inappropriate to interfere while they engage with the task in hand and ask about the importance of the investigation skill. I want my students to be aware of skills that they use to complete the task.

(TM, 4.2.2011)

On the other hand, TC1 wanted students to experience the scientific investigation while they were involved in practical work; she wanted them to develop experimental skills, where they were actively involved in planning and conducting activities, to test a certain hypothesis. These activities include collecting, analysing, and interpreting data, and drawing conclusions. Here TC1 explains what she thinks an investigation is:

Practical work begins with a problem. Identifying the starch in food samples is the problem. Students need to collect data by following the steps correctly before interpreting. From the investigation that they did in the 
laboratory, they would realise that the scientific investigation is not an easy process, but is a systematic process to get accurate results. If they do not follow the steps, they would not get the correct results.

(TC1, 4.3.2011)

All teachers believed that engaging in practical work helped students to practice manipulative and science process skills, however, not all teachers gave equal priority to both skills. Some teachers believed in teaching the skills separately while others thought they should be developed during an investigation. They believed that the skills developed could be transferred while engaged in the actual investigation. At least one teacher's description of practical work showed they considered a science investigation to involve a series of steps in order to solve a problem and get accurate results.

\subsubsection{Conceptual knowledge}

Teachers' (TJ, TR, TK, TC1, and TM) responses during the interviews showed they viewed one purpose of practical work as the development of conceptual knowledge. Three teachers (TJ, TR, and TM) perceived practical work as assisting students in memorising science facts by observation of concrete evidence. TK, TR, and TC2 believed that practical work enabled students to confirm the science ideas learnt in the theory lessons. Two teachers (TJ and TR) said practical work provided students with an opportunity to use their senses to make observations and that this helped them to remember the science concepts.

The teachers (TJ, TR, and TM) were emphatic that students could memorise scientific facts through practical work. TM said that her students found it difficult to memorise the facts she told them, but when they were able to see things, it helped them to remember, and used the example of water filtration to illustrate her belief:

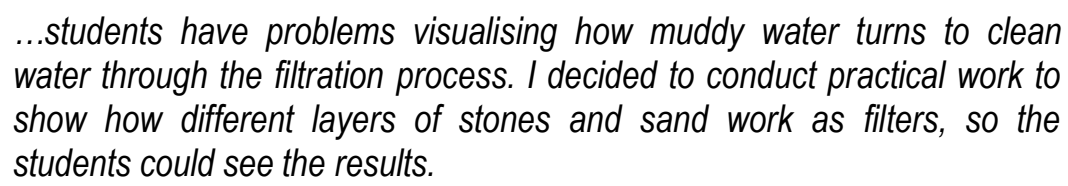

(TM, 14.2.2012)

TK, TR, and TC2 suggested they used practical work as a complementary teaching approach, to strengthen the concepts or facts they highlighted in theory lessons. During the interview, it became apparent that they usually taught the topic in class before doing practical work in the laboratory. TR argued that not all students could learn the topic in one theory lesson and that the practical provided another opportunity for them to learn. Similarly, TC2 said: 
...in the theory lesson, the students listen to me. Some of the students may get the facts that I deliver and some of them may not. Maybe some of the students fall asleep if they just listen. However, if they are involved in practical work, they have the chance to see how the model works and confirm the theory they heard in the theory lesson.

(TC2, 23.2.2011)

TR explained that students could memorise the facts if they engaged with the phenomenon several times. TR gave the following explanation:

...if the students have the opportunity to conduct practical work, they can observe the findings by using their senses to smell the fumes, touch the texture, and observe the changes. In that sense, they can remember the concept better. In contrast to a lecture-based approach, where the students might not be able to visualise the findings and may not remember the concepts.

(TR, 10.3.2011)

It appears the majority of teachers considered the aim of practical work as reinforcing the theory they taught in their theory lessons, and perceived practical work as a teaching approach. They believed that students could easily memorise concepts if they had the opportunity to practise them, and that when actively involved in producing and observing real phenomena, the concepts became more tangible.

\subsubsection{Essential skills (noble values)}

TM, TJ, and TC2 believed that practical work provided opportunities for students to develop essential skills, and in the interviews, they talked about fostering communication skills among students and considered practical work a teaching approach that could be used to develop students' self-confidence when talking in public. In their opinion, students did not have the opportunity to communicate with others and share their ideas in theory lessons. In her interview, TM highlighted the limitations that students might face in the theory lesson. She said:

In the theory lesson, the students work individually. They have limited opportunities to talk about the topic they learned. Yes, the students talk, but they sometimes talk about things irrelevant to the topic. However, in practical work, they talk more about the task; they share ideas about the task. They work in small groups, so they have more opportunity to talk to each other about their academic work.

(TM, 14.2.2011) 
While TM wanted the students to talk and discuss their ideas with other students in their groups, TC2's aim was to foster self-confidence among students when talking in public. She found that some of her students lacked communication skills and were hesitant when asked to speak in front of the class. She said that communication skills could not be mastered overnight, but required on-going teacher support. The approach she used to foster students' communication skills was to ask them to share the findings of their investigations and used the example of the neutralisation process to explain:

I did practical work on the neutralisation process. Students recorded the volume of alkali required to neutralise the acid. After they had completed the task, I asked a group representative from each group to come forward to share their results. I asked the students to write their findings on the whiteboard and talk about them.

(TC1, 4.3.2011)

As well as fostering communication skills, some teachers believed it was important for students to learn how to work as a team. They believed students could learn these skills by working in groups while carrying out practical tasks where each student had responsibility for a particular task. For example, when TJ organised a practical task he shifted the responsibility of explaining the method to the group leader, who had to explain the steps required to the other members of their group. He allocated other roles to students too, such as the responsibility for collecting the materials and to ensure the students worked well together he gave limited autonomy to them to choose their own group members.

TC2 and TM said that by assigning each student a different role within the group they avoided the likelihood of some students dominating during practical work. They had processes in place to ensure that each time they did practical work the students had different roles. For example, TC2 explained how she organised group work in her class:

I do not want my students to sit alone on the back row and do nothing. I want them to have the experience of handling laboratory equipment. Therefore, I assign different tasks to different students. Perhaps the first student handles the Bunsen burner. The second student takes the measurement. Their roles are not static. In the next practical, the students play a different role.

(TC2, 23.2.2011)

Two teachers aimed to foster essential skills through practical work and focused on developing communication skills, and teamwork. They used a cooperative learning strategy to foster these skills, and allocated roles to students in each group to complete a piece of 
practical work. This approach appeared to work, but if the teacher did not do practical work often, it was unlikely that all students would have the opportunity to take on different roles. Giving instructions to one group member with the expectation that they would share the instructions with other students in their group was limited by the student's ability to grasp and relay the instruction. In addition, it seemed that the teachers did not give enough attention to other essential skills such as being respectful and well mannered.

\title{
6.2.4 Positive scientific attitudes
}

TM and TK said that practical work could change the students' perceptions about science and science investigation in general. TK believed that students at all levels held misconceptions about science and science investigation. She explained that:

\begin{abstract}
...science is taboo among my students. When we talk about science, they have the perception that it is difficult, and practical work is dangerous. They are concerned about their safety. For example, they are afraid their hands will get burnt because of the chemical substances. I can see that my students lack confidence in handling the laboratory equipment. Science stream students have similar problems, if the students had opportunities to conduct practical work on a regular basis, their self-confidence might increase.
\end{abstract}

(TK, 24.2.2011)

Despite facing challenges and holding those views, the teachers also believed that practical work is an interesting teaching approach that offers excitement when learning science, and is preferable to a lecture-based teaching approach. They said not all students could learn by listening to the teacher talking and by taking notes, and that some preferred a teaching approach that provided opportunities for them to engage with the materials that were available in the laboratory. TM explained that:

...active students are very excited about doing practical work. I found they
get bored easily in the theory lesson. They need more than listening to my
lecture.

(TM, 14.2.2011)

It appeared that the teachers did not give attention to fostering scientific attitudes, although two teachers believed that practical work could be used to generate interest and reduce student anxiety about science being a dangerous subject. Some teachers believed that students held negative perceptions about science and that some preferred a lecture-based 
teaching approach. The teachers were concerned that students' negative attitudes towards science in lower secondary school may be carried through to upper secondary level.

\subsubsection{Assessment}

TK and TR did practical work to meet the demands of assessment known as PEKA, an ongoing school-based evaluation of students' performance in science practical work that takes place throughout the year using the students' learning profiles of evidence of their completed practical work. Teachers were also concerned with preparing students for mid-term and final examinations that include 'paper and pencil' tests of objective or structured questions about scientific concepts and practical work.

TK explained that she planned practical work to meet the demands of PEKA, although she found it challenging to complete the entire science syllabus. She managed student preparation for PEKA through a lecture-based approach or a demonstration and planned two or three practical tasks as evidence that the students had met the requirements of PEKA.

In Form two, teachers must evaluate at least two or three practical pieces of work from the syllabus during the year. I usually prepare everything for my students before they do practical work. It includes the materials, the procedure, the results, and the report. If I do not provide guidance for the report, the students might use everyday language to write it.

(TK, 24.2.2011)

In contrast, TR conducted practical work to prepare students for the examination. $\mathrm{He}$ explained there were questions about practical work suggested in the textbook and believed that given the opportunity to learn through practical work, students could memorise the results or the steps to help them in the examination. This is how TR put it:

I do all the suggested practical work from the textbook. I rarely use reference books or experimental books to plan my practical lessons because the examination questions are based on the textbook. I believe that students can memorise the results better if they are actively involved in producing the results. I hope they can perform well in the examination. They remember the colour of the solution because they have seen it.

(TR, 10.3.2011)

TK and TR used different approaches, TK carried out two or three well-prepared 'recipe practicals', and TR provided several opportunities to engage and learn from practical work. The teachers organised practical work to prepare students for examinations that aimed to help students memorise the results and procedures in order to answer the examination questions. 
Such an approach was likely to help students answer the examination questions but could be classified as rote learning which might limit learning for understanding. Some practical work was carried out to meet the requirements of the compulsory practical assessment (PEKA). In preparing students for PEKA, teachers took different approaches, they either made the students learn by rote what was required for assessment or provided opportunities for them to learn through practical work. In both cases, it appeared that the goal was to learn for assessment rather than learn for understanding.

\subsubsection{Summary}

It seems that teachers focus on developing procedural and conceptual knowledge in discussing the aims of conducting practical work. The majority of teachers perceived practical work as a teaching approach to practice scientific skills and reinforce theory. Only one teacher highlighted practical work as a scientific investigation to solve problems. It seemed that fostering essential skills and scientific attitudes was generally, not a priority for the participants but preparing students for examinations was considered important.

\subsection{Stage two: The teachers' practice}

There are some variations in the teachers' responses regarding their aims when conducting practical work, as discussed in section 6.2. Teachers' practical work included demonstrations, 'recipe practicals', computer simulations, and structured investigations. It seemed that almost all the teachers preferred demonstrations $(n=6)$ and a 'recipe practical', as opposed to a structured investigation $(n=1)$ and computer simulations $(n=1)$. Some teachers used different approaches to deal with various challenges, such as resources, student numbers, and assessment demands. It seemed that the approaches teachers took, helped them to run their lessons more smoothly, but might deny some students' the opportunity to experience the essence of scientific investigation. In the following section, the teachers' approaches in conducting practical work will be discussed in detail.

\subsubsection{Demonstration}

All teachers said they preferred to do demonstrations. Some teachers (TJ, TM, and TK) used demonstrations to show students the correct way to use the laboratory apparatus, whereas others (TK and TC2) used them for safety reasons. TR demonstrated because he said he did not have enough laboratory apparatus for all students to engage in a practical task. TC2 said he preferred demonstrations as it helped to manage students' behaviour. TJ, TC1, and TC2 
argued that by observing teacher demonstrations, students would learn the correct steps to complete tasks. Following whole class demonstrations, TM, and TK allowed students to use the equipment.

TK and TC2 were concerned for students' safety when they used laboratory apparatus and said that demonstrations helped avoid incidents that might cause injury. They argued that some investigations involved a heating process, which they found too dangerous for students.

TC2 explained:

...doing food tests involved a process where students had to heat the samples. It was too dangerous for them, and I did not want anyone to get hurt, so I conducted a demonstration and wrote the findings on the whiteboard. It did not mean that I neglected their rights, as I think it was better for them to observe the demonstration, than to do it on their own.

(TC2, 23.2.2011)

TR changed his plan to let students work in groups on an experiment, justifying his changes as follows:

In Form two, there are more than five classes. Each class has more than 30 students. If all classes do a similar experiment in the same week, some classes may not have the chance to do practical work at all. I modify the experiment to cope with the limited equipment. I did a demonstration to the whole class on how to prepare the apparatus. Then after a few days, they could see the results.

$(T R, 10.3 .2011)$

Three teachers (TJ, TC1, and TC2) conducted demonstrations to make sure that students were aware of the steps they needed to follow to undertake a practical task correctly and believed that through demonstration, they could minimise student mistakes. TC2 explained his approach of demonstrating one step at a time with students repeating each step:

Before I began, I asked my students to collect the equipment and materials before I conducted the demonstration. I had prepared a set for the experiment at the front of the laboratory. I demonstrated the first step and the students followed, performing the first step, and then so on. I told them the steps verbally and then showed them how to do each correctly.

(TC2, 3.2.2011)

The demonstration was a preferred teaching approach among the teachers that had both advantages and disadvantages. The advantages were they could control the flow of the lessons and manage student behaviour. In addition, the demonstration helped students to 
observe the correct ways of handling laboratory equipment. However, one disadvantage was that not all students were involved in manipulating the objects or materials to produce the results due to limited equipment and large student numbers, which raises the question whether all students could perform a similar investigation or follow the steps after a demonstration.

\subsubsection{A 'recipe practical'}

A 'recipe practical' was another approach that teachers TM, TR, TC1, TC2, and TK used in planning their practical lesson. They suggested that 'recipe practicals' were suitable for students at the lower secondary school level. One of the factors that led to the teachers using 'recipe practicals' was students' efficiency in planning their own investigations. They believed that this type of guidance could help students to produce results in a safe teaching and learning environment, and in the process believed that students could learn the intended science concept.

The teachers used different resources in planning the practical lesson. Some teachers (TC1, TC2, TR, and TK) followed the practical activities suggested in the authorised textbook, whereas TM used the practical work suggested in the recommended experiment book. Despite using different resources, the practical sessions they planned had similar characteristics in that they provided all the information including the aim, the materials, the procedure, a table to record the data, and the conclusion. They also assisted students in reporting on the practical they had completed.

It seemed that the teachers believed 'recipe practicals' could avoid students making mistakes or being confused. TR and TC1 highlighted any changes they made when setting up the apparatus, for example, TR drew the diagram on the board or he showed the diagrams in the textbook to make sure the students knew how to arrange the equipment correctly. He said:

...by showing them the diagram from the textbook, I could ensure that the students knew how to arrange the equipment correctly. I would also draw a diagram on the whiteboard, if I modified the set-up of the apparatus. They might get confused if I made changes without telling them.

(TR, 10.3.2011)

During the recipe practical, the teachers provided written or verbal guidance to ensure the students followed the 'recipe' accordingly to produce the right results. While students could observe and record the results, they might not learn the concepts from those results or 
understand the reason they followed the steps. It appeared that the teachers did not explain how the students could understand the concepts or facts from their own data.

\subsubsection{Computer simulation}

Two teachers (TK and TR) used a 'dry laboratory' or computer simulation, as their approach to practical work. Although the students were not actively involved in producing the results or observing, these teachers believed that the students had the opportunity to see changes in the responding variable, once the variable was manipulated. They said the courseware distributed by MOE was useful, as it contained graphics and animations that helped students' learning. TR explained:

\footnotetext{
...the graphics and animations were clear. They were easy to understand. For example, the students could see the condition of the ice cubes if they manipulated the temperature. If they dragged the cursor on the thermometer, the students could see the ice melting. Therefore, the students could see the effect of manipulating the variables. They also could see the procedure and the findings clearly.
}

(TR, 10.3.2011)

The teachers used the courseware for different reasons, for example, TR said that the availability of laboratory equipment influenced his decision in planning a practical lesson and said that some of the suggested practical work from the authorised textbook could not be done, due to limited resources, therefore computer simulations were a useful alternative.

I found some practical work could not be conducted in the laboratory, because it is a new school, so we still lack teaching resources. A computer simulation is a good way to start.

(TR, 10.3.2011)

TR and TK agreed that time constraints were another factor that made them opt for the courseware, in order to finish the syllabus on time. They argued that some of the suggested practical work needed more time to get results, for example, in conducting practical work about plant responses to stimuli, students had to wait three days to get the results, so TK found simulations an attractive alternative:

...it has good graphics and animations of the experiment and students do not have to wait to observe the results. With a single click, the students could see the direction of shoots and roots. 
While students observed good quality animations and graphics through a computer simulation, neither teachers nor students were manipulating any objects or materials in the laboratory. The computer simulation provided an aspect of the investigation that could not be done in the laboratory in a short time, however; the students missed the opportunity to develop procedural knowledge, by not conducting the investigation themselves. The teachers' reasons for using this mode of instruction included external factors such as limited resources, students' safety, and the nature of practical work itself. In using the computer simulation, it seemed that the teachers' practices were not aligned with their beliefs about student learning.

\title{
6.3.4 A structured investigation
}

During the interview, only one teacher (TJ) explained how he planned a structured investigation, which he said was similar to a 'recipe practical' but with some modification. He modified the practical task set out in the textbook/practical book to provide limited guidance for students, however, he still guided them in how to carry out the investigation, by providing detailed instructions, and the students decided certain aspects of the investigation by carrying out "fill in the blank" activities. It appears that through this structured investigation, the students had the opportunity to develop integrated science process skills. For example:

\begin{abstract}
...I asked the students to identify the variables, write the hypothesis, or write the conclusion by filling out the blanks in a worksheet. However, I had to provide the method for collecting the data. I know my students cannot do this alone.
\end{abstract}

\section{(TJ, 31.1.2011)}

Despite giving students some control, TJ explained the procedure in some detail. He demonstrated the correct way for handling and setting up the apparatus to the group representatives and believed students, regardless of their academic ability, needed continuous guidance. The students did the investigation under TJ's supervision. He explained:

...I printed the worksheet and distributed it to students. I provided details about the steps. If I asked the students to read the instructions and do the task, they might not be able do the task accordingly.

$$
\text { (TJ, 31.1.2011) }
$$

A structured investigation was a modified version of a 'recipe practical' with details of the investigation given only for certain aspects. Overall, it seemed that the structured investigation could develop science process skills, because students had opportunities to decide the hypothesis they wanted to test or the variables they wanted to manipulate or observe. On the 
other hand, the structured investigation that the teacher introduced could affect students' experiences of full-unstructured investigation where students planned their own investigation. Another issue associated with the structured investigation is that students might perceive the investigation as a fair test in which an experimental data set is compared with control data set to reject or accept the hypothesis and make a claim.

\subsubsection{Summary}

The teachers regularly used more than one strategy when conducting practical work in their lessons, including a 'recipe practical' and demonstrations. Only one teacher claimed he conducted a structured scientific investigation. He provided guidance but allowed the students to decide certain aspects of the scientific investigation. The teachers also described different modes of working that included students conducting practical work in a group or the teacher conducting a whole-class experiment. The teachers' aims in conducting practical work were clear; firstly, they wanted to ensure students followed procedures in order to produce the desired phenomenon and observe what they were supposed to observe. Secondly, the majority of the teachers believed that practical work was merely a set of procedures to be followed in order to get the desired results without getting the students to think about the reasons for following a procedure. Thirdly, the science investigation is testing a hypothesis, where the students followed a prescribed procedure from the textbook, or the experiment book.

\subsection{Considerations when conducting practical work}

The factors that the teachers considered when conducting practical work included, firstly, catering for the needs of diverse students (Section 6.4.1), secondly, the curriculum requirements (Section 6.4.2) and thirdly, the school setting (Section 6.4.3). In this context 'diversity' was seen as students' academic ability, their skills in handling the laboratory equipment, prior knowledge, behaviour and language proficiency. The requirements of the curriculum included covering too many topics, not enough time to carry out the suggested activities from the authorised textbook and experiment book, and preparing students for assessment. Thirdly, the school setting included the numbers of students in the class, the time allocation for practical lessons and the availability of apparatus in the laboratory. There were several other factors that influenced teachers' views about the aims of conducting practical work, and their considerations when choosing the type of practical work, which will be discussed in the following section. 


\subsubsection{Catering for diverse students}

Teachers were aware of the diverse nature of the students in their classes. They (TJ, TR, TC1, and TM) believed students' academic capacity had a significant effect on their ability to carry out practical work. Some teachers believed that conducting practical work with students of low academic ability was more challenging and that these students needed more guidance when doing practical work. However, not all teachers held the same view, for example, TR believed practical work could be a suitable teaching approach for low achievers, but added that the teacher would have to play a crucial role in ensuring those students achieved the aim of the task. He explained:

...I found that low achievers were excited about conducting practical work. They actively participated in my lesson. But, I have to guide them step-bystep or else they might not achieve the aim of practical work in the first place.

(TR, 10.3.2011)

TC2 and TK both suggested that regardless of their academic abilities, students needed guidance from the teachers when conducting practical work. As a result, teachers planned practical work that minimised students' involvement in manipulating objects and materials. It appears that teachers preferred demonstrations and lecture-based teaching approaches to teach with students' different academic abilities. During the interview, TK explained that she did whole class demonstrations and wrote the results on the board. She elaborated:

It does not make any difference when doing practical work with low or high achievers. They make a lot of noise. Maybe they are too excited or they do not know what they are supposed to do.

(TK, 24.2.2011)

Some of the teachers (TK, TC1) claimed that students with low academic ability usually had attitude problems as well, so they had to consider whether to allow them to do practical work on their own. The teachers said these students had problems paying attention to the lessons and showed a lack of interest in learning science. TC1 argued that:

...low achievers and higher achievers are different in terms of attitude. I found that low achievers are playful. They like to play even when I give the briefing. They cannot focus on the lesson for a long time. So, conducting practical work with the lower achievers is quite challenging and a demonstration is the solution to deal with these students.

(TC1, 4.3.2011) 
Another factor that all teachers considered in planning practical work for diverse students was safety issues in handling the laboratory apparatus. They said they needed to take extra care when doing practical work with low achievers. During TC2's interview, she said that practical work that involves combustion, such as food tests, was not suitable for low achievers, so she demonstrated rather than allowing the students to do investigations in groups. She expressed how she felt:

\begin{abstract}
...As a teacher, I have to teach them regardless of who they are. But I found it was too risky to allow the students to do it in groups or individually. Let's say, if I asked them to use the Bunsen burner to heat the sample, I am afraid that they may do something else. I have to consider all of it. So, I do a demonstration with $2 F$ and they see the changes.
\end{abstract}

(TC2, 4.3.2011)

Some teachers (TK, TC1, and TR) found that language was another challenge that they had to consider in planning practical work. In their view, it was a bigger challenge when they did practical work with low achievers. For example, TK explained that if students had low English language proficiency and were not able to read and write English, the practical work was more challenging for them because they did not understand the instructions. TK explained the challenges this held:

...the students do not understand the instructions from the textbook. It is in
English and I have to translate the instructions in Malaysian so they know
the steps to follow. I rewrite the instructions in Malaysian on the whiteboard.

(TK, 24.2.2011)

Students' lack of ability in handling the laboratory equipment was another factor that influenced the teachers' decisions when conducting practical work. TJ, TM, and TK found that most students lacked the ability to handle the laboratory equipment correctly, and said that students were expected to have learnt the skill of using equipment such as a thermometer and a measuring cylinder in primary school; however, they found that students came to lower secondary school with little prior knowledge. The issues related to students' ability to use equipment was also a problem in the upper secondary school for students in the science stream, and TJ shared his experiences of conducting practical work with them: 
...Last year I taught Form five a science subject. I was surprised that some of the students did not know how to use the measuring cylinder and they did not know how to take the measurement correctly. I asked them to give the readings and they gave the reading up to two decimal places, instead of one. I do not know how they got those readings really.

(TJ, 31.1.2011)

The teachers (TM, TJ, and TK) also supervised the students' work to ensure they did not have problems in using the equipment correctly and were safe. It seemed that practical work added to the teachers' workload.

The teachers claimed it was a challenge to teach practical work to diverse students because they had to consider their academic abilities, attitudes, language proficiency, and prior knowledge when planning practical work. Such challenges influenced the selection of practical work and they tended to conduct 'recipe practicals', demonstrations, and lecture-based teaching instead of unstructured investigation. Although the teachers used different strategies in engaging the students with practical work, they were more concerned about developing manipulative skills especially in handling laboratory equipment correctly rather than other scientific skills and they did not engage students in thinking about the effects of those skills on the science investigation.

\subsubsection{School setting}

School related factors contributed to how teachers conducted practical work, and they highlighted issues relating to the duration of the practical lesson, the numbers of students in the class, the availability of the laboratory equipment and the selection of experiment books as factors that influenced what practical work they carried out.

The teachers (TK, TM, TR, and TC1) highlighted the issue related to the duration of the practical work and claimed it was a long process that required more time, compared to other teaching approaches, such as a lecture. Practical work began with the teachers preparing the materials for students, followed by the teachers delivering instructions about the investigation, and then they gave either verbal instructions or demonstrations. Later, the students carried out the task in groups or individually, and then had to write their own report of the investigation. They claimed that preparing the equipment for practical work was time consuming. TC1 explained how she prepared the materials so students could do food tests:

...the materials and equipment to test the presence of starch, glucose, fat, and protein, was prepared by the laboratory assistant, in accordance with 
the textbook. The students did not have to bring food samples from home. If they did bring food samples from home, they may bring solid foods and then we would need more time to modify them.

(TC1, 4.3.2011)

TK, TM, TR, and TC1 highlighted how some investigations took a long time to complete, and in some cases, took a few days to get results, so some of her colleagues refused to do practical work in these instances and chose to lecture instead:

I found that some of my colleagues were not keen on practical work. They do not want to wait for a long time just to get the results. They prefer to tell the results or teach the theory.

(TM, 14.2.2011)

They also said that the time allowed for lessons was sometimes insufficient for the duration of practical work and there was not enough time to complete the whole investigation. Normally, practical work was conducted in double periods or ninety minutes. TK said:

.... spent about 30 minutes waiting for the students to come to the laboratory, taking the register and doing the demonstration. So only one period was left for the students to do the practical work, record the data, and complete the report. It is not enough.

(TK, 24.2.2011)

The teachers (TC1 and TR) managed practical work by allocating a separate lesson for the students to prepare the reports, before they embarked on the practical lesson, which ensured that they could complete the practical work within the double lesson period. TC1 explained:

...So I allocated 45 minutes or one period just for them to write the report. I wrote the report on the board including the results. Then the students copied the report into the experiment books.

(TC1, 4.3.2011)

Another factor highlighted by TK and TR that affected how teachers carried out practical work was the number of students in the class. Where there were large numbers of students in the class, this could create behaviour management issues for the teacher, and they said that controlling students and keeping them on task added to the challenge of engaging them in practical work. TR explained:

...I have 40 students in my science class. I do not know why they make a lot of noise. Are they too excited or do they not understand? I do not know really. Last week, this school had visitors from the ministry. They walked 
into my class to supervise my lesson. I thought the students would behave because the visitors were at the back of the lab. They acted as normal, like nobody was there.

(TR, 10.3.2011)

A large number of students also created problems for teachers when preparing materials. TR explained there are limited resources, and choices had to be made about individual or group work. He shared his experiences of organising practical work to investigate plant responses to different stimuli with limited resources:

...In Form two, there are more than five classes. Each class has more than thirty students. If all the classes do a similar experiment in the same week, some classes may not have the chance to do practical work at all. I modify the experiment to cope with the limited equipment. I did a demonstration to the whole class on how to prepare the apparatus. Then after a few days, they could see the results.

(TR, 10.3.2011)

TK had a problem delivering instructions to a large number of students especially when she demonstrated to the whole class. In the following quotation, TK elaborates on the challenges:

...I have 40 students in my class. Every time they come to the lab, all the benches are full. Sometimes, the students cannot hear my instructions. They make a lot of noise. If I do a demonstration, the students at the back cannot see the demonstration clearly.

(TK, 24.2.2011)

The school selected and prescribed a commercial experiment book, but it seemed that teachers had different views about the activities suggested in it. TC1 believed that the suggested activities were unrealistic and were too demanding in terms of time and energy. She would have preferred to have a choice so she could use other teaching aids. She explained:

...in my school, the head of department suggested a practical book as guidance in conducting practical work. I found that the activities in the commercial practical book are too time consuming. For example, in teaching the topic related to sound and hearing, the students were required to develop a model of an ear. I preferred to show the diagrams or 3D models. The lab had a lot of diagrams and models that could be used as teaching aids.

(TC1, 4.3.2011) 
TM used the experiment book to plan practical work and needed other resources to plan the practical lesson. The activities in the experiment book were suitable for PEKA practical assessment, as they included the assessment criteria for students' practical work.

Sometimes I use the experiment book to plan my lesson. If we look at the experiment book, it does not give all the information to students. They have to find out the answers. It is easier for teachers to give marks on skills or attitudes that they have achieved.

(TM 14.2.2011)

TJ believed that regardless of their academic abilities, students needed guidance when doing practical work. He found that modifying the tasks suggested in the books to suit the needs of the students worked best. He allowed students the freedom to decide parts of the investigation; however, he provided detailed information about how to collect the data. He explained:

...if I do not tell the students the steps, they may not be able to do the task accordingly. However, I left some aspects for the students to decide. For example, the students have to identify the variables, write the conclusion, and analyse the data.

$$
\text { (TJ, 31.1.2011) }
$$

Other factors that affected the teachers' decision in planning and conducting practical work were the school setting, the lack of laboratory apparatus, a large number of students, and the school selection of the practical book, all of which were challenging for teachers. Some teachers conducted a lecture-based teaching approach, or used demonstrations to deal with these challenges. Although these approaches had advantages for the flow of the lesson and classroom management and might help the students observe what they are supposed to observe or learn theory, they might miss opportunities to develop scientific skills.

\subsubsection{Curriculum and assessment requirements}

Teachers considered the demands of the science syllabus and assessment when planning and conducting practical work. It seemed that all teachers found the form two science syllabus overwhelming compared to the science syllabus for forms one and three, because there was too much content to cover within the year. Teachers responded to managing the content by selecting particular science topics to teach. TC1's strategy was to give more time and attention to topics she considered the most difficult for students to understand and she reduced the suggested practical work. She explained: 
...there are ten topics in the form two syllabus. Some topics are longer and take more time to finish. Chapter one is considered the longest chapter compared to other chapters in this syllabus. I also spend more time teaching difficult topics like force and stability.

(TC1, 4.3.2011)

However, teachers did not make these decisions lightly and felt under pressure to prepare students for assessment. TK and TJ prepared the students for the examinations at school and national levels and in order to meet the demands of assessment, they resorted to a lecturebased approach to teach the concepts. TJ said he selected topics that had always been covered in examinations. He explained:

...there are too many topics in the form two syllabus. If I do not plan my lessons carefully, maybe I do not have time to do revision with the students before they sit the exam. I teach the topics that are quite popular in exams and I skip those I think the students can learn by themselves from the textbook.

(TJ, 31.1.2011)

Teachers had different views about the required textbook. TM and TC1 agreed that the required textbook was insufficient as the main reference for teachers to plan lessons. TC1 added that the notes from the textbook were too brief, and could limit opportunities for students to see things from different perspectives. The following quote exemplifies her view:

The textbook uses the national emblem, the hibiscus, to show the structures of flowers. They do not have the opportunity to see petals, anthers, filaments, and so on from different types of flowers. It is very limited.

(TC1, 4.3.2011)

On the other hand, TR relied on the textbook as the main resource and did not use other resources, arguing that the contents of the textbook were sufficient for students as they were aligned with the curriculum specification. He explained:

...I do not use reference or experiment books in my teaching. The textbook is good enough to be the main resource. I try to do all the suggested activities from the textbook.

(TR, 10.3.2011)

The students' performances were measured by the results of the assessment, so the teachers put more effort in ensuring students could perform in the examination. It seemed that the teachers were more concerned with teaching the concepts that students were supposed to 
know for the assessment, or demonstrating the phenomenon, so they chose a lecture-based teaching approach to ensure they covered the content or conducted demonstrations of the phenomenon before the examination.

\subsubsection{Summary}

Factors such as the diversity of students, school setting, curriculum, and assessment had influenced teachers' practice and they preferred to conduct 'recipe practicals', demonstrations, or shift to a lecture-based approach when conducting practical work. The challenges had made the teachers focus on talking about the concepts that students should know, and so they put less emphasis on developing procedural knowledge or fostering positive attitudes towards science. It seemed those factors had shifted the teachers' aims of conducting practical work as mentioned in section 6.1.

\subsection{Summary of the chapter}

This chapter highlights the aims of practical work from the teachers' perspective, how they conduct it, and the challenges they face when doing it. From the interviews, the majority of teachers were concerned with practicing scientific skills and memorising scientific concepts as opposed to essential skills, positive scientific attitudes, and assessment. The scientific skills that the teachers highlighted were aligned with the curriculum specification. However, they were concerned about practicing manipulative skills, especially handling laboratory equipment, as opposed to other skills. Their aims influenced the teachers' approaches to conducting practical work and they preferred to engage students with demonstrations or organised a separate lesson, to teach students how to use the laboratory equipment. Through both approaches, the students might know and be aware of how to handle the equipment correctly but they might not be able to apply those skills in an actual scientific investigation as a holistic process to solve problems. The teachers believed that the students could understand the scientific concept through observations, so they preferred to use computer simulations or demonstrations to show the phenomenon instead of waiting for some time to produce the actual phenomenon themselves. However, teachers admitted that practical work was not easy to do due to different factors (e.g. school setting, diversity of students, and curriculum and assessment). It seemed that they preferred to conduct demonstrations, 'recipe practicals', or take a lecture-based approach in response to those factors. Although those approaches might help teachers to deliver the concepts more easily, the students might or might not understand the concepts. The findings from this chapter highlight practical work from the teachers' 
perspectives but might not be able to portray the teachers' practices when conducting practical work, so in the following chapter the teachers' actual practices when conducting practical work will be described. 


\section{Chapter 7: Results of a Common Lesson Taught by all Three Case Study Teachers}

\subsection{Introduction}

This chapter presents the results of practical lessons taught by the three case study teachers investigating a common aspect of human digestion, the absorption of food in the small intestine. The data were collected using classroom observations, teachers' post-lesson interviews, student focus group interviews, and document analysis (e.g. student reports and curriculum specification). The structure of each lesson delivered by the three case study teachers (TR, TJ, and TM) is outlined in Section 7.2. Section 7.3 analyses and compares each teacher's approach to their respective practical lessons. This is followed by Section 7.4, where the analysis gives particular attention to student learning in each lesson, and how this differs from teacher to teacher. Finally, Section 7.5 presents the teachers' own reflections on their lessons.

\subsection{The structure of the lesson taught by each teacher}

The practical work undertaken by the teachers had similar structures that could be examined using the framework developed by Domin (2007). The practical lesson tended to be divided into three different phases, beginning with the pre-laboratory activity phase, followed by the students' practical activity phase or in-laboratory activity and the post-laboratory activity phase. The teachers seemed to decide what practical work they undertook, and planned the lessons in order to achieve the learning objectives of the topic (the absorption of digested foods in the small intestine). The teachers used the models suggested in the textbook, the experiment book, and the curriculum specification to teach the absorption process.

Before the students carried out their practical work (individually or in groups), the prelaboratory activity (which took approximately 10-15 minutes) is conducted. Based on classroom observations, the pre-laboratory activity was generally dominated by the teachers, who tended to use this time for administrative purposes, such as taking attendance registers while they waited for students to arrive for the lesson. They also used this time to explain to the students the scientific concepts that would be taught and the procedures that would be followed for the practical activity. The teachers also used this time to highlight the safety issues relating to the practical task. 
The students' practical activity or in-laboratory activity refers to what the students did to complete the practical task. A number of issues emerged as students engaged with the task in groups. This chapter will firstly discuss the approaches students took for conducting practical work, and then highlight the problems they experienced when doing so, then, it will outline the teachers' expectations of their students as they conducted the practical task.

The post-laboratory activity refers to activities undertaken after the students completed their practical, during which the teachers discussed the expected results, and helped the students to answer the analysis questions and write a conclusion. Finally, the students were asked to produce reports of their practical work. The following section presents detailed information about each phase of practical work conducted by each teacher.

\subsubsection{TM's Lesson}

TM conducted her practical work at SMK Meranti on Friday 22 ${ }^{\text {nd }}$ April 2011 from 10.40 am to $12.00 \mathrm{am}$ in Laboratory one. She planned to do the practical to show the absorption of glucose through the Visking tubing. The equipment and materials were prepared by the laboratory assistant beforehand and the solutions were placed in separate beakers and labelled. TM's lesson seemed to be aligned with Domin's (2007) framework of conducting practical tasks. Figure 7-1 shows the structure of TM's lesson. 
10.40 am: The bell rings.

10.43 am: TM arrives in Laboratory one.

10.46 am: The students arrives in Laboratory 1

1

$10.47 \mathrm{am}-10.48 \mathrm{am}$ : The students go to the benches and put their belongings underneath the benches or outside the laboratory. They put their books and stationery on the tables. The students continue chatting with their peers. They become silent after the class representative greets the teacher.

$10.49 \mathrm{am}-10.52 \mathrm{am}$ : TM begins the lesson by introducing the apparatus and materials to be used in the practical task after she distributes the worksheets. She then demonstrates the steps required to set up the apparatus. She then explains the aims of the practical task.

$10.53 \mathrm{am}-10.55 \mathrm{am}:$ TM communicates the expected positive results of Benedict's and lodine test before the students carry out the practical task. She stated the reasons why they get these results.

$10.56 \mathrm{am}-11.02 \mathrm{am}$ : TM allows the students to collect the necessary apparatus and materials for the practical task from the front bench.

$11.03 \mathrm{am}-11.30 \mathrm{am}$ : The students do the practical in groups.

$11.31 \mathrm{am}-11.45 \mathrm{am}$ : TM tells students to stop and she communicates the expected results to the whole class.

$11.46 \mathrm{am}-11.50 \mathrm{am}$ : TM calls students' names to answer the analysis questions and suggests a conclusion from the practical task.

$12.00 \mathrm{am}$ : The lesson ends.

Figure 7-1: The flow of TM's lesson 


\section{Pre-practical Phase in TM's Lesson.}

TM arrived early, placed her preparation book and handbag on the bench at the front of the laboratory, went to the preparation room, and returned with a book in her hand. She sat at the front bench and read the book while she waited for the students to arrive. The laboratory assistant had prepared the equipment and materials and there was a clearly labelled beaker of glucose solution and another of starch solution. The Benedict's and iodine solutions were placed next to the Visking tubing that was placed into a beaker containing water.

The lesson started behind schedule as the students arrived six minutes late and the students took a few minutes to settle down before TM started the lesson. She distributed the worksheets from the practical book (Kheng \& Yassin, 2005) to all students (Appendix 7-1). She began the lesson by asking the students to state the aim of the practical and only one student seemed to be responding to her questions while the other students remained quiet. She then quickly explained what equipment and materials were required for the task, but did not explain or ask why those materials and equipment were needed. The dialogue between the teacher and the student was as follows:

TM: OK students, what is the aim of the practical task? M13: To investigate the absorption of digested food.

TM: Thanks, M13. The materials are the Visking tube, glucose solution, distilled water and the glucose solution.

(The observation note, 22/4/2011)

TM continued the lesson by detailing the procedure that should be used to complete the task, including steps that were not written in the worksheet. For example, TM explained the importance of preparing the Visking tubes in detail, before they added the solutions (glucose and starch solutions). Although she explained all the steps to be followed, she did not emphasise the need to measure the amounts of solution put in the Visking tubes and the need to immerse the Visking tube in the test tube containing distilled water and for how long. TM gave students the opportunity to follow the procedure; however it is possible that students did not understand why they were following the procedure. In essence it gave students the opportunity to perhaps develop procedural knowledge but not procedural understanding. For example, when describing the procedure she said: 
TM: Before you add the starch and the glucose solutions in the Visking tube make sure you tie one end of the Visking tube. Then, tie the other end of the Visking tube with the thread. Then rinse the Visking tube with distilled water. Later put the Visking tube into the boiling tube that contains distilled water.

(The observation note, 22/4/2011)

TM continued by asking questions that related to the steps taken to identify the presence of starch and glucose. She asked the students to identify the differences between the tests for starch and glucose. Both of these questions had the potential to make the students reflect upon the practical that they had carried out in the previous practical, therefore taking into consideration the students' prior knowledge. As she progressed with the lesson, she asked the following questions, including "recall" type questions:

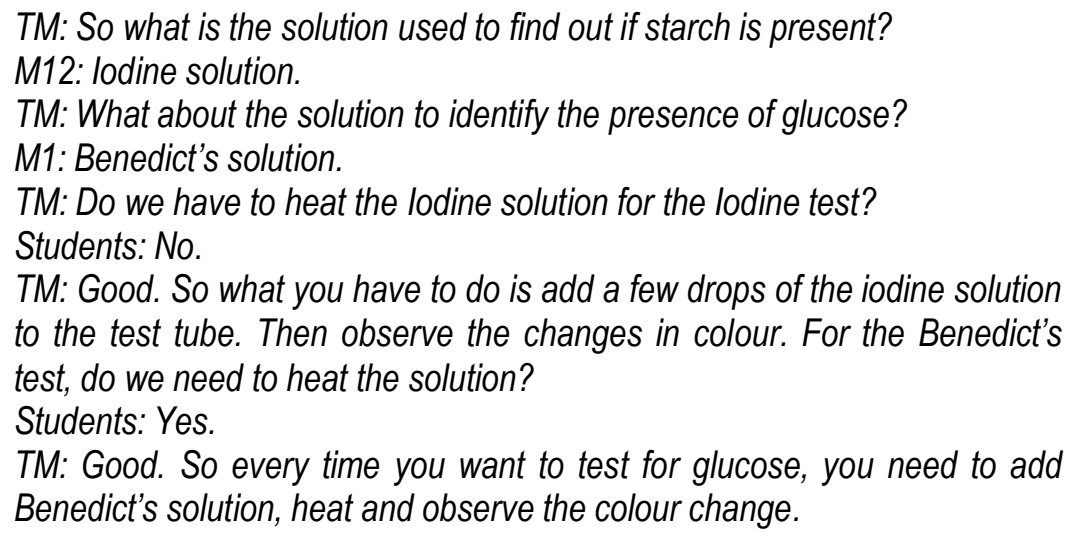

(The observation note, 22/4/2011)

As well as explaining the procedure to the students, TM went on to ask the students questions relating to the initial results of the experiment. Although prediction questions such as these might provide the students with opportunities to predict the results of both tests, no student was able to do so. One student did attempt to answer the question. It seemed that the student had a prior knowledge about what colour Benedict's solution was before it reacted with the glucose solution. M5 was not sure about what changes Benedict's solution would undergo if glucose solution were added. When it was clear that no student knew (or wanted to give) the correct answer, TM gave the initial results and the reasons for getting those results. She explained: 
TM: So if glucose is present, what is the colour of the Benedict's solution?

M5: Blue changes to ...

TM: Blue changes to red-orange precipitate. Is glucose or starch present at the beginning of the practical task?

(The students did not respond to her question.)

TM: Both of them are not present at the beginning of the practical task. The colour of iodine solution remains brownish and the colour of Benedict's solution remains blue. The glucose solution and the starch solution have not diffused from the Visking tube yet. So the glucose solution or the starch solution is not present yet.

(The observation note, 22/4/2011)

TM told the students what results to expect in both tests before they carried out the practical task on their own. She also explained the reasons why the colour of the lodine solution remained unchanged. After asking the students and failing to get a response, she then explained the potential results and the reasons for getting them. Her explanation was as follows:

TM: Ok, the apparatus is left to stand for 30 minutes. Then the distilled water in the boiling tube is tested for the presence of starch and glucose. So which solution will diffuse from the Visking tube? Starch solution or glucose solution?

(The students did not respond to her question)

TM: The glucose solution will diffuse from the Visking tube. Starch solution cannot diffuse from the Visking tube. Do you know why?

(The students did not respond)

TM: The starch solution cannot diffuse form the Visking tube because starch is a large molecule. So what is the colour of lodine solution at the end of the practical task?

M5: Brownish.

TM: Correct. The colour remains brownish because the starch solution is not present.

(The observation note, 22/4/2011)

TM then explained what the expected result of the Benedict's test would be at the end of the practical. She also explained what the reason would be for getting a negative result. Some of the students managed to state the results of the test after she asked the 'fill in the blank question'. She explained:

TM: The starch is absent. What is the result of the Benedict's test? The colour changes from blue to....

Students: Blue to red orange precipitate. 
TM: Good. Glucose is present because glucose has small molecules that can diffuse from the Visking tube

(The observation note, 22/4/2011).

TM spent approximately seven minutes introducing the aim of the investigation, the materials, and equipment for setting up the apparatus and the steps to be followed. She also engaged with the students in predicting the initial and final results of both tests through questioning. Some of the questions that she asked had the potential to engage students with scientific process skills such as making predictions. However, some of the questions held the danger of leading students to guess the answers. Only a few students were involved in answering the questions; other students remained silent. Although TM's approach seemed to help her to give an overview of how to perform the practical task and what results to expect, the students were not necessarily left with an understanding of why they were performing such steps, therefore, may be unable to provide the reasons for performing those steps. This was perhaps because the students were not given an opportunity to reflect individually upon the steps of the procedure before they split into groups to do the practical task.

\section{Practical Activity Phase in TM's Lesson}

The students began the practical task in groups after TM allowed them to collect the apparatus. The students supposedly worked as a group to conduct practical work but it seemed that each group member did not have a specific role. For example, almost all the students including the focus group students went to TM's bench located in front of the laboratory to collect the equipment. The laboratory became very noisy as students crowded at the bench because there was only one station from which the students could collect the materials.

The students had some difficulties setting up the apparatus although TM had explained the steps in the pre-laboratory phase. TM showed concern about ensuring the students could set up the apparatus correctly and she demonstrated the procedure to set up and prepare the Visking tube A. She took the Visking tube from the beaker and tied one end of it, she added the starch solution before tying the other end of the Visking tube with thread and then carried out similar steps for preparing the Visking tube B. She then transferred the solutions into separate Visking tubes, without measuring the volume of either before doing so. Finally, she immersed both Visking tubes in separate boiling tubes containing distilled water. Although she performed a comprehensive demonstration, not all students observed it. 
It seemed that the focus group students did not plan to complete the practical task as a group, as they did not distribute the task among the group members. Consequently, two students did a similar task. For example, M5 and M4 returned with the boiling tube that contained the Visking tubes and then a few minutes later, M3 returned with the Visking tube that was already immersed in a boiling tube containing distilled water. M3 placed the boiling tube into the test tube rack and did not tell her group what she had added to the Visking tube until TM came to the focus group and asked the following:

TM: What did you put in the Visking tube?

M3: Distilled water.

TM: What? How many times do I have to tell you? Pour the glucose solution or starch solution. Not distilled water.

M1: 'Itulah tak baca instruction betul-betul'. You make mistakes because you didn't read to the instruction properly.

TM: Please repeat these steps.

M3: I'm sorry, teacher.

TM: M5, pour the distilled water from the boiling tube into two test tubes. Then label one test tube $A$ and the other test tube $B$. Then add lodine to test tube $A$ and Benedict's solution to $B$.

M5: OK, Teacher.

(The observation note, 22/4/2011)

The focus group students (M5 and M4) demonstrated that they did not really understand the procedure for the practical work. After they worked together to transfer the solutions into separated Visking tubes, neither of them seemed to know what to do next nor relied on TM's instruction to complete the procedure. M5 asked:

M5: Teacher, what should we do next?

TM: Rinse the Visking tube with tap water. Then, you have to immerse the Visking tube in the boiling tube that contains tap water. Immediately test the water surrounding the Visking tube with the lodine solution and the Benedict's solution. Do you understand that?

M5: Yes.

(The observation note, 22/4/2011)

Although the students could perform the lodine and Benedict's tests as intended by TM, they did not reflect on the task they performed. The students were able to observe the results of the Benedict's test but they did not appear to understand why the Benedict's solution changed colour. They stated:

M1: It changes to blue solution.

M2: It changes to the orange precipitate.

(The observation note, 22/4/2011) 
The students appeared to be excited when they observed the changes in colour, and excited to share their findings with TM after they discovered that the colour of the Benedict's solution had changed to a red precipitate. The positive comments may suggest that doing the task correctly and getting the right results had a positive impression on the students. However, TM might have missed an opportunity to extend the interaction with the students by not asking them why they thought they achieved such results. M4 made the following comments:

M4: Teacher, look! The solution changes colour.

TM: Wah! Good work girl. Ok, now turn off the Bunsen burner. Ok, listen everyone. Turn off your Bunsen burner. I want to discuss the results and the analysis questions.

(The observation note, 22/4/2011)

It seemed that cooperative learning did not take place in TM's lesson. The focus group students did not assign a specific task to each group member and it was obvious that one of the group members (M3) performed steps that were not written on the worksheet or stated by the teacher. The students appeared to be able to follow some of the steps and managed to complete the steps correctly with assistance from TM. The focus group students showed they were able to state the observation correctly, but they did not have the opportunity to reflect on the results they produced.

\section{Post-practical Phase in TM's Lesson}

The post-practical activity took place after the students carried out the lodine and Benedict's tests to test the presence of starch and glucose. At the end of the practical, TM involved students with different activities. Firstly, she gave the results of both tests and highlighted the possible reasons why some students were not able to produce the expected results. Secondly, she asked students to answer the analysis questions. Finally, and before the lesson ended, she carried out the reflection activity with students.

TM stated the initial result of the iodine test when she discovered that some groups did not achieve the expected results. At the beginning of the practical, she highlighted some of the reasons why some students might have unexpected results for the iodine test. She explained that:

TM: [...] if you get a green colour, it showed that starch solution was present. Maybe you did not rinse the Visking tube with water before you immersed it in the boiling tube that contained distilled water. Or you did not 
immediately conduct the iodine and Benedict's test right after you immersed the Visking tube into distilled water. So starch and glucose were absent at the beginning of the practical task.

22/4/2011)

(The observation note,

TM continued the lesson by asking the students to recall the final observation of the Benedict's test. The students were able to state the expected observation but could not explain why they got their results. TM explained why the colour of the Benedict's solution had remained unchanged and asked a recall question:

TM: What colour is this?

(TM pointed at the test tube that contained the Benedict's solution).

Students: Blue.

TM: Why does the colour remain blue after 30 minutes?

M7: Because the water bath is not really hot.

TM: No. It is because glucose is not presence.

(The observation note, 22/4/2011)

TM continued the lesson by asking students to answer the analysis questions. The students did not seem to have enough time to answer the analysis questions before TM read the questions out loud. She began by asking the students to make an analogy of the apparatus or the materials used in the practical task with human organs involved in digestion. As the students could not provide the "correct" answers, she provided the answers. TM read the questions:

TM: What does the Visking tube represent in the human digestive system?

(There was no response from the students. She then answered her own question).

TM: It represents the small intestine.

TM: What does the distilled water in the boiling tube represent in the human digestive system?

(The students did not respond to her question).

TM: It represents the bloodstream. Ok, write the answers in your experiment book.

(The observation note, 22/4/2011)

One of the analysis questions required students to recall the observation and the inference for both tests at the end of the practical. The teacher called out students' names to answer the questions and it appeared that some students could not state the results correctly while some students were able to. 
TM: Can anyone state the observation and the inference of the lodine test? I want the correct answers for that. M13 please answer the question.

M13: The colour of the starch is brownish.

TM: What? The colour of starch is brownish. M3 please answer my question.

M3: At the beginning of the experiment, the colour of lodine is brownish. At the end of the experiment, the colour of lodine remains brownish. (After the third attempt, she managed to give the expected answer.)

TM: Why did the colour of the lodine solution remain brownish?

M3: Because the starch is absent.

(The observation note, 22/4/2011)

TM did not discuss all the answers of the analysis questions. She spent about 10 minutes checking the answers of the reinforcement activities in Chapter Two that she had distributed in the previous lesson. By the end of the lesson, TM had yet to ask the students to write a conclusion for the practical task they had completed, and the students left the laboratory without cleaning their benches and tidying the equipment.

It seemed that at each stage of the lesson, TM played a dominant role to ensure that the practical work ran smoothly. She explained the procedure and the concepts they should follow and learn. While the students engaged with the task, she monitored their work by moving from one group to another. Despite all the support, some did not follow instructions and relied on TM's additional or repeated instructions. The students might work in groups due to external factors such as time and resources, but overall, they did not show that they worked cooperatively as a group. The students demonstrated they could recall the results of both tests, but there was no evidence to say they understood what they had observed.

\subsubsection{TJ's Lesson}

TJ taught the practical lesson at Jati School on Thursday 28 th March 2011 between $1.20 \mathrm{pm}$ and $2.40 \mathrm{pm}$ in Laboratory three. The duration of the lesson was ninety minutes. TJ and the researcher arrived five minutes before the lesson began as all the equipment for the practical was prepared beforehand by the laboratory assistant who placed glucose and starch solutions side by side on the front bench and placed Visking tubes, test tubes, Bunsen burner and beakers on the trolley next to the front bench. The materials were glucose solution, starch solution, Benedict's solution and iodine solution and she had prepared approximately $200 \mathrm{ml}$ of food samples. She arranged the food samples and the solutions to detect the presence of the food classes side by side on the front bench and placed the starch solution and the iodine solution together on the right of the front bench. The glucose solution and the Benedict's 
solution were placed together in the middle of the front bench. All solutions and reagents were clearly labelled.

While waiting for the students to arrive, TJ drew a grid for an observation table on the board, (Table 7-1) which was different from the table suggested in the textbook (Table 7-2) and did not have the headings set out. It seemed that TJ wanted the students to record the observation without inferring results. Figure 7-2 shows the flow of TJ's lesson.

Table 7-1: The observation table written by TJ on the whiteboard

\begin{tabular}{|l|c|c|}
\hline Test & $\begin{array}{c}\text { The beginning of the practical } \\
\text { task }\end{array}$ & $\begin{array}{c}\text { The end of the practical } \\
\text { task }\end{array}$ \\
\hline lodine test & & \\
\hline Benedict test & & \\
\hline
\end{tabular}

Table 7-2: The observation table suggested by the textbook (Tong \& Neo, 2003, p. 52)

\begin{tabular}{|l|l|l|l|l|l|}
\hline \multirow{2}{*}{$\begin{array}{l}\text { Boiling } \\
\text { tube }\end{array}$} & \multirow{2}{*}{ Food test } & \multicolumn{2}{|c|}{$\begin{array}{r}\text { The beginning of the } \\
\text { experiment }\end{array}$} & \multicolumn{2}{|c|}{ The end of the experiment } \\
\cline { 3 - 6 } & & Observation & Inference & Observation & Inference \\
\hline A & lodine test & & & & \\
\hline B & Benedict test & & & & \\
\hline
\end{tabular}




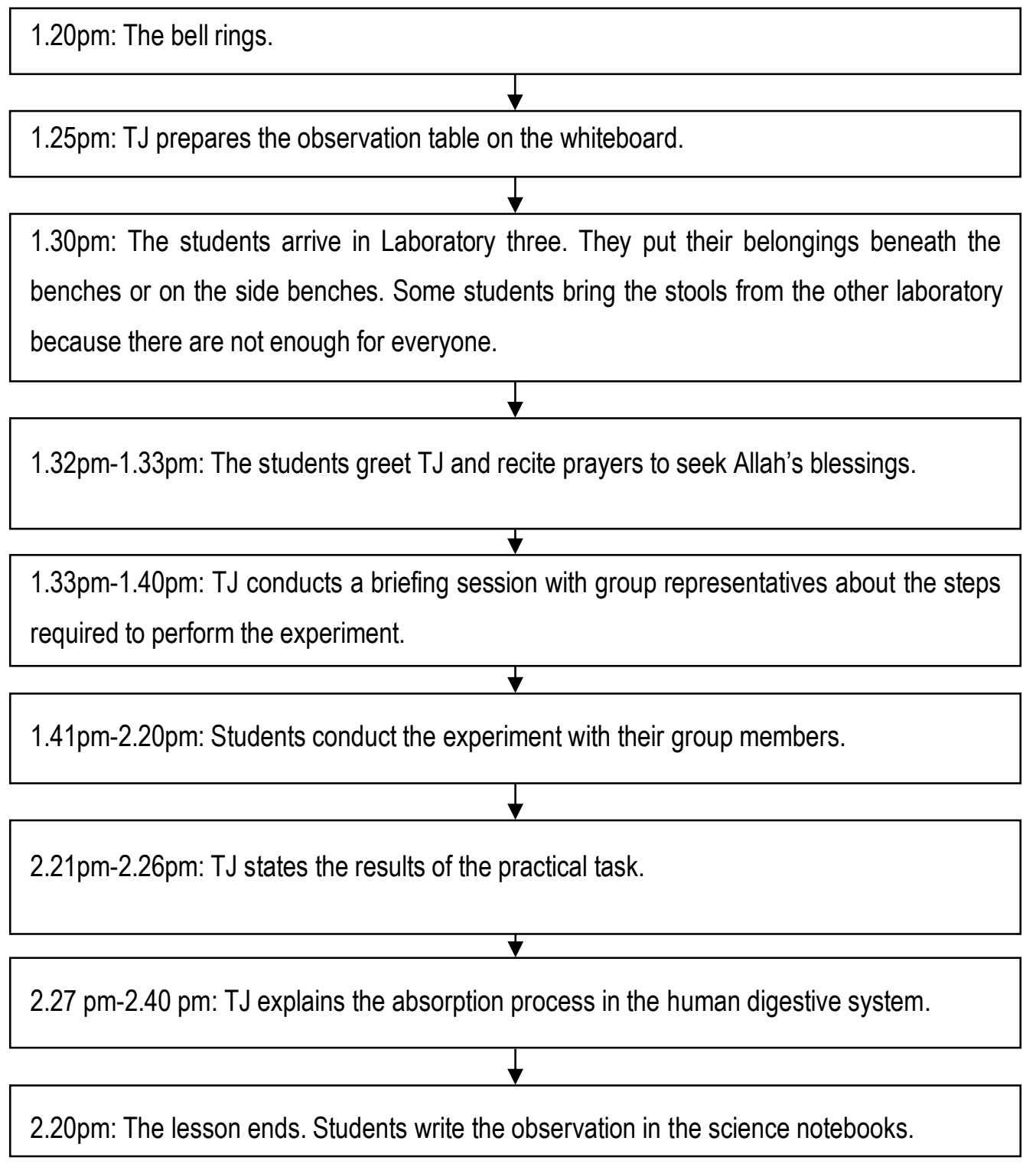

Figure 7-2: The flow of TJ's lesson

\section{Pre-practical Phase in TJ's Lesson}

TJ did not begin the lesson by explaining the procedure for the practical task to the whole class. Instead, he called representatives from each group to the front and asked the rest of the class to read the instructions on page 52 of the textbook (Appendix 7-2). Then TJ demonstrated the procedure to the group representatives. It seemed that the other students did not listen to his instructions as, instead of reading the instructions from the textbook, they included those in the focus group, ( 2 2, J3, and J4) talked: 
...the focus group students talked about their lives and what they were doing which was not what $T \mathrm{~J}$ wanted them to do. $\mathrm{J} 3$ and $\mathrm{J} 4$, talked about last night's TV programme. J2, sharpened her pencil.

(Observation note, 28/3/2011)

The focus group students attempted some group work. They tried to appoint a new group representative, which led to an argument between $\mathrm{J} 1$, (the previous group representative) and $\mathrm{J} 3$ before $\mathrm{J} 3$ agreed to be the next group representative:
J1: Last time J2 and I were the group representatives. This time we should choose someone else; J3, will you be the group representative? J3: Me? Why me? (She appeared unhappy with the decision). J5: Don't worry. You just have to listen to him. That's all. J3: Fine, l'll go. (She did not smile at all).

(Observation note, 28/3/2011)

The six group representatives crowded around TJ's bench at the front of the laboratory and some of them talked with their peers while some remained quiet. $\mathrm{J} 3$ stood back from the bench, arms folded, and looked at TJ and did not talk to the students standing next to her. TJ began the demonstration by asking the students to stand in a straight line in front of him and reminded them to observe the demonstration carefully because he had changed some of the instructions in the textbook. None of the students had a notebook to write down TJ's instructions.

TJ provided guidance before he allowed students to do practical work in groups, however, he did not share the aims of the practical task at the beginning of the briefing or explain the whole procedure. He began with a demonstration to prepare the Visking tube and told the students to add the glucose and the starch solutions to similar Visking tubes, but did not say how much of the liquid they should add. He ended the briefing by telling the students to do the Benedict's and iodine tests and continued with the following instructions:

TJ: Then pour the distilled water into the boiling tube. Dip the Visking tube into the boiling tube that contains distilled water. Then immediately pour the distilled water for the boiling tube into two test tubes. Test the first test tube with lodine solution and the other with Benedict's solution. Place the test tube that contains the Benedict solution into the water bath. Do you understand? Do you have any questions so far?

Students: No.

(The observation note, 28/3/2011) 
Before asking the students to return to their benches, TJ repeated the instructions and reminded them to record their observations of the Benedict's and lodine tests in the observation table. However, he did not tell them that they needed to repeat the test after 30 minutes.

TJ: Record your observation. Do you understand? Don't forget to pour the distilled water from the boiling tubes into two separate test tubes. Test the first test tube with lodine and the second test tube with Benedict's solution. Place the test tube that contained Benedict's solution into the water bath. Record your observations in the table. Do you understand?

Students: Yes.

TJ: Return to your group and share the tasks with other members of your group.

(The observation note, 28/3/2011)

TJ took approximately eight minutes to brief the group representatives about the prelaboratory activity. TJ explained the steps required to set up the apparatus, but did not explain why the students should take such steps. The practical he explained to the group representatives was different to the practical work suggested in the textbook. The focus group students attempted to exchange roles with other group members and argued about selecting a new group representative.

\section{Practical Activity Phase in TJ's Lesson}

It seemed that most students did not cooperate to complete the practical work as intended by TJ. After the briefing, the group representatives did not return to the benches to explain the procedure to the other group members and other students left their benches, approached the bench in front of the laboratory, and began collecting the equipment. The laboratory became very noisy and less than 10 students, including all the focus group students, were at their benches. It appeared that the students did not know what they were supposed to do, as some of them asked about the procedure and what materials they needed for the practical work.

Student (M?): What should I do next?

Student (F?): How many test tubes do we need?

(Both of the students called out and directed these questions randomly at the crowd in the front of the class. None of the students in the crowd answered their question).

(The observation note, 28/3/2011)

The classroom observation showed that the focus group students were not able to perform some of the steps as intended by TJ, possibly because they did not read the instructions, 
and/or the group representative did not explain the procedure very well. Although they were provided with a detailed procedure in the book, they relied on J3's explanation to complete the task. J3 gave instructions that resembled neither what TJ had outlined, nor those set out in the book. For example, although the procedure did not require heating the Visking tube containing the mixture of starch and glucose solutions, J3 gave the following instructions:

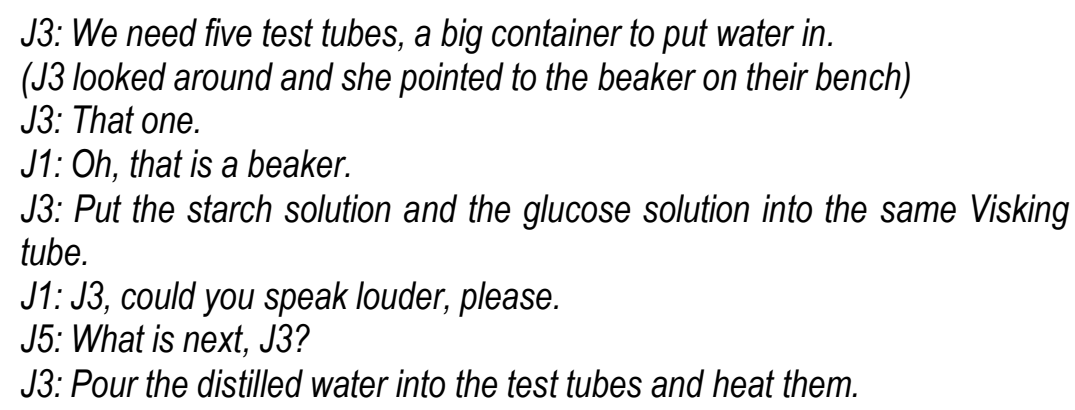

(The observation note, 28/3/2011)

J3 did not have the opportunity to explain the complete procedure because the focus group students rushed off to complete the practical. J1 made the following comments:

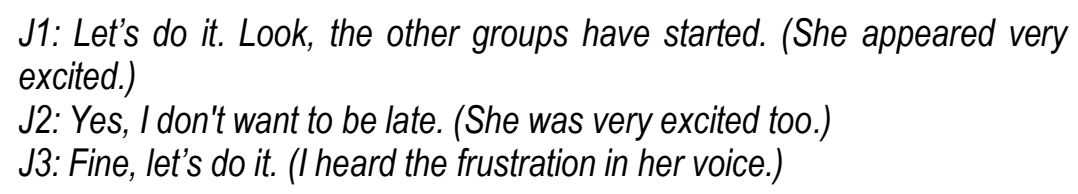

(The observation note, 28/3/2011)

It seemed that $\mathrm{J} 3 \mathrm{knew}$ the procedure quite well compared to other students and $\mathrm{J} 1$ and $\mathrm{J} 5$ managed to perform the steps with the assistance of J3. For example, following J3's instruction $\mathrm{J} 1$ and $\mathrm{J} 5$ managed to prepare the Visking tube before adding glucose and starch solutions to it. The student (J1) showed some understanding of the steps:

J5: J3, I want to prepare the Visking tube. What should I do first?

J3: Take the Visking tube and tie one end with the thread.

(J1 seemed unsure about the length of the thread, and then she asked the researcher.)

J1: Is this enough, Teacher?

Researcher: I don't know, perhaps you can ask J3. Maybe she knows.

$\mathrm{J1}: \mathrm{J}$, is this enough?

J3: I don't know. Just cut it.

(J1 cut some of the thread. She tied one end of Visking tube.)

J1: I'll tie it tightly. Hehehe. (She laughed) So it won't leak.

(The observation note, 28/3/2011) 
$\mathrm{J} 3$ delivered instructions to $\mathrm{J} 1$ and $\mathrm{J} 5$ about what they were supposed to do after tying one end of the Visking tube, that were not quite correct. She failed to mention the volume of each solution they were supposed to add to the Visking tube. As a result, the students estimated the volumes. They did not carry out this task carefully; the solutions were overflowing and the tubes were not rinsed with distilled water after tying them at the other end. J3 then asked $\mathrm{J} 1$ to put the Visking tube into a boiling tube containing distilled water. J1 and J5 left the bench with the apparatus while J3 stayed at the bench. She said:

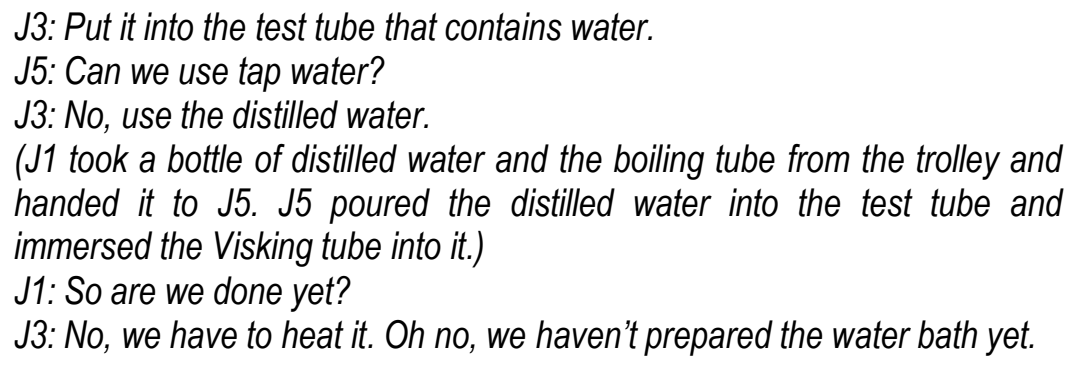

(The observation note, 28/3/2011)

Despite the focus group students being told the necessary steps to prepare the Visking tube, their knowledge of the steps to complete the task seemed limited. A few incidents showed the students either had misunderstood the instructions or did not know them. They did not know what they were supposed to do with the equipment after they had collected the materials from TJ's bench. For example, J2 took two test tubes from the trolley and then asked the researcher:

J2: Teacher, what should I do next?

Researcher: Have you read the instruction or asked J3? I think she knows. (J2 did not ask $\mathrm{J} 3$ or look in the textbook. She stood at the front bench and watched $\mathrm{J} 1$ and $\mathrm{J} 3$ complete the task.)

(The observation note, 28/3/2011)

The students also showed they did not really understand the procedure as firstly, they performed steps that were not in the textbook. J3 added Benedict's and iodine solutions into separate test tubes that contained distilled water before returning to her bench. She did not label either test tube correctly. J3 and the other group members could not make sense of what they had observed, which is evident in the following observation:

Researcher: Why did you add the lodine solution?

J3: I saw everyone do the same thing.

Researcher: What is your observation?

J4: It's yellowish. 
Researcher: If the colour of the lodine solution is yellowish, what does it mean?

(None of the students in the focus group responded. They just smiled and continued with the Benedict's test. I saw J3 add a few drops of Benedict's solution to the test tube.)

Researcher: Why did you do that?

(J3 smiled at me. She shook her head from side-to-side)

J3: I don't know.

(Then $\mathrm{J} 3$ immersed the test tube containing a few drops of Benedict's solution into the water bath.)

Researcher: Why do you need to put it into the water bath?

J3: Teacher TJ asked us to do so.

(The observation note, 28/3/2011)

Secondly, the students did not perform the steps they were supposed to, they did not conduct iodine and Benedict's tests immediately after they placed the Visking tubes into the boiling tubes containing distilled water and they placed the boiling tube and the test tube that contained Benedict's solution into the water bath for a few minutes. The steps they performed were not from the textbook or given by the teacher. TJ asked the students to remove the boiling tube and the test tube from the water bath. He told the students to do the Benedict's test and the lodine test on the distilled water surrounding the Visking tube:

TJ: Turn off the Bunsen burner. Remove the test tubes from the water bath. J5: Both of them?

$T J$ : Yes, both of them.

TJ: Take the distilled water from the boiling tube (TJ pointed to the boiling tube that contained the Visking tube). Pour it into two different test tubes. Test the first test tube with the lodine solution and the other one with the Benedict solution.

(TJ helped the students to pour the distilled water into two test tubes. Although he helped the students to complete the task, he did not tell the students the reasons for following these steps.)

(The observation note, 28/3/2011)

Although they were able to produce the expected results, they could not make sense of what they had observed and there was no evidence that they knew the reasons for doing the iodine test. For example, J4 conducted the lodine test on the distilled water surrounding the Visking tube as instructed and the colour of the distilled water turned yellowish after she added a few drops of lodine solution. J4 did not know why the lodine test must be conducted on the distilled water, and there was no evidence that the students knew the reasons for doing the iodine test. It appeared that even though TJ moved around the class and observed the 
students engage in the practical work, the opportunity to ask questions and encourage students to reflect was often lost.

Overall, the students did not perform the practical as intended by TJ. They displayed a limited understanding of the steps required to set up the apparatus, which might have been due to a number of factors. Firstly, not all students received teacher instructions. The group representatives (who received their instructions directly from the teacher) seemed to have more information about the task than other group members who relied on them to tell them what they were supposed to do. Secondly, the focus group students did not listen to J3's instructions before beginning the practical.

\section{Post-practical Phase in TJ's Lesson.}

Even though not all students had not completed the practical, TJ chose to discuss the results with the class. He asked the students to stop the practical and turn off the Bunsen burners and to record their observations in the table (Table 7-1). TJ continued by describing how the glucose solution could diffuse from the Visking tube, and then explained the results. He used a diagram (Figure 7-3) to explain how and why the absorption process occurred.

TJ: Everyone please look at me. Look at the whiteboard. The simple structure diffuses from the Visking tube. Which one is the simple structure? The glucose is the simple structure.

TJ: Glucose is the simple structure. So it diffuses through the Visking tube. Can the starch solution diffuse from the Visking tube?

(The students answered the question together.)

Students: No.

(The observation note, 28/3/2011)

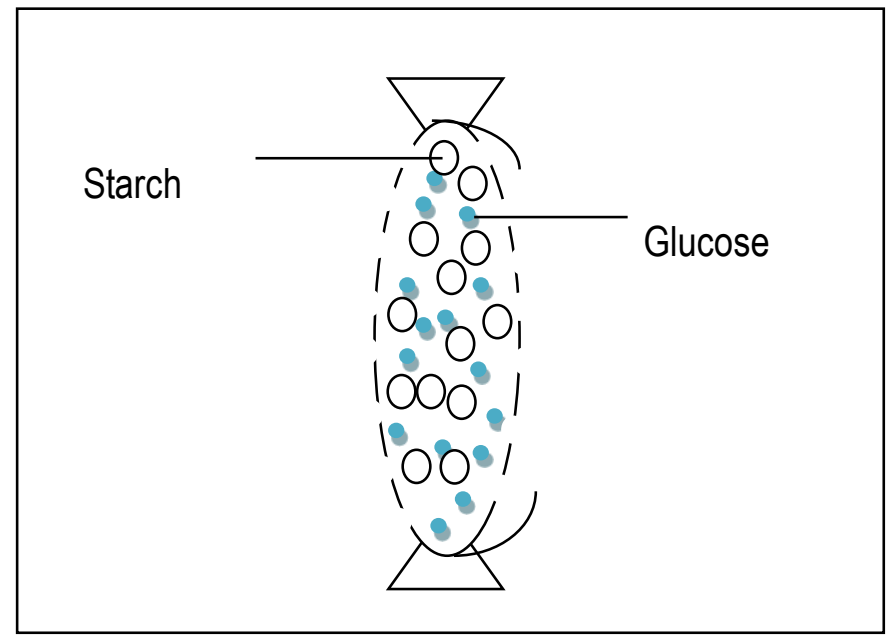

Figure 7-3: The schematic diagram that TJ drew on the whiteboard. 
TJ later explained the factors that allowed the glucose solution to diffuse out of the Visking tube. One of the factors that influenced the absorption process was the structure of the solutions. He differentiated between the structures of the glucose and starch solutions by drawing circles of different sizes and colours. He drew small circles to represent the glucose solution and big circles to represent the starch solution. He then confirmed (based on the positive results of the Benedict's test) that the glucose solution was able to diffuse through the Visking tube. The results that he talked about were the expected results and not the results the students had achieved. This was evident in the following observation:

TJ: Glucose has small molecules. So it diffused through the Visking tube easily. Can the starch solution diffuse through the Visking tube?

(The students answered the question together.)

Students: No.

$T J$ : Yes, the starch solution cannot diffuse from the Visking tube because the starch molecule is big. Look at the diagram (he pointed to Figure 7-3). So when you test the distilled water with the Benedict's solution, you will get redbrick precipitate. Do you understand? Why did you get the blue colour at the beginning of the activity?

(The students made a lot of noise and it was difficult to understand what they were saying.)

TJ: How do you know that glucose has diffused through the Visking tube? Does the starch solution diffuse from the Visking tube? (The students did not respond.)

$\mathrm{TJ}$ : We conducted the lodine test.

(The observation note, 28/3/2011)

It seemed that TJ's brief explanation of the link between the representations of the model with the actual organs of the human digestive system was unclear to the students. The students did not understand the purpose of the Visking tube and the function of glucose and starch solutions, and distilled water. He made the following comment:

$T J$ : Remember the Visking tube represented the villi in the small intestine. Remember that.

(The observation note, 28/3/2011)

Students did not produce a complete report of the practical. They only wrote down the expected results rather than their own findings. For example, although they wrote the initial results of the Benedict's test, they had not done the Benedict's test at all. Figure 7-4 shows J4's report. 


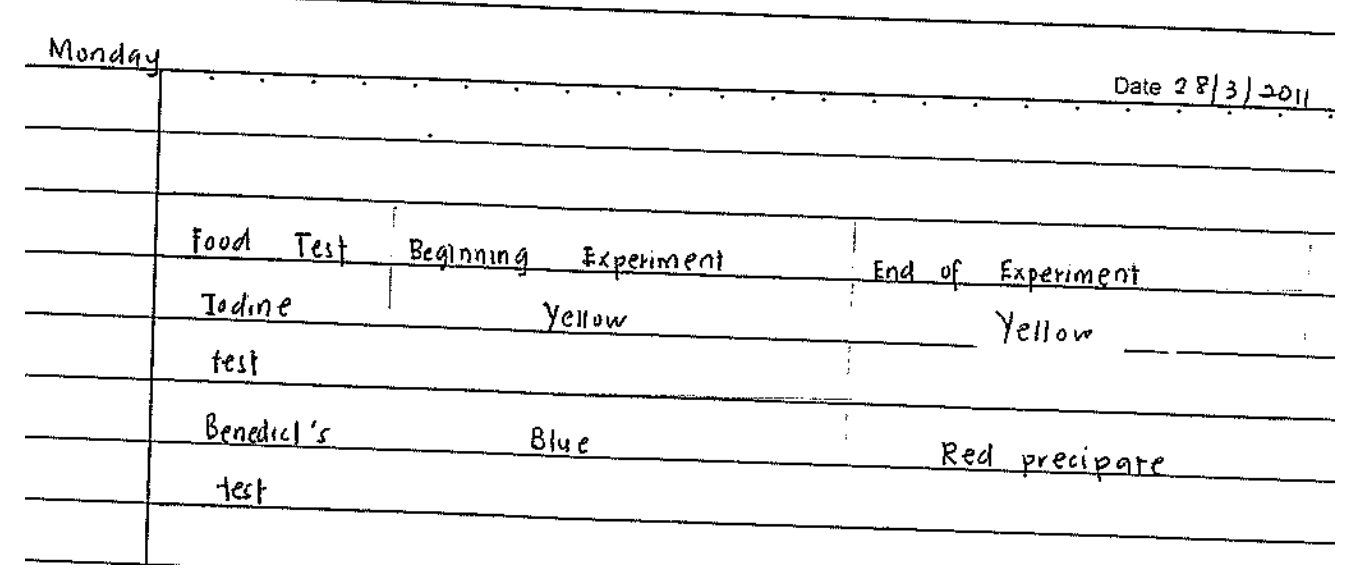

Figure 7-4: The report written by $\mathrm{J} 4$ after the practical task.

In the post-activity, TJ told the students the results they should expect, the factors that influence the absorption process, and how the materials represent the behaviour of the organ involved in the human digestive system. The opportunity to reflect upon their results and draw their own conclusions was not offered to the students. It is not known whether the students understood the model or concept of absorption in human digestive system.

The curriculum requires that students learn specific science concepts and principles through systematic investigation, but it appears this was not achieved in TJ's lesson. Not all students were able to access information about the aims and procedure of the practical task, consequently, students either made mistakes when completing the task, or did not understand the task. Although some students managed to produce the expected results, opportunities for students to make sense of the results were limited. The reports that the students produced might help the students to reflect upon the results, but probably did not help them to relate the results to the concept of absorption that occurs in the small intestine.

\subsubsection{TR's Lesson}

TR's practical lesson was conducted in Resak School on Monday $5^{\text {th }}$ April 2011 from 10.40 am until $12.00 \mathrm{am}$. TR arrived to set up the laboratory before the lesson, and when the bell rang 40 students arrived, took out their books and settled down. The teacher introduced the researcher and the focus group students (recommended by TR) to the class and the focus group students sat down at the back of the room with the researcher. R1 sat next to the researcher on the left followed by $\mathrm{R} 2, \mathrm{R} 3, \mathrm{R} 4$, and $\mathrm{R} 5$. The students then became quiet, 
greeted the teacher and recited the dua' to seek Allah's forgiveness, a routine followed by all classes in the school. Figure 7-5 shows the structure of TR's lesson.

10.40am: The bell rings.

10.41am: TR arrives at Laboratory three.

10.42am: The students arrive at Laboratory three.

10.43am-10.53am: TR allows students to write the report in their experiment book. He states the aim followed by the steps for conducting the practical task. He also briefly explains the process of absorption of digested foods in the human digestive system.

10.54am-10.56am: TR allows the group representatives to collect the apparatus and materials necessary for conducting the practical task.

10.57am-11.11am: TR conducts the demonstration for the group representatives. $\mathrm{He}$ shows the steps necessary for preparing the Visking tube. He takes two Visking tubes and adds the glucose solution to the first, and starch solution to the second. Next, he tells the students to immerse the Visking tubes in two different test tubes containing distilled water. He asks the students to conduct the lodine test and the Benedict's test on the distilled water surrounding the Visking tubes. Then the students return to their benches with the materials and apparatus and begin the practical task.

11.12am-11.30am: The students conduct the practical task with their group members. The students conduct the practical task without referring to the procedure of the practical task.

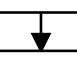

11.31am-11.50am: TR discusses the expected results of the practical task. He begins with the results of the lodine and Benedict's tests at the beginning of the practical task. Then he discusses the results of the tests at the end of the practical task. He explains that the glucose molecules are able to diffuse from the Visking tube because the glucose molecules are smaller than the starch molecules.

11.51am-11.59am: The students complete the reports in their experiment books.

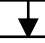

12.00am: The bell rings and the students leave the laboratory.

Figure 7-5: The flow of TR's lesson. 


\section{Pre-practical Phase in TR's Lesson}

This section explained how TR introduced the lesson, gave instructions, and prepared the students to carry out the practical. Before beginning the lesson, TR allowed the students to write a report of the practical carried out in the previous lesson, which led to the focus of the practical lesson presented here. TR explained that the aim of the practical task in this lesson was to investigate the absorption of glucose through the Visking tube. He indicated that they would be using a representative model that showed how digested food is absorbed.

TR: The absorption of digested foods in the small intestine could be shown by developing a model. In this model, the function of the small intestine could be represented by the Visking tube whereas digested foods could be represented with glucose solution.

(The observation note, 5/4/2011)

The instructions were given to students orally using a lecture-based approach which closely followed the task set out in the textbook in terms of the aim or problem, the hypothesis, the variables, the materials, the apparatus to be used and the procedure. The students were to record the results in a table provided in the textbook.

TR then explained the factors that allowed the glucose solution to diffuse from the Visking tube. He explained the factors by using diagrams that he drew on the whiteboard. He compared the structure of glucose and starch molecules using shapes and colours. Figure 7-6 shows the schematic diagram representing the comparative structure of the starch and glucose molecules.

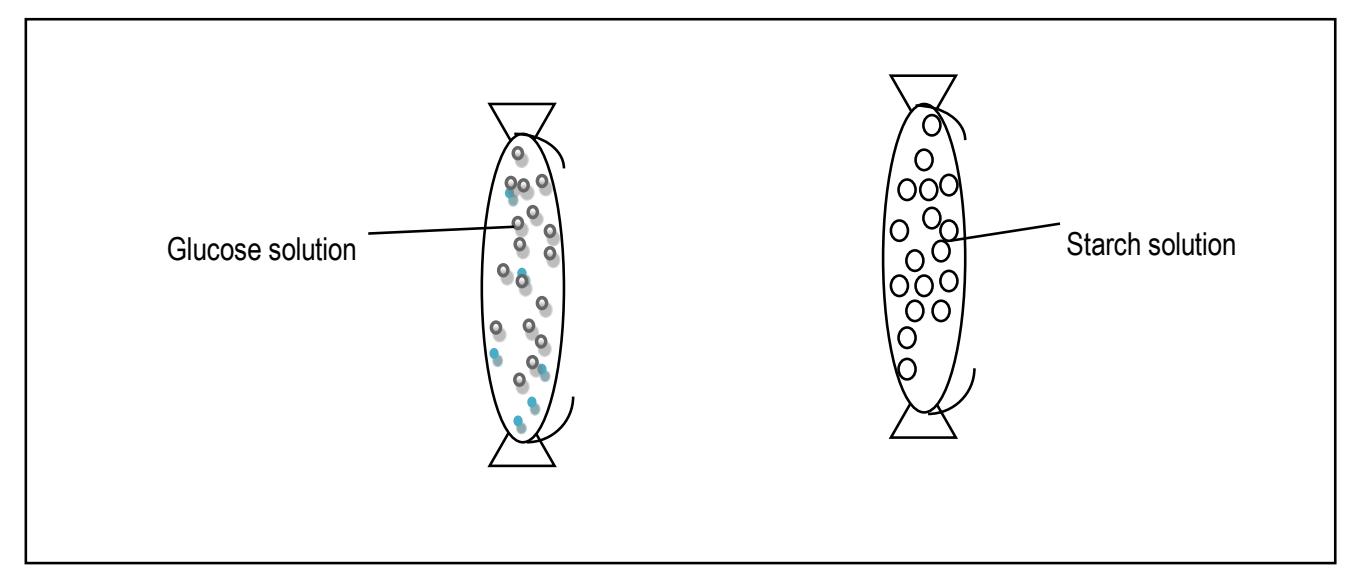

Figure 7-6: The schematic diagrams that TR drew on the whiteboard to compare the structure of starch molecules with glucose molecules. 
TR then explained the procedure to be followed in some detail and began by telling the students to label two boiling tubes as A and B. He then told the students to tie one end of the Visking tube with cotton thread before pouring the starch solution into it and instructed the students to tie the other end of the Visking tube before rinsing with the distilled water. He then told the students to immerse the Visking tube and its contents into boiling tube $A$ that contained distilled water. He asked the students to repeat these steps with the glucose solution in another Visking tube before immersing this Visking tube and its contents into boiling tube $B$. Then he told the students to do the iodine and Benedict's tests twice. The students were told to conduct both tests at the beginning of the practical before repeating the tests after 30 minutes. They would then record the results in the observation table as suggested from the textbook (Table 7-3). It appeared that the purpose for doing the test was not made clear to the students. Figure 7-7 shows the apparatus used in the practical to study the absorption of glucose through the Visking tube.

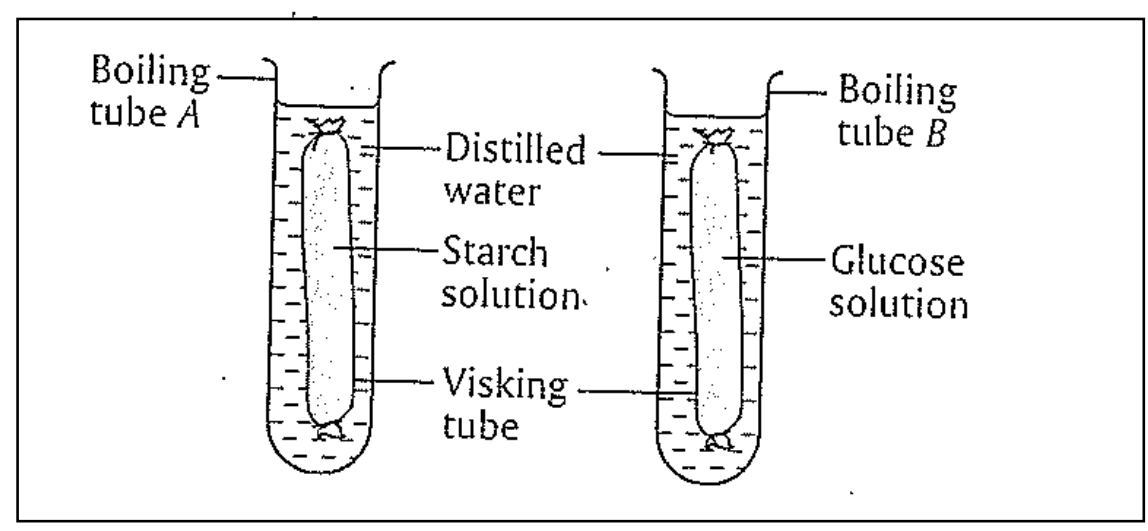

Figure 7-7: The set-up of apparatus to investigate the process of absorption through the Visking tube from the textbook (Tong \& Neo, 2003, p. 52). 
Table 7-3: The observation table for the experiment from the textbook (Tong \& Neo, 2003, p. $52)$.

\begin{tabular}{|l|l|l|l|l|l|}
\hline \multirow{2}{*}{$\begin{array}{l}\text { Boiling } \\
\text { tube }\end{array}$} & Food Test & \multicolumn{2}{|c|}{$\begin{array}{c}\text { At the beginning of the } \\
\text { practical task }\end{array}$} & \multicolumn{2}{|l|}{$\begin{array}{l}\text { At the end of the practical } \\
\text { task }\end{array}$} \\
\cline { 3 - 6 } & Observation & Inference & Observation & Inference \\
\hline \multirow{2}{*}{ A } & lodine Test & & & & \\
\cline { 2 - 6 } & Benedict's Test & & & & \\
\hline \multirow{2}{*}{ B } & lodine Test & & & & \\
\cline { 2 - 6 } & Benedict's Test & & & & \\
\hline
\end{tabular}

In the pre-activity, student involvement was quite limited, as the students just listened to TR talking or copied the reports into their experiment book. TR delivered the information that the students should know before doing the practical task in groups and the concepts that they should learn from it in detail. It seemed that the level of understanding among the students about the procedure and concepts was less than adequate due to the lost opportunity to reflect and discuss their findings.

\section{Practical Activity Phase in TR's Lesson}

After TR concluded his instructions, he allowed the students to do the practical task in groups. It seemed that the students did not really follow his instructions or work as a group. For example, although he had called just one student from each group to collect the equipment required, almost all the students including the focus group students rushed up to the side bench to collect the equipment and only five remained in their seats (observation notes). The noise level in the laboratory increased as students moved about and talked in raised voices. Then, some of the students asked TR to explain the steps to prepare the Visking tube again, and others asked him what they should be doing. Seeing that students had not understood the instructions, TR decided to demonstrate how to prepare the Visking tube. However, only a few students observed the demonstration. The demonstration was as follows: 
TR: Look at me. (He took one Visking tube from the beaker). Take the Visking tube and tie one end of it. Then add starch solution in the Visking tube and tie the other end of the Visking tube. Do it like this. Next, immerse the Visking tube in the boiling tube that contained distilled water. Do you understand?

Students: Yes.

(The observation note, 5/4/2011)

It seemed that the focus group students worked together to do practical work and began the practical task by collecting the materials and equipment. R1 and R4 worked together to collect the materials and a few minutes later the focus students returned to their bench with laboratory equipment. R1 brought a bottle of distilled water and a test tube rack, R4 brought two small beakers containing two different solutions and R1 seemed to know which materials were needed for the task and was able to spot the missing equipment before they began to set up the apparatus. R2, R3, and R5 returned to their bench after joining the crowd at the bench with the equipment and materials.

$R 1: R 2$, where is the Visking tube?

$R 2$ : Oh, I thought you already took it.

R3: Never mind. l'll take it.

(The observation note, 5/4/2011)

It seemed that they did not really understand the procedure for the practical work, so some students made mistakes setting up the apparatus. For example, the students added distilled water into the Visking tube instead of glucose or starch solutions. The mistakes might be caused by students who did not follow the instructions properly, or did not refer to the procedure in the textbook. They also relied on TR's instruction to confirm what steps they should perform.

R1: What did you add in the Visking tube?

R5: Distilled water.

R1: That's wrong. We should add starch solution or glucose solution.

R5: Teacher, we should add distilled water, right?

TR: No, add glucose solution or starch solution.

(The observation note, 5/4/2011)

R5 repeated the steps. He threw away the distilled water and replaced it with glucose solution in Visking tube $(\mathrm{A})$ and starch solution in Visking tube (B). He did not measure the volume of the starch solution before adding it into the Visking tube and he did not rinse the Visking tube 
with distilled water before immersing it and its contents in the boiling tube containing water. R5 seemed to be able to redo the task correctly after receiving comments from the teacher.

While students set up the apparatus, TR still provided guidance. He gave instructions to the whole class on how to conduct the lodine and the Benedict's tests on the distilled water surrounding the Visking tubes. He delivered these instructions after the focus group students filled Visking tubes with glucose and starch solution. The students followed TR's instruction to do the iodine test first and were able to state the observation correctly but did not know the reasons why the iodine solution changed to dark blue. TR did not just deliver the instruction, he also told the students the reasons why they got such results instead of asking the students to repeat the tests.

TR: Ok, now pour the distilled water surrounding the Visking tube into two different test tubes. Test the solution in the first test tube with the lodine solution and the second test tube tests with the Benedict's solution.

( $R 2$ added the lodine solution into the test tube)

$R 3$ : Look, the colour changes to dark blue.

R4: Teacher, look the colour changed to blue.

(TR approached the focus group)

TR: Oh, maybe you didn't tie the Visking tube properly or you did not rinse the Visking tube with water thoroughly.

(The observation note, 5/4/2011)

TR continued to guide students in conducting practical work by telling them the next step of the task. He emphasised the procedure and the correct results instead of engaging students with the scientific investigation. Although TR had delivered the instruction, some of the students, especially the focus group students, made mistakes in setting up the apparatus. They also demonstrated that they could make the correct observation but did not know the reasons why they had produced those results. There was no evidence that the students had reflected on the results they observed.

\section{Post-practical Phase in TR's Lesson}

TR communicated the expected results and concepts despite the fact that some students had not yet completed the practical task. He asked the students to stop what they were doing, before they had the chance to repeat the tests after 30 minutes. He stated the expected results and the reasons why some students achieved them and explained the results of the iodine test for set $A$ at the beginning of the practical task but did not explain the results of the Benedict's test on the same sample: 
TR: Suppose the result of the lodine test at the beginning of the practical task is yellow because the starch solution could not diffuse from the Visking tube. So what is your result for the lodine test?

Student: The colour changes to blue.

TR: Oh. Maybe you did not tie the Visking tube properly or you did not rinse the Visking tube with water thoroughly. So, write the observation is yellow at the beginning of the practical task. The inference is starch is not present.

(The observation note, 5/4/2011)

TR continued the lesson communicating the expected results of the Benedict's test at the beginning of set $B$. He did not say what the results of the iodine test were on the same sample. He said:

TR: The result of the Benedict's test on test tube $B$ is blue at the beginning of the practical task. The glucose solution does not diffuse from the Visking tube yet. Please write, the observation is blue and the inference is glucose is not present.

(The observation note, 5/4/2011)

TR then explained the expected result of the lodine test at the end of the practical task on set A. He told the students to write the results that included the observation and the inference in the table provided (Table 7-3). He related the results to the size of the starch and glucose molecules and explained:

TR: The results of the lodine test on test tube A remains yellow at the end of the practical task. Why? The starch solution cannot diffuse from Visking tube because starch molecules are bigger compared with glucose solution. Write the observation is, the colour remained yellow and the inference is starch is not present.

(The observation note, 5/4/2011)

He followed this with an explanation of the expected results of the Benedict's test at the end of the practical.

TR: The results of the Benedict's test on test tube $B$ changed from blue to the redbrick precipitate at the end of the practical task. Write in your report, as the observation is the colour changed to red brick precipitate and the inference is glucose is present. Glucose has small molecules that can diffuse from the Visking tube.

(The observation note, 5/4/2011)

TR explained the concepts that the students should know as a result of their practical work for the second time, distributed the notes about the model that represented the absorption of 
glucose in the Visking tube, and explained how the materials and equipment represent the human digestive system. However, the diagram on the worksheet did not represent the model that the students performed, and it was obvious that they did not add saliva to the Visking tube. The diagram might lead to confusion among some if they were to refer to the worksheet in the future. Figure 7-8 shows the notes that TR presented to the students after they completed the practical task.

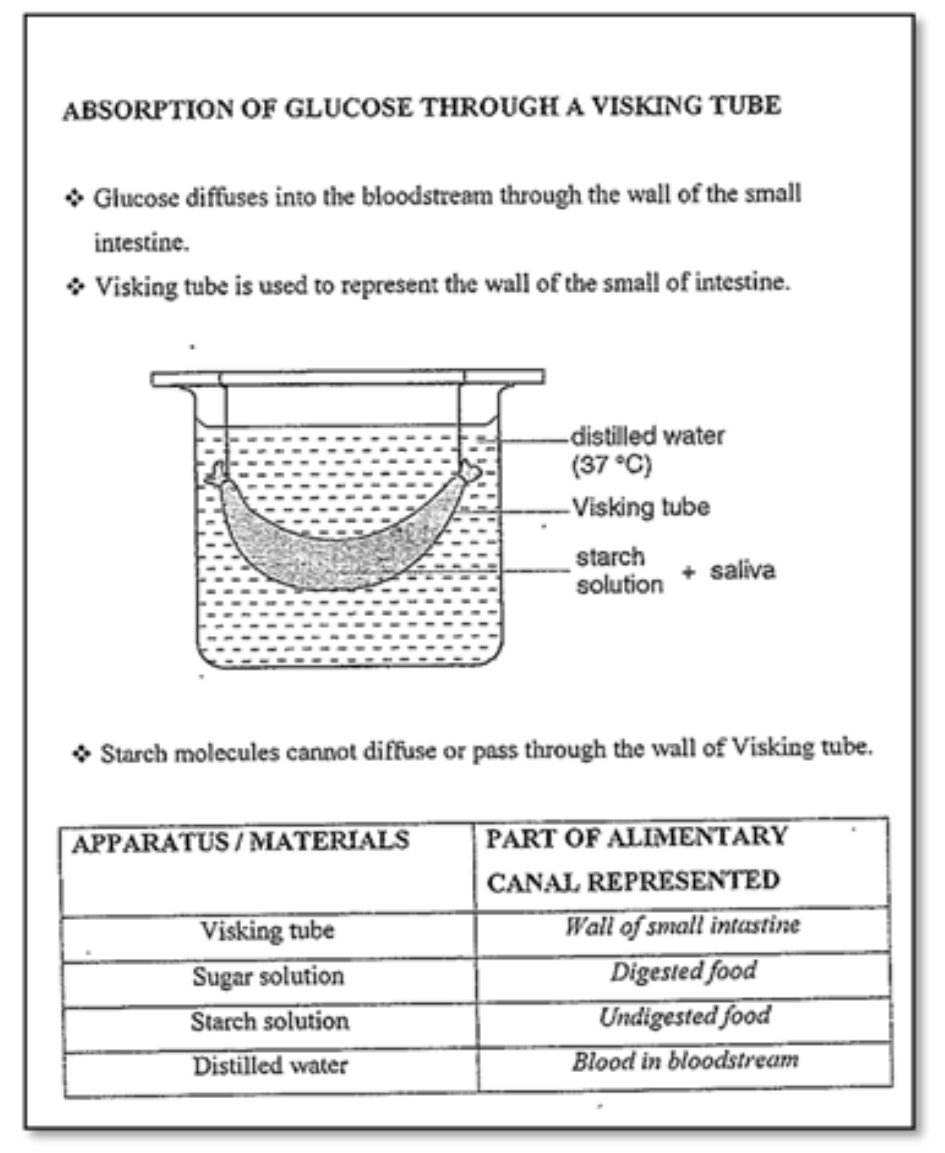

Figure 7-8: The hand-out that TR distributed to the students.

It seemed that TR played a dominant role in confirming the results of the practical. However, he did not provide all of the results; he only highlighted the results of the iodine and Benedict's tests on different samples. He related the results to the presence or absence of the food sample and suggested some possible reasons why some students did not get the expected results. Students could use the hand-out in making the conclusion as the worksheet he distributed had the potential to act as an engaging conclusion to the task. 


\subsection{Similarities and differences in the teaching of the three lessons}

This section presents the teaching of all three case study teachers TJ, TR, and TM. All three lessons shared some similarities and differences in learning outcomes, teaching approaches, and the type of practical work.

\subsubsection{Learning outcomes and teaching approaches}

The practical lessons all shared the same learning outcomes, which was to understand the process of the absorption of digested food. The learning outcomes were as follows:

$$
\begin{aligned}
& \text { v. Explain the process of absorption of the products of digestion } \\
& \text { vi. Make inferences about the absorption of glucose through a Visking tube } \\
& \text { (MOE, 2002, p 24). }
\end{aligned}
$$

In the lessons observed, TM and TR shared the same learning outcomes. In TM's lesson, she asked the students to state the aim of the practical at the beginning of the lesson, whereas TR told the students what the aim was. TJ did not mention aims at all and began his lesson by asking the students to read the instructions from the textbook.

All the teachers used the pre-practical activity to deliver instructions for the practical work, but they used different approaches to deliver these instructions, including a lecture-based approach and a demonstration. They used different resources including the textbook and the experiment book and they all succeeded in outlining the aims, materials and the steps to be followed. The amount of time the teachers took to deliver these instructions differed, and some teachers took slightly longer than others did. Table 7-4 shows the time taken and the mode of lesson delivery.

Table 7-4: The methods used and time taken to deliver the instructions.

\begin{tabular}{lllll}
\hline $\begin{array}{l}\text { Practical } \\
\text { work }\end{array}$ & Teacher & $\begin{array}{l}\text { Method or approach used } \\
\text { to present the procedural } \\
\text { information }\end{array}$ & $\begin{array}{l}\text { Time taken to } \\
\text { present the } \\
\text { procedural } \\
\text { information }\end{array}$ & $\begin{array}{l}\text { Duration of } \\
\text { time to explain } \\
\text { the procedure }\end{array}$ \\
\hline 3 & TJ & $\begin{array}{l}\text { Lecture/demonstration } \\
\text { Lecture/textbook/ }\end{array}$ & 7 minutes & Short \\
10 & TR & $\begin{array}{l}\text { demonstration } \\
\text { Lecture/textbook }\end{array}$ & 16 minutes & Medium \\
9 & TM & 16 minutes & Long \\
\hline
\end{tabular}


In the pre-practical activity, all three case study teachers used a lecture-based approach to deliver the lesson. TJ gave oral instructions to group representatives whereas TR gave an oral presentation supported by students reading out instructions to the whole class. When TR found that students were still unclear about what to do, he demonstrated the process to a small group of students who were asking questions. TM was better prepared in delivering the instructions to the students. She gave an instruction to the whole class and students had already written up the instructions in the previous lesson (including the expected results).

All three case study teachers organised the equipment to ensure it was accessible to the students, preparing it before the students arrived at the laboratory. Students did not bring their own materials, and if they had all conducted the practical activity individually, the availability of equipment and materials would have been insufficient. This was probably one reason why the teachers planned practical work that could be completed in groups.

In the pre-practical activity, the teachers talked about the scientific ideas, the procedure, and the expected results. TR started the lesson by going over the scientific concepts that he wanted the students to learn. He used a model for the students to understand the function of the small intestine and the absorption of digested and undigested materials in the intestine. TJ began his lesson by drawing a results table and instructing the students to read the instructions from the textbook. TM delivered oral instructions and reminded the students of what results to expect, and related the concept of absorption to the previous and present lesson. TR and TJ also used visual drawings to explain the function of the Visking tube.

In the students' practical activity, the students demonstrated that they did not really understand the instructions; TR realised this and proceeded to demonstrate. TJ and TM moved around the class monitoring how the students were carrying out the practical task and TM commented on students' work and gave them instructions on how to complete the practical task. It appeared that All three case study teachers were focused on the students' procedural knowledge and practical application of the task rather than on students' understanding of why they were doing it. The teachers gave explanations for the unexpected results that the students produced. It appeared that the students were not encouraged to make the links between observation and inference, missing an opportunity to engage with the scientific investigation.

It seemed that hardly any students demonstrated cooperative working when conducting practical work. The distribution of the task among group members was unclear, as some of the 
students did not know what they were supposed to do. Some students dominated the task when setting up the apparatus while others observed, meaning that not every group member had the opportunity to actively participate in practical work. It seemed that the students were forced to work in a group because of the laboratory setting and limited resources.

In the post-practical phase, the teachers were concerned with communicating the concepts or the expected results and missed an opportunity to reflect on the process of the practical work. No teacher discussed verifying the results nor did they highlight students' mistakes in following the procedure. TR concluded the lesson without going over the students' results but he did give the class a hand-out and discussed the scientific idea of absorption with them. He made a comparison between the model and the function of the body part and asked the students to complete the practical report. TJ concluded the lesson by communicating the expected results to the students without finding out what the students had discovered by themselves. He did not ask the students to write a full report, and told them to record their observations in the experiment book. Some of the questions posed as analysis questions did not require students to critique their findings; in essence they were recall questions.

\subsubsection{Types of practical work}

The teachers used a 'recipe practical' or 'structured practical work' when conducting their practical work. The 'recipe practical' focused on the procedure to ensure the students could produce the desired phenomenon. A profile form developed by Millar et al. (2002) was used to examine to what extent different aspects of practical work were open or closed. The profile form examined the degree of openness of practical work in terms of the transfer of the decision-making responsibility from teacher to student. There were five aspects of practical work examined in this study:

i. The question to be asked.

ii. The equipment to be used.

iii. The procedure to be followed.

iv. The method for reporting the phenomenon and/or handling any data collected.

v. How the data is to be interpreted.

The task could be classified as fully open, fully closed, or partially decided by students or teacher. The practical work was considered totally open if all aspects were determined by 
students and fully closed if the responsibility to decide each aspect was retained by the teacher. Between the two extremes, there were opportunities for the teacher to transfer the responsibility for deciding some aspects of practical work to students.

In conducting practical work to investigate the absorption of glucose through the Visking tube (sections 7.2.1, 7.2.2, and 7.2.3), the students did not have the opportunity to determine the questions to be asked or the phenomenon to be produced. The teachers (TR and TM) used the prescribed practical work from the textbook or the experiment book in planning the practical lessons, as the questions were clearly stated in the both books. TJ modified the suggested practical work from the textbook to suit the availability of the laboratory equipment and the needs of the students, although he did not mention the questions clearly, but he did state the aim of conducting the practical work to the group representatives.

The responsibility to prepare the materials and apparatus required for the task was retained by teachers. In all lessons observed, the equipment and materials were prepared by the laboratory assistants before lessons started. Some equipment and materials were placed on the teacher's bench located at the front of the laboratory and some, such as beakers or test tubes were placed in a trolley or in a tray. The teachers prepared the materials and equipment in accordance with the suggested practical work in either the textbook or the experiment book. All teachers drew the students' attention to the materials and equipment in the pre-practical phase.

The teachers also determined the procedure to be followed. As shown in Table 7-4, the teachers used various methods and took different amounts of time to deliver the procedural information. TR and TM stated the procedure based on the suggested practical work from the textbook or the experiment book, while TJ improvised the suggested practical work from the textbook. However, TJ did not provide written instructions for students. TM spent approximately 16 minutes delivering information about setting up the apparatus and began by explaining the procedure verbally to the whole class at the pre-practical activity phase (section 7.2.1), and then conducting a demonstration to help a group of students to set up the model at the 'in practical activity phase' (section 7.2.1). She monitored students' work by visiting students at their benches and pointing out their mistakes. Similarly, in TR's lesson (section 7.2.3), he spent 13 minutes delivering the procedural information. Firstly, he allowed the students to read and copy the instructions from the textbook before explaining the procedure through a lecture-based approach to the whole class. At 'the in-practical activity phase', he also conducted a demonstration to a small group of students after he found that some of them 
did not know the steps to set up the model correctly. In contrast, TJ spent the shortest time to deliver the procedural information before he allowed the students to conduct practical work in groups. He explained the steps verbally followed by a brief demonstration on how to set up the apparatus to the group representatives (section 7.2.2). He also monitored the students' work at their benches. Although the approaches to and time spent delivering the information varied, all the focus groups were able to set up the apparatus correctly after a few attempts, but they were unable to follow the entire procedure correctly.

The teachers decided the method for handling data and/or recording the phenomenon. They used the table to record results as shown in the textbook and the experiment book. TJ drew the table on the whiteboard. The teachers presented the methods of recording the results in the pre-practical phase. In TM's lesson, the students had already written in the table to record data in the experiment book. TR allocated time for students to record the table in the experiment book before explaining the procedure to conduct practical work in the pre-practical phase. During the practical work to investigate the absorption of glucose through the Visking tube, the students were required to record non-numerical data about the changes in chemical indicators. In recording the results, the students were required to write down the colour of the chemical indicators at both the beginning and end of the practical work and make an inference based on their results. In TJ's lesson, the students were required to state the results of both tests at the beginning and at the end of practical work without making the inferences. It seemed that TJ's method of recording the results was quite different from the suggested practical work.

The teachers took full responsibility for interpreting the results. The process had taken place in the post-practical phase after the students conducted practical work in groups. There was no evidence that the students were involved in making interpretations based on their results. Firstly, it seemed that the students relied on the teacher to explain their results. The teachers related the failure to produce the expected results to the handling of laboratory apparatus and materials. For example, group $\mathrm{R}$ was unable to produce the desired result when they conducted the iodine test for the first time. TR explained that the failure to produce the result was due to the mistakes the students made in adding the starch solution to the Visking tube. Secondly, the results that the teachers interpreted were theory laden and not based on the students' results per se. For example, the teachers (TM and TR) stated the results of the Benedict's test in different situations (at the beginning and at the end of practical work) 
although the students only carried out both tests once, and no-one repeated them a second time. They also made the inferences based on the results.

\subsubsection{The effectiveness of practical work}

This chapter applies Abraham and Millar's (2008) framework to analyse the practical work conducted in the three classes. A $2 \times 2$ effectiveness matrix of practical work consists of two levels of effectiveness that examine what students do with objects and ideas. The effectiveness at level one includes:

i. Level one (observable) - shows that students are able to do what teachers ask them to do and observe what they are meant to observe.

ii. Level one (idea) - refers to students' abilities to think about what they are doing and observe and use the ideas as intended by the teachers.

The effectiveness at level two includes:

i. Level two (observable) - refers to students' abilities to recall and describe the practical that they have conducted and observed.

ii. Level two (idea) - examines the students' abilities to discuss the conceptual ideas that the teachers present.

Based on the theoretical model of effectiveness developed by Abrahams and Millar (2008), it is possible to construct a $2 \times 2$ effectiveness matrix for the practical work conducted by the case study teachers. The matrix was constructed based on the learning outcomes of the lesson as stated in the curriculum specification:

i. A student is able to explain the process of absorption of the products of the digestive system.

ii. Make inferences about the absorption of glucose through a Visking tube (MOE, 2002c, p. 24).

The first learning outcome relates to the domain of ideas and the second to the domain of the observable. The effectiveness matrix for this practical work is shown in Table 7-5. 
Table 7-5: The effectiveness matrix to investigate the absorption of glucose through the Visking tube

\begin{tabular}{lll}
\hline $\begin{array}{l}\text { Intended learning } \\
\text { outcome }\end{array}$ & The domain of observable & The domain of idea \\
\hline $\begin{array}{l}\text { Level } 1 \text { (what students } \\
\text { do) }\end{array}$ & $\begin{array}{l}\text { The students can follow the } \\
\text { instruction in setting up the } \\
\text { model to investigate the } \\
\text { absorption of glucose through a } \\
\text { Visking tube. }\end{array}$ & $\begin{array}{l}\text { The students can make an } \\
\text { inference about the absorption of } \\
\text { glucose through the Visking tube, } \\
\text { due to the smaller size of glucose } \\
\text { molecules when compared to the } \\
\text { larger size of starch molecules. } \\
\text { They can explain the representation } \\
\text { of the materials and equipment and } \\
\text { the actual digestive system } \\
\text { process. }\end{array}$ \\
\end{tabular}

Level 2 (what students learn)
The students can state the steps to build a model. They can explain the reasons for performing the steps.
The students can relate the results of practical work with the actual absorption process that occurred in the human digestive system. They can explain that only the digested food can be absorbed into the bloodstream before it is transported to other parts of body.

The data to analyse the level one effectiveness was gathered through classroom observation and spontaneous conversation with students while they conducted the practical, whereas the data to examine effectiveness level two was gathered from focus group interviews and students' reports. A new category was created (discussed later in this chapter) because some students were unable to demonstrate that they could follow the procedure, or use, think, or learn from the ideas that they were presented. A new level zero is proposed and is incorporated into the framework.

Level one referred to students' actions while engaged with practical work and was related to their actions in the 'students' practical activity phase' especially in stating materials and equipment, setting up the model, following procedure, and recording the data. It seemed that the practical work was moderately effective at level one (observable). There were a few occasions in the classroom when students showed they had achieved certain aspects of level one (observable). Firstly, from classroom observation, all the focus group students were aware of the equipment and materials required for practical work. For example in TR's lesson, it was clear that the focus group students (group R) knew the equipment they needed for the 
practical as they managed to bring almost all of it along with the materials to their bench. One student (R1) was able to see which materials they forgot and realised that they did not have a Visking tube. Similarly, group M and group J brought materials such as the Bunsen burner, the test tube rack, and the test tube holder to their bench.

Secondly, the students could follow certain steps in setting up the model. All focus groups showed that they could set up the apparatus especially in preparing the Visking tube. For example, J3 managed to give the instructions to her group members ( $\mathrm{J} 1$ and $\mathrm{J} 5$ ) on how to add both solutions (glucose and starch solutions) to the Visking tube correctly. Similarly, in group R, R1 could see the mistake that R5 made in adding solutions to Visking tube and explained that R5 should add starch or glucose solutions to the Visking tube instead of distilled water. M4 and M5 worked together to add starch and glucose solutions to the Visking tube without TM's assistance. It seemed that the focus group students managed to prepare the Visking tube successfully as intended by the teachers because:

i. The steps to prepare the Visking tube with both solutions were fully explained verbally in the pre-practical phase by teachers.

ii. The teachers demonstrated the steps to add both solutions to separate Visking tubes or a similar Visking tube in the pre-practical phase or while the students began to do practical work in groups.

iii. The steps to prepare the Visking tube were highly structured, simple and required basic non-scientific skills.

Thirdly, the students showed some weaknesses when completing the practical work procedure, as even though the teachers provided the procedure, it seemed that the students did not follow it as stated in the textbook, the hand-out, or as verbally explained by the teachers, and the students were unable to follow the instruction correctly. From the classroom observation of TJ's lesson, some students asked the teacher, the researcher, or their peers what to do and what they needed for the task, after TJ had explained the steps of the procedure and the required materials. For example, a female and male student both asked questions about what they were supposed to do to the rest of the class who also wanted to conduct their practical work. A similar situation happened in TR's lesson, where the students asked about the steps just after TR had explained each step of the procedure in the prepractical phase, and realising that the students did not appear to understand the instructions, he demonstrated how to perform the task. In TM's lesson, no student referred to the 
instructions they had written in their experiment book and some relied on TM's instruction to set up the apparatus.

Fourthly, during observation there was further evidence to show that students did not achieve level one (observable) in following the procedure. Some of them performed their own version of the procedure and did not refer to the textbook or to the teachers' instructions to complete the task. J3 added distilled water to two separate test tubes, and added lodine solution to the first and Benedict's solution to the second and said she was simply copying other students' work. In TR's lesson, the student (R1) added distilled water to the Visking tube instead of glucose and starch solutions and group $\mathrm{M}$ also made a similar mistake preparing the Visking tube, because M3 added distilled water to it. It seemed that the students did not follow the procedure to test the presence of glucose and starch solutions. All the focus group students conducted lodine and Benedict's tests at the beginning but none of them repeated either test at the end of the practical. The students might not be able to perform the procedure as intended by teachers because:

i. They did not understand the instructions. It was observed that they did not refer to the written instructions or ask the group representative how to set up the apparatus.

ii. The teacher (TJ) did not give clear instructions to the whole class.

iii. The students did not refer to the group representative (Group J) before they conducted practical work.

Level two (observable) refers to students thinking about their actions in the 'the practical activity phase'. The data was drawn from classroom observations while students engaged with practical work, when the teachers explained the steps, from spontaneous conversation while students conducted practical work in groups, and from focus group interviews. It seemed that practical work was moderately effective at level two (observation). There was a lack of evidence to support that students knew how and why they were meant to follow detailed procedures and they were unable to state the aims of doing the practical task. In the focus group interview with Group $M$, the students were unable to state the aims of the practical correctly: 
Researcher: What is the aim of conducting the practical task in the first place?

M2: To investigate the presence of starch and glucose.

(Group M focus group interview, 05/05/2011)

Similarly, Group J had difficulty stating the aim of practical work correctly:

Researcher: What is the aim of the previous practical task?

J3: To investigate the presence of glucose.

(Group J focus group interview, 31/03/2011)

Group $\mathrm{R}$ was able to state the aim of the practical correctly because they referred to practical work reports before answering the researcher's question:

Researcher: What is the aim of conducting the practical task in the first place?

R1: To investigate the presence of protein and carbohydrate, right?

(R1 opened the experiment book).

R1: To show that the glucose could diffuse from the Visking tube.

(Group R focus group interview, 28/04/2011)

Some students demonstrated that they were unable to recall all the steps and identify all the materials they used in the practical. However, some students were able to partially recall the procedure and the steps but not in the correct order. In the focus group interview, group $\mathrm{J}$ demonstrated that they were unable to accurately recall the steps or identify the materials they had used:

Researcher: Do you remember the steps you followed to conduct the practical in the previous practical lesson?

J5: Firstly, I took the plastic.

Researcher: What do you mean by 'the plastic'?

J3: It's a Visking tube.

Researcher: What did you do with the Visking tube?

J3: We poured the glucose solution followed by the starch solution into the Visking tube, tied both ends and immersed it in the test tube that contained distilled water. Then we put it in the water bath.

(Group J focus group interview, 31/03/2011)

Although the students could recall some of the steps in the procedure correctly, they created their own version of it, and one that they had not performed in the previous lesson. The focus group interview with group $\mathrm{R}$ showed how they explained these steps: 
R1: Firstly, tie one end of the Visking tube. Then add starch solution.

R2: Then tie the other end of the Visking tube with cotton thread. Rinse the Visking tube with distilled water.

R4: Then immerse the Visking tube into the boiling tube that contained distilled water.

R5: We repeated similar steps for the glucose solution.

R4: Then we boiled both boiling tubes in the water bath. The temperature of the water bath was $37^{\circ} \mathrm{C}$.

(Group R focus group interview, 28/04/2011)

Group M demonstrated that they were unable to recall the steps of the practical work correctly, despite the fact that TM had provided detailed instructions in a lecture, a demonstration, and had made the students write the instructions in their experiment books beforehand. The following quote shows the students' responses in the focus group interview when they were asked to explain the steps of the practical they had performed:

\footnotetext{
Researcher: Can you describe the steps to conduct the practical task to investigate the absorption of the digestive food through the Visking tube? M3: I can't recall the steps.

Researcher: Why?

M3: There were lots of steps. I can't remember them all.

Researcher: But TM already explained the steps before you conducted the experiment.

M1: Yes, that was true, teacher. But, we were really confused. We made lots of mistakes.

Researcher: What kind of mistakes?

M1: We did not follow the instruction correctly. We prepared more than one Visking tube.
}

(Group M focus group interview, 05/05/2011)

There were a few instances in the classroom that showed students understood the rationale of following certain steps. Some of the reasons they gave for this were aligned with the scientific explanation. It seemed that they could explain the reasons for performing certain steps of the practical work correctly. In TJ's lesson, J1 explained the reason she tied the Visking tube as hard as she did:
$\mathrm{J1}: \mathrm{J} 3$, is this enough?
J3: I don't know. Just cut it.
(J1 cut some of the thread. She tied one end of Visking tube).
J1: I'll tie it tightly. Hehehe. (She laughed) So it won't leak.

(The observation note, 28/3/2011)

Most students demonstrated that they did not know the reasons for conducting certain steps. For example, in TM's post lesson activity, the students demonstrated that they had 
misunderstood the reasons for heating the mixture of Benedict's and glucose solutions in conducting the Benedict's test, although they were able to state the results of the test correctly. Similarly, in the focus group interview, it was obvious that group M did not know the reason for conducting the tests, as they were unable to make sense of their actions and some of them had misconceptions, which became apparent when they explained their reasons for performing the steps:

Researcher: So why did you immerse the test tube that contained the mixture of Benedict's and glucose solutions?

M2: To test the presence of starch and glucose in the test tubes.

M1: TM told us to do so

(Group M focus group interview, 05/05/2011)

The focus group interview with group $\mathrm{J}$ also highlighted that they had misunderstood and did not know the reasons for conducting the lodine test. They explained:

J1: To observe whether the starch solution could not mix or not... Researcher: What do you mean by the starch solution could not mix? J1: Well, when we immersed the test tube in the water bath...then we observed whether the starch solution could or could not diffuse from the Visking tube.

(Group J focus group interview, 31/03/2011)

Group R also demonstrated that they had misunderstood the purpose of the steps they followed and could not explain the reasons for maintaining the temperature at $37^{\circ} \mathrm{C}$. For example:

Researcher: Why did you have to maintain the temperature at $37^{\circ} \mathrm{c}$ ? R1: Uhm. Because the temperature of our body is $37^{\circ} \mathrm{C}$.

(Group R focus group interview, 28/04/2011)

It seemed that practical work was ineffective at level one (ideas). Firstly, there was limited evidence of scaffolding from the teachers to help students think about the factors that might affect the absorption process. All the teachers highlighted the size of the molecules that affected the absorption of glucose through the Visking tube. The teachers TM, TR, and TJ highlighted the factors that affected the absorption of glucose through the Visking tube at the pre-practical and post-practical phases, and identified the size of the glucose molecules as one factor affecting the absorption process. In TJ and TR's lessons, they explained the reasons why glucose solution could diffuse from the Visking tube by using diagrams they drew on the whiteboard. TM gave a verbal explanation of the factors that might affect the absorption 
of glucose, but although the teachers stated the factors, there was limited evidence to show that the students related the absorption of glucose through the Visking tube to the size of the glucose molecules.

It seemed that the teachers did not involve the students in making inferences based on the results. It seemed that teachers focused on getting the students to produce the desired results rather than using the intended scientific ideas. There were a few occasions where the teachers missed opportunities to involve the students in thinking about the results they had produced. It seemed that the focus group students (group $\mathrm{J}$ and group $\mathrm{R}$ ) got positive results when they conducted the Benedict's test at the beginning of practical work, but they did not reflect on their results. In TR's lesson, when a focus group student shared his results with the class, it appeared that they were not the expected results. The teacher offered the possible reasons why they had produced such results and could have enhanced student understanding by asking them to explain their theory first.

The teachers could have used the opportunities that arose during the post practical phase to engage students in using scientific ideas to understand the objects and materials they had manipulated. All teachers highlighted the representation of the model of the human digestive system in the post-practical phase but the opportunity to relate how the model they constructed in the laboratory was related to the actual human digestive system was largely lost. Often the questions asked in TM's lesson were rhetorical questions. There were differences in the way the three teachers approached the explanation of the model. While TJ and TR highlighted the representation of the Visking tube in the model as villi in the human small intestine the role of the materials used in the model was not clearly defined. In TR's lesson students were given the notes about the model which told the students the functions of the different materials before they set up the model. It seemed that the students did not have opportunity to consider the function represented by the materials used in the model they had constructed.

It seemed that the practical work was also ineffective at level two (ideas). The teachers did not relate the model to the absorption process in the human digestive system. In the post-practical phase, TM concluded the practical work by asking students to state the results of the Benedict's and iodine tests, but she did not allude to the results of the actual human digestive system absorption process. Similarly, TJ and TR also highlighted the results of both tests without asking the students to reflect upon their practical work, which might affect their understanding of the concepts. 
In the focus group interviews, some of the students showed they did not learn the intended scientific concept. Although they were able to recall the initial and final results of both tests, they lacked the ability to make sense of the results of their practical task. For example:

Researcher: What were your initial observations of the Benedict's test and the lodine test?

J4: For the Benedict's test, the colour remained blue and the lodine test, the colour is yellowish.

Researcher: What does it mean?

(The students did not respond to my question).

Researcher: What is your final observation?

J2: The lodine test, the colour is yellowish and for the Benedict's test, the colour is orange.

J4: No, the colour is red.

Researcher: What does it mean?

(The students did not respond to my question)

(Group J focus group interview, 31/03/2011)

The students were also unable to relate the materials they were using to the scientific concept, i.e. the concept of absorption in the small intestine. The students seemed to lack understanding of the scientific ideas behind the human digestive system process.

Researcher: Okay, how do we relate the results to the absorption of glucose in the human digestive system?

R1: Glucose is sugar, isn't it? It means that glucose can...(R1 did not continue).

R2: The glucose cannot diffuse from the skin.

Researcher: Skin?

R4: It is about sugar in blood. The blood can diffuse from small intestine...

(Group R focus group interview, 05/05/2011)

Group $\mathrm{M}$ were unable to link some of the materials used in the practical with the organs involved in the absorption process. They were also unable to draw conclusions from doing this practical task about how the process of absorption takes place.

M2: Starch could not diffuse from the Visking tube because it is larger compared to glucose.

Researcher: How do you relate this information to the human digestive system?

M2: The Visking tube is the small intestine and water represents the blood stream.

Researcher: How about glucose solution?

M3: It is replaced with lodine. Hang on. No it's not. It replaced the Benedict's solution.

M1: I give up, teacher.

(Group M focus group interview, 05/05/2011) 
The practical work that teachers carried out was moderately effective at level one (observable) but less effective at level one (ides), level two (observation), and level two (ideas). It seemed that throughout the practical work, the focus was on the domain of observation as opposed to the domain of ideas. Students spent more time in manipulating the objects to build up the model rather than learning the scientific concepts. Although the teachers did highlight the concepts they wanted the students to learn during the lecture, there was limited evidence that showed what students had learnt. As a result, most of the focus group students were unable to relate the results they had from the procedure with the intended scientific concept, although they could recall the results correctly.

\subsection{Summary of the chapter}

All case study teachers conducted the practical work in slightly different ways, but shared similarities in the way they planned their lessons. All practical work was suggested in the science curriculum specification and TR used the suggested practical work from the textbook (Tong \& Neo, 2003) and TM used the experiment book (Kheng \& Yassin, 2005) as guidance for planning practical lessons. TJ did not use any of the resources to plan the practical lesson but aligned the task with the curriculum specification.

It seemed that all teachers focused on the steps students should follow, instead of the reasons why. They used 'recipe practicals' and demonstrations to structure their practical lessons by providing all the necessary information including materials, procedures, tables to record results, sets of analysis questions, and a closing exercise to conclude tasks. The teachers seemed to play a dominant role in the classroom to ensure that students completed the tasks as they intended, yet despite this detailed presentation, the students showed a lack of understanding of the investigation.

The teachers were concerned to communicate the concepts that students should learn and highlighted specific concepts either inductively or deductively. TM and TR highlighted the concepts before they introduced the procedures for the practical work, whereas TJ highlighted these concepts before the students had the chance to conduct the investigation, and before they were able to observe the results of the demonstration. It seemed that the teachers used tools other than the results to explain the concepts and played an important role in verbally helping the students to make sense of their results. The students seemed to infer/deduce these concepts in a number of ways, including observation of the practical experiment and teacher instruction. The approaches the teachers took to deliver the instruction and teach the 
concepts might have helped the students to develop conceptual and procedural knowledge. They were able to follow the steps and memorise the results or concepts in the classroom without necessarily understanding why they were following such steps, or what the results meant. 


\section{Chapter 8: The Teachers' Questions in Practical Lessons}

\subsection{Introduction}

The aim of this study is to gain an insight into the issues related to the teaching and learning of science through practical work by exploring interaction in the classroom and the flow of the lesson. Three different lessons from TM, TJ, and TR in two learning situations suggested in the curriculum document (MOE, 2002a) are analysed. Each teacher had a slightly different pattern of communication, and they all used English and Malaysian when doing practical work, which varied in duration and purpose. The teachers' approaches to teaching concepts, delivering instructions, and making sense of concepts through practical work will be presented in the following section.

\subsection{TM's lesson: The characteristics of sound}

The learning objective of TM's practical lesson was Understanding Sound and Hearing (MOE, 2002a, p. 20). The learning objective is part of the learning area The World through Our Sense. The students' learning outcome was to Describe the Properties of Sound by the end of their practical work. The teacher prepared a set of apparatus for the students and began the practical lesson by asking questions to recall the concepts related to the production of sound that students had learned in the previous lesson. Later she related the production of sound to the need to hear sound before explaining the procedure for the investigation in a demonstration to the whole class. She planned to do the demonstration herself because there were insufficient materials and equipment to allow all students to do an investigation on their own. She also explained the steps in setting up the apparatus and involved students to help make sense of the phenomenon they observed and relate them to the concepts. The approaches she used when conducting practical work will be presented in the following section.

\subsubsection{Introducing the concept}

In TM's lesson, the student-teacher interaction focused on introducing the scientific concepts. It was common practice for TM to introduce these before she allowed students to do the task in groups or individually. In one observed lesson, she engaged students with a lecture on sound before she asked a series of questions that required them to reflect on the concepts of the production of sound that they had been taught before she embarked on the characteristics 
of sound. For example, at the beginning of the lesson TM asked questions regarding the production of sound before she demonstrated the characteristics of sound. TM had two tasks planned, the first was to investigate how sound travels and the second, was to study the absorption and reflection of sound. She simplified the transformation of energy from kinetic to sound by showing the equation of the transformation of energy as shown in Figure 8-1. She also wrote the following notes on the board before the students arrived at the laboratory:

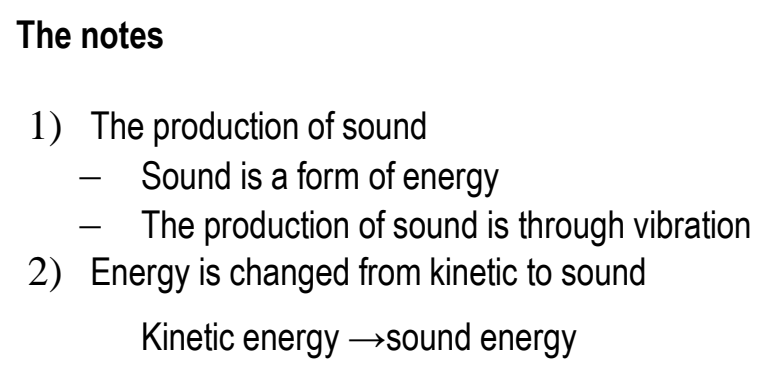

1) The production of sound

- Sound is a form of energy

- The production of sound is through vibration

2) Energy is changed from kinetic to sound

Kinetic energy $\rightarrow$ sound energy

Figure 8-1: TM's notes about the production of sound energy on the whiteboard.

Vignette one shows the discourse between students and TM in the lesson on the concept of the production of sound before she explained the characteristics of sound. Vignette one is presented in Table 8-1. 
Table 8-1: Vignette 1.

\begin{tabular}{|c|c|c|c|}
\hline Turn & Speaker & Utterance & Observation \\
\hline 1. & TM & $\begin{array}{l}\text { Last Monday [she paused]; we did the practical } \\
\text { related to the production of sound [her voice } \\
\text { began to rise in volume]. Sound is a form of } \\
\text { energy [her voice remained loud]. The sound is } \\
\text { produced through vibration. What is vibration? } \\
\text { [She asked the question loudly]. }\end{array}$ & $\begin{array}{l}\text { TM stood at the front of the class. } \\
\text { The students remained in their } \\
\text { places. TM gave the instruction in } \\
\text { English. She pointed to the notes } \\
\text { she had written on the board. }\end{array}$ \\
\hline 2. & $\mathrm{~m} 13$ & $\begin{array}{l}\text { Vibration is 'getaran' [she answered in a loud } \\
\text { voice]. }\end{array}$ & $\begin{array}{l}\text { M3 translated the word vibration } \\
\text { in Bahasa Malaysia. She } \\
\text { answered the question promptly. }\end{array}$ \\
\hline 3. & TM & $\begin{array}{l}\text { Correct [she said loudly]. Objects must vibrate to } \\
\text { produce the sound [she paused]. How has the } \\
\text { sound energy produced? [she asked the question } \\
\text { loudly]. Transmission [she said slowly]. }\end{array}$ & $\begin{array}{l}\text { TM took a short pause after she } \\
\text { said the word 'Transmission'. She } \\
\text { explained in English. }\end{array}$ \\
\hline 4. & Students & Kinetic energy to sound energy. & $\begin{array}{l}\text { The students answered the } \\
\text { question together. They } \\
\text { answered the question promptly } \\
\text { in English. }\end{array}$ \\
\hline 5. & TM & $\begin{array}{l}\text { What is the meaning of the transmission of } \\
\text { sound? [she asked in a loud voice]. }\end{array}$ & TM asked the question in English. \\
\hline 6. & M5 & Permindahan & $\begin{array}{l}\text { M5 answered the question in } \\
\text { Bahasa Malaysia. She answered } \\
\text { promptly. }\end{array}$ \\
\hline 7. & TM & $\begin{array}{l}\text { Transmission of sound [she paused]. } \\
\text { Permindahan bunyi [she translated in Bahasa } \\
\text { Malaysia]. For example, the objects vibrate so } \\
\text { you can hear the sound [she paused]. Sound } \\
\text { needs a medium to travel. So what is medium? } \\
\text { [she asked in a high volume]. }\end{array}$ & $\begin{array}{l}\text { TM used both languages. } \\
\text { She paused after she asked the } \\
\text { question. }\end{array}$ \\
\hline 8. & M1 & Not too small or too big [she said in a soft voice]. & $\begin{array}{l}\text { She gave the answer in Bahasa } \\
\text { Malaysia. There is no response } \\
\text { from other students. }\end{array}$ \\
\hline 9. & TM & $\begin{array}{l}\text { Medium is bahan tara. So, the sound can travel in } \\
\text { solid, liquid, and gas. What is the example of } \\
\text { medium in this laboratory? [she asked in a rising } \\
\text { voice]. }\end{array}$ & $\begin{array}{l}\text { She translated the meaning of } \\
\text { 'medium' and asked the question } \\
\text { in Bahasa Malaysia. }\end{array}$ \\
\hline 10 & Students & Table [they said in a high volume]. & \\
\hline 11 & Students & Chairs. & \\
\hline
\end{tabular}

Vignette one shows that TM conducted the whole class discussion on the characteristics of sound. She introduced the facts and questions concurrently (turns three, seven, and nine). The nature of TM's statements and questions (turns one and five) showed how she focused 
on scientific facts with the purpose of developing students' conceptual knowledge. She stated the scientific facts to the whole class about a topic they had been taught in the previous lesson, and followed with questions related to the topic. For example, in turn one she stated, sound is a form of energy, and it is produced through vibration of objects. After these statements, she asked the students to define the term 'vibration', which they had learned in the previous lesson. In turn one, she also asked the students a question to make the connection to the previous scientific concept learnt before they embarked on the current topic.

A series of TM's questions appeared to invite different responses from students. It seemed that the students gave a single answer without further explanation. In some questions, students engaged in translating the term from Bahasa Malaysia to English instead of defining the term. For example, TM stated that the production of sound is a form of energy. The sound is produced through vibration (turn one). Following this statement she asked, What is vibration? One of the students (M13) translated the term vibration into Bahasa Malaysia as getaran. This knowledge might have come from personal experience or a previous lesson.

TM asked questions that had the potential to engage the students in explaining the term. The students gave both correct and incorrect responses. In turn seven, TM asked the students to define the term medium by asking the following question, So what is medium? Student M1 defined it by clothes' size. She explained, Not too small or too big. She had given a correct definition, but the definition was not suitable for the current context. Although M1 did not give her response loudly enough for the other students to hear, her response and attempt to explain the term shows she tried to engage with the lesson.

TM also used different ways of asking questions when teaching the characteristics of sound. The previous two questions had the potential to engage students and encourage them to recall and explain their answers. For example, in asking students to state the meaning of transmission she says, Objects must vibrate to produce sound. How is sound energy produced? She makes a statement first and then follows it with a question. In response to the student's answer in turn two, she paused for a few seconds before she said the word transmission loudly, after no students answered the question. Immediately after she stated the term transmission some students gave the following answer, kinetic energy to sound energy. Their responses referred to the transformation of energy instead of the transmission of energy. It appears that the students managed to structure their answers after TM asked questions using the students' responses, TM provided feedback. 
Turn three shows the response TM gives to the students' answers. Firstly, she acknowledged them by saying correct in a loud voice followed by a comment on their answers. Later she built on this knowledge by asking a fill in the blank question based on the previous statement and then commented on the response and asked a question. She accepted the students' answers by repeating the answers in English and Bahasa Malaysia before she asked other questions to extend the discourse. For example, in turn six, student M5 translated the meaning of transmission into Bahasa Malaysia as permindahan when TM asked the following question (turn five), What is the meaning of the transmission of sound? Based on the students' response she repeated the term transmission of sound in English and then in Bahasa Malaysia as permindahan bunyi. She then stated, For example, the objects vibrate so you can hear the sound. Sound needs a medium to travel. She did not give the actual definition, but she used an appropriate example to state the meaning of the transmission of sound. When giving feedback later she asked, So what is medium? This has the potential to expand the students' thinking.

TM appeared to react neutrally to silence from the students, although she provided time for students to respond. She continued the lesson by telling students the correct answers and giving explanations, she then asked another question based on the previous statement. For example, in turn eight, the majority of students in the laboratory did not respond when she asked the meaning of medium. Student M1 referred to the term medium in terms of the size of clothes, but she did not verbalise the answer publicly. In turn nine, TM translates the term medium into Bahasa Malaysia, Bahan tara. Based on the translation, the students managed to identify the meaning of medium as relevant to the laboratory. In response to the silence, TM gave the correct answers, followed by a supporting statement. It appeared that her feedback had the potential to help the students reflect on different types of meanings of the term medium. She also attempted to make a connection between previous concepts and the current topic.

\subsubsection{Instruction for practical work}

TM planned two demonstrations to teach the characteristics of sound. While setting up the apparatus, she created opportunities to teach procedural skills to the students. In the demonstration, she introduced the materials before she explained how to perform the task. She taught the functions of materials using questions because the students could not 
manipulate the objects to produce the phenomenon due to lack of availability of the equipment and apparatus. Vignette two shows TM's demonstration to the first group in Table 8-2.

Table 8-2: Vignette 2.

\begin{tabular}{|c|c|c|c|}
\hline Turn & Speaker & Text & Observation \\
\hline 1. & $\mathrm{TM}$ & $\begin{array}{l}\text { This is the vacuum pump [said softly]. So what is } \\
\text { the function of the vacuum pump? [Asked in a } \\
\text { rising voice]. }\end{array}$ & $\begin{array}{l}\text { She pointed at the vacuum } \\
\text { pump. }\end{array}$ \\
\hline 2. & $\mathrm{~m} 6$ & To suck the air [answered the question loudly]. & $\begin{array}{l}\text { He answered the question } \\
\text { promptly. }\end{array}$ \\
\hline 3. & $\mathrm{TM}$ & $\begin{array}{l}\text { Correct [said in a rising voice]. } \\
\text { To suck the air from the bell jar [short pause]. } \\
\text { M9 [called M9 with a firm voice]. Be quiet [voice } \\
\text { remained high]. Listen to me. Ok [voice remained } \\
\text { loud]. Now the air has not been sucked from the } \\
\text { bell jar yet. Why can you still hear the sound? } \\
\text { [asked loudly]. }\end{array}$ & $\begin{array}{l}\text { The students stood closer to } \\
\text { the apparatus. She stated } \\
\text { feedback in Bahasa Malaysia, } \\
\text { but she asked the question in } \\
\text { English. }\end{array}$ \\
\hline 4. & $\mathrm{~m} 7$ & [The] battery [is] on [answered loudly]. & $\begin{array}{l}\text { He answered the question } \\
\text { quickly in English. }\end{array}$ \\
\hline 5. & TM & $\begin{array}{l}\text { No [short pause] it is related to the sound [pause]. } \\
\text { Ok [pause] now can you hear the sound? [Asked } \\
\text { loudly]. }\end{array}$ & $\begin{array}{l}\text { TM turned on the vacuum } \\
\text { pump. She asked the question } \\
\text { in Bahasa Malaysia. }\end{array}$ \\
\hline 6. & m6 & $\begin{array}{l}\text { Ah ah I can hear but it is very low [he responded in } \\
\text { a cheerful voice] teacher [said loudly]. }\end{array}$ & $\begin{array}{l}\text { He stated the answer in } \\
\text { Bahasa Malaysia. He stood } \\
\text { closer to the bell jar. }\end{array}$ \\
\hline 7. & TM & $\begin{array}{l}\text { So when you turn on the electrical bell and turn off } \\
\text { the vacuum pump, the sound of the bell is [said in } \\
\text { a rising voice]. }\end{array}$ & $\begin{array}{l}\text { She stated the instruction in } \\
\text { English. }\end{array}$ \\
\hline 8. & M11 & 'is hear'. & $\begin{array}{l}\text { M11 completed the sentence, } \\
\text { but he used the wrong word. }\end{array}$ \\
\hline 9. & $\mathrm{TM}$ & $\begin{array}{l}\text { No [said in a soft voice] it should be [short pause] } \\
\text { is heard not is hear [she highlighted the word } \\
\text { heard]. Ok, ok now I turn on the vacuum pump } \\
\text { [pause]. The air is pumped out the air from the bell } \\
\text { jar [loudly]. What happened to the sound? [loudly]. }\end{array}$ & $\begin{array}{l}\text { TM provided the correct } \\
\text { answer. She gave the } \\
\text { instruction in Bahasa Malaysia } \\
\text { but she asked the question in } \\
\text { English. }\end{array}$ \\
\hline 10. & Students & $\begin{array}{l}\text { The sound cannot be heard [the students } \\
\text { answered loudly]. }\end{array}$ & $\begin{array}{l}\text { The students answered } \\
\text { together. }\end{array}$ \\
\hline 11. & $\mathrm{TM}$ & $\begin{array}{l}\text { The sound becomes softer and softer and finally } \\
\text { cannot be heard. The bell jar is in a vacuum. Ok, } \\
\text { now go back to your places and complete the } \\
\text { reports. Next group. Hurry up girls [said loudly]. }\end{array}$ & \\
\hline
\end{tabular}

In Vignette two, TM explains the function of the materials before she demonstrates to a small group. She demonstrates first to a group of male students and second to a female group. The demonstration was given after she explained to the whole class how sound travels. During the 
demonstration, she introduced some of the materials before explaining what would happen to the sound of the bell before and after the vacuum pump was turned on or off. TM directly involved the students in the demonstration by asking the students to state their observations through questioning.

Initially, it appeared that students did not interrupt the lesson while TM gave instructions on how to set up the apparatus and then followed it with questions. The first questions required the students to observe the function of the materials. She asked why and what and how and fill in the blank questions, and those that required yes or no answers to engage students with the demonstration. She structured the lesson by asking the why questions followed by fill in the blank questions. For example, in turn three she asks, Why can you still hear the sound? She asks the students to answer based on what they observe. In turn five, she asks the yes or no questions by checking with the students if they can hear the sound after they gave the wrong answer in turn three. Later, in turn seven, she asks a fill in the blank question, So when you turn on the electrical bell and turn off the vacuum pump, the sound of the bell is [..... It appears that she lowers the difficulty level of the questions each time students do not answer correctly, which might help them answer the questions but will not assist them in understanding the reasons behind it. The questions shaped the type of responses the students gave.

The students tended to give quick, short, single word answers, and sometimes they answered in English and sometimes in Bahasa Malaysia, this depended on the language TM used to ask the questions. The students elaborated their answers if TM asked the questions in Bahasa Malaysia. For example, in turn five, TM asks the students to state their observations, Now, can you hear the sound? Student $\mathrm{m} 6$ states the observation correctly and comments on the quality of the sound. He says, Ha ah I can hear, but it's very slow. The student gives a short answer if TM asks the question in English. For example, in turn three, TM asked the students to predict the reason why they could still hear the bell ring when the vacuum pump was switched off. Student M7 answered promptly, [The] battery [is] on. Student M7 was referring to the electrical circuit and did not answer the question with reference to the presence of air, which supported the propagation of sound, or any other factors that might cause the bell to still ring. It appeared that M7 translated the sentence from Bahasa Malaysia to English. The students also gave a single answer because TM had asked a fill in the blank question. For example, in turn seven, she said, So when you turn on the electrical bell and turn off the vacuum pump, the sound of the bell is [...]. Student M1 answered the question in English with, is hear. M1 attempted to 
answer the question in English but the answer was grammatically incorrect, which showed that the students not only observed the demonstration but also attempted to use English in their science lessons. In response to the students' answers, TM gave feedback not only on their use of language but also on their skills in making observations and predictions.

TM responded to the students' answers with a mixture of evaluation, commentary, and questions. TM evaluated incorrect answers by asking questions or giving comments. For example, in turn five, she responded to the incorrect answers by saying, No. She then commented, It's related to the sound as a clue that the answer was incorrect and that she wanted an answer related to sound. Finally, she asked, Ok. Now can you hear the sound? She engaged the students by making the observation after they were unable to predict the answer. TM's feedback seemed to shift the students' focus away from trying to predict the answer (i.e. the reason why they can still hear the sound) to observing it (i.e. whether they can hear the sound or not). TM also commented on the students' use of English. For example, in turn eight, student M1 says is hear. TM answers with, No before correcting this by saying, is heard not is hear. It seemed that her response may make the students aware of which tense is the correct one to use. In turn ten, the students corrected their own answers, The sound can't be heard.

When giving feedback on correct answers, TM also evaluated followed by a question. For example, in turn three, TM acknowledged student M6's answer by saying Yes and repeating the answer. Repetition of the students' answers was another strategy that TM used to evaluate. Then she said, Ok, now the air hasn't been sucked from the bell jar yet before she asked, why can you still hear the sound? This question is more difficult than the question she asked in turn one. The questions were different from the questions she asked in response to incorrect answers, as they were an attempt to probe and get more response from students while allowing them to explore the possible reasons why they could still hear the sound when the vacuum pump was switched off.

To conclude, in Vignette two, TM shows a model to help explain how sound travels. In the demonstration, she shows what happens to the electrical bell when the vacuum pump is switched off. She involved the students in the lesson through questioning and the questions she asked depended on the students' responses. It seemed that she made the questions easier if the students were unable to answer a challenging question and changed the format of the questions from why to what or fill in the blanks. The students answered what and fill in the 
blank questions easily with a single answer without further explanation that showed they understood.

\subsubsection{Making sense of the concept through practical work}

After the students had conducted a task, a discussion followed that allowed the students to make sense of the concept being taught and the phenomenon observed. TM continued the lesson by assisting the students in answering a set of four analysis questions. The answers for each were provided in the form of incomplete sentences and the students were required to fill in the blanks. There were also questions with yes or no answers and the students were asked to provide reasons why they made their choices. Each question tested a different cognitive process and some questions required students to describe their findings, suggest different materials to set up the apparatus and use the results to explain the phenomenon. Vignette three in Table 8-3 shows the student-teacher interaction in answering one of the analysis questions. 
Table 8-3: Vignette 3.

\begin{tabular}{|c|c|c|c|}
\hline Turn & Speaker & Text & Observation \\
\hline 1. & TM & $\begin{array}{l}\text { M2 [called student's name loudly], please answer the } \\
\text { third question. }\end{array}$ & $\begin{array}{l}\text { All the students sat at their } \\
\text { places quietly. } \\
\text { She gave the instruction in } \\
\text { Bahasa Malaysia. }\end{array}$ \\
\hline 2. & M2 & $\begin{array}{l}\text { Can sound travel in outer space? [Read in a soft voice]. } \\
\text { Give your reason [spoken softly; long pause].I don't } \\
\text { understand the question, teacher. }\end{array}$ & $\begin{array}{l}\text { M2 stood up before } \\
\text { answering the question. He } \\
\text { read the question, but } \\
\text { responded in Bahasa } \\
\text { Malaysia. }\end{array}$ \\
\hline 3. & $\mathrm{TM}$ & $\begin{array}{l}\text { First you have to answer whether it is correct or not } \\
\text { [said softly]. }\end{array}$ & $\begin{array}{l}\text { She helped students to } \\
\text { answer the question. She } \\
\text { responded in Bahasa } \\
\text { Malaysia. }\end{array}$ \\
\hline 4. & M2 & Yes. The sound can travel in outer space [said softly]. & M2 responded in English. \\
\hline 5. & TM & What is outer space? [Asked loudly]. & \\
\hline 6. & m6 & Udara luar. & $\begin{array}{l}\text { M6 answered the question } \\
\text { in Bahasa Malaysia. He } \\
\text { answered the question } \\
\text { promptly. }\end{array}$ \\
\hline 7. & TM & $\begin{array}{l}\text { 'Udara luar' is wrong [in a loud voice]. Outer space is } \\
\text { 'angkasa lepas' [voice remained loud]. Can you hear } \\
\text { the sound in outer space? [asked loudly]Why can't you } \\
\text { hear sound in outer space? [pause] }\end{array}$ & $\begin{array}{l}\text { TM gave the response in } \\
\text { Bahasa Malaysia. }\end{array}$ \\
\hline 8. & M6 & Because [voice remained low]. & He took a long pause. \\
\hline 9. & TM & $\begin{array}{l}\text { Outer space is a vacuum. It doesn't contain air. So } \\
\text { there is no medium that allows the sound to travel. The } \\
\text { answer is 'No, because the sound can't travel in a } \\
\text { vacuum condition. Write in your report. }\end{array}$ & $\begin{array}{l}\text { She gave the answer in } \\
\text { English. }\end{array}$ \\
\hline
\end{tabular}

The approach that TM used to initiate the discourse was quite different from the previous vignettes (one and two). She nominated the students to answer the analysis questions. For example, in turn one, she nominates student M2 to answer the third question. She says, M2, please answer the third question. TM nominating a student to answer the question changed the students' behaviour, they all sat at their places quietly, and nobody attempted to answer the question except M2. She answered the question in English.

M2 read the question before she attempted to answer the question in English. She read the question softly. She said, Can sound travel in outer space? Give your reason. M2 admitted that she did not understand the question. In response to M2's concern TM assisted her in answering the question without evaluating her initial response. 
None of the students in the class could answer the question correctly. TM did not give the correct answer immediately but moved on to the next question. TM used a different strategy to deal with incorrect answers. She did not evaluate students' responses promptly after student M2 failed to answer the third question correctly. She guided the students in answering the question by breaking it into two parts and provided a structure to answer the question. For example, she said, First you have to answer whether it is correct or not. This narrows the possible responses down to yes or no and lessens any stress due to language for the student and focuses them on answering the initial question.

Secondly, when dealing with incorrect answers, TM asked the students to define the terms used in the question. She asked the students to define the term outer space. It might help the students to understand the terms. However, student M6 gave the literal meaning in Bahasa Malaysia, udara luar. Student M6's answer was correct literally but irrelevant to the context of the question. The student's answer showed that he did not understand the question. TM then translated the meaning of outer space as angkasa lepas before she asked two questions, Can you hear sound in outer space? And Why can't you hear sound in outer space? After waiting for the students to reply, she explained why sound could not travel in outer space, Outer space is a vacuum. It does not contain air. So there is no medium that allows sound to travel. The answer is no, because sound cannot travel in a vacuum.

To conclude, TM used questions to make sense of the concept with the phenomenon that students observed in the demonstration. The analysis questions were different from the type of questions TM normally asked. She required students to compare the phenomenon they observed (i.e. the electrical bell in a vacuum jar) with a real world one (i.e. the nature of outer space). TM did not immediately evaluate the students' answers or give the correct answers but she engaged the students with a series of questions. These were what type questions and questions with a yes or no answer, which helped the students to participate in the discourse of the classroom. TM knew the students did not understand the term outer space, which could be one of the reasons why they were not able to answer the questions. In addition, there is no information about the nature of outer space in the textbook or the curriculum specification. The style of discourse changed when TM nominated a student to answer a question. The students volunteered to answer when TM asked questions of the whole class but when she nominated students to answer; it meant that those who rarely volunteered participated in the discourse. 


\subsection{TJ's lesson: The responses of plants to different stimuli}

TJ's lesson involved an investigation to study how plants responded to three different stimuli; to water, gravity and light (hydrotropism, geotropism, and phototropism). He planned three different tasks to investigate responses to each stimulus. He introduced the terms that represented the plants' responses before he gave the instruction to set up the apparatus and then conducted a demonstration to a small group of representatives from each practical group and then those representatives helped their groups to carry out the practical task. He communicated the concepts that students should learn from the task before they observed the results.

\subsubsection{Introducing the concept}

TJ taught the practical lesson, which included a series of tasks to investigate how plants respond to different stimuli such as light, water, and gravity. The first task looked at how plants responded to water, the second at the response to gravity and the third, to light. He introduced the terms to the whole class before he discussed the procedure they should follow. Table 8-4 shows Vignette four on the student-teacher interaction in defining the terms that represent the plants' responses and how TJ introduced the terms by breaking them down into two parts (prefix and suffix). 
Table 8-4: Vignette 4.

\begin{tabular}{|c|c|c|c|}
\hline Turn & Speaker & Utterance & Observation \\
\hline 1. & TJ & $\begin{array}{l}\text { So [said loudly] there are three types of tropisms } \\
\text { [he paused] hydrotropism [he paused] geotropism } \\
\text { and phototropism [said loudly]. }\end{array}$ & $\begin{array}{l}\text { He stood in front of the class. } \\
\text { Then he walked slowly to the } \\
\text { first row. He said the terms } \\
\text { quickly. } \\
\text { He gave the instruction in } \\
\text { Bahasa Malaysia. }\end{array}$ \\
\hline 2. & TJ & $\begin{array}{l}\text { Remember the words at the beginning [he paused] } \\
\text { hydro [paused] geo and photo [said loudly]. } \\
\text { The word tropism is similar at the end of the term } \\
\text { [said loudly]. }\end{array}$ & $\begin{array}{l}\text { He stood in the third row. } \\
\text { The students sat in their } \\
\text { places. } \\
\text { He gave the instruction in } \\
\text { Bahasa Malaysia. }\end{array}$ \\
\hline 3. & TJ & $\begin{array}{l}\text { Last year [he paused] sorry last two years [he } \\
\text { paused] there were questions about hydro, photo, } \\
\text { and geotropism [TJ loud]. } \\
\text { So remember this (the terms) [he paused and } \\
\text { stressed the phrase] hydro [pause], what is hydro? } \\
\text { (Hydro itu apa) [Asked loudly]. }\end{array}$ & $\begin{array}{l}\text { The students did not interfere } \\
\text { as TJ continued with the } \\
\text { lecture. The students } \\
\text { remained quiet at their } \\
\text { places. } \\
\text { He walked back to the second } \\
\text { row. } \\
\text { He asked the question in } \\
\text { Bahasa Malaysia. }\end{array}$ \\
\hline 4. & Students & Air [the students say softly]. & $\begin{array}{l}\text { The students answered } \\
\text { promptly after TJ posed the } \\
\text { question. } \\
\text { The students gave the } \\
\text { answer in Bahasa Malaysia. }\end{array}$ \\
\hline 5. & TJ & What is hydro? [Asked loudly]. & $\begin{array}{l}\text { TJ repeated the question in } \\
\text { Bahasa Malaysia. }\end{array}$ \\
\hline 6. & Students & $\begin{array}{l}\text { Air (water) [the students answered the question } \\
\text { loudly]. }\end{array}$ & $\begin{array}{l}\text { More students answered the } \\
\text { question in Bahasa Malaysia. } \\
\text { They answered the question } \\
\text { in turn five louder compared } \\
\text { to turn four. }\end{array}$ \\
\hline 7. & TJ & $\begin{array}{l}\text { Yes [he said loudly]. Hydro [he stressed the word } \\
\text { hydro] is water. It is like hydroelectric. We generate } \\
\text { electric from water [paused]. }\end{array}$ & $\begin{array}{l}\text { He stood in front of the class. } \\
\text { He explained the meaning of } \\
\text { hydro in Bahasa Malaysia. }\end{array}$ \\
\hline 8. & TJ & Geo [said loudly]. & \\
\hline 9. & J4 & Gravity [answered loudly]. & $\begin{array}{l}\text { The student responded with } \\
\text { the answer promptly. }\end{array}$ \\
\hline 10. & Students & Gravity [the students answered promptly]. & $\begin{array}{l}\text { They gave the same } \\
\text { responses. }\end{array}$ \\
\hline 11. & TJ & Photo [said loudly]. & He said promptly. \\
\hline 12. & $\mathrm{~J} 7$ & Gambar (picture) [answered loudly]. & $\begin{array}{l}\text { Some students stopped } \\
\text { writing, and some students } \\
\text { completed their reports. }\end{array}$ \\
\hline
\end{tabular}




\begin{tabular}{|c|c|l|l|}
\hline & & & $\begin{array}{l}\text { He gave the answer in } \\
\text { Bahasa Malaysia. }\end{array}$ \\
\hline 13. & TJ & $\begin{array}{l}\text { If you take photos you see the flash (Kalau kamu } \\
\text { ambil gambar kamu akan nampak flash) [pause] } \\
\text { What is flash? [Answered loudly]. }\end{array}$ & $\begin{array}{l}\text { He stood at the front bench. } \\
\text { He made the statement in } \\
\text { Bahasa Malaysia and asked } \\
\text { the question in English. }\end{array}$ \\
\hline 14. & J8 & The flash is cahaya [Answered loudly]. & $\begin{array}{l}\text { She gave the response } \\
\text { promptly in both languages. }\end{array}$ \\
\hline 15. & TJ & $\begin{array}{l}\text { So the meaning of phototropism is cahaya. [Said } \\
\text { softly but also loud enough to be heard by } \\
\text { students]. } \\
\text { Please memorise the terms [pause] photo means } \\
\text { cahaya [pause] geo means gravity [pause] and } \\
\text { hydro means air [pause; said loudly]. }\end{array}$ & $\begin{array}{l}\text { Some of the students stopped } \\
\text { writing, and some of the } \\
\text { students continued with their } \\
\text { works. } \\
\text { He said the second statement } \\
\text { in Bahasa Malaysia. }\end{array}$ \\
\hline
\end{tabular}

In TJ's talk, he gave an overview of how plants respond to stimuli. He began by stating the terms used to represent the responses of plants towards different stimuli and then defined each of the terms. He separated each term into two parts, prefix, and suffix and engaged students by giving them information and questioning them. The students answered the questions in both Bahasa Malaysia and English and some students used everyday language. For example in turn 12, J7 answered the question as gambar to define the word photo. It seemed that $\mathrm{J} 7$ was correct but the answer given was not in the correct context. In general, when giving feedback, TJ asked another question not linked to the students' responses or he provided clues based on the students' answers before he asked another question.

It seemed that TJ initiated the discourse in the lesson by stating what the plants' responses to various stimuli were. He gave both statements and questions in Bahasa Malaysia and sometimes he used both English and Bahasa Malaysia. For example, in turn one, TJ said in Bahasa Malaysia, There are three types of tropisms; hydrotropism, geotropism, and phototropism to list the responses of plants to different stimuli. In turn two, he was breaking down the terms into suffixes and prefixes and said photo, geo, and hydro as the prefixes and the term tropism as the suffix. He also provided a strategy for students to memorise the terms of plants' responses by memorising the prefix. He said, Remember the words at the beginning, hydro, geo, and photo. The suffix tropism is similar at the end of each term. He also asked the students to define the prefix accordingly and the questions invited a single answer from the students.

It appears that questions played an important role in TJ's communication with the students. He posed questions to the whole class that required them to define the meaning of the prefix and 
suffix for each term. The questions helped the students to describe the meaning of each term. In turns one and two he spoke about the different responses plants have and the students listened quietly and remained in their seats. However, after he asked the questions, the students engaged in the lesson by answering them. In turn three, TJ asked the students to define the meaning of hydro by asking, What is hydro? TJ and his students spoke in Bahasa Malaysia when discussing the definitions of the terms.

Students answered TJ's questions in Bahasa Malaysia. Some students voluntarily answered the questions and some students remained quiet. TJ also asked specific students to answer questions and they responded promptly when TJ posed the question in both languages. For example, in turn four, the majority of the students defined the term hydro as air in Bahasa Malaysia which meant water. In some situations, however, the students answered the question in both languages, for example, in turn 12, TJ asked the students to define the meaning of flash. Student $\mathrm{J} 8$ replied, The flash is cahaya and in English, the word cahaya means light. TJ switched between both languages to help students answer questions.

Students used everyday language to respond to questions and those who chose to answer questions spoke louder than others did in order to attract the teacher's attention. In turns four and six students said air (water) to answer the question, Hydro itu apa? (What is hydro?). They gave the same answer in turn six, but spoke more loudly compared to turn four as more students were trying to answer the question. Similarly, in turn 10, TJ asked the meaning of the word photo and $\mathrm{J} 7$ volunteered the answer. $\mathrm{J} 7$ was more vocal than the other students in trying to answer the question, and translated the term photo into Bahasa Malaysia as gambar (pictures). It seemed that $\mathrm{J} 7$ gave the literal meaning of the word photo which was correct, but which could not be used in the context of the response of plants to stimuli. TJ gave statements and asked questions when giving feedback, which potentially helped elicit more response from students.

TJ provided different feedback to the students' answers depending on whether they were correct or incorrect. He did not evaluate correct answers immediately; he either repeated the question or continued the lesson with the next question without giving any comment. In some cases, he accepted the answer and continued with the next question or statement. For example, in turn five, TJ repeated the question although a group of students had already correctly translated the term hydro. However, in some cases TJ acknowledged and commented on the answers. In turn seven, he said, Yes. Hydro is water. It is like hydroelectric. We generate electricity from water. He accepted the students' answers by saying yes. He 
used the term hydroelectric as an example and separated the term into its prefix (hydro) and suffix (electric), explaining the word hydro by using an example from everyday life.

However, in answer to the incorrect responses, TJ did not respond immediately but asked further questions that required students to reflect on a possible definition of the term hydro. He gave a clue to assist the students in defining the word photo correctly, which he linked to a student's earlier comment. For example, student $\mathrm{J} 7$ translated the word photo as gambar (picture) in Bahasa Malaysia. In response, TJ said in Bahasa Malaysia, If you take photos you see a flash. He then asked students to define the word flash. It seemed TJ used this strategy to give the responsibility of defining the term to the students. In giving feedback, TJ gave other students an opportunity to think of another possible definition of the term photo.

To conclude, TJ delivered a general overview of how plants respond to different stimuli before engaging the students with a series of questions. TJ's focus on defining terminology indicated this might be important for the examination. His technique to introduce terms was to separate the words (e.g. phototropism, hydrotropism, and geotropism) into their prefix and suffix (e.g. hydro and tropism). It seemed that most of the questions elicited a single answer without further explanation. The questioning technique might assist students with limited language abilities to learn the terms by remembering the prefix and encourage them to think and talk. It appeared that the questions might not assist students to think of possible reasons why plants need to respond to these stimuli in order to survive.

\subsubsection{Instruction for practical work}

When discussing the procedure to investigate how plants respond to water, TJ described the function of the materials. Through questioning and direct instruction, he involved students in identifying the function of the materials. TJ asked the students to state the function of silica gel and the question seemed to elicit various responses from the students. TJ used more Bahasa Malaysia than English in the lesson but highlighted some of the terms in English. Table 8-5 outlines Vignette five on the student-teacher interaction in discussing the function of some of the materials. 
Table 8-5: Vignette 5.

\begin{tabular}{|c|c|c|c|}
\hline Turn & Speaker & Text & Observation \\
\hline 1 & TJ & $\begin{array}{l}\text { Then we put the silica gel in the beaker [raised his } \\
\text { voice]. They are purple in colour [continued in a } \\
\text { raised voice]. What is the function of the small } \\
\text { beads? }\end{array}$ & $\begin{array}{l}\text { He lifted the beaker so the } \\
\text { students could see the colour of } \\
\text { the silica gel. } \\
\text { He gave the instruction in } \\
\text { Bahasa Malaysia. }\end{array}$ \\
\hline 2 & $\mathrm{~J} 20$ & $\begin{array}{l}\text { To make the experiment smell good [she answered } \\
\text { TJ's question promptly in a loud voice]. }\end{array}$ & $\begin{array}{l}\text { She put her hand up and } \\
\text { answered the question in a loud } \\
\text { voice. } \\
\text { J20 answered the question in } \\
\text { Bahasa Malaysia. Some } \\
\text { students also attempted to } \\
\text { answer the question but their } \\
\text { answers were unclear. }\end{array}$ \\
\hline 3 & Students & Ha ha ha [students laughed loudly], & The students laughed. \\
\hline 4 & $\mathrm{~J} 20$ & $\begin{array}{l}\text { But [pause] I saw my mum hang it in the cupboard } \\
\text { [loud voice]. }\end{array}$ & $\begin{array}{l}\text { J20 stood up to give the } \\
\text { answer. } \\
\text { J20 answered the question in } \\
\text { Bahasa Malaysia. }\end{array}$ \\
\hline 5 & TJ & $\begin{array}{l}\text { To make it smell good [repeated in a soft voice]. } \\
\text { That's ridiculous [smiles]. }\end{array}$ & $\begin{array}{l}\text { He put the beaker on the } \\
\text { bench. He gave the comment in } \\
\text { Bahasa Malaysia. }\end{array}$ \\
\hline 6 & $\mathrm{~J} 5$ & $\begin{array}{l}\text { To accelerate the growth of plants [said in a loud } \\
\text { voice] ha ha ha. }\end{array}$ & $\begin{array}{l}\mathrm{J} 5 \text { put his hand up and } \\
\text { answered promptly. J5 } \\
\text { answered in Bahasa Malaysia. }\end{array}$ \\
\hline 7 & TJ & $\begin{array}{l}\text { This beaker contains the silica gel [pause]. The } \\
\text { function of silica gel is to absorb the water vapour. } \\
\text { We assumed that the water vapour does not exist } \\
\text { in the beaker [pause]. } \\
\text { If there is a question in the exam that asks the } \\
\text { function of the silica gel, please say the function of } \\
\text { silica gel is to absorb the water vapour that is } \\
\text { trapped in the air. }\end{array}$ & $\begin{array}{l}\text { The students listened quietly as } \\
\text { TJ explained the function of } \\
\text { silica gel. He gave the feedback } \\
\text { in Bahasa Malaysia. }\end{array}$ \\
\hline
\end{tabular}

TJ states the materials by giving a direct instruction followed by a question. He states the steps in setting up the experiment to investigate how plants respond to water. In turn one, he tells the students to place a small amount of silica gel in the beaker, and then he briefly explains the physical characteristics of the silica gel. TJ's questions demonstrated that he wanted to ensure that the students knew the steps but also that they understood why they were following each step in the process. His questioning provided an opportunity for the students to become familiar with the objects they would manipulate later in the lesson. The questions elicited different responses from students based on personal experiences and guesses. 
In responding to the questions, some students put their hands up while others shouted out their answers. It appeared that the students did not know the function of the silica gel when setting up the apparatus and they based their answers on personal experience and guesswork. For example, in turn two, J20 said, To make the experiment smell good. She answered the question in a loud voice, loud enough for the researcher at the back of the laboratory to hear the response clearly. In turn four, J20 said, But, I saw my mum hang it in the cupboard. She was referring to her mother placing beads in the cupboard for their fragrance. In turn six, J5 attempted to give the answer after TJ had given a negative response to J20's answer. J5 said, To accelerate the growth of [the] plant. It seemed that the students were confident enough to engage in the discourse as they were speaking in Bahasa Malaysia and TJ gave feedback to the answers in Bahasa Malaysia.

TJ paused before giving feedback if the students gave an incorrect answer, which provided them with an opportunity to clarify their answers. TJ used two different approaches to deal with incorrect responses, firstly, he commented negatively. In turn five, TJ repeated J20's answer before he rejected it. TM said, To make it smell good. That's ridiculous. TM's response might have embarrassed J20 after her classmates laughed at her answer; it also might have discouraged other students from answering. After two incorrect answers, he finally gave the correct one. In turn seven he said, The function of silica gel is to absorb the water vapour. Although he stated the function of silica gel, he did not explain the importance of ensuring that the apparatus was dry and if it was not, how it might affect the results. He also reminded the students to memorise the function of silica gel as the question was frequently asked in the examination.

To conclude, TJ asked a question about the function of one of the materials (silica gel) before allowing the students to do the practical part of the lesson. Although he uses the what question, he does not immediately evaluate the students' responses. Thus, the students have the opportunity to explore the functions of silica gel before they embark on the task. TM stresses the function of silica gel to remind the students that it is frequently asked in the examination. Although he states the function of silica gel, he does not explain the importance of ensuring that water vapour is not trapped inside the beaker and how this might affect the results. The students engage with the discourse confidently as it is conducted in Bahasa Malaysia. 


\subsubsection{Making sense of the concept through practical work}

TJ discussed the responses of plants towards different stimuli before the students did the observation and attempted to make the connection between the task and concepts by using everyday examples with which the students might be familiar. He seemed to use a questioning technique and a direct instruction technique, in engaging the students in learning the links between the task and the concept. Table 8-6 shows Vignette six that highlights the studentteacher interaction in establishing those links.

Table 8-6: Vignette 6.

\begin{tabular}{|c|c|c|c|}
\hline Turn & Speaker & Text & Observation \\
\hline 1. & TJ & $\begin{array}{l}\text { Now we will discuss phototropism [said softly]. Let's } \\
\text { say you are driving a car. There are rubber trees on } \\
\text { both sides of the road. Do you notice the direction of } \\
\text { the leaves that are close to the road? [asked loudly] }\end{array}$ & $\begin{array}{l}\text { Class discussion was in Bahasa } \\
\text { Malaysia. }\end{array}$ \\
\hline 2. & Students & & $\begin{array}{l}\text { Silent. None of the students } \\
\text { answered the question. }\end{array}$ \\
\hline 3. & TJ & $\begin{array}{l}\text { Do the leaves grow towards the road or away from } \\
\text { the road? [asked loudly] }\end{array}$ & $\begin{array}{l}\text { He asked the question in Bahasa } \\
\text { Malaysia. }\end{array}$ \\
\hline 4. & Students & To[wards] the road [shouted]. & $\begin{array}{l}\text { The students answered together. } \\
\text { They answered the question in } \\
\text { Bahasa Malaysia. }\end{array}$ \\
\hline 5. & TJ & $\begin{array}{l}\text { Why do the leaves bend towards the road? [asked } \\
\text { loudly] }\end{array}$ & \\
\hline 6. & Students & & No answer from the students. \\
\hline 7. & TJ & $\begin{array}{l}\text { The rubber trees are planted close to each other. } \\
\text { They competed with each other to get the sunlight. } \\
\text { The rubber trees on the roadsides get better sunlight } \\
\text { compared to the others. So the shoots grow towards } \\
\text { the road to get the sunlight. Do you understand so } \\
\text { far? [asked loudly] }\end{array}$ & $\begin{array}{l}\text { TJ explained the reason in } \\
\text { Bahasa Malaysia. He asked the } \\
\text { question in English. }\end{array}$ \\
\hline 8. & Students & Yes. & $\begin{array}{l}\text { They answered the question } \\
\text { together. }\end{array}$ \\
\hline 9. & TJ & $\begin{array}{l}\text { Look here [said loudly]; one of your friends has } \\
\text { created a hole here [said loudly].Where will the } \\
\text { seedling grow? [said loudly] }\end{array}$ & $\begin{array}{l}\text { He took the box and pointed at } \\
\text { the hole. }\end{array}$ \\
\hline 10. & Students & & Students remained quiet. \\
\hline 11. & TJ & Where the seedling will grow? & $\begin{array}{l}\text { He drew the diagram on the } \\
\text { board. Figure 8-2. } \\
\text { Then he repeated the question. }\end{array}$ \\
\hline 12. & Students & Towards the hole. & $\begin{array}{l}\text { The students answered the } \\
\text { question loudly in Bahasa } \\
\text { Malaysia. }\end{array}$ \\
\hline 13. & TJ & $\begin{array}{l}\text { That is correct [pause]. Seedlings will grow towards } \\
\text { the hole. Why will the seedlings grow towards the } \\
\text { hole? [asked loudly; short pause]. The plants need }\end{array}$ & \\
\hline
\end{tabular}




\begin{tabular}{|c|c|l|l|}
\hline & & $\begin{array}{l}\text { sunlight [spoken softly]. So what is photo? [said } \\
\text { loudly] }\end{array}$ & \\
\hline 14. & Students & Light. & $\begin{array}{l}\text { The students responded in a loud } \\
\text { voice. }\end{array}$ \\
\hline 15. & TJ & $\begin{array}{l}\text { Ok [said loudly]. Do you have any problem? [asked in } \\
\text { a loud voice] }\end{array}$ & $\begin{array}{l}\text { He asked the question in Bahasa } \\
\text { Malaysia. }\end{array}$ \\
\hline 16. & Students & No [answered loudly]. & \\
\hline
\end{tabular}

In establishing the links between the task and the concept of phototropism, TJ used an example from real life. He explained the nature of a rubber plantation before he asked the students to describe the condition of rubber trees which grow close to the road (turn one). The phenomenon he described shifted the focus of the lesson. It seemed that TJ wanted the students to use their personal experience to explain how plants respond to sunlight in nature. He then asked the students to describe the direction of the plants in response to the sunlight. It seemed that the questions had the potential to engage the students in predicting results based on what they might have experienced in real life, but there was little response. Thus, TJ elicited students' responses through questioning and by using drawings.

TJ changed the questioning strategy to assist the students in answering the questions as he had used a funnelling questioning technique in this vignette. He asked a difficult question initially but no response was forthcoming, so he then gave some support by providing a choice of answers. For example in turn three, he simplified the question after the students could not identify the direction of leaves in response to sunlight. He provided options for students to answer the question. He asked, Do the leaves grow towards the road or away from the road? In response, the students answered together, To[wards] the road. These options assisted the students in answering the question correctly, but have a negative effect by encouraging them to guess the answer. Providing the options might hinder students from exploring other possible answers but might help those with limited language proficiency to participate in the lesson.

TJ provided support for students to make predictions of the results. He asked the students to predict the direction of the growth of the seedling they placed in the box. He asked the following question, Where will the seedling grow? And none of the students answered. Then, he drew the diagram (Figure 8-2) that clearly showed the direction of growth of the seedlings. The students could answer the question after he completed the drawing, which it seemed had helped the students give the expected results. However, the drawing reduced the students' 
opportunities to engage with making predictions about the task they had performed by themselves.

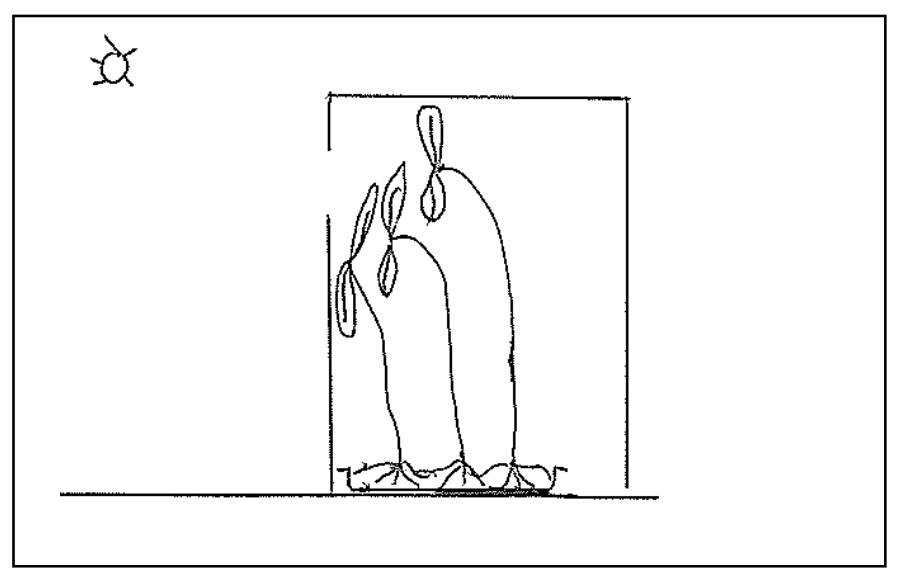

Figure 8-2: A schematic diagram drawn by $\mathrm{TJ}$ on the whiteboard to show the plants' response to light.

In conclusion, TJ used different approaches to help students understand the responses of plants to sunlight. He used real phenomena and drawings to make the links between the task and the concepts. It seemed that his approaches hindered the students' opportunities to learn how plants respond to sunlight from the observation. Despite verbal and visual support, TJ did not highlight how important it is for the plants to respond to the light in order to survive.

\subsection{TR's Lesson: The absorption of glucose through the Visking tube}

TR conducted practical work to achieve the learning objective Understanding the Process of Absorption of Digested Food for Nutrition, the fourth learning area in the curriculum specification. The investigation aimed to achieve the learning outcome, Make Inferences about the Absorption of glucose through a Visking Tube (MOE, 2002, p. 24) by conducting an experiment to show the absorption process. TR planned the practical task according to the suggested activity in the textbook and all materials and equipment were prepared beforehand. He explained the concepts of absorption before he explained the steps to perform the task and the students worked in groups to complete the task. He also established the concepts with the task they performed. TR's approaches in delivering the concepts, explaining the procedure, and making sense of the concepts from the task will be elaborated on in the following section. 


\subsubsection{Introducing the concept}

TR started by communicating the concept of the absorption of digestible food in the human digestive system. He used both English and Bahasa Malaysia languages to explain this, primarily using English and then repeating statements in Bahasa Malaysia. He explained the concepts before introducing the procedure to examine the absorption process. Through the instruction, he made a series of statements without asking any questions, which appears to be an efficient teaching method to deliver facts to students, but it did restrict their involvement in the lesson. Table 8-7 shows vignette seven as a part of TR's talk on delivering the facts about the absorption of food to the whole class.

Table 8-7: Vignette 7.

\begin{tabular}{|c|c|c|c|}
\hline Turn & Speaker & Classroom interaction & Observation \\
\hline 1. & TR & $\begin{array}{l}\text { You can refer to your textbook, page 52, experiment } 2.1 \\
\text { [said softly]. }\end{array}$ & $\begin{array}{l}\text { TR stood in front of the } \\
\text { students. } \\
\text { He gave the instruction in } \\
\text { English. }\end{array}$ \\
\hline 2. & TR & $\begin{array}{l}\text { Ok, the glucose is absorbed in the bloodstream through } \\
\text { the wall of the small intestine [pause]. Glucose akan } \\
\text { diserap ke dalam salur darah melalui dinding usus kecil } \\
\text { [said softly]. }\end{array}$ & $\begin{array}{l}\text { TR translated the sentence } \\
\text { into Bahasa Malaysia after } \\
\text { he explained in English. }\end{array}$ \\
\hline 3. & TR & $\begin{array}{l}\text { Jadi, untuk faham proses penyerapan dalam small } \\
\text { intestine, kita tukar function. Fungsi small intestine } \\
\text { ditukar dengan Visking tube. } \\
\text { So [emphasis on the word so] to understand the } \\
\text { absorption of glucose in small intestine [pause] we } \\
\text { changed the function [pause]. We can use Visking tubing } \\
\text { as the small intestine [pause]. Refer to the diagram in the } \\
\text { textbook [said softly]. }\end{array}$ & $\begin{array}{l}\text { He made the statement in } \\
\text { both English and Bahasa } \\
\text { Malaysia. He showed the } \\
\text { diagram to students (Figure } \\
\text { 8-3). }\end{array}$ \\
\hline 4. & Student & & $\begin{array}{l}\text { TR drew the diagram on the } \\
\text { whiteboard (Figure 8-4). } \\
\text { Students remained quiet } \\
\text { and in their places. }\end{array}$ \\
\hline 5. & TR & $\begin{array}{l}\text { Glucose molecules are smaller than starch molecules. So } \\
\text { glucose can be absorbed through the Visking tubing. }\end{array}$ & $\begin{array}{l}\text { He pointed at the diagrams } \\
\text { on the whiteboard. He } \\
\text { explained in Bahasa } \\
\text { Malaysia. }\end{array}$ \\
\hline 6. & TR & $\begin{array}{l}\text { Visking tubing has small holes that allow glucose } \\
\text { molecules to diffuse more quickly than starch [paused]. }\end{array}$ & $\begin{array}{l}\text { TR drew a dotted line on } \\
\text { the diagram on the } \\
\text { whiteboard (Figure 8-5). He } \\
\text { explained in both } \\
\text { languages. He did not } \\
\text { change the word glucose in } \\
\text { Bahasa Malaysia as } \\
\text { glukosa and kanji for starch. }\end{array}$ \\
\hline 7. 8 & TR & $\begin{array}{l}\text { So, glucose can diffuse from across the Visking tubing } \\
\text { [voice remained low]. }\end{array}$ & $\begin{array}{l}\text { TR drew arrows that } \\
\text { pointed to the left. He used } \\
\text { a mix of both languages to }\end{array}$ \\
\hline
\end{tabular}




\begin{tabular}{|c|c|l|l|}
\hline & & & $\begin{array}{l}\text { explain the solution that } \\
\text { diffused from the Visking } \\
\text { tube. He did not change the } \\
\text { word glucose and starch } \\
\text { into Bahasa Malaysia. }\end{array}$ \\
\hline 8. & TR & $\begin{array}{l}\text { So, the glucose solution represents the digested food. } \\
\text { Whereas starch solution represents the undigested food } \\
\text { and distilled water represents the blood stream [long } \\
\text { pause]. }\end{array}$ & $\begin{array}{l}\text { He drew the dotted line } \\
\text { quickly. He explained the } \\
\text { absorption process in } \\
\text { Bahasa Malaysia. }\end{array}$ \\
\hline 9. & Students & & Students remained quiet. \\
\hline
\end{tabular}

TR explained the absorption process to the class in three parts. Firstly, he described the human digestive system absorption process. Secondly, he explained how the model represents the actual absorption process and how this means students can study the process. Finally, he explained how digestible foods are absorbed through the wall of the small intestine at the molecular level. He drew diagrams on the board to show how the absorption process occurs in the small intestine.

TR used both English and Bahasa Malaysia languages to explain the absorption process in the human digestive system. He used English first, and then repeated the statement in Bahasa Malaysia. In turn one, he said, Ok, the glucose is absorbed in the bloodstream through the wall of the small intestine. Glucose akan diserap ke dalam salur darah melalui dinding usus kecil. By using both languages, he helped the students with limited English proficiency to understand the information. However, he did not explain the structure of the small intestine, which allowed the absorption process to take place. He then explained a possible way to understand the process by using materials available in the laboratory as a model.

He used the model of the small intestine built using laboratory materials, to explain in both English and Bahasa Malaysia, the absorption process. In turn three, he said, Jadi, untuk faham proses penyerapan dalam small intestine, kita tukar function. Fungsi small intestine ditukar dengan Visking tube. So, to understand the absorption of glucose in the small intestine, we use the Visking tubing to represent the small intestine. It seemed he made the function of the Visking tubing clear by stating the phases in both languages, however, he did not explain the function of other materials and equipment such as the distilled water, starch, and glucose solutions. He continued the lesson by introducing the structure of the small intestine by referring to the diagram in the textbook without further explanation of it. Figure 8-3 below shows the notes and diagrams provided on the absorption process from the textbook. 


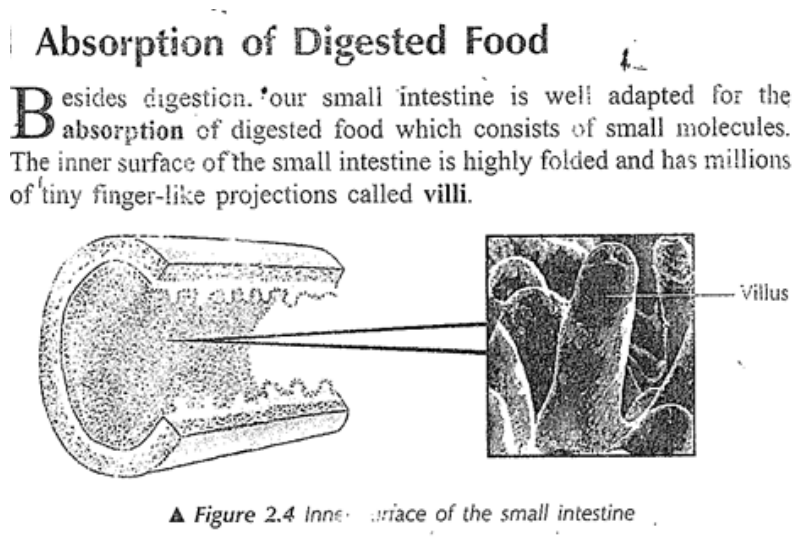

Figure 8-3: The diagram of the absorption process in the small intestine from the textbook (Tong \& Neo, 2003, p. 51).

In turns one to three TR explained the absorption process at the molecular level, having briefly explained the model and absorption process using the diagrams he drew on the board (Figure 8-4), which he used to show the differences between glucose and starch solutions. He drew small round shapes to represent glucose molecules and big round shapes to represent starch molecules. In turn five, he said, Glucose molecules are smaller than starch molecules and so can be absorbed through the Visking tubing and he pointed to the diagrams on the board. He used scientific terms, such as 'molecules' which are not defined in the textbook without explaining their meaning. The symbols he used to represent starch and glucose molecules are seen in Figure 8-4.

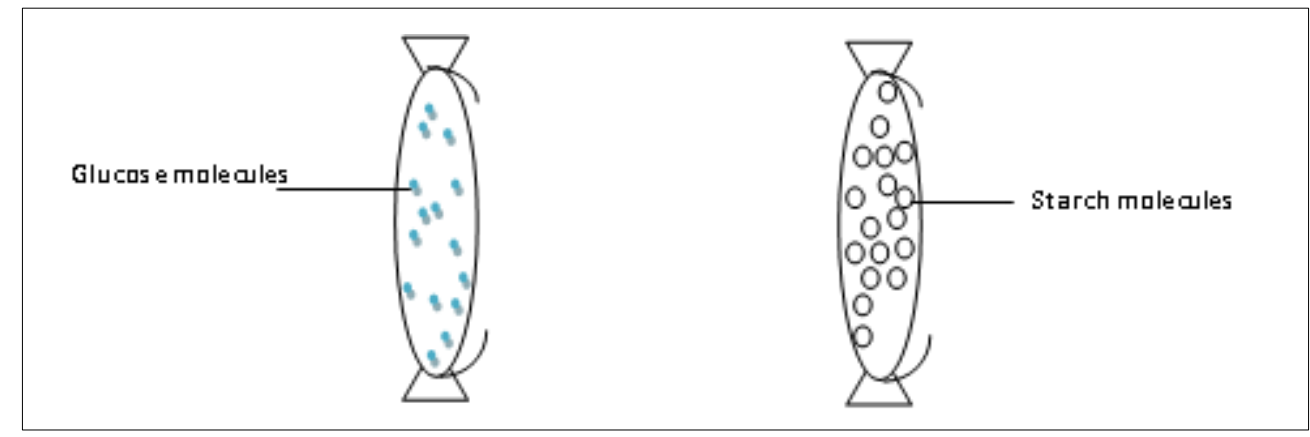

Figure 8-4: The schematic diagram that TR drew on the whiteboard to show the size differences between the glucose and starch molecules.

TR verbally explained the absorption process through the Visking tubing while referring to his diagrams, which he modified to explain the structure of Visking tubing. He drew a dotted line to show that Visking tubing has pores, and in turn 6 he said, The Visking tubing has small holes which allow glucose molecules to diffuse more quickly than starch. He concluded that 
the glucose solution could diffuse through the Visking tubing before the students did the practical task and drew three arrows on his diagram to help explain the diffusion process, as shown in Figure 8-5.

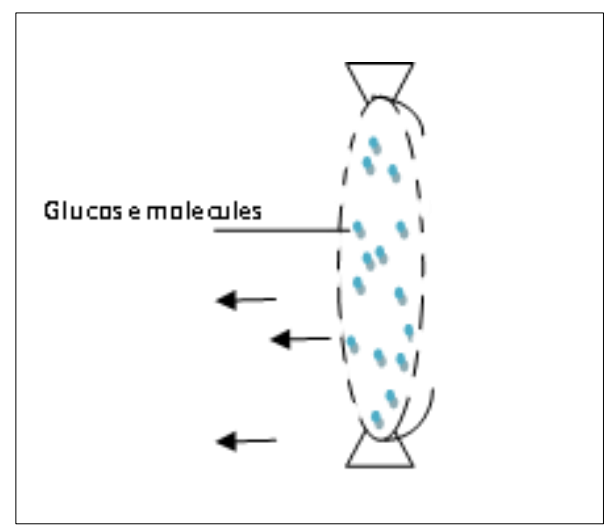

Figure 8-5: The schematic diagram that TR drew on the whiteboard to show small pores that allow small molecules to diffuse.

In conclusion TR taught the concept of absorption using two different approaches. Firstly, he explained the concept of the absorption process in the small intestine and then described the absorption process at molecular level and, finally, he compared the model with the actual absorption process in a small intestine. TR supported his explanation with diagrams from the textbook and ones he drawn on the board. It seemed that the series of statements reduced the student voice because there was no interaction between teacher and student in the classroom. TR's approach was effective in delivering the information that students might need to know, but it was unclear whether they understood the concept and how it was related to the model.

\subsubsection{Instruction for practical work}

After TR gave the instructions to the whole class about which steps to follow, he asked each group representative to collect the materials from the side bench. Although he gave the instruction in Bahasa Malaysia, some students could not remember them. Vignette eight in Table 8-8 shows the problems students experienced in following the instructions and how TR dealt with these. 
Table 8-8: Vignette 8.

\begin{tabular}{|l|l|l|l|}
\hline Turn & Speaker & \multicolumn{1}{|c|}{ Text } & Observation \\
\hline 1. & TR & $\begin{array}{l}\text { Ok, [stressed] group representatives please } \\
\text { take the apparatus. }\end{array}$ & $\begin{array}{l}\text { Almost all students walked to the } \\
\text { side bench to collect the } \\
\text { apparatus. TR did not talk to } \\
\text { students. }\end{array}$ \\
\hline 2. & R1 & What should we do, teacher? [Said loudly]. & $\begin{array}{l}\text { A female student who stood by } \\
\text { the bench asked what to do. }\end{array}$ \\
\hline 3. & R9 & $\begin{array}{l}\text { Teacher [pause] how much starch solution? } \\
\text { [asked in a rising voice] }\end{array}$ & $\begin{array}{l}\text { The level of noise in the } \\
\text { laboratory increased. }\end{array}$ \\
\hline 4. & TR & $\begin{array}{l}\text { Look here, [called students in a loud voice] take } \\
\text { the Visking tube and tie one end like this [long } \\
\text { pause]. Then add starch solution to the Visking } \\
\text { tube and tie the other end of the Visking tube } \\
\text { [loud voice]. Next, immerse the Visking tube in } \\
\text { the boiling tube that contains distilled water for } \\
30 \text { minutes. }\end{array}$ & $\begin{array}{l}\text { Some students continued to talk } \\
\text { while TR gave instructions. } \\
\text { He demonstrated how to tie one } \\
\text { end of the Visking tube. Not all } \\
\text { the students watched as he } \\
\text { demonstrated. Some of the } \\
\text { students continued to collect the } \\
\text { materials. Some of the students } \\
\text { remained seated in their places. }\end{array}$ \\
\hline 5. & TR & Do you understand? [loud voice] & $\begin{array}{l}\text { The students answered the } \\
\text { question together. }\end{array}$ \\
\hline 6. & Students & Yes. & \multicolumn{2}{|l}{} \\
\hline
\end{tabular}

As many of the vignette cases show, the teacher often asks questions to initiate discourse, however, vignette eight shows the students initiating discourse by asking questions. Although TR explained in detail what he wanted the students to do, some of them showed that they did not understand his instructions. They did not know what they were supposed to do or how to set up the apparatus. In turn one, almost all the students leave their places and walk to the side bench, even though TR asked only the group representatives to collect the materials and the level of noise in the laboratory increased. In turns two and three, students asked questions about the procedure. In turn two, student R1 asked, What should we do, teacher? and in turn three, student R2 asked, Teacher, how much starch solution? It seemed that because of all their questions, TR realised that the students had not understood his instructions, and their questions influenced his subsequent actions.

In response to the students' questions, TR changes his approach, and instead of telling them what to do, he demonstrates. In turn four, he raised his voice to gain attention from the students before he performed the demonstration, saying Look here, but, only a few students moved closer to him. He started the demonstration by taking a Visking tube and giving the instruction, Take the Visking tubing, and tie one end like this. He tied the Visking tubing with a thread after he had explained the steps and then showed the next step, that of adding the 
starch solution. After he had demonstrated the task, he asked the students, Do you understand? TR had used two approaches to ensure the students understood the steps, beginning with a verbal explanation and following this with a demonstration in response to students' questions. This may or may not help the students to perform the steps as required by TR.

The vignette shows that the students did not entirely understand the steps TR explained and that he took proactive steps to overcome this by demonstrating the procedure. The students' questions changed the nature of the discourse in TR's lesson, and TR was not always in control of the lesson when asking questions. However, the students' questions showed that they were concerned about following the instructions correctly rather than with why they were following them.

\subsubsection{Making sense of the concept through practical work}

TR linked the experiment concept to the materials by explaining the results from the digestive system model, and discussed the results of the Benedict's and iodine tests after the students completed the task in groups. The students conducted two sets of each test, the first set of tests was conducted immediately after the Visking tubing had been immersed in boiling, distilled water, and the second set was conducted 30 minutes later. TR explained the reasons why glucose solution could diffuse across the wall of the Visking tube unlike the starch solution, and then explained how the materials and apparatus represented the organs of the digestive system and the nutrients absorbed into the blood stream. Vignette nine in Table 8-9 outlines the whole class discussion of the results and the model. 
Table 8-9: Vignette 9.

\begin{tabular}{|c|c|c|c|}
\hline Turn & Speaker & Text & Observation \\
\hline 1. & TR & $\begin{array}{l}\text { Ok [said loudly] now we discuss the results [pause]. } \\
\text { The results of lodine test on test tube A remains yellow } \\
\text { at the end of the experiment. Why? [asked softly] }\end{array}$ & $\begin{array}{l}\text { He took a set of the students' } \\
\text { apparatus and showed it to } \\
\text { them. He spoke in Bahasa } \\
\text { Malaysia. }\end{array}$ \\
\hline 2. & Students & & No response from students. \\
\hline 3. & TR & $\begin{array}{l}\text { The starch solution could not diffuse from the Visking } \\
\text { tube because starch molecules are bigger compared } \\
\text { with glucose solution [voice remained low]. So write the } \\
\text { observation as the colour remained yellow, and the } \\
\text { inference is starch is not present [said loudly]. }\end{array}$ & $\begin{array}{l}\text { He put the test tube back and } \\
\text { took the second test tube. } \\
\text { He explained in Bahasa } \\
\text { Malaysia. He stated the } \\
\text { observation in English. }\end{array}$ \\
\hline 4. & TR & $\begin{array}{l}\text { Ok [said loudly]. Now the results of the Benedict's test } \\
\text { [said loudly]. Test tube B changed from blue to the } \\
\text { redbrick precipitate at the end of the practical task. } \\
\text { Why? [asked in a rising voice; paused for a few } \\
\text { seconds] }\end{array}$ & $\begin{array}{l}\text { He showed the test tube to } \\
\text { students. He explained the } \\
\text { results and asked the question } \\
\text { in English. }\end{array}$ \\
\hline 5. & Students & & No response from students. \\
\hline 6. & TR & $\begin{array}{l}\text { Glucose is a small molecule that can diffuse from the } \\
\text { Visking tube. Understand? [Said loudly]. }\end{array}$ & $\begin{array}{l}\text { He used the key words in } \\
\text { English such as glucose, } \\
\text { diffuse. }\end{array}$ \\
\hline 7. & Students & & No response from students. \\
\hline 8. & TR & $\begin{array}{l}\text { So [said loudly] write in your report [he paused], the } \\
\text { observation is [said loudly] the colour changed to red } \\
\text { brick precipitate, and the inference is glucose is present } \\
\text { [said loudly]. Faham (understand) [said loudly]. }\end{array}$ & $\begin{array}{l}\text { He stood at the front bench. He } \\
\text { explained the results in English. }\end{array}$ \\
\hline 9. & Students & Yes [they answered loudly]. & \\
\hline 10. & TR & $\begin{array}{l}\text { Now [raised voice] look at the worksheet [pause]. The } \\
\text { task represents a model of absorption of digestible } \\
\text { foods in the small intestine [pause]. So the Visking tube } \\
\text { represents small intestines [said loudly], starch } \\
\text { represents [pause; said loudly], look at the worksheet. }\end{array}$ & $\begin{array}{l}\text { TR took the worksheet and } \\
\text { showed it to the students. } \\
\text { Some of the students wrote the } \\
\text { reports, and some of the } \\
\text { students looked at the } \\
\text { worksheet figure. }\end{array}$ \\
\hline 11. & Students & Starch. & $\begin{array}{l}\text { Students answered the } \\
\text { question together. }\end{array}$ \\
\hline 12. & TR & $\begin{array}{l}\text { Correct [said loudly]. How about glucose? [Asked } \\
\text { loudly]. }\end{array}$ & \\
\hline 13. & Students & Glucose. & $\begin{array}{l}\text { They answered the question } \\
\text { together in English. }\end{array}$ \\
\hline 14. & TR & $\begin{array}{l}\text { Good, and the distilled water is bloodstream [said } \\
\text { loudly]. }\end{array}$ & \\
\hline
\end{tabular}

TR described the results of both tasks before he asked students to explain the reasons why they got those results. He also explained the model and how it is related to the actual absorption process. In turns one and four, TR described the results of the iodine and 
Benedict's tests respectively. In turn one, he described the result of the lodine test, saying, Ok, now we discuss the results. The results of the lodine test on test tube A remained yellow at the end of the practical task. Then he showed the test tube to students and asked why the colour of the iodine solution remained unchanged. In turn four, he described the results of the Benedict's test before he asked why the colour of the Benedict's solution had changed from blue to a red precipitate after 30 minutes. Both questions required the students to think beyond the results they had observed. However, none of the students responded to either question, so TR explained why in the end, the iodine solution remained unchanged while the Benedict's solution changed.

When the students did not answer, TR gave the correct answers and moved on with the lesson. He stated the reasons for the results, for example, in turn three, he explained that starch solution could not diffuse across the wall of the Visking tube because the starch molecules are bigger than the glucose molecules. He used Bahasa Malaysia to explain why starch could not diffuse across the Visking tube but used English to remind them to write the observation. Similarly, when he discussed the results of the Benedict test, he used English because the students were required to report the experiment in English. He also used the hand-out (Figure 8-6) he had distributed to show the human digestive system and used fill in the blank questions to engage them in discussion. In turn 10, he emphasised the phrase starch presence in a loud voice and paused before he asked students to refer to the worksheet. He used the same questioning strategy to ask students to state how glucose solution is represented in the model. Although the students could do this, their ability to link the task and the concepts must be questioned, as TR did not assess their understanding of it. 


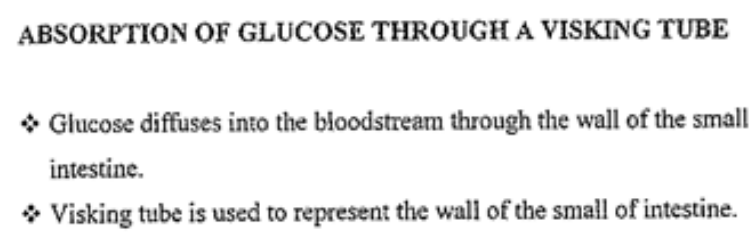

$*$ Visking tube is used to represent the wall of the small of intestine.

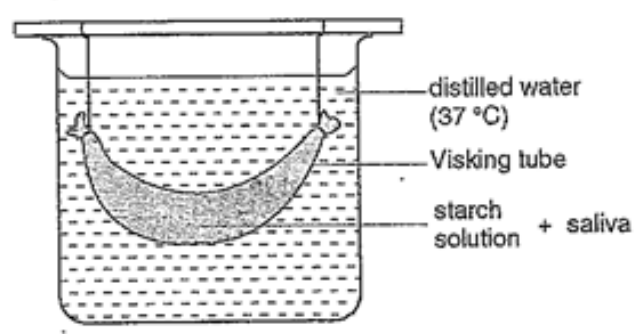

* Starch molecules cannot diffuse or pass through the wall of Visking tube.

\begin{tabular}{|c|c|}
\hline APPARATUS / MATERIALS & $\begin{array}{l}\text { PART OF ALIMENTARY } \\
\text { CANAL REPRESENTED }\end{array}$ \\
\hline Visking tube & Wall of small intastine \\
\hline Sugar solution & Digesled food \\
\hline Starch solution & Undigested food \\
\hline Distilled water & Blood in bloodstream \\
\hline
\end{tabular}

Figure 8-6: TR's hand-out on the absorption of glucose through a Visking tube.

To conclude, TR used a different method to help students make sense of the absorption process through the model they had built. First, he provided verbal support by explaining the initial and final results of both tests and he asked questions to encourage the students to explain the results. The questions required students to explain something that they could not see and when none of the students answered the questions, TR continued the lesson by providing the correct answers. He also used a diagram to show how the model represented human digestive organs. Student-teacher interaction seemed limited; as the students were involved in recalling facts from the worksheet they had been given.

\subsection{Summary of the chapter}

Each teacher used a similar approach to teach scientific concepts, delivering the contents using a lecture-based teaching approach and they sometimes followed this with a series of questions. The teacher (TJ) involved the students in defining scientific terms before explaining the concept of plants' responses, and another (TM) frequently used a combination of speaking to students followed by a series of questions to introduce the concept. TR used a similar approach in explaining the concept, but he used both English and Bahasa Malaysia to explain it. It seemed that the teachers initiated the classroom discourse and the students answered 
questions by giving a short single answer without detail. Typically, the teachers used these approaches before the students did their practical in groups.

Teachers used different approaches to explain the task procedure. TM explained the steps verbally followed by a demonstration, which she did due to limited apparatus for all students. TJ explained the function of the materials as he was setting up the apparatus. TR asked the students to follow the instructions from the textbook then followed with a demonstration once he realised that some students did not understand how to set up the apparatus. It seemed that the teachers focused on the procedure, and not the rationale. This type of student-teacher interaction provides students with information about the procedure and the function of the materials, but is not as suitable for making them think about the importance of following the procedure.

The student-teacher interaction focused on making sense of the concepts by performing practical work and took place after students had completed the group practical work or observed the demonstration. It seemed that the teachers did not rely on the results of the practical work to establish the concepts, as they also used real phenomena, drawings, and questions. It seemed the approach might hinder the students in formulating a conclusion based on the observation. It was difficult to conclude that students developed their conceptual knowledge from practical work as the teachers used other approaches in developing that knowledge. 


\section{Chapter 9: Discussion}

\subsection{Introduction}

The purpose of this study was to understand the aims of form two teachers' when conducting practical work, and to observe the effectiveness of their teaching approaches. This study also attempted to understand the influence of teacher talk, especially questioning, in shaping classroom interactions. The implementation of practical work was investigated through teacher interviews, classroom observations, student focus group interviews, and document analysis of student laboratory reports and the form two curriculum specifications. Seven themes emerged from analysis of the data. The first theme demonstrates how the focus of the implemented practical work was mostly on students doing science rather than on learning science investigation. The second theme, explores teachers' decisions in selecting practical work. The third theme highlights the consequences of teachers' questioning strategies on teaching and student learning experiences. The fourth theme explores students' approaches in conducting practical work. Theme five looks at the teachers' approaches in implementing a constructivist teaching approach, and themes six and seven discuss what students do and learn from practical work.

\subsection{Theme one: Teachers focused on doing science rather than science investigations}

Doing science involves hands-on activities that focus on developing scientific skills (Millar, 1998). Such activities engage students in manipulating objects so they understand abstract science concepts. However Millar (2004), argues that engagement in a single hands-on practical task is unlikely to help students develop an understanding of the underlying science concept. This kind of practical work is likely to be aligned with a 'process approach' where the teachers expect students to learn and develop science process skills, for example, gathering, processing, and interpreting data (Harlen, 1999). Hands-on activities such as a 'recipe practical' or a 'controlled exercise' can be categorised as a low-level enquiry where students follow a set procedure to produce results their teachers already know (Baillie \& Hazel, 2003).

According to Minstrell and Van Zee (2000), science educators consider scientific investigation as a special teaching approach that provides authentic learning experiences to students. $A$ scientific investigation is a holistic process to solve problems or answer questions. To carry out a science investigation students need to draw upon their conceptual and procedural 
understanding to design an empirical study and collect, process and interpret data to answer questions (Pekmez et al., 2005; Roberts, Gott, \& Glaesser, 2009). In such an investigation, students would critically evaluate the procedure to produce reliable results. According to Roberts et al. (2009), the science investigation is more than doing science in the sense that it requires students to think about data before they can draw the conclusion based on the evidence.

From the interviews, it seemed that the participating teachers took a narrow view of practical work and perceived it as doing science rather than scientific investigation, and focused on getting students to practise certain manipulative skills. During the interviews, most teachers' responses showed they were concerned about ensuring students could handle the laboratory equipment correctly rather than focusing on the manipulative skills stated in the curriculum, such as handling specimens appropriately. Teachers gave priority to skill development, which is useful, however, it was often observed that the skills taught before students conducted practical work in groups, were not always transferred to the new context. Some teachers $(n=4)$ said that they taught manipulative skills in separate lessons which is contrary to Hodson's (1991) view that skills learnt in one context are unlikely to be transferred to a new one. However, Hodson (2014) argues that students have to do science and practise to develop procedural knowledge. Teachers in the study argued that students at this level should have already learnt the skills of handling laboratory apparatus, so it appeared they expected the students to already have the skills and to use them to complete practical work in groups. However, some of the focus group students were unable to use the laboratory equipment correctly even after teacher demonstrations, for example, R5 did not measure the volume of both solutions before transferring it to the Visking tube although TR had demonstrated this. This inability to apply the skills is criticised by Hodson (1996), as a shortcoming of the process approach to practical work.

In the interviews, most of the participating teachers $(n=5)$ explained that the practical work they planned for students was from the mandated textbook or the experiment book, where all details regarding practical work procedures and materials were provided. The observation data revealed that the case study teachers told students how to record the data before they allowed them to conduct the set practical task in groups. Some of the case study teachers $(n=2)$ also provided the outline for report writing. The practical work that teachers carried out was similar to the practical work described by Baillie and Hazel (2003) and Marimuthu (2005), as a 'controlled exercise' or by Woolnough (1991) as a 'cookbook approach'. It seemed that 
the practical work the teachers conducted provided limited room for students to engage with a higher level of enquiry such as structured or unstructured investigations, as explained by Baillie and Hazel (2003), where students are afforded the opportunity to be creative.

Practical work where students follow set steps to arrive at a known result can at best lead to the development of procedural knowledge, which is a low-level skill and does not lead to students understanding why they are following a particular procedure. There were several observations made in the classes of all three case study teachers where some students were able to follow the set procedure, however, when asked, only a few students demonstrated an understanding of the purpose of each step. For example, in setting up the laboratory apparatus to investigate the absorption of glucose solution from the Visking tube, TM reminded the students to rinse the Visking tube that contained glucose or starch solutions with distilled water before putting it into a boiling tube that contained distilled water. The focus group students did not perform the step and it seemed they did not comprehend the purpose of those steps or the consequences of not performing the steps as directed by the teachers or stated in the textbook. In their research into practical work, Abrahams and Millar (2008) found that sometimes students might be involved in manipulating objects without understanding the reasons for doing so in the first place. Practical work that the teachers planned might help students to produce the desired results and develop skills, but the students might not understand the reasons for performing those steps and the consequence of not following the steps. It appears that the focus on doing science is unlikely to enable students to develop an understanding of the nature of science promoted by Lederman et al. (2014). Roberts et al. (2009) argue that students need procedural understanding to make sense of the data they have collected. It was apparent during post-practical discussions that students did not develop procedural understanding during practical work in most lessons.

\subsection{Theme two: Influences on the implementation of practical work}

The findings of this study showed that the teachers preferred to plan and carry out practical work such as a 'recipe practical' or 'controlled exercise' classified as low level enquiry. The findings are consistent with Abrahams and Millar's (2008) study, where they found that regardless of subject specialism, teachers preferred to carry out a 'recipe practical' where students followed a set of instructions provided in a worksheet. Teachers' decisions are influenced by different factors that can be categorised into external and internal factors (Marx, Blumenfeld, Krajcik, \& Soloway, 1997; Minstrell \& van Zee, 2000; Zion, Cohen, \& Amir, 2007). 
The internal factors include teachers' understanding of the nature of science investigation, content knowledge, and preferred method of instruction. The external factors were the curriculum, assessment, syllabus, resources, school settings (e.g. the timetabling of practical work) and student diversity (e.g. students' academic abilities).

In this study, it seemed that the teachers were focused on the external factors rather than the internal ones when planning practical work. One of the factors that influenced teachers' decisions was the mandated Bahasa Malaysia curriculum specification that describes a science investigation as a systematic approach following a linear process to test a hypothesis (MOE, 2002a). The curriculum suggests that practical work starts with a question or a problem and ends with reporting a result. However, based on that, there is no room for students to engage in an iterative process where they are actively involved in asking questions, posing problems, reviewing the steps that they performed, or recording the results they produced. The curriculum does not suggest different approaches for conducting practical work such as pattern seeking, classifying, or developing a system as described by Watson et al. (2002) in their typology of different kinds of investigations. The suggested activities listed in the curriculum specification may also have prevented teachers from trying different types of practical work. Hipkins, Barker, and Bolstad (2005) agree that teachers' practices were often bounded by several factors, particularly the examination-based curriculum.

Resources were another external factor that influenced teachers' practices. The textbook (Tong \& Neo, 2003) and the experiment book (Kheng \& Yassin, 2005) are based on the curriculum specification designed to support teaching and learning activities. Practical work is designed as 'a recipe practical' or 'a controlled exercise'. According to Bailie and Hazel (2003), this type of practical work may help teachers to plan ahead as the answers, and what students learn from the practical, are predictable. However, the limitation of such practical work is that students develop a narrow view of science practical work as a learning process in which one follows instructions to manipulate objects to arrive at a known answer to a question, which is contrary to how science works. Yet these highly structured methods of teaching using prescribed texts and experiment books may have limited student learning in the 21 st century.

Participating teachers' expressed their concerns about the school timetabling of science lessons as another external factor that influenced their decisions in choosing the instructional approach. During the interviews the teachers $(n=4)$ explained that practical work was a time consuming teaching approach, with time required to prepare materials, to wait for results from experiments, and for students to report on what they have done. The observations showed 
that the teachers (TR, TJ, and TM) had less than two periods for the practical lesson because they spent more time waiting for students to arrive at the laboratory and time for them to write their reports of the practical work before they could start the lessons. Similarly, in Baillie and Hazel's (2003) research, they found that although teachers conducted low-level inquiry practicals such as a 'controlled exercise', it still took at least two lessons to complete. Marx et al. (1997) suggest that time is one of the factors that influenced teachers' practices in and after lessons. Marx et al. explained that teachers may find it difficult to complete the lesson within the allocated time and argued that outside the classroom they may not have time to reflect on the effectiveness of their teaching approach. Therefore, time may be one of the factors that prevented the teachers from conducting a high level of practical work on a regular basis.

Another external factor that the teachers $(n=3)$ considered in conducting practical work was the need to cover content that would be tested in examinations. They claimed that the form two science syllabus contained too much content for one year. During his interview, for example, TR described the education system in Malaysia as 'examination-oriented' focusing on student performance in tests and exams. It seemed that completing the syllabus and preparing students for exams was a concern for all participating teachers. The findings were congruent with a study conducted by Lee, Tan, Goh, Chia, and Chin (2000) who also found that teachers spent time on engaging the students in tasks that would enable students to answer the examination questions and allow teachers to complete the syllabus on time. Taridi's (2007) research in Malaysia also found that preparing for examination was a priority for senior secondary school teachers and Daniel (2005) reported similar priority in primary school.

The diversity of students is one of the external factors that the teachers considered in planning practical work. All teachers believed that students at the lower secondary level still required guidance from them and were concerned about poor literacy skills and students being unable to read and write. It seems their findings are supported by the poor Malaysian student performance in PISA especially in reading, where Malaysia scored 420 points, which was below the global average scores (501 points) (MOE, 2012). During the interview, some participating teachers $(n=3)$ said that a weakness in English language might affect how students perform the practical task, for example, TK explained that students regardless of their education level still needed teacher support. She said that when preparing for practical work, she translated the instruction from the textbook into Bahasa Malaysia because some students 
could not read and write fluently in English. In the classroom, it was observed that TM explained the concepts and procedures in English and followed this in Bahasa Malaysia for all students regardless of their academic abilities.

A related issue was the diversity of skill level and the wide range of student abilities within the class. Based on the interviews, participating teachers complained that students arrived in class with a lower level of skills than expected. For example, the teacher expectation was that all students should know the laboratory apparatus and be able to handle it correctly. TK related student academic ability with their ability in handling the laboratory equipment and argued that low achieving students needed extra support because their English was poorer and this required her to repeat the instructions in Bahasa Malaysia. Chin, Goh, Chia, Lee, and Soh (1994) also highlighted that student academic ability is one of the factors that influenced teachers' decisions in choosing a particular mode of instruction.

Content knowledge is an internal factor that may influence teachers' decisions in conducting practical work at a low inquiry level as opposed to a high level. Classroom observation showed that not all case study teachers had appropriate subject knowledge. Shulman (1986) defines subject matter knowledge as facts, concepts, and underlying principles of the subject. Shulman emphasises, "[t]he teacher need not only understand that something is so, the teacher must further understand why it is so" (p.9). Therefore, at a more advanced level, it is about knowing the connection between the science ideas within a particular topic. For example, when TM taught the topic of sound, she explained how sound is produced. She wrote that sound is produced through vibration but she did not write how the sound is transmitted within one medium and from one medium to another medium. While she explained the notes to the whole class, she talked about the transmission of sound but she did not explain the relationship between the vibrations of medium and the transmission of sound. Similarly, TJ while teaching plant movement, did not explain each term that represented the plant movement. Sometimes teachers themselves may hold misconceptions that are transmitted to the students and these misconceptions might be caused because the teachers did not have sound subject knowledge. According to Ball (2000), teachers with a lack of subject knowledge plan and teach lessons that are focused on facts and procedures as opposed to teachers with a sound content knowledge who tended to plan teaching and learning activities that focus on conceptual understanding, problem-solving, and inquiry. Anderson and Moeed (2013) report that a lack of subject knowledge is a barrier to teaching science in primary schools. 
Another internal factor that influenced teachers' practices was related to teacher understanding of the nature of scientific investigation. Moeed (2013) argues that teachers who are required to teach students how to investigate often do not understand science investigation themselves. It seems that the teachers in this study may have had inadequate understanding about how to carry out a scientific investigation. In the interviews, the teachers did not show that they understood science investigation as a subset of practical work, and were not aware of different types of scientific investigations. During the interviews, none of the teachers mentioned 'fair testing' as one of the approaches to science investigation which is a common practice in other countries such as the United Kingdom (UK) Watson, Goldsworthy, and Wood-Robinson (1999) and New Zealand (Hume \& Coll, 2008). There was little evidence during observations, that case study teachers planned practical work that engaged the students with important aspects of science investigation such as asking researchable question(s). Teachers did not emphasise the importance of the science investigation to answer a question or understand the natural world. Lederman (2007) points out that a lack of understanding about the nature of science among teachers is one of the reasons that contribute to the failure of planned lessons that can promote student understanding of how science works. Some researchers attribute this to inadequate training in undergraduate studies (Ryder, Leach, \& Driver, 1999).

The teacher's instruction is another internal factor that influenced the teachers' practices. During the interviews, the participating teachers $(n=6)$ said they provided information on practical work in great detail that included the questions to be asked, materials to be used, the procedure to be followed, and how to record the data. It was observed that all the teachers also provided an outline on how to write the report. For example, TR provided time for students in the pre-practical activity to copy the instruction from the textbook into their experiment book before he gave detailed instructions on how to carry out the practical task. TM also allowed the students to copy the procedure to investigate the absorption process before the students embarked on conducting practical work. They preferred to deliver the instruction in detail so students could follow the instructions accurately. According to Berg, Bergendahl, Lundberg, and Tibell (2003), systematic guidance during practical work may help the students to solve the problem or answer the question but is insufficient to develop critical thinking and scientific thinking. Conversely, Hodson (2014) supports the need for teacher guidance initially, with the ultimate aim for students to do practical work independently. 
To conclude, the teachers' preferences in conducting practical work were influenced by both internal and external factors. The mandated curriculum and the resources including textbook and experiment books were the most influential external factors in conducting practical work. Other external factors highlighted by the teachers included perceived students' academic abilities, language barriers, and curriculum time to complete practical work. It seemed that the teachers did not include reflection on their own practices in conducting practical work as an internal factor influencing their practice. The teachers showed a lack of content knowledge and understanding of the nature of science investigation. The overall impact of these factors limited student experience of practical work to 'recipe practicals' and constrained student learning through practical work.

\subsection{Theme three: Teacher questioning promoted 'traditional' teaching and learning experiences}

The teachers' questions were evaluated using a framework developed by Chin (2007). Chin's framework has five criteria to classify the questions that teachers asked during lessons and included the purpose of questioning, the structure of the questioning sequence, the nature of teachers' questions and students' responses, teachers' feedback, and authority for judging the answers. In this study, the questions that the teachers asked appeared to share some similarities. Throughout the lessons, the teachers usually initiated the classroom interaction by asking questions (initiation). The questions that teachers asked required that students recalled facts, stated the results, or restated the instructions. The students tended to give short answers (response) that consisted of a few words without elaboration, and then teachers assessed the correctness of the answers (feedback/evaluation). It appeared that the sequence of teachers' questioning was based on the IRE/IRF (Initiate-ResponseEvaluate/Feedback) sequence. This flow of interaction is known as the IRE sequence (Mehan, 1979) or triadic dialogue (Lemke, 1990). The IRF sequence (Sinclair \& Coulthard, 1975) was slightly different from the IRE sequence in how teachers responded to students' answers. Based on the lessons observed, the teacher feedback was not necessarily aimed at evaluating students' answers, and included comments to extend their thinking and ideas. The teacher questioning promoted traditional teaching and learning experiences. According to Chin (2007) in traditional lessons, teacher talk aims to transmit knowledge, and give instructions through a lecture-based approach and the nature of teacher questions is to accumulate student knowledge rather than promote understanding. The teachers tended to ask low-level questions, that required students to recall answers or repeat instructions. The 
students typically gave short answers that consisted of a single word without further explanation in response to those questions before the teachers evaluated the answers based on accepted scientific facts or theories. In taking such a traditional approach the teachers have more control of the lessons and achieve the learning objectives, but constrain student opportunities to extend thinking and generate ideas.

The teachers used different strategies in presenting the questions. Firstly, a common practice of the case study teachers was to ask questions of the whole class without nominating any particular student to answer. Such a teacher questioning approach might affect student responses, as the students either called out the answers together or did not respond at all, perhaps opting not to answer because they did not know the answer or might not be comfortable in answering (Baird \& Northfield, 1992). Secondly, where the teacher nominated an individual student to answer the question after he/she posed it, the teachers could assess individual students' knowledge. However, using this strategy it was difficult for the teachers to assess whether other students had the same knowledge. Although the teachers' questioning might help students to strengthen their existing knowledge about the topic it might not help them to develop higher-level knowledge and understanding by making comparisons or developing hypotheses, as suggested by Chin (2007). The teachers tended to ask questions that required the students to recall the information or state the procedure. In Roberts et al.'s (2009) view such an approach is unlikely to support the development of the skill of argumentation which ought to be a priority in these lessons.

A common feature of the lessons observed was the structure of interaction. All the case study teachers practiced the IRF structure in orchestrating whole classroom discussions. They maintained their position as the source of knowledge to control the flow of the lessons and their talk was mostly aimed on 'delivering instruction and knowledge' and 'asking questions to evaluate' at a superficial level. Through the questions they asked and the information they delivered, they exposed the students to canonical scientific knowledge. According to Mortimer and Machado (2000), often the questions that teachers asked, related to the mode of teachers' instruction. When teachers take a traditional teaching approach focused on transmitting knowledge from teacher to student, they tend to evaluate only the knowledge they intended to pass on.

Anderson et al. (2001) have reviewed Bloom's classical taxonomy of the cognitive domain. They found that Bloom classified knowledge as requiring a lower level of thinking if it only requires the students or learners to recall information. Based on the lessons observed, the 
case study teachers asked questions to elicit student knowledge and that required students to recall the facts, state the procedure, recall the function of particular equipment, or state the observation after they had conducted practical work. In the pre-practical activity, the teachers tended to ask questions that mostly required the students to recall facts or technical questions that focused on the procedure and the results. Although in the post-practical activity the students were answering the questions from the textbook or the experiment book, those questions did not engage the students with higher-level thinking. Even though the textbook and experiment book questions were called 'analysis questions', they only required the students to recall facts, re-state observations, fill in the blanks, or were closed requiring a yes or no answer. It seemed that the nature of the student response was influenced by the teacher questions or the questions in the textbook and often students tended to give a single word answer without further explanation. Koufetta-Menicou and Scaife (2000), argue that the disadvantage of this low level questioning approach was that it did not challenge student thinking. Those questions led to memorising and recalling facts and did not stimulate students to think deeply about what they were learning (Chin \& Langsford, 2004).

In response to incorrect answers from students, the teachers often provided the 'correct answers' and explained why the answers given had been incorrect. Such an approach did not afford the students time to consider explanations that required them to think critically about the answers they provided and the science concepts they were learning. It seemed that teacher feedback did not provide opportunities for students to evaluate their own or their peers' answers. It was noted during classroom observations that hardly any of the teachers provided opportunities for students to justify their own answers. Thinking with evidence and justification of conclusions are essential ideas that demonstrate an understanding of the nature of scientific investigation (Lederman et al., 2014; Roberts, Gott, \& Glaesser, 2010). Teachers' feedback on students' answers had implications for students' engagement with the lessons. According to Chin (2006), students might not be able to provide answers beyond the initial questions and the teachers might miss the opportunity to elicit more responses from students to extend their answers. Most of the teacher feedback was aimed at evaluating the students' knowledge rather than ascertaining student understanding and scaffolding students' conceptual development. Some of the teachers tended to repeat the students' answers to the whole class. Chapin, O'Connor, and Anderson (2003), have described this phenomenon as 'revoicing' where the teachers affirm students' answers and make the answers available to other students. Zee and Minstrell (1997) argued that teachers can improve their approach by 
changing the way they respond to students' answers. In this study, the teachers had not necessarily given evaluative comments on students' answers, and in doing so they lost the opportunity to extend students' responses by asking questions that required the students to make sense of their own answers.

To conclude, the flow of interaction in the lessons observed in this study showed that the teachers still followed a traditional pattern of classroom interaction. For instance, the teachers asked closed questions that invited students to give short answers without elaboration. Then, the teachers evaluated students' responses by giving evaluative comments and expected students to accept these as the correct answers. The teachers wanted to hear correct answers rather than encourage students to give the rationale for their answers. According to Lemke (1990), the IRF mode of interaction may not involve students in talking science and may reduce the interaction to single word correct answers. In this study, students were unable to talk through their ideas or make sense of the things they manipulated and observed because of the mode of interaction and the type of questioning. In science learning, it is critical that students develop the understanding that theories are generated by making sense of what is observed (Millar, 2011). It appears that the teachers' approach to teaching and questioning is unlikely to help students develop an understanding of the nature of scientific investigation, which is an essential aspect of school science learning (MOE, 2007).

\subsection{Theme four: Limited student opportunities to construct understanding}

Chin and Brown (2000), identify aspects of student learning in conducting practical work that included approaches to asking questions, giving explanations, completing practical work, and generating ideas. Entwistle (2005), defines the learning approach as "what the students intended to learn and how they learn it" (p. 2). In this study, the focus group students mostly used a surface approach rather than a deep approach in each of these aspects of learning.

Following the Chin and Brown's (2000) definition, students adopted a surface learning approach, as they tended to ask low cognitive level questions that focused on seeking information about facts and procedures. Based on the lessons observed, focus group students rarely asked questions while they worked together to complete the practical work. If they asked questions, they tended to get clarification from teachers or peers about the procedure to facilitate them in completing practical work, such as the steps to be followed, the materials to be used, or the results to be recorded. For example, they formulated questions such as What should we do? or What should I add to the Visking tube? After teachers or peers responded to 
those questions, they accepted the information or ideas without being thoughtful about the reasons for performing the particular steps. According to Chin and Brown (2000), student questioning is related to their thinking. The findings of this study showed that the students did not use a deep learning approach in conducting practical work such as "linking course content with real life" (The Higher Education Academy, 2011) or linking the domain of ideas to the domain of objects and materials through practical work (Millar, 2004).

In both the classroom observations and focus group interviews, it was apparent that students adopted a surface approach in conducting practical work, especially explanation. They only explained at "the macroscopic level" (Chin \& Brown, 2000, p. 121) as they tended to describe the observable entities without making any connection to the concepts that they should learn or the phenomenon they observed. It was apparent during classroom observation that students could state the observation correctly but could not explain how the results related to the concepts they were expected to learn, or the phenomenon they observed. Similarly, during spontaneous conversation while students conducted practical work, and in focus group interviews, students could repeat the steps of conducting practical work but were unable to explain the reasons for performing those procedures. They showed procedural knowledge but not procedural understanding. In the observed lessons, students did not discuss the reasons for, and importance of, performing certain steps, with other group members, which demonstrated they could not make sense of what they had done in their practical work because they were focused on manipulating objects rather than on understanding the importance of handling them following a particular process. They conducted practical work without considering the reasons for their own actions and could not highlight the importance of validating data or the accuracy of the measurement, or engage in what Roberts and Gott (2006) describe as "the thinking behind the doing" (p. 47).

Generative thinking refers to student abilities to generate answers when there is no readymade solution to problems with which they are not familiar, or when they answer by recall of facts they have rote learned (Chin \& Brown, 2000). The students' answers could be classified into two main categories; in the first, they were unable to generate any answers at all, and in the second, they attempted to give a short answer that could be scientifically correct or incorrect. While conducting practical work, most of the focus group students could not generate ideas when they were asked about the practical work they were conducting. They were stuck for an answer, and said, I do not know, The teacher asked us to do it, or when they were asked to explain what they were doing, they did not respond at all. However, in the focus 
group interviews, when they were asked to explain their practical work or facts they had learned, they attempted to give a short answer without elaborating and their responses were either scientifically correct or incorrect. The scientifically incorrect responses demonstrated that they still held alternative conceptions on that particular topic even though they had carried out the practical work and had been taught the theory in class.

There seemed to be a number of factors that encouraged students to use a surface approach in conducting practical work. Firstly, they relied on using external resources such as peers, teachers, textbooks and the experiment book (Chin \& Brown, 2000). The textbook was used nationally, whereas the experiment book was selected by the participating schools, and both provided a set of 'recipes' for students to conduct practical work. The advantages of using the prescribed activities were that students could use the 'recipes' and follow the instructions to produce the desired results. However, not all the students could understand the written instructions, and some made mistakes collecting the materials and apparatus, or when following the steps in setting up the apparatus. It seemed that the prescribed instructions also prevented the students from reflecting on what they had done. They did not think critically about the procedures in terms of the quality of the collected data or the validity of the results achieved from conducting multiple trials, and did not draw evidence-based conclusions from their investigations, passively accepting the conclusions suggested by their teachers. In the focus group interviews, students demonstrated they could not recall all the steps to conduct practical work in the correct order. The findings are supported by a study conducted by Roberts and Gott (2006) in the UK, where students showed a lack of understanding of the procedure in conducting science investigations.

The second factor was the type of questions asked during practical work. It seemed that teachers asked questions, which required the students to recall information or state an observation. Although students were required to answer a set of analysis questions from the textbook or the experiment book, those questions did not lead them to be analytical in their practical work. Some of the questions required the students to recall the observation rather than interpret the results and make evidence-based inferences. The questions did not require students to find out the advantages or disadvantages of practical work or evaluate their own results. If the teachers continue to conduct the practical work as suggested in the books, the students will not be able to engage with authentic science investigation and their learning will continue to be limited to memorisation of "fact and procedures routinely" (Entwistle, 2005). The findings find congruence with a study conducted by Moeed (2010) on a science 
investigation. Moeed reported students taking a similar surface approach to learning due to a narrow focus on a linear and sequential investigation for the purpose of assessment.

To conclude, the implemented 'recipe practical' appeared to be instrumental in students taking a surface approach to learning alongside the commonly practised teaching approaches. The students merely followed procedures to manipulate materials to get the desired results without thinking about the implications of their own actions. Entwistle (2005) stated that a deep approach to learning requires the "intention to understand material for oneself, interacting vigorously and critically on content, relating to previous knowledge/experiences, using organising principles to integrate ideas, relating evidence to conclusions, and examining the logic of the argument". There was little evidence of any of this to demonstrate a deep approach to learning among the students in this case study. Trigwell, Prosser, and Waterhouse (1999) highlighted that the teachers who adopt the teacher-centred approach were only likely to involve students in a surface approach to learning.

\subsection{Theme five: Limited constructivist practice and social-constructivist practice}

Constructivist notions of knowing and learning suggest that teaching practices ought to move away from didactic teaching approaches and engage students in learning experiences where knowledge construction takes place in real life situations during socially negotiated tasks (Nie et al., 2013). The basic constructivist belief is that knowledge is constructed by the mental activity of the learner and that it cannot be transmitted (Driver et al., 1994). With reference to science teaching and learning, Leach and Scott (2003), argued that to practise constructivist pedagogical approaches it is imperative that teachers understand which teaching approaches are likely to help students grasp concepts, develop skills, or understand about the nature of science.

Analysis of the interview data showed little teacher understanding of the constructivist approach to teaching, and the notion of learning through the construction of one's own understanding. This was also apparent in classroom observations, as most teaching was teacher-led. It has been noted that teachers often presented work, such as the concepts or the laboratory instructions, by using transmission approaches and that students carry out practical work by following highly structured instructions (Berry et al., 1999; Hume \& Coll, 2008). Students did not have opportunities to plan or design practical work to develop their understanding of the concepts. As discussed earlier, students mostly experienced their learning as the delivery of content by the teacher or by participating in structured practical work with little room for collaboration and 
discussion. As observed, the practical work that teachers conducted did not allow students to develop their own understanding because the teachers decided all aspects of it. Practical work appeared to be used as a way to get students involved in lessons, and as is often the case with large classes of students with diverse needs, the teachers had little opportunity to address the needs of each individual, so often conducted, and managed practical work with groups of students. Leach and Scott (2003) argued that with large classes teachers have "little possibility of responding to each individual student's cognitive processes over a sustained period of time" (p. 95).

Social constructivist approach to learning emphasises the need for learning from each other during the learning process. It seemed that the nature of practical work, class size, and the duration of lesson were factors that discouraged such interactions during practical work. The main factor that seemed to be hindering the implementation of social constructivist approaches in the current study was the approach to practical work. The students engaged with a 'recipe practical' where all aspects of practical work that might engage students in constructing the meaning with peers or teachers such as questions to be asked, method to be used, data to be collected, and method to analyse data were already given to students. It seemed that a predetermined procedure allowed students to follow the instruction so that they could get expected results but they had limited opportunities to try new ideas, argue, or debate with peers as they followed the procedures. Often, students did not have the opportunity to engage in discussion that would allow sharing of ideas which could potentially help them to make personal sense of what they have done or heard while engaging in the practical activity.

According to Leach and Scott (2002), in a social constructivist approach, teachers plan a lesson that provides opportunities for students to talk about their understanding with teachers or peers. In this research it seemed large class sizes were a barrier for providing opportunities for sharing and critiquing each other's ideas. Teachers found it difficult to monitor student progress and to intervene when necessary to scaffold individual student's learning. In most lessons it appeared that the class was a single unit doing things together rather than learning from each other.

The duration of lesson is also an important aspect to implement a social constructivist approach in planning practical work. Leach and Scott (2002) suggest that in a social constructivist approach, a teacher not only allows students to engage with a particular practical in a small group, but also plans how students can talk and discuss with peers around that practical work. Such planned discussion is a strong social constructivist pedagogical approach. The dialogic communicative approach in expressing their views to peers in meaning making process is 
encouraged by Aguiar et al. (2010). The findings of the case study show that an authoritative communicative approach was preferred to a dialogic communicative approach especially in 'the pre-practical phase' and 'the post-practical phase'. It seemed that the participants found 90 minutes for each practical lesson was not enough to involve students with the dialogic communicative approach because time was taken up with the procedure, learning about expected results, and preparing for what is required in the examination. Additionally, teachers have to deal with logistic issues such as preparing material and laboratory equipment, delivering instruction to students, monitoring students' work, and managing student behaviour.

This study set out to look at teaching and learning through a constructivist lens and found very few examples of constructivist approaches to either teaching or learning. It appears that the focus on 'covering' the content within a tight time frame to prepare students for examinations took priority on what and how students learned through practical work. The case study teachers did not have an in-depth understanding about a constructivist teaching approach, especially when conducting practical work. They had full control in the classroom, from the beginning of the practical work until the end of the lessons, and there was a lack of evidence to support that students were actively involved in constructing understanding through their own ideas. Although students were involved in manipulating the objects to produce the desired phenomenon, the teachers were the ones who made sense of the phenomenon.

\subsection{Theme Six: Students showed a lack of procedural knowledge}

Procedural knowledge is knowledge related to technical skills that enable students to know how to do practical task. According to Abrahams and Millar's (2008) matrix of effectiveness of practical work, procedural knowledge is related to effectiveness at level one (observable) that focuses on students' ability to carry out practical work and produce the phenomenon intended by teachers. Procedural understanding refers to students' ability to rationalise decisions for following certain procedures. The findings show that many students have the procedural knowledge to carry out practical work, but they did not demonstrate an understanding of why they conducted it or the importance of following certain procedures.

Lesson observations showed that; the teachers made a lot of effort to help students to understand what they were supposed to do with the materials and equipment to produce the intended phenomenon successfully. Following the profile form developed by Millar et al. (2002) the analysis revealed that teachers carried out a 'recipe practical'. It seemed that all aspects of practical work were decided by teachers and that they used the suggested practical 
work stated in the textbook or experiment book. Students did not have the opportunity to determine any aspects of the practical work such as the questions to be asked, equipment to be used, the procedure to be followed, the method of recording data, or how to interpret the data. According to Baillie and Hazel (2003), structured practical work can assist students to produce the intended phenomenon by following the instructions. It also has benefits for the teachers or instructors as they can easily repeat similar practical work.

Despite the transmission of detailed information about the practical work from teacher to student, it seemed it was not really effective in getting the students to produce the intended phenomenon. This might be because students did not follow the entire procedure correctly, or because they might not have the appropriate procedural knowledge. What emerged from the classroom observations was the students did not fully understand what they were supposed to do with the materials and equipment, and tended to ask teachers or peers. They might not understand the procedure for conducting practical work even though the teachers delivered the instructions using several different approaches. It seemed that students might not be willing to conduct practical work by following the procedure due to "cognitive overload" as discussed by Tamir (1991, p. 16). Cognitive overload occurs when there is a great demand on students' working memory to absorb information that teachers present to them in a short time.

Another factor that hindered students carrying out practical work successfully was student commitment to learning. It seemed that some students did not pay attention to the written instructions or listen carefully to any instructions given by teachers or group representatives and so may not have any idea how to carry out the practical work correctly. They relied on others, such as teachers or peers, to tell them what they were supposed to do with the materials and equipment. The findings were similar to those in a study conducted by Berry et al. (1999) who claimed that most students do not read the instructions before they carried out practical work as they considered practical work a 'hands-on' activity and were focused on completing it.

Evidence from the observed lessons showed students demonstrated a lack of manipulative skills in conducting practical work and some did not know how to use the materials correctly. They struggled to use a piece of equipment correctly despite a demonstration given by the teacher before they embarked on practical work in groups. The lack of skill in using laboratory equipment correctly influenced other scientific skills, such as taking the measurements or making observations. Students' failure to grasp the manipulative skills correctly, influenced the quality of results they generated. Johnstone and Al-Shuaili (2001) argued that a lack of 
manipulative skills might lead to poor data collection or failure to make an important observation. Even though science education scholars promote procedural understanding as the most desirable aim for practical work, the some participants in this study appeared unable to even develop procedural knowledge.

In this study, the students showed moderate procedural knowledge, sufficient to conduct practical work based on the teachers' 'cookbook approach' or 'recipe style' practices. Teachers used multiple approaches to delivering the procedural information as they considered the generation of desired phenomenon as the main priority in conducting practical work, and some students were able to manipulate the objects and materials to produce the intended phenomenon after a few attempts. This situation might have occurred because students cannot digest procedures or because of their lack of scientific skills to carry out practical work.

\subsection{Theme Seven: Students showed a lack of conceptual knowledge}

According to Millar, Le Maréchal, and Tiberghien (1999), "the students should not only be involved in observing and/or manipulating the objects and materials, they should also be involved in using, applying, and perhaps extending their ideas" (p. 44). What the students do with materials is clear because we can directly observe them while they engage in practical work. However, what the teachers wanted the students to do in the domain of ideas, cannot be directly observed. 'Doing with ideas' or conceptual knowledge refers to the scientific ideas that students are expected to develop through observation of the manipulation of objects and materials. Students' thinking about ideas could not be directly observed from their actions, but can be inferred from their conversations while carrying out practical work (Abrahams \& Reiss, 2012).

The findings show that students did not fully develop conceptual knowledge through practical work. There was less evidence to support that students discussed scientific concepts with peers or teachers or used scientific terminologies correctly while they carried out practical work, although it appeared that teachers used scientific terminologies when delivering the procedural information. They used those terminologies to familiarise students with the materials and equipment they would be using in practical work. Although teachers explained the procedures using scientific vocabulary, not all the focus group students were able to use the terms correctly. It was observed that the students tended to use terminology that was not scientific when conducting practical work, and there was evidence to support that students 
were unable to name the laboratory equipment correctly. Although students showed some weaknesses in using scientific terminologies, it did not mean that the students who used unscientific terminology in expressing their understanding did not think about their practical work. The scientific ideas that students developed through practical work can vary. Abrahams and Millar (2008) suggested that students may think about the practical work they have conducted in different ways. Abrahams and Millar's framework for the analysis of effectiveness is based on whether students are able to do what the teacher wants them to do (level 1) or if students have learnt what the teacher intended them to learn (level 2). In this study some students were able to perform at level 1 but others, it appeared, could not even achieve that.

There were a number of factors that influenced students' opportunities to develop conceptual knowledge. Firstly, the teachers did not make the conceptual knowledge available to students before they carried out the practical work. Based on the lessons observed, some of the case study teachers (e.g.TJ) did not make those scientific ideas or terminologies available to students. The findings show that some students understood the procedure they were doing but not always know why they were doing it. They tended to ask questions related to the steps to be followed or the materials to be used, and there was less evidence to support that they discussed the scientific concepts. It seemed that if the sole aim of conducting practical work was to ensure students produced the intended results or phenomenon, then the opportunities for students to learn the scientific concepts were limited. Edmondson and Novak (1993) also pointed out that if students were focused on completing the task, they would not have a lot of opportunity to learn about the concepts. Hodson (2014) contends that teachers can support the development of conceptual knowledge through well-crafted practical tasks or demonstrations. Students need teachers' supports to help them build the bridge between 'knowledge what' and 'knowledge why' (Wellington, 1998; 2006). Manipulation of objects can be done by students but manipulation of ideas requires teacher scaffolding to make the links between the domains of object and ideas (Millar, 2004). Practical work, carefully crafted, can lead to conceptual understanding.

Secondly, students might not be able to use the scientific concepts as they did not fully understand the meaning of them. Some of the scientific concepts were associated with scientific terminologies (e.g. molecules or wall of small intestine) with which students might not be familiar. It was observed that some of the case study teachers (TM and TR) explained the concepts that they wanted students to learn prior to the lessons; they used different approaches such as verbal and visual aids before allowing students to carry out practical work 
in groups. They did not define the scientific terms as they explained the concepts. It seemed that as students carried out practical work, they focused on manipulating the objects and materials without relating them to the concepts. According to Abrahams and Reiss (2012), students might have some difficulty relating the objects they used when conducting practical work to the scientific concepts, because they might not be familiar with the scientific terms used to explain the scientific concepts.

Thirdly, students did not have the opportunity to make sense of the phenomenon they observed, due to the manner in which the teachers responded to students' findings. During the observed lessons it was clear that the students did not have the opportunity to consider their results and provide evidence-based explanations. It seemed that teachers tended to explain the reasons why students produced such results instead of asking the students to try to explain the results themselves. Teachers did not initiate students in using scientific ideas to make sense of the phenomenon they produced or observed, and tended to give possible answers rather than allowing the students to think about what they were doing, and articulate how their results related to the intended scientific ideas. Abrahams and Millar (2008) suggest that students must be familiar with, and know how to apply the intended ideas, as one of the requirements to ensure they could explain the intended phenomenon.

In conclusion, the practical work that students carried out was ineffective in developing conceptual knowledge. There was little evidence to show that students discussed scientific ideas while they carried out practical work and used the correct scientific terminology to discuss their ideas. There were different factors that influenced the development of their conceptual knowledge. The external factors included the time allocated to scaffolding scientific concepts, teacher feedback on students' work, and students' knowledge of scientific concepts. Teachers played an important role in delivering the scientific concepts and, as Abrahams and Millar (2008) pointed out, teachers need to allocate appropriate time to scaffolding the development of scientific concepts. Students need the teachers to help them to build the bridge between 'knowledge what and knowledge why' (Wellington, 1998; 2006)

\subsection{Summary of the chapter}

To summarise, the emerging themes suggest that teachers focussed on the doing of science rather than providing opportunities for students to carry out science investigations. Although the curriculum requires students to learn through doing practical work, learning was limited by a number of factors including teachers' limited understanding of the nature of science 
investigation, the textbooks and workbooks, time constraints, and teacher belief about students' ability to learn the ideas. The nature of teacher questioning, the manner in which the class discussions were conducted, and the traditional didactic teaching style all constrained students' opportunities to learn. Although the Malaysian science curriculum is underpinned by the constructivist views of learning, there was little evidence of constructivist pedagogies. Students did learn what the teachers intended them to, and in the process did not develop either procedural or conceptual understanding. Overall, learning from practical work appeared limited. 


\section{Chapter 10: Conclusion and Implications}

\subsection{Introduction}

The aim of this study was to investigate the current practice of teaching and learning from practical work in the lower secondary schools in Malaysia. To gain a deeper insight, practical work taught by teachers and experienced by students was explored in several schools in Melaka. The purpose was to understand the teachers' views for conducting practical work with the aim of finding out how the teaching approach of practical work taking place in the classrooms aligned with the requirements of the curriculum mandated by the Ministry of Education (MOE, 2002a). The study looked into why and how practical work was done; the impact of teacher talk on student learning opportunities; teacher - student interactions; and the effectiveness of getting students to do practical work to learn science concepts. The findings of this research, towards which teachers and students have contributed, have the potential to make a difference to the teaching and learning of science through practical work at the Malaysian lower secondary school level. Finally, the implications of the findings and recommendations for teacher practice and science education policy are presented. Future directions for research in this area are suggested.

\subsection{Research Question 1: How did form two science teachers understand practical} work at the lower secondary school level in different types of schools in Melaka?

\subsubsection{How did form two science teachers understand practical work?}

Teachers' understanding of practical work was in accordance with their espoused purposes for practical work, particularly:

i. Teachers understood that the purpose of practical work was to illustrate science concepts.

ii. They believed that through practical work students could develop conceptual knowledge.

iii. Teachers considered the development of manipulative and process skills important and thought this could be achieved through student engagement in practical work.

iv. In the teachers' views, through doing practical work, students could develop positive attitudes and beliefs about science. 
The participating science teachers understand practical work according to its purposes. They believed that through practical work students were be able to develop conceptual knowledge and procedural knowledge and develop positive scientific attitudes and essential skills.

Participating science teachers referred to procedural knowledge as manipulative and science process skills. Most of the participating teachers only focused on certain aspects of those skills and neglected other skills suggested in the curriculum specification. They engaged students with basic science process skills especially in making the observations and inferences and developing skills in manipulating objects correctly. Students had limited opportunity to experience other skills as the participating teachers tended to tell their students what they were supposed to do with the materials and how to record data. It might reflect their practices and views of conducting practical work. They might perceive practical work as a teaching approach that aimed to produce the intended phenomenon before students could draw the conclusion.

Teachers also suggested that practical work was a unique teaching approach. It was different from the lecture-based teaching approach as students' participation in teaching and learning activity went beyond listening to teacher talk. Students could develop conceptual knowledge, through active participation in producing the phenomenon. They believed that students could link the phenomenon that they produced through manipulating objects, with scientific ideas. Teachers' beliefs were concurrent with the framework developed by Millar et al. (2002).

Teachers inculcated positive scientific attitudes and essential skills implicitly through practical work. It seemed that they assumed that students could develop those attitudes and skills through observing them conduct practical work with other students.

\subsubsection{How did form two science teachers practise practical work?}

Teachers' approaches to practical work demonstrated that they used it as a pedagogical approach because it was a requirement of the curriculum, and because they believed it helped prepare the students for examination. It had the following characteristics:

i. Most practical work was done as 'recipe practicals' with little input from the students.

ii. Instructions were either given in detail by the teacher orally, step by step or from text and experiment books. 
iii. Often the science ideas were taught during the theory lesson and practical work was done for students to 'see' the phenomenon take place before their eyes.

iv. Skill development through practical work was a priority, with focus on using equipment 'correctly'.

v. The 'doing' of practical work was followed by teacher-led discussion to ascertain that the students had 'learnt' the facts that the teacher intended them to learn.

vi. Teachers' approach to practical work was constrained by limited resources; heavy reliance on the prescribed text and experiment books; the requirement to prepare students for examinations; and the large quantity of course content to be covered in classes with large numbers of students.

Teachers talked about three different approaches to conducting practical work including; demonstration, computer simulation, and structured investigation. In practice, what they saw as a 'structured practical' was conducted as a 'recipe practical'. The 'recipe practical' was the most common approach in most classes observed.

The 'recipe practical' conducted by the case study teachers shared some similarities. It can be classified as at the lowest enquiry level of practical work as highlighted by Gott and Duggan (1995). All aspects of practical work were given to students that included what was to be investigated; material to be used; the procedure to be followed; and the data to be collected. The results that students would produce were already known to the teachers. Students were not involved in designing practical work directly as all the procedure was provided by teachers who implemented 'recipe practicals' based on the suggested approach in the textbook or the experiment book. Depending on the availability of resources, some teachers adapted the tasks in the textbook or experiment book to meet the needs of diverse students.

The practical lessons provided limited opportunities for students to be involved in iterative processes. They rarely involved in criticizing the method or evaluating the quality of data before they made a conclusion. Practical work was presented in a linear sequence that began with question(s) and ended with writing a report. It appeared that teachers did not emphasize the concepts behind the doing or the scientific thinking as students carried out practical work, as highlighted by Roberts (2001). 
Practical work carried out by the three case study teachers focused on producing the phenomenon. Teachers conducted practical work to produce the discrepant events so as to provide opportunities for students to 'see' the phenomenon. However, the suggested practical work did not embrace different types of investigation as highlighted by Watson et al. (2002). There was limited evidence that participating students were involved in the fair testing, approach as suggested in the curriculum, although Tytler (2007) found this to be the most preferred science investigation among science teachers internationally.

Practical work conducted by the case study teachers neglected other aspects of students' learning. In the interviews, teachers had explicitly stated that the aim of conducting practical work was to develop conceptual knowledge, essential skills, and scientific attitudes. However, in practice, there was a lack of evidence to support that teachers had planned practical work to achieve those aims explicitly. The time allocation for students and teachers to engage with materials was greater than the time for students to make sense of the phenomenon by using scientific ideas. For example, teachers also did not plan 'how' students might use scientific ideas to explain what they did. The teachers assumed that students could develop the scientific concepts implicitly through results that they had produced or the phenomenon that they had observed. It appeared that teachers conducted practical work inductively assuming students could learn the scientific ideas from the observed phenomenon or the results that they produced. The teachers' practices were consistent with a view of learning as suggested by Solomon (1994) whereby scientific ideas would emerge from the observation. There appeared to be a mismatch between teacher beliefs about learning through practical work and their practice.

Teachers' practice of conducting practical work was influenced by internal and external factors. The external factors included the availability of laboratory equipment, the limited time slot for practical lessons, the resources (the textbook and experiment book), the demand for completing the science syllabuses, the preparation for examination, students' ability to carry out open-ended investigations, inadequate process skills; and limited English language proficiency amongst students. The internal factors that constrained teacher approaches to conduct practical work were; teachers' understanding of the nature of practical work, the method of instruction, and content knowledge. 


\subsection{Research Question 2: How did teacher talk especially questioning, facilitate classroom interactions in conducting practical work?}

Teacher talk dominated classroom discussion before, during and after practical work where;

i. the main purpose of questioning at the start of most lessons observed was to confirm that students 'knew' the steps they needed to follow to do the practical work.

ii. in post-practical activity the limited teacher led discussion and questioning was to ascertain that students had learnt the science idea the teacher wanted them to learn.

iii. as the language of instruction was a main barrier for most students, teachers were helpful by offering alternative words for the science concepts in Bahasa Malaysia.

Practical work that had been conducted by the case study teachers promoted the traditional classroom discourse following the IRE/IRF sequence (Crawford, 2005). Through the IRF/IRE sequence, teachers took on an active role in delivering the information through teacher questioning. Students participated in the classroom talk by answering teachers' questions which were largely factual and recall in nature. Often such questions invited students to give a single answer with limited opportunity to present an argument.

Teachers wanted to hear a correct answer from students rather than for probing detailed responses. In giving feedback, teachers tended to acknowledge 'correct' answers and provide positive reinforcement through praising students for correct answers rather than eliciting further responses from students about why they chose those answers. In response to wrong answers, teachers gave negative feedback rather than rephrasing the questions or providing clues that would assist students in answering the questions.

Through those teaching approaches, teachers played the role of a master or a coach in orchestrating the flow of the classroom discourse (Ko \& Marton, 2004). As a result, the teachers dominated the classroom talk and the students were unwilling to participate in the lesson as they perceived teachers as the authorized person to speak in the classroom (Chin, 2007).

Although sometimes teachers got the students to work in groups, the groups were not encouraged to share their ideas and discuss what they were going to do, how they were going 
to it, and why they were doing the practical. This limited effective discourse amongst the students in terms of opportunities to discuss scientific ideas. Large classes and limited resources were reasons offered by teachers for taking a lecture approach and reducing discourse opportunities. However, skilfully managed discourse using think, pair, and share strategies are possible even in large classes.

An important finding is that classroom discourse was constrained by the language barrier. The teachers had to move between two languages to make themselves understood. Due to the competing tensions of a lack of time, wanting to cover the content, and preparing the students for examination the language was often limited to providing the Bahasa Malaysia word for the English term rather than ensuring the understanding of the associated scientific idea.

\subsection{Research Question 3: To what extent were practical work tasks effective in helping students to do what the science teacher intended?}

i. Teachers gave instructions either orally or from text and experiment books. Some students understood what was required and were able to do what the teacher intended them to do. Others did not follow the instruction and were unable to do the task.

ii. When teachers delegated the responsibility of giving instructions to the class representatives they did not ensure that these students understood the instructions which often led to confusion.

iii. Teachers expected students to already have skills to do the practical tasks they had set. Some students did not have these skills which became a barrier for these students to accomplish what the teacher intended them to do.

iv. Teachers often gave step-by step instructions for doing the practical but the students were not told why they were following those steps, which was not helpful in developing skills to do the task on hand.

Practical work that had been carried out by teachers was limited effective in getting students to produce the intended phenomenon even though teachers provided detailed instructions sometimes verbally, and at other times in writing. Students often made mistakes in following instructions or they produced the phenomenon after several attempts. Two main factors that influenced students being able to do what the teacher wanted them to do were, the time allocated for the task, and the strategies that teachers used to deliver the instruction. Firstly, it 
was observed that teachers allocated only a short time to deliver the instruction and students had more time to engage with the materials to produce the phenomenon. Secondly, some teachers delegated the responsibility to deliver the instructions to the group representatives. It seemed that most of the group representatives did not explain the procedure to other group members clearly. This was because either they did not understand the instruction themselves or were not able to explain them to the group.

Students seldom had the opportunity to discuss why they should conduct practical work. There was limited evidence to show that teachers and students discussed or talked about the rationale for following the given procedure. Often students tended to ask peers or teachers questions about the procedure to be followed instead of referring to the written instruction. Most students were unable to articulate why they followed the suggested steps. After the teachers delivered the instructions students appeared to immediately embark on conducting practical work rather than taking time to consider the method and the reasons for doing it. They tended to get practical work done as quickly as possible rather than being thoughtful about the method they were following, what data they were collecting and why. There was no evidence of students being thoughtful about what they were learning through engaging in the practical work or what the teacher may have wanted them to learn. Secondly, teachers did not devote time in the pre-practical activity for students to think of the importance of using the materials or producing the intended phenomenon.

10.5 Research Question 4: To what extent were practical work tasks effective in helping students to learn what the science teachers intended?

i. Teacher expectation of learning through practical work was limited to low-level following of procedures, rather than to develop procedural knowledge and it appears even that this was not achieved by most students.

ii. Teachers often expected that students would do the practical work and learn the science idea they wanted students to learn, but this did not often happen during practical work.

iii. The post practical activity teacher-led discussion, was commonly used to 'check' that student had 'learnt' the science idea or to give them the 'right' idea. 
iv. Teachers did not expect development of procedural or conceptual understanding and there was little evidence to suggest that students understood why they were following the particular procedure and what the science ideas they had been told meant.

The practical work that had been carried out promoted surface learning. It encouraged the development of procedural knowledge (knowing how to follow the steps) rather than procedural understanding. It was unclear whether the teachers wanted students to develop conceptual understanding as most teaching was focused on students conducting practical work and learning the correct answers to questions. If the teachers intended students to produce and observe a phenomenon to confirm a fact they wanted the students to learn, this was achieved by some students. It seemed that, teachers tended to state the scientific ideas at the end of practical lessons based on the results of practical work. Teachers also did not allocate time to scaffold conceptual understanding. Students' inability to explain the scientific concepts may have been influenced by students' understanding of the terminology that teachers used to explain the scientific concepts. The unfamiliar scientific terminology might be the reasons why students were not able to explain the scientific ideas as intended by teachers.

\subsection{The implications}

It seemed that the findings of the study may have the implications for teacher practice in the participating case study schools and education policy.

\subsubsection{The implications for teacher practice}

The findings of the study showed that practical work as implemented in the participating case study schools may have the following implications on teacher practice:

i. Participating Malaysian form two students may be developing a narrow view of practical work and in particular science investigation. Their experience is likely to lead to the understanding that practical work in science is about following a set procedure to arrive at a known conclusion.

ii. They may perceive practical work as merely a hands-on activity that involves manipulations of objects and materials to arrive at the known conclusion. 
iii. Form two students are not experiencing authentic science investigation as they appeared not to have the opportunity to do so.

iv. Students may believe that there is only one way to investigate in science as they are not experiencing the many ways in which scientists investigate.

v. Students may be able to make observations and state results but they probably are not able to plan, carry out an investigation, critique each other's results and draw evidence based conclusions.

vi. The recipe practical these students are experiencing appears to be at a lower level of inquiry compared to the fair testing type of investigation, which is not ideal but commonly practised internationally.

vii. At best, students may be developing procedural and conceptual knowledge rather than procedural and conceptual understanding. The students may know how to carry out practical work but students' understanding about the principle behind it is questionable.

viii. The text books and experiment books that are used as support material provide tasks that are mostly recall of facts and even the questions called "analysis questions" do not require analysis. The continued use of these books as support material is constraining students' opportunity to be critical and thoughtful learners.

ix. Although the curriculum promotes student-centred pedagogies and is underpinned by constructivist ideas of learning, the implemented curriculum does not appear to achieve this.

$\mathrm{x}$. English as a language of instruction appears to be a barrier to science learning for most students. Students may not be able to understand a challenge to know if the students are not able to understand the science ideas because of the language in which it is being communicated.

\subsubsection{Implications for policy}

There are two major implications that arise from the findings for science education policy for the lower secondary school level: 
i. There appears to be a mismatch between the mandated curriculum and the implemented curriculum experienced by students.

ii. The assessment policies appear to be driving the teaching and learning of science through practical work in schools.

\subsection{The recommendations}

There are a few recommendations for teacher practice and policy makers in improving teaching science particularly through practical work.

\subsubsection{The recommendations for teacher practice}

i. Generally, teachers need to raise their expectations of student learning through practical work.

ii. Teachers should aim to teach science through practical work so that students develop both procedural and conceptual understanding. To achieve this teacher thinking has to move from hands-on to a more minds-on approach to learning.

iii. Even with very large classes, students need to be given the opportunity to talk with each other and construct their developing understandings.

iv. The focus needs to shift from preparing for examinations through rote learning, to learning science concepts, skills and how science works.

\subsubsection{Recommendations for policy}

The most significant change needed in policy is to consider how much science do students in form two need to learn. The greatest pressure on teachers is the amount of content that needs to be covered and that they have to prepare students for examination. At the lower secondary level we need to teach science for understanding science concepts, development of skills and positive attitudes and how science works. This is unlikely to happen if the focus is on "covering content" rather than "uncovering" what science has to offer. The recommendation therefore is to carefully consider reducing the syllabus.

Teachers need appropriate professional development to raise their own content knowledge and understanding about the nature of science and science investigation if the intention is to encourage students to carry on with science at the upper secondary school level. 
Pre-service teachers in a science education programme should be given opportunities to experience different types of practical work. It may change the ways teachers' view practical work and the approach to conducting practical work. Teachers should not only be concerned about managing students while they are conducting practical work but also should engage students in the thinking behind the practical work in which they have been involved. They also should be shown how they could scaffold students' thinking while they conduct practical work.

\subsection{Future research}

Case studies have their limitations, this research has only looked at a small number of case. The findings of the case study provide an insight into teachers views of practical work and their practices. It also examines the effectiveness of 'recipe' practical work in engaging students with doing and learning from practical work in three different schools in Melaka. The study adds to the understanding about teachers' views of practical work and the effectiveness of a 'recipe' practical work conducted particularly in Malaysia. Further research is needed to investigate whether these findings are common practice in Malaysian lower secondary classrooms.

Further investigation is required to examine whether practical work has impacted on affective outcomes. The affective domains may refer to students' emotions or feelings and positive attitudes towards science. Research on the relationships between the enjoyment in conducting practical work to motivate students to learn science can be conducted. The findings of the study may give insights to teachers or the curriculum developers in identifying factors that may influence student learning through practical work. It may contribute to managing behaviour issues while conducting practical work.

Other than that, further study is required to examine variation in classroom talk as students carry out different types of practical work. A comparison study can be conducted to identify types of questions initiated by teachers and how teachers give feedback on students' answers. Student argumentation during practical work is also worth exploring.

Beyond this, teacher education programmes can be researched to find out what prospective teachers are learning about teaching through practical work. 


\section{References}

Abrahams, I. (2009). Does practical work really motivate? A study of the affective value of practical work in secondary school science. International Journal of Science Education, 31(17), 2335-2353. doi: 10.1080/09500690802342836

Abrahams, I., \& Millar, R. (2008). Does practical work really work? A study of the effectiveness of practical work as a teaching and learning method in school science. International Journal of Science Education, 30(14), 1945-1969. doi: 10.1080/09500690701749305

Abrahams, I., \& Reiss, M. J. (2012). Practical work: Its effectiveness in primary and secondary schools in England. Journal of Research in Science Teaching, 49(8), 1035-1055.

Abrahams, I., \& Saglam, M. (2010). A study of teachers' views on practical work in secondary schools in England and Wales. International Journal of Science Education, 32(6), 753-768.

Aguiar, O. G., Mortimer, E. F., \& Scott, P. (2010). Learning from and responding to students' questions: The authoritative and dialogic tension. Journal of Research in Science Teaching, 47(2), 174-193. doi: 10.1002/tea.20315

Ahtee, M., Juuti, K., Lavonen, J., \& Suomela, L. (2011). Questions asked by primary student teachers about observations of a science demonstration. European Journal of Teacher Education, 34(3), 347-361. doi: 10.1080/02619768.2011.565742

Anderson, C. W., Holland, J. D., \& Palincsar, A. S. (1997). Canonical and sociocultural approaches to research and reform in science education: The story of Juan and his group. The Elementary School Journal, 97(4), 359-383. doi: 10.2307/1002352

Anderson, D. M., \& Moeed, A. (2013). Breaking down the barriers to learning science. In A. Fitzgerald (Ed.), Learning and teaching primary science (pp. 19-38). New York: Cambridge University Press.

Anderson, L. W., Krathwohl, D. R., Airasian, P. W., Cruikshank, K. A., Mayer, R. E., Pintrich, P. R., . . . Wittrock, M. C. (Eds.). (2001). A taxonomy for learning, teaching, and assessing: A revision of Bloom's taxonomy of educational objectives. New York: Longman. 
Atan, R. M., \& Noordin, S. (2008). Hubungan antara amalan kerja amali dengan pencapaian pelajar tingkatan empat dalam tajuk daya. Paper presented at the Seminar Kebangsaan Pendidikan Sains \& Matematik 2008, Universiti Teknologi Malaysia.

Atkin, J. M., \& Black, P. (2007). History of science curriculum reform in the United States and the United Kingdom. In S. K. Abell \& N. G. Lederman (Eds.), Handbook of research on science education (pp. 782-806). New Jersey: Lawrence Erlbaum.

Baillie, C., \& Hazel, E. (2003). Teaching materials laboratory classes. Liverpool: The UK Centre for Materials Education.

Baird, J. R., \& Northfield, J. R. (1992). Learning from the PEEL experience. Melbourne, Australia: Monash University Printing.

Ball, D. L. (2000). Bridging practices. Intertwining content and pedagogy in teaching and learning to teach. Journal of Teacher Education(51), 241-247.

Baviskar, S. N., Hartle, R. T., \& Whitney, T. (2009). Essential criteria to characterize constructivist teaching: Derived from a review of the literature and applied to five constructivist-teaching method articles. International Journal of Science Education, 31(4), 541-550. doi: 10.1080/09500690701731121

Beatty, J. W., \& Woolnough, B. E. (1982). Practical work in 11-13 science: The context, type, and aims of current practice. British Educational Research Journal, 8(1), 23-30.

Bell, B. (2005). Learning in science: The Waikato research. New York: Routledge Falmer.

Berg, C. A. R., Bergendahl, V. C. B., Lundberg, B., \& Tibell, L. (2003). Benefiting from an open-ended experiment? A comparison of attitudes to, and outcomes of, an expository versus an open-inquiry version of the same experiment. International Journal of Science Education, 25(3), 351-372. doi: 10.1080/09500690210145738

Berg, E. V. D. (2003). Teaching, learning, and quick feedback methods. Australian Science Teaching Journal, 28-34.

Berg, E. v. d. (2009). The PCK of teaching in the laboratory: Turning manipulation of equipment into manipulation of ideas. In O. d. Jong \& L. Halim (Eds.), Teachers' Professional Knowledge in Science and Mathematics Education: Views from Malaysia and Abroad (pp. 85-110). Malaysia Faculty of Education, Universiti Kebangsaan Malaysia. 
Berry, A., Mulhall, P., Gunstone, R., \& Loughran, J. (1999). Helping students learning from laboratory work. Australian Science Teachers Journal, 45(1), 27-32.

Bloom, B. S., Engelhart, M. D., Furst, E. J., Hill, W. H., \& Krathwohl, D. R. (1956). Taxonomy of educational objectives: The classification of educational goals. Handbook 1: Cognitive domain. New York: David McKay.

Brooks, J., \& Brooks, M. (1999). In search of understanding: The case for constructivist classrooms (Vol. America): Valerie Sprague.

Bryman, A. (1988). Quantity and quality in social research. London: Routledge.

Burrell, G., \& Morgan, G. (1979). Sociological paradigms and organizational analysis. London: Heinemann.

Bybee, R. (2000). Teaching Science as Inquiry. In J. Minstrell \& E. H. v. Zee (Eds.), Inquiry into inquiry learning and teaching in science (pp. 20-46). Washington DC.: American Association for the Advancement of Science.

Cazden, C. B. (1988). Classroom discourse: The language of teaching and learning. Portsmouth, $\mathrm{NH}$ : Heinemann.

Chapin, S., O'Connor, C., \& Anderson, N. (2003). Classroom discussions: Using math talk to help students learn. Sausalito, CA: Math Solutions Publications.

Chin, C. (2006). Classroom Interaction in Science: Teacher questioning and feedback to students' responses. International Journal of Science Education, 28(11), 1315-1346. doi: 10.1080/09500690600621100

Chin, C. (2007). Teacher questioning in science classrooms: Approaches that stimulate productive thinking. Journal of Research in Science Teaching, 44(6), 815-843. doi: 10.1002/tea.20171

Chin, C., \& Brown, D. E. (2000). Learning in science: A comparison of deep and surface approaches. Journal of Research in Science Teaching, 37(2), 109-138. doi: 10.1002/(sici)1098-2736(200002)37:2<109::aaid-tea3>3.0.co;2-7

Chin, C., Goh, N. K., Chia, L. S., Lee, K. W. L., \& Soh, K. C. (1994). Pre-service teachers' use of problem solving in primary science. Research in Science Education, 24, 41-50. 
Chin, C., \& Kayalvizhi, G. (2005). What do pupils think of open science investigations? A study of Singaporean primary 6 pupils. Educational Research, 47(1), 107 - 126. doi: $10.1080 / 0013188042000337596$

Chin, C., \& Langsford, A. (2004). Questioning students in ways that encourage thinking. Teaching Science, 50(4), 16-21.

Christensen, C., \& McRobbie, D. C. (1994). Group interactions in science practical work. Research in Science Education, 24(1), 51-59.

Clandinin, D. J., \& Connelly, F. M. (1990). Narrative inquiry: Experience and story in qualitative research. San Francisco: Jossey-Bass Publishers.

Cobb, P., Wood, T., Yackel, E., Nicholls, J., Grayson, W., Trigatti, B., \& Perlwitz, M. (1991). Assessment of a problem-centered second-grade mathematics project. Journal for Research in Mathematics Education, 22(1), 3-29. doi: 10.2307/749551

Cobern, W. W. (1993). Contextual constructivism: The impact of culture on the learning and teaching of science Retrieved September 16, 2013, from http://scholarworks.wmich.edu/science slcsp/11/?utm_source=scholarworks.wmich.e du\%2Fscience_slcsp\%2F11\&utm_medium=PDF\&utm_campaign=PDFCoverPages

Cohen, E. G. (1994). Restructuring the classroom: Conditions for productive small groups. Review of Educational Research, 64(1), 1-35. doi: 10.2307/1170744

Cohen, L., Manion, L., \& Morrison, K. (2007). Research method in education. London: Routledge.

Coles, A., \& McGrath, J. (2010). Your education research project handbook. Edinburgh: Longman.

Crawford, T. (2005). What counts as knowing: Constructing a communicative repertoire for student demonstration of knowledge in science. Journal of Research in Science Teaching, 42(2), 139-165. doi: 10.1002/tea.20047

Creswell, J. W. (2008). Educational research: Planning, conducting, and evaluating quantitative and qualitative research (3rd ed.). New Jersey: Pearson Prentice Hall.

Creswell, J. W. (2009). Research design: Qualitative, quantitative and mixed methods approaches (3rd ed.). California: SAGE Publications 
Daniel, E., \& Idris, N. (2007). Malaysian science and mathematics education: Reflection and reinvention. Masalah Pendidikan, 30(2), 65-84.

Daniel, E. G. S. (2005). Paddy fields, cyber cafes and science teachers: Urban and rural primary science teaching in Malaysia. The Eletronic Journal of Literacy Through Science, 4(11), 1-35.

Daud, Z., \& Noordin, S. (2008). Status penglibatan pelajar tingkatan empat sekolah menengah teknik di dearah Johor Bahru dalam aktiviti kerja amali Fizik. Jurnal Pendidikan Universiti Teknologi Malaysia, 13 Oktober 2008(44-57).

Dawson, C. (2000). Upper primary boys' and girls' interests in science: Have they changed since 1980? International Journal of Science Education, 22(6), 557-570.

Denzin, N. K., \& Lincoln, Y. S. (2005). Introduction: The discipline and practice of qualitative research In N. K. Denzin \& Y. S. Lincoln (Eds.), The SAGE handbook of qualitative research (3rd ed., pp. 1-32). Thousand Oaks: SAGE Publications.

Department of Agriculture Fisheries and Forestry. (2012). Keruing Retrieved 2 December, 2012, from http://www.daff.gld.gov.au/29_5297.htm

Devetak, I., Glažar, S. A., \& Vogrinc, J. (2010). The role of qualitative research in science education. Eurasia Journal of Mathematics, Science \& Technology Education, 6(1), 77-84.

Dickson, D., \& Hargie, O. (2006). Questioning. In O. Hargie (Ed.), The handbook of communication skills (pp. 121-145). London: Routledge.

Dillon, J. T. (1985). Using questions to foil discussion. Teaching and Teacher Education, 1(2), 109-121. doi: http://dx.doi.org/10.1016/0742-051X(85)90010-1

Domin, D. S. (1999). A Review of laboratory instruction styles. Journal of Chemical Education, 76(4), 543-547. doi: 10.1021/ed076p543

Domin, D. S. (2007). Students' perceptions of when conceptual development occurs during laboratory instruction. Chemistry Education Research and Practice, 8(2), 140-152. 
Driver, R., Asoko, H., Leach, J., Scott, P., \& Mortimer, E. (1994a). Constructing Scientific Knowledge in the Classroom. Educational Researcher(23), 5-12. doi: 10.3102/0013189X023007005

Driver, R., \& Easley, J. (1978). Pupils and paradigms: A review of literature related to concept development in adolescent science students. Studies in Science Education, 5(1), 6184. doi: 10.1080/03057267808559857

Driver, R., Squires, A., Rushworth, P., \& Wood-Robinson, V. (1994b). Making sense of secondary science: Research into children's ideas. New York: Routledge.

Duit, R., \& Treagust, D. (1998). Learning in science: From behaviourism towards social constructivism and beyond. In B. J. Fraser \& K.G.Tobin (Eds.), International handbook of science education (pp. 3-25). Dordrecht: Kluwer Academic Publishers.

Edinin, R. (2005). Perlaksanaan pendidikan inkuiri penemuan dalam pendidikan sains. (PhD Thesis, Universiti Kebangsaan Malaysia, Bangi, Malaysia).

Edmondson, K., \& Novak, J. D. (1993). The interplay of epistemological views, learning strategies, and attitudes of college students. Journal of Research in Science Teaching, 30(6), 547-559.

Edwards, A. D., \& Westgate, D. P. G. (1994). Investigating classroom talk. London, UK: Falmer Press.

Edwards, D., \& Mercer, N. M. (1987). Common Knowledge: The development of understanding in the classroom.

Eisner, E. W. (2003). Questionable assumptions about schooling. Phi Delta Kappan, 84(9), 648-657.

Elstgeest, J. (1985). The right question at the right time. In H. Wynne (Ed.), Primary science: Taking the plunge (pp. 36-46). Oxford, England: Heinemann.

Entwistle, N. (2005). Learning and studying: Contrasts and influences Retrieved December 14 http://www.newhorizons.org/future/Creating_the_Future/crfut_entwi9stle.html 
Erdogan, I., \& Campbell, T. (2008). Teacher questioning and Interaction patterns in classrooms facilitated with differing levels of constructivist teaching practices. Journal of Science Education, 30(14), 1891-1914.

Fairbrother, R., \& Hackling, M. (1997). Is this the right answer? International Journal of Science Education, 19(8), 887-894.

Fensham, P. J. (1992). Science and technology. In J. P. W. (Ed.), Handbook of reseach on curriculum (pp. 789-829). New York: Macmillan.

Forman, E. A., \& Ansell, E. (2002). Orchestrating the multiple voices and inscriptions of a mathematics classroom. Journal of the Learning Sciences, 11(2-3), 251-274. doi: 10.1080/10508406.2002.9672139

Fradd, S. H., Lee, O., Sutman, F. X., \& Saxton, M. K. (2001). Promoting science literacy with English language learners through instructional materials development: A case study. Bilingual Research Journal, 25(4), 479-501.

Francis, L. J., \& Greer, J. E. (1999). Measuring attitude towards science among secondary school students: the affective domain. Research in Science \& Technological Education, 17(2), 219-226. doi: 10.1080/0263514990170207

Freedman, M. P. (1997). Relationship among laboratory instruction, attitude toward science, and achievement in science knowledge. Journal of Research in Science Teaching, 34(4), 343-357. doi: 10.1002/(sici)1098-2736(199704)34:4<343::aid-tea5>3.0.co;2-r

Gardner, P. L. (1975). Attitudes to science : A Review. Studies in Science Education, 2(1), 141. doi: $10.1080 / 03057267508559818$

Geelan, D. R. (1997). Epistemological anarchy and the many forms of constructivism. Science \& Education, 6(15), 15-28.

Geertz, C. (2001). Thick description: Toward an interpretive theory of culture. Retrieved August 29, 2010, from http://hypergeertz.jku.at/GeertzTexts/Thick_Description.htm

Glaesser, J., Gott, R., Roberts, R., \& Cooper, B. (2009). Underlying success in open-ended investigations in science: Using qualitative comparative analysis to identify necessary and sufficient conditions. Research in Science \& Technological Education, 27(1), 5 30 . 
Glasser, B., \& Strauss, A. (1999). The discovery of grounded theory: Strategies for qualitative research. Hawthorne: Aldine De Gruyter.

Gott, R., \& Duggan, S. (1995). Investigative work in the science curriculum. Buckingham: Open University Press.

Gott, R., \& Duggan, S. (1996). Practical work: Its role in the understanding of evidence in science. International Journal of Science Education, 18(7), 791-806.

Guba, E. G. (1990). The alternative paradigm dialog. In E. G. Guba (Ed.), The paradigm dialog (pp. 17-30). Newbury Park: Sage.

Hand, B., Treagust, D. F., \& Vance, K. (1997). Student perceptions of the social constructivist classroom. Science Education, 81(5), 561-575. doi: 10.1002/(sici)1098237x(199709)81:5<561::aid-sce4>3.0.c0;2-8

Harlen, W. (1999). Purposes and procedures for assessing science process skills. Assessment in Education: Principles, Policy \& Practice, 6(1), 129-144.

Hart, C., Mulhall, P., Berry, A., Loughran, J., \& Gunstone, R. (2000). What is the purpose of this experiment? Or can students learn something from doing experiments? Journal of Research in Science Education, 37(7), 655-675.

Hassard, J. (2005). The art of teaching science: Inquiry and innovation in middle school and high school. Oxford: Oxford University Press.

Hassard, J., \& Dias, M. (2009). The art of teaching science: Inquiry and innovation in middle school and high school (2nd ed.). New York: Routledge.

Hazel, E., \& Baillie, C. (1998). Improving teaching and learning in laboratories. Australia: Higher Education Research and Development Society of Australia.

Herron, M. D. (1971). The Nature of Scientific Enquiry. The School Review, 79(2), 171-212. doi: $10.2307 / 1084259$

Hipkins, R., Bolstad, R., Baker, R., Jones, A., Barker, M., Bell, B., . . Haigh, M. (2002). Curriculum, learning and effective pedagogy: A literature review in science education. University of Waikato, Hamilton, New Zealand: Ministry of Education.

Hitchcock, G., \& Hughes, D. (1995). Research and the teacher (2nd ed.). London: Routledge. 
Hodson, D. (1990). A critical look at practical work in school science. School Science Review, 70(256), 33-40.

Hodson, D. (1996). Laboratory work as scientific method: three decades of confusion and distortion. Journal of Curriculum Studies, 28(2), 115-135. doi: $10.1080 / 0022027980280201$

Hodson, D. (1998). Mini-Special Issue: Taking practical work beyond the laboratory. International Journal of Science Education, 20(6), 629-632. doi: $10.1080 / 0950069980200601$

Hodson, D. (2014). Learning science, learning about science, doing science: Different goals demand different learning methods. International Journal of Science Education, 1-20. doi: 10.1080/09500693.2014.899722

Hofstein, A., \& Kind, P. (2012). Learning in and from science laboratories. In B. J. Fraser, K. Tobin \& C. J. McRobbie (Eds.), Second International Handbook of Science Education (Vol. 24, pp. 189-207): Springer Netherlands.

Hofstein, A., \& Lunetta, V. N. (2004). The laboratory in science education: Foundations for the twenty-first century. Science Education, 88(1), 28-52.

Hume, A., \& Coll, R. (2008). Student experiences of carrying out a practical science investigation under direction. International Journal of Science Education, 30(9), 12011228. doi: 10.1080/09500690701445052

Jimenez-Aleixandre, M. P., \& Diaz de Bustamante, J. (1997). Analysing classroom discourse: Practical work in the biology laboratory. Paper presented at the Annual meeting of American Educational Research Association, Chicago.

Johnson, B., \& Christensen, L. (2008). Educational research: Quantitative, qualitative, and mix method (Vol. 3). Los Angeles: SAGE Publications.

Johnstone, A. H., \& Al-Shuaili, A. (2001). Learning in the laboratory: Some thoughts from the literature. The Higher Education Chemistry Journal of the Royal Society of Chemistry, 5(2), 41-50. doi: 10.1023/A:1008778120803

Kamarudin, N., Halim, L., Osman, K., \& Meerah, T. S. M. (2009). Management of students' involvement in science practical work. Jurnal Pendidikan Malaysia, 34(1), 205-217. 
Kang, N.-H., \& Wallace, C. S. (2004). Secondary science teachers' use of laboratory activities: Linking epistemological beliefs, goals, and practices. Science Teacher Education, 89(1), 140-166.

Kerr, J. F. (1963). Practical work in school science. Leicester: Leicester University Press.

Kheng, Y. T. (2013). Science process skills Form 2. Petaling Jaya: Pearson Malaysia.

Kheng, Y. T., \& Yassin, S. M. (2005). Science process skills Form 2. Petaling Jaya: Pearson Malaysia.

Knorr-Cetina, K. (1999). Epistemic cultures: How the sciences make knowledge. America: Harvard University Press.

Ko, P. Y., \& Marton, F. (2004). Variation and the secret of the virtuoso. In F. Marton \& A. B. M. Tsui (Eds.), Classroom discourse and the space of learning (pp. 43-62). New Jersey: Lawrence Erlbaum Associates.

Koufetta-Menicou, C., \& Scaife, J. (2000). Teachers' questions-Types and significance in science education. School Science Review, 81(296), 79-84.

Kuhn, T. (1962). International encyclopedia of unified science: The structure of scientific revolutions Vol. $2 . \quad$ Retrieved from https://www.Iri.fr/ mbl/Stanford/CS477/papers/Kuhn-SSR-2ndEd.pdf

Lazarowitz, R., \& Tamir, P. (1994). Research on using laboratory instruction in science. In D. L. Gabel (Ed.), Handbook of research on science teaching and learning (pp. 94-130). New York: Macmillan.

Leach, J., \& Scott, P. (2003). Individual and Sociocultural Views of Learning in Science Education. Science \& Education, 12(1), 91-113. doi: 10.1023/a:1022665519862

Lederman, N. G. (2007). Nature of science: Past, present and future. In S. K. A. a. N. G. Lederman (Ed.), In Handbook of research on science education (pp. 31-79). New Jersey: Erlbaum Publishers.

Lederman, N. G., Antink, A., \& Bartos, S. (2014). Nature of science, scientific inquiry, and socioscientific issues arising from genetics: A pathway to developing a scientifically literate citizen. Science \& Education, 23(2), 285-302. 
Lee, K.-W. L., Tan, L.-L., Goh, N.-K., Chia, L.-S., \& Chin, C. (2000). Science teachers and problem solving in elementary schools in Singapore. Research in Science \& Technological Education, 18(1), 113-126.

Lee, M. N. N. (1992). School science curriculum reforms in Malaysia: world influences and national context. International Journal of Science Education, 14(3), 249-263. doi: 10.1080/0950069920140302

Lee, M. N. N. (1999). Education in Malaysia: Towards Vision 2020. School Effectiveness and School Improvement, 10(1), 86-98. doi: 10.1076/sesi.10.1.86.3514

Lembaga Peperiksaan Malaysia. (2004a). Laporan prestasi. Kuala Lumpur: Kementerian Pelajaran Malaysia.

Lembaga Peperiksaan Malaysia. (2004b). Panduan pentaksiran PEKA Fizik. Kuala Lumpur: Kementerian Pelajaran Malaysia.

Lembaga Peperiksaan Malaysia. (2011). Ujian Pencapaian Sekolah Rendah Retrieved March 12 , 2014, from http://web.moe.gov.my/lp/files/upsr/2012/SENARAl\%20MATA\%20PELAJARAN\%20U PSR.pdf

Lemke, J. L. (1990). Talking Science: Language, learning and values. Norwood, JN: Ablex.

Lu, T.-N. (2006). An exploration of senior high school student learning in biology in Taiwan. (PhD Thesis, University of Waikato, Hamilton, New Zealand).

Lunetta, V. N. (1998). The school science laboratory: Historical perspectives and contexts for contemporary teaching. In B. J. Fraser \& K. G. Tobin (Eds.), International Handbook of Science Education (pp. 249-262). Dordrecht: Kluwer Academic Publishers.

Lunetta, V. N., Hofstein, A., \& Clough, M. P. (2007). Learning and teaching in school science laboratory: An analysis of research, theory, and practice. In S. K. Abell \& N. G. Lederman (Eds.), Handbook of Research on Science Education (pp. 393-441). New Jersey: Lawrence Erlbaurn Associates, Inc.

Lynch, P. P., \& Ndyetabura, V. L. (1983). Practical work in schools: An examination of teachers' stated aims and the influence of practical work according to students. Journal of Research in Science Teaching, 20(7), 663-671. doi: 10.1002/tea.3660200707 
Marimuthu, T. (2005). An insight into constructivism and discovery inquiry in the teaching of science by secondary school trainee teachers during practicum Retrieved May 17, 2010, from http://www.ipbl.edu.my/inter/penyelidikan/seminarpapers/2005/thangaveloMPSAH.pdf

Martin, A. M., \& Hand, B. (2009). Factors affecting the implementation of argument in the elementary science classroom: A longitudinal case study. Research in Science Education, 39(1), 17-38.

Marx, R. W., Blumenfeld, P. C., Krajcik, J. S., \& Soloway, E. (1997). Enacting project-based science. The Elementary School Journal, 97(4), 341-358. doi: 10.2307/1002351

Matthews, M. R. (1995). Challenging New Zealand science education. Palmerston North: Dunmore Press.

Matthews, M. R. (2002). Constructivism and science education: A further appraisal. Journal of Science Education and Technology, 11(2), 121-134. doi: 10.1023/a:1014661312550

McNeill, K. L., \& Pimentel, D. S. (2010). Scientific discourse in three urban classrooms: The role of the teacher in engaging high school students in argumentation. Science Education, 94(2), 203-229. doi: 10.1002/sce.20364

Meerah, T. S. M. (1999). Dampak Penyelidikan Pembelajaran Sains terhadap Perubahan Kurikulum. Bangi, Malaysia: Penerbit Universiti Kebangsaan Malaysia.

Mehan, H. (1979). Learning lessons: Social organization in the classroom: Harvard University Press Cambridge, MA.

Merriam, S. B. (2001). The new update on adult learning theory. New directions for adult and continuing education. San Francisco: Jossey-Bass Publishers.

Millar, R. (1998). Rhetoric and reality: What practical work in science education is really for. In J. Wellington (Ed.), Practical work in school science: Which way now? (pp. 16-31). London: Routledge.

Millar, R. (1999). A means to an end: The role of process in science education. In B. E. Woolnough (Ed.), Practical science. Milton Keynes: Open University Press. 
Millar, R. (2001). Teaching and learning science through practical work Retrieved 25th May, 2010, from http://nordlab.emu.dk/pub/pdf/BidragRobinMillar.pdf

Millar, R. (2004). The role of practical work in the teaching and learning of science. Paper presented at the The Meeting of High School Science Laboratories: Role and Vision, Washington, DC.

Millar, R. (2009). Analysing practical activities to assess and improve the effectiveness: The Practical Activity Analysis Inventory (PAAI) Retrieved June 30, 2010, from http://www.york.ac.uk/depts/educ/research/ResearchPaperSeries/index.htm

Millar, R. (2010). Practical work. In J. Osborne \& J. Dillon (Eds.), Good Practice In Science Teaching: What Research Has To Say: What research has to say (pp. 108-134). Berkshire, England: McGraw-Hill International.

Millar, R. (2011). Reviewing the National Curriculum for science: opportunities and challenges. The Curriculum Journal, 22(2), 167-185. doi: 10.1080/09585176.2011.574907

Millar, R., \& Driver, R. (1987). Beyond processes. Studies in Science Education, 14, 33-62.

Millar, R., Le Maréchal, J.-F., \& Tiberghien, A. (1999). Mapping the domain: Varieties of practical work. In J. Leach \& A. Paulsen (Eds.), Practical work in science educationRecent research studies Roskilde/Dordrecht, The Netherlands: Roskilde University Press/Kluwer.

Millar, R., Tiberghien, A., \& Marechal, J.-F. L. (2002). Varieties of labwork: A way of profiling labwork tasks. In D. Psillos \& H. Niedderer (Eds.), Teaching and learning in the science laboratory (pp. 9-20). Dordrecht: Kluwer Academic Publishers.

Ministry of Finance. (1986). Economic report, 1986/1987. Kuala Lumpur, Malaysia: National Printing Department.

Minstrell, J., \& van Zee, E. H. (2000). Inquiring into inquiry learning and teaching in science Retrieved January, 24, 2014, from http://www.aaas.org/report/inquiring-inquirylearning-and-teaching-science

MOE. (2002a). Integrated curriculum for secondary schools curriculum specifications science Form 2. Kuala Lumpur: Curriculum Development Centre, Ministry of Education. 
MOE. (2002b). Integrated curriculum for secondary schools curriculum specifications science Form One. Kuala Lumpur: Curriculum Development Centre.

MOE. (2002c). Integrated curriculum for secondary schools curriculum specifications science Form Three. Kuala Lumpur: Curriculum Development Centre.

MOE. (2003a). Intergrated curriculum for primary schools. Kuala Lumpur: Curriculum Development Centre.

MOE. (2003b). Science syllabus. Kuala Lumpur: Curriculum Development Centre.

MOE. (2006a). The Malaysia Education Blueprint 2006-2010. Putrajaya: Ministry Of Education.

MOE. (2006b). Surat pekeliling bahagian perancangan dan penyelidikan dasar pendidikan Kementerian Pelajaran Malaysia Bil. 1/2006. Retrieved May 21, 2010, from http://www.moe.gov.my/bppdp/mainpage.php?module=MuatTurun

MOE. (2007). The New Zealand curriculum. Wellington: Learning Media.

MOE. (2011). Offical Portal Malaysian Examinations Council Retrieved November 15 2013, from http://www.mpm.edu.my/en/sukatan-pelajaran-stpm-modular

MOE. (2012). The preliminary report of Malaysia education blueprint 2013-2025. Kuala Lumpur: Ministry Of Education Retrieved from http://www.moe.gov.my/userfiles/file/PPP/Preliminary-Blueprint-Eng.pdf.

Moeed, A. (2010). Science investigation in New Zealand secondary schools: Exploring the links between learning, motivation and internal assessment in year 11. (PhD Thesis, Victoria University of Wellington, Wellington, New Zealand).

Moeed, A. (2013). Science investigation that best support student learning: Teachers understanding of science investigation. International Journal of Environmental and Science Education, 8(4), 537-559.

Mohammad, M. (1997). Vision 2020: The way forward. The Journal of The Malaysian Institute of Management, 32(2). Retrieved from http://mgv.mim.edu.my/MMR/9706/frame.htm

Monk, M. (2006). How science works? School Science Review, 88(322), 119-121. 
Morrow, J. (1999). When pupils design experiments. The Science Teacher, 66(9), $44-47$.

Mortimer, E. F. (1998). Multivoicedness and univocality in classroom discourse: an example from theory of matter. International Journal of Science Education, 20(1), 67-82. doi: $10.1080 / 0950069980200105$

Mortimer, E. F., \& Machado, A. H. (2000). Anomalies and conflicts in classroom discourse. Science Education, 84(4), 429-444. doi: 10.1002/1098-237X(200007)84:4<429::AIDSCE1>3.0.CO;2-\#

Mortimer, E. F., \& Scott, P. H. (2003). Meaning-making in secondary science classrooms. Berkshire, England: Open University Press.

Muhammad, M. Y. (1990). Bimbingan akhlak mulia \& nilai-nilai murni. Kuala Lumpur: Jasmin Enterprise.

Newman, D., Griffin, P., \& Cole, M. (1989). The construction zone: Working for cognitive change in school. Cambridge, UK: Cambridge University Press.

Nie, Y., Tan, G., Liau, A., Lau, S., \& Chua, B. (2013). The roles of teacher efficacy in instructional innovation: its predictive relations to constructivist and didactic instruction. Educational Research for Policy and Practice, 12(1), 67-77. doi: 10.1007/s10671-012-9128-y

Niedderer, H., Aufschnaiter, S. v., Tiberghien, A., Buty, C., Haller, K., Hucke, L., .. . Fischer, H. (2002). Talking physics in labwork context: A category based analysis videotapes. In D. Psillos \& H. Niedderer (Eds.), Teaching and learning in science laboratory (pp. 31-40). Dordrecht: Kluwer Academic Publishers.

Nik Kar, N. Z., \& Saleh, S. (2012). The effect of inquiry discovery approach towards student achievement in the subject of chemistry. Asia Pacific Journal of Educators and Education(27), 159-174.

O'Loughlin, M. (1992). Rethinking science education: Beyond Piagetian constructivism towards sociocultural model of teaching and learning. Journal of Research in Science Teaching, 29, 791-820.

Osborne, J., \& Dillon, J. (2010). Good practice in science teaching: What research has to say. Berkshire, England: McGraw-Hill International. 
Osborne, J., Shirley, S., \& Collins, S. (2010). Attitudes towards science: A review of the literature and its implications. UK: King's College London Institute of Education. University of London.

Osborne, R. (1985). Building on children's intuitive ideas. In R. Osborne \& P. Freyberg (Eds.), Learning in science (pp. 41-50). Auckland, New Zealand: Heinemann.

Osborne, R. J., \& Wittrock, M. C. (1983). Learning science: A generative process. Science Education, 67(4), 489-508. doi: 10.1002/sce.3730670406

Osman, K., Iksan, Z. H., \& Halim, L. (2007). Sikap terhadap sains dan sikap saintifik di kalangan pelajar sains. Jurnal Pendidikan Malaysia, 32, 39-60.

Ottander, C., \& Grelsson, G. (2006). Laboratory work: The teachers' perspective. Teachers' views of labwork 40(3), 113-120.

Palincsar, A. S. (1998). Social constructivist perspectives on teaching and learning Annual Review Phychology, 49, 345-375.

Palmer, D. H. (2009). Student interest generated during an inquiry skills lesson. Journal of Research in Science Teaching, 46(2), 147-165.

Parkinson, J., Hendley, D., Tanner, H., \& Stables, A. (1998). Pupils' attitudes to science in Key Stage 3 of the national curriculum: A study of pupils in South Wales. Research in Science \& Technological Education, 16(2), 165-176. doi: 10.1080/0263514980160206

Patton, M. Q. (2002). Qualitative research \& evaluation methods. (3rd ed.). Thousand Oaks: SAGE Publications.

Pekmez, E. S., Johnson, P., \& Gott, R. (2005). Teachers' understanding of the nature and purpose of practical work. Research in Science \& Technological Education, 23(1), 323. doi: $10.1080 / 02635140500068401$

Piburn, M. D., \& Baker, D. R. (1993). If I were the teacher ... qualitative study of attitude toward science. Science Education, 77(4), 393-406. doi: 10.1002/sce.3730770404

Punch, K. F. (2005). Introduction to social research quantitative and qualitative approaches (2nd ed.). Thousand Oaks: SAGE Publications. 
Razali, S. N., Lee, V. M., Lew, T. S., Lim, M. M., Lim, L. F., Siow, H. L., \& Daniel, E. G. (1996). Menilai pencapaian, minat dan daya kreatif pelajar dalam sains. Kuala Lumpur, Malaysia: Faculty of Education, University of Malaya.

Richardson, L. (2003a). Writing: A method of inquiry. In Y. S. Lincoln \& N. K. Denzin (Eds.), Turning point in qualitative research: Tying knots in a handkerchief (pp. 379-398). Oxford. UK: Altamira Press.

Richardson, V. (2003b). Constructivist pedagogy. Teacher College Record, 105(9), 16231640.

Roberts, R. (2001). Procedural understanding in biology: the 'thinking behind the doing'. Journal of Biological Education, 35(3), 113-117. doi: 10.1080/00219266.2001.9655758

Roberts, R., \& Gott, R. (2004). A written test for procedural understanding: A way forward for assessment in the UK science curriculum? Research in Science \& Technological Education, 22(1), 5 - 21.

Roberts, R., \& Gott, R. (2006). Assessment of performance in practical science and pupil attributes. Assessment in Education, 13(1), 45-67.

Roberts, R., Gott, R., \& Glaesser, J. (2009). Students' approaches to open-ended science investigation: The importance of substantive and procedural understanding. Research Papers in Education, 25(4), 377-407. doi: 10.1080/02671520902980680

Roberts, R., Gott, R., \& Glaesser, J. (2010). Students' approaches to open-ended science investigation: The importance of substantive and procedural understanding. Research Papers in Education, 25(4), 377-407. doi: 10.1080/02671520902980680

Roth, W.-M. (1996). Teacher questioning in an open-inquiry learning environment: Interactions of context, content, and student responses. Journal of Research in Science Teaching, 33(7), 709-736. doi: 10.1002/(SICI)1098-2736(199609)33:7<709::AIDTEA2>3.0.CO;2-R

Rowe, M. B. (1986). Wait time: Slowing down may be a way of speeding up! Journal of Teacher Education, 37(1), 43-50. doi: 10.1177/002248718603700110

Ryder, J., Leach, J., \& Driver, R. (1999). Undergraduate science students' images of science. Journal of Research in Science Teaching, 36(2), 201-219. doi: 10.1002/(SICI)10982736(199902)36:2<201::AID-TEA6>3.0.CO;2-H 
Schwab, J. J. (1962). The teaching of science as enquiry. In J. J. Schwab \& P. F. Brandwein (Eds.), The teaching of science. Cambridge, MA: Harvard University Press.

Schwandt, T. A. (2007). The sage dictionary of qualitative inquiry (3rd ed.). Los Angeles: SAGE publications.

Scott, P. (1998). Teacher talk and meaning making in science classrooms: a Vygotskian analysis and review. Studies in Science Education, 32(1), 45-80. doi: $10.1080 / 03057269808560127$

Seth, S. S., T., \& Ismail, O. (1993). Report of Research on Process-based Learning in Malaysian Primary School. Penang: RECSAM.

Shulman, L. S. (1986). Those who understand: Knowledge growth in teaching. Educational Researcher, 15(2), 4-14. doi: 10.2307/1175860

Sinclair, J. M., \& Coulthard, R. M. (1975). Towards an analysis of discourse: The English used by teachers and pupils. Oxford: Oxford University Press.

Smart, J., \& Marshall, J. (2013). Interactions between classroom discourse, teacher questioning, and student cognitive engagement in middle school science. Journal of Science Teacher Education, 24(2), 249-267. doi: 10.1007/s10972-012-9297-9

Smith, J. P., diSessa, A. A., \& Roschelle, J. (1994). Misconceptions reconceived: A constructivist analysis of knowledge in transition. The journal of the learning sciences, 3(2), 115-163.

Solomon, J. (1987). Social influences on the construction of pupils' understanding of science. Studies in Science Education, 14(1), 63-82. doi: 10.1080/03057268708559939

Solomon, J. (1994). The laboratory comes of age. In R. Levinson (Ed.), Teaching science (pp. 7-21). London: Routledge.

Solomon, J., \& Harrison, K. (1991). Talking about science based issues: Do boys and girls differ? British Educational Research Journal, 17(3), 283-294. doi: 10.1080/0141192910170307

Stake, R. E. (1995). The art of case study research. Thousand Oaks: Sage Publications. 
Stake, R. E. (2006). Multiple case study analysis. New York: The Guilford Press.

Surif, J., Arshad, M. Y., \& Ibrahim, N. H. (2008). Perbandingan proses penyiasatan pelajar Malaysia dan United Kingdom: Kajian merentas usia. Paper presented at the Seminar Penyelidikan Pendidikan Pasca ljazah 2008 Universiti Teknologi Malaysia.

Swain, J., Monk, M., \& Johnson, S. (1999). A comparative study of attitudes to the aims of practical work in science education in Egypt, Korea and the UK. International Journal of Science Education, 21(12), 1311-1323. doi: 10.1080/095006999290093

Tamir, P. (1991). Practical science: The role and reality of practical work in school science In B. E. Woolnough (Ed.), Practical work in school science: An analysis of current practice. Buckingham: Open University Press.

Taridi, N. A. (2007). Perlaksanaan pendekatan inkuiri dalam pengajaran sains secara eksperimen. (PhD Thesis, Universiti Kebangsaan Malaysia, Bangi, Malaysia).

Taylor, P. (1996). Mythmaking and mythbreaking in the mathematics classroom. Educational Studies in Mathematics, 31(1-2), 151-173. doi: 10.1007/bf00143930

The Higher Education Academy. (2011). Deep and surface approaches to learning Retrieved December 16, 2013, from http://exchange.ac.uk/learning-and-teaching-theoryguide/deep-and-surface-approaches-learning.html

Thijs, G. D., \& Bosch, G. M. (1995). Cognitive effects of science experiments focusing on students' preconceptions of force: a comparison of demonstrations and small-group practicals. International Journal of Science Education, 17(3), 311-323. doi: 10.1080/0950069950170304

Thompson, J., \& Soyibo, K. (2002). Effects of lecture, teacher demonstrations, discussion and practical work on 10th graders' attitudes to chemistry and understanding of Electrolysis. Research in Science \& Technological Education, 20(1), 25-37. doi: 10.1080/02635140220130902

Thompson, J. J. (1975). Practical work in sixth form science. Oxford, UK: Department of Educational Studies, University of Oxford.

Thulstrup, E. W. (1999). School laboratories in developing countries: Are they worth the effort and expense? Retrieved 17th May 2010, from http://projects.edte.utwente.nl/smarternet/version2/cabinet/ware/08-Thulstrup.pdf 
Tiberghien, A. (2000). Designing teaching situations in the secondary school. In R. Millar, J. Leach \& J. Osborne (Eds.), Improving science education: The contribution of research (pp. 27-47). Buckingham, UK: Open University Press.

Tiberghien, A., Veillard, L., Maréchal, J.-F. L., Buty, C., \& Millar, R. (2001). An analysis of labwork tasks used in science teaching at upper secondary school and university levels in several European countries. Science Education, 85(5), 483-508. doi: 10.1002/sce. 1020

Tobin, K. (1987). The role of wait time in higher cognitive level learning. Review of Educational Research, 57(1), 69-95. doi: 10.2307/1170357

Tobin, K. (1992). Constructivism and the teaching of college science. Paper presented at the Symposium on teaching and learning science and math, Tallahassee.

Tobin, K. (1993). The practice of constructivism in science education. New Jersey: Lawrence Erlbuam Associates.

Tobin, K. G., Tippins, D. J., \& Gallard, A. (1994). Research on instructional strategies for teaching science. In D. L. Gabel (Ed.), Handbook of research on science teaching and learning. New York: Macmillan.

Tong, C. Y., \& Neo, L. S. (2003). Science Form 2 (Vol. 1). Shah Alam: Media Network SDN. BHD.

Trigwell, K., Prosser, M., \& Waterhouse, F. (1999). Relations between teachers' approaches to teaching and students' approaches to learning. Higher Education, 37(1), 57-70. doi: 10.1023/A:1003548313194

Tsai, C.-C. (1999). "Laboratory exercises help me memorize the scientific truths": A study of eighth graders' scientific epistemological views and learning in laboratory activities. Science Education, 83(6), 654-674. doi: 10.1002/(sici)1098237x(199911)83:6<654::aid-sce2>3.0.co;2-y

Tytler, R. (2007). Austrailan education review: Re-imagining science education, engaging students in science for Australia's future. Camberwell, Victoria: ACER Press.

Ulijn, J. M., \& Verweij, M. J. (2000). Questioning behaviour in monocultural and intercultural technical business negotiations: The Dutch-Spanish connection. Discourse Studies, 2(2), 217-248. doi: 10.1177/1461445600002002004 
van Zee, E., \& Minstrell, J. (1997). Using questioning to guide student thinking. The Journal of the Learning Sciences, 6(2), 227-269. doi: 10.2307/1466870

van Zee, E. H., Iwasyk, M., Kurose, A., Simpson, D., \& Wild, J. (2001). Student and teacher questioning during conversations about science. Journal of Research in Science Teaching, 38, 159-190.

von Glaserfeld, E. (2007). von Glaserfeld. Rotterdam: Sense Publishers.

von Glasersfeld, E. (1989). Cognition, construction of knowledge, and teaching. Synthese, 80(1), 121-140. doi: 10.1007/bf00869951

von Glasersfeld, E. (1991). Questions and answers about radical constructivism. In M. K. Pearsall (Ed.), Scope, sequence, and coordination of secondary school science (Vol. 2, pp. 169-182). Washington, D.C: The National Science Teachers Association.

von Glasersfeld, E. (1993). Questions and answers about radical constructivism. In M. K. Pearsall (Ed.), Scope, sequence, and coordination of secondary school science (Vol. 2, pp. 169-182). Washington, D.C: The National Science Teachers Association.

Watson, R., Goldsworthy, A., \& Wood-Robinson, V. (1999). What is not fair with investigations? School Science Review, 80(292), 101-106.

Watson, R., Goldsworthy, A., \& Wood-Robinson, V. (2002). What is not fair with investigations? Retrieved July 25, 2010, from http://books.google.co.nz/books?hl=en\&lr=\&id=TFKPxGFgzoYC\&oi=fnd\&pg=PA60\&d $\mathrm{q}=$ Watson, +et. $+\mathrm{al},+1999+$ scientific+investigation+in+school\&ots=c18fX6ljCH\&sig=Xh 3BVSCBSrs849edR5FxgKdHIWE\#v=onepage\&q\&f=false

Watson, R., Prieto, T., \& Dillon, J. S. (1995). The effect of practical work on students' understanding of combustion. Journal of Research in Science Teaching, 32(5), 487502. doi: $10.1002 /$ tea. 3660320506

Wellington, J. (1998). Practical work in science: Time for re-appraisal. In J. Wellington (Ed.), Practical work in school science; Which way now? (pp. 3-15). New York: Routledge.

Wellington, J. (2005). Practical work and the affective domain: What do we know, what should we ask, and what is worth exploring further? In S. Alsop (Ed.), Beyond Cartesian dualism. York University, Toronto, Canada: Springer. 
Wellington, J. (2006). Teaching and learning secondary science: Contemporaray issues and practical approaches. New York: Routledge.

Wellington, J., \& Ireson, G. (2008). Science learning, science teaching. London: Routledge.

Wellington, J., \& Osborne, J. (2001). Talk of the classroom: Language interactions between teachers and pupils. In J. Wellington \& J. Osborne (Eds.), Language and literacy in science education (pp. 24-40). Buckingham, UK: Open University Press.

Wheatley, G. H. (1991). Constructivist perspectives on science and mathematics learning. Science Education, 75(1), 9-21. doi: 10.1002/sce.3730750103

Wilkinson, J., \& Ward, M. (1997). A comparative study of students' and their teacher's perceptions of laboratory work in secondary schools. Research in Science Education, 27(4), 599-610.

The Wood Database. (2010) Retrieved 30 November, 2012, from http://www.wooddatabase.com/contact-form/

Woolnough, B. E. (1991). Setting the scene. In B. E. Woolnough (Ed.), Practical Science (pp. 1-10). Philadelphia: Open University Press.

Woolnough, B. E. (1994). Effective Science Teaching. Buckingham: Open University Press.

Woolnough, B. E., \& Allsop, T. (1985). Practical work in science. Cambridge Cambridgeshire and New York: Cambridge University Press.

Wragg, E. C. (1996). Explaining and explanations. In E. Wragg (Ed.), Primary teaching skills (pp. 11-36). London: Routledge.

Yin, R. K. (2003). Applications of case study research (2nd ed.). Thousand Oaks: Sage Publications.

Yin, R. K. (2009). Case study research: Design and methods (4th ed.). Los Angeles: Sage Publications.

Yip, D. Y. (2004). Questioning skills for conceptual change in science instruction. Journal of Biological Education, 38(2), 76-83. doi: 10.1080/00219266.2004.9655905 
Zainudin, U. R. (2008). Keberkesanan pelaksanaan amali terhadap pemahaman konsep asid dan bes di kalangan pelajar kimia Tingkatan 4. (Master's Thesis, Universiti Pendidikan Sultan Idris, Tanjong Malim, Malaysia).

Zin, S. M. S. (2003). Reforming the science and technology curriculum: The smart school initiative in Malaysia. Prospects, 33(1), 39-50. doi: 10.1023/a:1022608230500

Zion, M., Cohen, S., \& Amir, R. (2007). The Spectrum of Dynamic Inquiry Teaching Practices. Research in Science Education, 37(4), 423-447. doi: 10.1007/s11165-006-9034-5 


\title{
Appendices
}

\section{Appendix 5-1: The information sheet for school principal.}

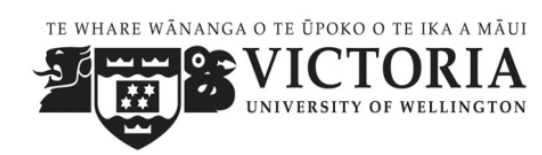

\section{FACULTY OF EDUCATION}

\author{
Title of project: Practical work at the lower secondary school in Malaysia \\ Information sheet for Principal
}

\begin{abstract}
Researcher's Introduction: My name is Siti Shamsiah Binti Sani. I am a PhD student at the School of Education Policy and Implementation, Faculty of Education, Victoria University of Wellington. I would like to invite science teachers and students in your school to participate in my research. I am interested in investigating the implementation of practical work as suggested in the curriculum specification particularly in Form 2 . The participation of your science teachers and students is important to provide information about the effectiveness of practical tasks in promoting learning in science. This research is supervised by Dr. Joanna Higgins and Dr. Azra Moeed. This research has been approved by the Economy Planning Unit, Prime Minister Department in Malaysia and Victoria University of Wellington Faculty of Education Ethics Committee application no. SEPI/2010/114 RM18189.
\end{abstract}

My contact details and those of my doctoral supervisors are:

$\begin{array}{ll}\text { Siti Shamsiah Binti Sani } & \text { Dr Joanna Higgins } \\ \text { Victoria University of } & \text { Victoria University of Wellington } \\ \text { Wellington } & \text { Email: } \\ \text { Email: } & \text { joanna.higgins@vuw.ac.nz } \\ \text { sitishamsiah@gmail.com } & \text { Ph: }+644639576\end{array}$

Dr Azra Moeed

Victoria University of Wellington

Email: azra.moeed@vuw.ac.nz $\mathrm{Ph}:+644639643$

Participation: If you agree to take part in this study, science teachers and students in your school will be involved in a case study. All Form 2 science teachers will be invited participate in an initial interview to seek information about their understanding and practice in conducting practical work as a teaching strategy. The interview will take approximately 30-45 minutes. Then, one science teacher will be invited to be a case study science teacher. This will involve classroom observations, post-lesson follow-up interviews, and a final interview. The post-lesson follow-up interviews will be conducted to clarify questions arise during practical work. The post-lesson follow-up interviews will take approximately 30 minutes during the science teacher's non-contact period or after school. Lastly, the case study teacher will be involved in a final interview approximately $30-45$ minutes to help me to clarify and refine data from interviews and observations.

All Form 2 students in a case study class will be invited to answer a questionnaire. The questionnaire will take about 20 minutes to be completed. The questionnaire will ask your students to say what they do and learn through practical work. The science teacher and students will be involved in classroom observations during practical work. The length of the classroom observation will be approximately 90 minutes. The number of classroom observations is based on the number of practical lessons that the case study science teacher conducts for each learning area. In the classroom observations, students may be asked a fews questions related to the practical task. Then, four students will be recruited to participate in focus group. Two focus group interveiws will be conducted. These interviews will be audio-taped to provide a record for later analysis and will take approximatey 45 minutes. Your student's permission will be sought to access their notes, laboratory reports, and assessment grades.

Privacy and Confidentiality: The identity of your school, students, and science teachers will be kept confidential and anonymous. No personal information that would enable anyone to identify you, your science teachers, students, or school will be used in any report generated from this research. Please note that your school is under no obligation to take part in this study. If you give consent to allow your school, science teachers, and students to participate in this study, please complete the attached consent form and return it to me. You have the right to withdraw that consent at any time during the data collection process which will end in May 2011.

Data Storage and Deletion: Any instruments used during this study such as observation schedules and notes that use to obtain information from students and science teachers, will be kept in a locked cabinet for five years in Faculty of Education, before it will be destroyed. All digital files including digital audio records will be securely stored on a password-protected computer, and hard copies will be kept in secure storage for five years after the conclusion of the research before being deleted or destroyed. 
Reporting/Dissemination: The results of this study will be submitted as part of a PhD thesis. Aspects of this study may also be submitted for publication in research journals or presented at educational conferences. If you are interested in receiving a copy of the report generated from this study you can do so by contacting me.

Ethics:If at any time you have any questions or concerns about the treatment of your science teachers and students during this study, contact Dr. Allison Kirkman who is the Chair of Victoria University of Wellington Human Ethics Committee (ph: +64 463 5676).

Further information: If you have any inquiries regarding the procedure or require further information, do not hesitate to contact me or my supervisors. 
Title of project: Practical work at the lower secondary school in Malaysia

\section{Principal Consent Form}

I have read the information sheet and am aware of the following:

(Please tick the circles to indicate your understanding and/or agreement with each of the following statements).

- I understand that any information students and science teachers provide will be kept confidential and that neither they nor the school will be identified in the research or in any reports on the project or to any party.

- I understand that any information from this project will be destroyed after five years.

- I understand that names of students, science teachers, and school will remain confidential.

- I understand that I will not use the findings of the study for evaluation or promotion purposes.

- I understand that students and teachers can withdraw from the study at any time up till the final point of data collection which will end in May 2011.

- I understand that the research findings will be published and shared with teachers and other interested people.

- I agree to allow students and science teachers at my school to take part in this research project.

- I would like to have a written report of the findings.

Signature of principal:

Name of principal :

Date 


\title{
Appendix 5-2: The information sheet for the science teachers and consent form
}

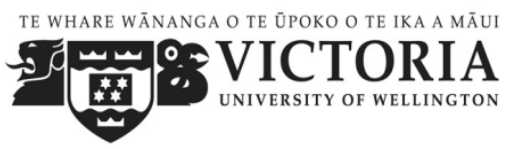

\author{
FACULTY OF EDUCATION
}

\author{
Title of project: Practical work at the lower secondary school in Malaysia \\ Information sheet for science teachers
}

\begin{abstract}
Researcher's Introduction: My name is Siti Shamsiah Binti Sani. I am a PhD student at the School of Education Policy and Implementation, Faculty of Education, Victoria University of Wellington. I would like to invite you to participate in my research. I am interested in investigating the implementation of practical work as suggested in the curriculum specification particularly in Form 2. Your participation is important to provide information about the effectiveness of practical tasks in promoting learning in science. This research is supervised by Dr. Joanna Higgins and Dr. Azra Moeed. This research has been approved by the Economy Planning Unit, Prime Minister Department in Malaysia and Victoria University of Wellington Faculty of Education Ethics Committee application no. SEPI/2010/114 RM18189.
\end{abstract}

My contact details and those of my doctoral supervisors are:

Siti Shamsiah Binti Sani Dr Joanna Higgins

Victoria University of Victoria University of Wellington

Wellington

Email:

Email: joanna.higgins@vuw.ac.nz

sitishamsiah@gmail.com Ph: +644639576

Dr Azra Moeed

Victoria University of Wellington

Email:

azra.moeed@vuw.ac.nz Ph: +644639643

Participation: If you agree to take part in this study, you will be invited to participate in an initial interview to seek information about your understanding and practice in conducting practical work as a teaching strategy. The initial interview may take approximately 30-45 minutes. Then, you will be invited to participate as a case study science teacher that will involve classroom observations, post-lesson follow-up interviews, and a final interview. The postlesson follow-up interviews will be conducted for approximately 30 minutes during non-contact period or after school to clarify any questions arising during practical work. Lastly, you will be involved in a final interview approximately 30 45 minutes to help me to clarify and refine issues that emerge from an initial interview and classroom observations.

You and four Form 2 students will be involved in classroom observations during practical work. The length of the classroom observation will be approximately 90 minutes. The number of classroom observations is depended on the number of practical lesson that you conduct in two learning areas which are: The World through our senses and Nutrition in the theme of Management and Continuity of Life. In the classroom observations, four students in your class will be studied in details. They may be asked a fews questions related to the practical work tasks. Your students will also be involved in focus group interviews. Two focus group interveiws will be conducted taking approximatey 45 minutes. These interviews will be audio taped to provide a record.

Privacy and confidentiality: Your identity will be kept confidential and anonymous throughout this study. No personal information that would enable anyone to identify you will be used in any report generated from this research. Your participation is voluntary and it will not affect your performance evaluation. Please note that you are under no obligation to take part in this study. If you give consent to participate in this study, please complete the attached consent form and return it to me. You have the right to withdraw that consent at any time during the data collection process which will end in May 2011.

Data Storage and Deletion: Any instruments used during this study such as observation schedules and notes that use to obtain information from students and science teachers, will be kept in a locked cabinet for five years in Faculty of Education, before it will be destroyed. All digital files including digital audio records will be securely stored on a password-protected computer, and hard copies will be kept in secure storage for five years after the conclusion of the research before being deleted or destroyed.

Reporting/Dissemination: The results of this study will be submitted as part of a PhD thesis. Aspects of this study may also be submitted for publication in research journals or presented at educational conferences. If you are interested in receiving a copy of the reports generated from this study you can do so by contacting me.

Ethics: If at any time you have any questions or concerns about this study, contact Dr. Allison Kirkman who is the Chair of Victoria University of Wellington Human Ethics Committee (ph: +64 463 5676).

Further information: If you have any inquiries regarding the procedure or require further information, do not hesitate to contact me or my supervisors. 


\section{Title of project: Practical work at the lower secondary school in Malaysia}

\section{Science Teacher Consent Form}

I have read the information sheet and am conscious of the following:

(Please tick the circles to indicate your understanding and/or agreement with each of the following statements).

- I have had the project explained to me and I have had a chance to ask questions.

- I understand that taking part in this project will not affect my performance evaluation.

- I understand that I do not have to take part in the research and that I may withdraw from this project without having to give a reason up until the final point of data collection (May 2011).

- I understand that any information I provide will be kept confidential and that I will not be identified in the research or in any reports on the project or to any party.

- I understand that any information from this project will be destroyed after five years.

- I understand that if I am interviewed the researcher will summarize the key points at the end of my interview.

- I understand that if I am interviewed I will be given a chance to review a transcript of my interview and I will be able to make changes to the wording of my responses if I wish.

- I understand that the research findings will be published and shared with teachers and other interested people.

- I agree to take part in an initial interview.

- I agree to take part in this study as a case study science teacher.

- I understand that if I agree to participate as a case study science teacher, I will not use the results from this study to evaluate my students' performance.

$\mathrm{OR}$

- I do not want to participate in this research.

Signature of teacher:

Name of teacher :

Date 
Appendix 5-3: The information sheet for students and consent form.

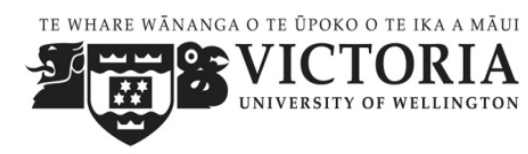

\section{FACULTY OF EDUCATION}

Title of project: Practical work at the lower secondary school in Malaysia

\section{Information sheet for students}

Researcher's Introduction: My name is Siti Shamsiah Binti Sani. I am a PhD student at the School of Education Policy and Implementation, Faculty of Education, Victoria University of Wellington. I would like to invite you to participate in my research. I am interested in investigating the implementation of practical work as suggested in the curriculum specification particularly in Form 2. Your participation is important to provide information about the effectiveness of practical tasks in promoting learning in science. This research is supervised by Dr. Joanna Higgins and Dr. Azra Moeed. This research has been approved by the Economy Planning Unit, Prime Minister Department in Malaysia and Victoria University of Wellington Faculty of Education Ethics Committee application no. SEPI/2010/114 RM18189.

My contact details and those of my doctoral supervisors are:

Siti Shamsiah Binti Sani Dr Joanna Higgins

Victoria University of Victoria University of

Wellington

Wellington

Email:

sitishamsiah@gmail.com

joanna.higgins@vuw.ac.nz

Ph: +644639576

Dr Azra Moeed

Victoria University of

Wellington

Ph: +60136380416

Email:

Participation: If you agree to take part in this study, you will be involved in classroom observations during practical work and focus group interviews. The length of the classroom observation will be approximately 90 minutes. The number of classroom observations will depend on the number of practical lesson you have in this topic. During classroom observations you may be asked a fews questions related to the practical work task. You may be involved in two focus group interviews throughout this study which will be approximatey 45 minutes. The focus group interviews will be conducted during lunch break or after school. These interviews will be audio- taped to provide a record. You may be asked for permission to access your notes, laboratory reports, and assessment grades.

Privacy and Confidentiality: Your identity will be kept confidential and anonymous throughout this study. No personal information that would enable anyone to identify you will be used in any report generated from this research. Your participation is voluntary and it will not affect your achievement in science subject. Please note that you are under no obligation to take part in this study. If you give consent to participate in this study, please complete the attached consent form and return it to me. You have the right to withdraw from this research at any time during the data collection process which will end in May 2011.

Data Storage and Deletion: Any instruments used during this study such as observation schedules and notes that use to obtain information from students and science teachers, will be kept in a locked cabinet for five years in Faculty of Education, before it will be destroyed. All digital files including digital audio records will be securely stored on a password-protected computer, and hard copies will be kept in secure storage for five years after the conclusion of the research before being deleted or destroyed.

Reporting/Dissemination: The results of this study will be submitted as part of a PhD thesis. Aspects of this study may also be submitted for publication in research journals or presented at educational conferences. If you are interested in receiving a copy of the reports generated from this study you can do so by contacting me.

Ethics: If at any time you have any questions or concerns about this study, contact Dr. Allison Kirkman who is the Chair of Victoria University of Wellington Human Ethics Committee (ph: +64 463 5676).

Further information: If you have any inquiries regarding the procedure or require further information, do not hesitate to contact me or my supervisors. 
Title of project: Practical work at the lower secondary school in Malaysia

\section{Student Consent Form}

I have read the information sheet and am aware of the following:

(Please tick the circles to indicate your understanding and/or agreement with each of the following statements).

- I have had the project explained to me and I have had a chance to ask questions.

- I understand that taking part in this project will not affect my achievement in science.

- understand that I do not have to take part in the research and that I may withdraw from this project without having to give a reason up until the final point of data collection (May 2011).

- I understand that any information I provide will be kept confidential and that I will not be identified in the research or in any reports on the project or to any party.

- I understand that any information from this project will be destroyed after five years.

- I understand that if I am interviewed the researcher will summarize the key points at the end of my interview.

- I understand that the research findings will be published and shared with teachers and other interested people.

- I would like to have a written report of the findings.

- I agree to take part as a focus group student.

OR

- I do not want to participate in this research.

\section{Signature of student:}

Name of student

Date 


\section{Appendix 5-4: The approval of ethic committee}

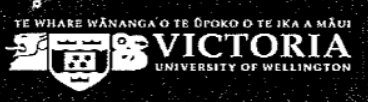

FACULTY OF EDUCATION TE WHĀNAU O AKO PAI

DONALD STREET PO BOX 17310 , Karori 6147 , Wellington, New Zealand

Phone $+64-4-4639500$ Fax $+64-4-4639649$ Website www. vuw ac nz/education

23 December 2010

Siti Sani

PhD Student

Victoria University of Wellington Faculty of Education

$\mathrm{C} /$ - School of Education Policy and Implementation

Donald Street

Wellington

Dear Siti

\section{RE: Ethics application SEPI/2010/114 RM 18189}

I am pleased to advise you that your ethics application 'Practical work at the lower secondary school level in Malaysia', with the required changes, has been approved by the Victoria University of Wellington Faculty of Education Ethics Committee. Please note that the approval for your research to commence is from the date of this letter.

Best wishes for your research.

Yours Sincerely

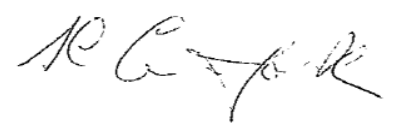

Dr Sue Cornforth

Co-Convener

Victoria University of Wellington Faculty of Education Ethics Committee 


\section{Appendix 5-5: The approval letter from EPU}

UNIT PERANCANG EKONOMI

Economic Planning Unit

JABATAN PERDANA MENTERI

Prime Minister's Department

BLOK B5 \& B6

PUSAT PENTADBIRAN KERAJAAN PERSEKUTUAN

62502 PUTRAJAYA

MALAYSIA

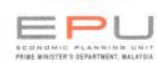

Telefon : 603-8872 3333

Siti Shamsiah San

$$
\begin{array}{r}
\text { Ruj. Tuan: } \\
\text { Your Ref.: } \\
\text { Ruj. Kami: }
\end{array}
$$

Your Ref:: $\quad$ UPE: $40 / 200 / 19 / 2740$

Tarikh:

Tarikh:
Date:

5 January 2011

3/23 Campbell St

Karori

Wellington 6005

Email: sitishamsiah@gmail.com

\section{APPLICATION TO CONDUCT RESEARCH IN MALAYSIA}

With reference to your application, I am pleased to inform you that your application to conduct research in Malaysia has been approved by the Research Promotion and Co-Ordination Committee, Economic Planning Unit, Prime Minister's Department. The details of the approval are as follows:

Researcher's name :

Passport No. / I. C No:

Nationality

Title of Research
SITI SHAMSIAH SANI

810515-04-5078

MALAYSIAN

PRACTICAL WORK AT THE LOWER SECONDARY SCHOOL IN MALAYSIA"

Period of Research Approved: 4 MONTHS

2. Please collect your Research Pass in person from the Economic Planning Unit, Prime Minister's Department, Parcel B, Level 4 Block B5, Federal Government Administrative Centre, 62502 Putrajaya and bring along two (2) passport size photographs. You are also required to comply with the rules and regulations stipulated from time to time by the agencies with which you have dealings in the conduct of your research. 
3. I would like to draw your attention to the undertaking signed by you that you will submit without cost to the Economic Planning Unit the following documents:

a) A brief summary of your research findings on completion of your research and before you leave Malaysia; and

b) Three (3) copies of your final dissertation/publication.

4. Lastly, please submit a copy of your preliminary and final report directly to the State Government where you carried out your research. Thank you.

Yours sincerely,

Wheramk

(MUNIRAH ABD. MANAN)

For Director General,

Economic Planning Unit.

E-mail: munirah@epu.gov.my

Tel: 88882809

Fax: 88883961

ATTENTION

This letter is only to inform you the status of your application and cannot be used as a research pass.

Cc:

Ketua Setiausaha

Bahagian Perancangan dan Penyelidikan Dasar Pendidikan

Kementerian Pelajaran Malaysia

Aras 1-4, Blok E-8

Kompleks Kerajaan Parcel E

Pusat Pentadbiran Kerajaan Persekutuan

62604 Putrajaya. 


\section{Appendix 5-6: The approval letter from the State Education Department.}

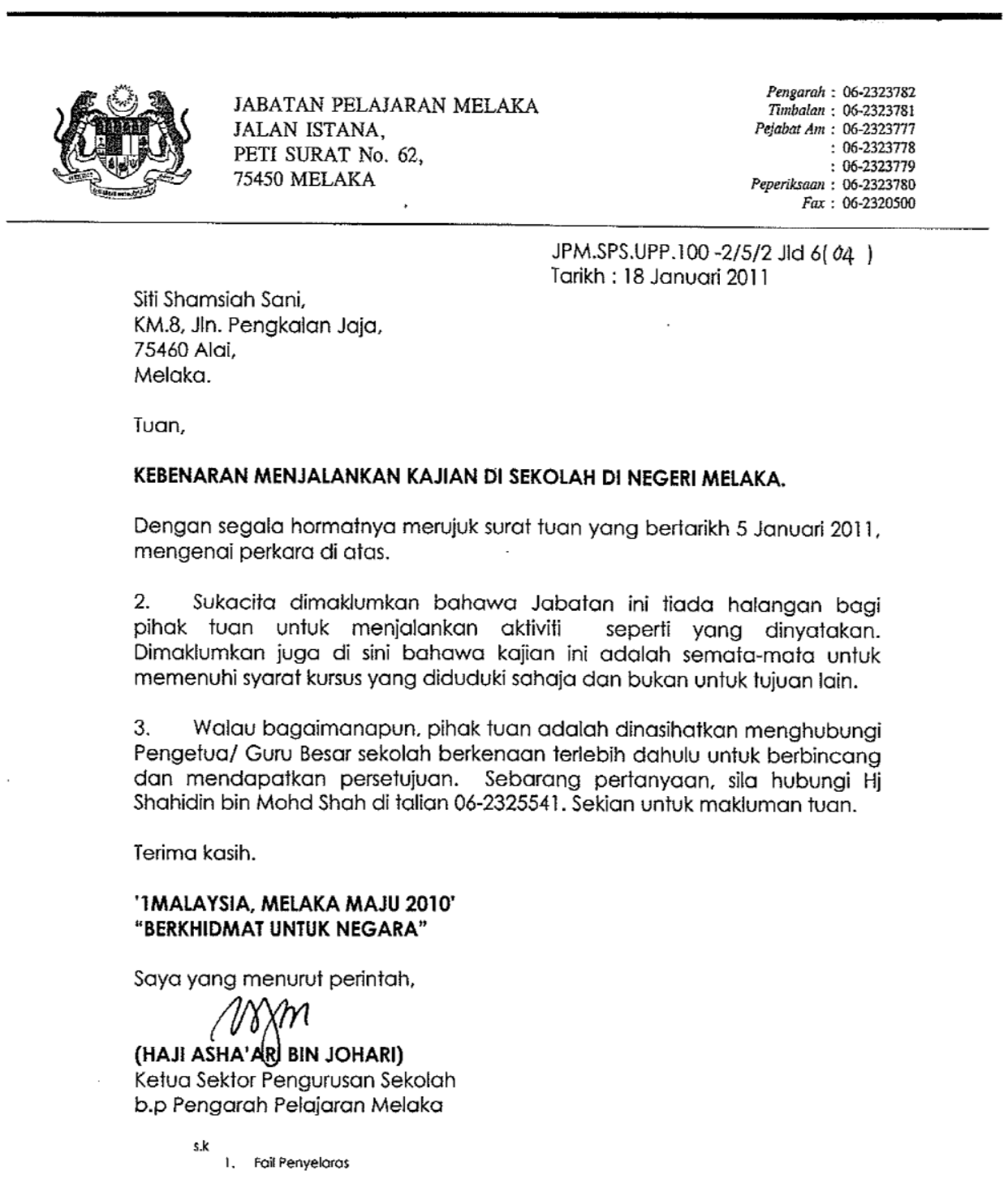

(Sila catatkan rujukan Jabatan ini bila berhubung) 


\title{
Appendix 5-7: Information sheet and consent form for parents
}

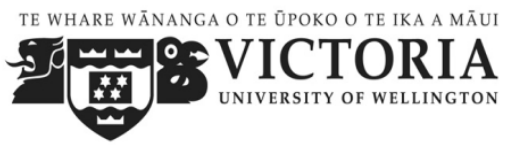

\section{FACULTY OF EDUCATION}

\author{
Title of project: Practical work at the lower secondary school in Malaysia \\ Information sheet for parents and caregivers
}

Researcher's Introduction: My name is Siti Shamsiah Binti Sani. I am a PhD student atthe School of Education Policy and Implementation, Faculty of Education, Victoria University of Wellington I would like to invite your child to participate in my research. I am interested in investigating the implementation of practical work as suggested in the curriculum specification particularly in Form 2. The participation of your child is important to provide information about the effectiveness of practical tasks in promoting learning in science. This research is supervised by Dr. Joanna Higgins and Dr. Azra Moeed. This research has been approved by the Economy Planning Unit, Prime Minister Department in Malaysia and Victoria University of Wellington Faculty of Education Ethics Committee application no. SEPI/2010/114 RM18189.

My contact details and those of my doctoral supervisors are:

Siti Shamsiah Binti Sani
Victoria University of
Wellington
Email:
sitishamsiah@gmail.com
Ph: +60136380416

Siti Shamsiah Binti Sani

Wellington

sitishamsiah@gmail.

\author{
Dr Joanna Higgins \\ Victoria University of \\ Wellington \\ Email: \\ Joanna.higgins@vuw.ac.nz \\ $\mathrm{Ph}:+644639576$
}

\author{
Dr Azra Moeed \\ Victoria University of \\ Wellington \\ Email: \\ Azra.moeed@vuw.ac.nz \\ Ph: +6444639643
}

Participation: Your child has been invited to participate in this about practical work in science at the lower secondary school level. If your child agrees to take part in this study, he/she will be recruited as a focus group student. In the focus group, your child will involve in classroom observations during practical work and focus group interviews. The length of the classroom observation will be approximately 90 minutes. The number of classroom observations will depend on the number of practical work conducted by her/his teachers. During the classroom observations your child may be asked a fews questions related to the practical work task they are engaged in. Your child will may also be invited to participate in focus group interviews. Two focus group interveiws will be conducted. Each of the focus group interviews will take approximatey 45 minutes. These interviews will be audio-taped to provide a record. Your child's permission will be sought to access her/his notes, laboratory reports, and assessment grades.

Privacy and Confidentiality: The identity of your child and school will be kept confidential and anonymous throughout this study. No personal information that would enable anyone to identify your child will be used in any report generated from this research. Your child's participation is voluntary and it will not affect her/his achievement in science subject. Your child is under no obligation to take part in or to complete this study. If your child gives consent to take part in this study he/she would has the right to withdraw at any time during the data collection process which will end in May 2011. If you give consent to allow your child to participate in this study, please complete the attached consent form and return it to your child's school. You have the right to withdraw that consent at any time during the data collection which will end in May 2011.

Data Storage and Deletion: Any instruments used during this study such as observation schedules and notes in order to obtain your child's information, will be kept in a locked cabinet for five years in Faculty of Education, before its been destroyed. All digital files including digital audio records will be securely stored on a password-protected computer, and hard copies will be kept in secure storage for five years after the conclusion of the research before being deleted or destroyed.

Reporting/Dissemination: The results of this study will be submitted as part of a PhD thesis. Aspects of this study may also be submitted for publication in research journals or presented at educational conferences. If you are interested in receiving a copy of the reports generated from this study you can do so by contacting me. Ethics: If at any time you have any questions or concerns about the treatment of your child during this study, contact contact Dr. Allison Kirkman who is the Chair of Victoria University of Wellington Human Ethics Committee (ph: +64 4635676 ).

Further information: If you have any inquiries regarding the procedure or require further information, do not hesitate to contact me or my supervisors. 
Title of project: Practical work at the lower secondary school in Malaysia

Parents and Caregivers Consent Form

I have read the parents and caregivers information sheet and am conscious of the following:

(Please tick the circles to indicate your understanding and/or agreement with each of the following statements).

- I understand that participation in this project will not affect my child's achievement in science.

- I understand that my child does not have to take part in the research and that he/she may withdraw from this project up until the final point of data collection.

- I understand that any information my child provides will be kept confidential and that he or she will not be identified in the research or in any reports on the project or to any party.

- I understand that any information from this project will be destroyed after five years.

- I understand that the names of students and school will remain confidential.

- I understand that the research findings will be published and shared with teachers and other interested people.

- I would like to have a written report of the findings.

- I agree to allow my child to take part as a focus group student.

\section{Or}

Please tick the box if....

I do not want my child to participate in this study

Signature of Parents/Caregivers:

Name of Parents/Caregivers:

Name of Student

Date 
Appendix 5-8: The initial interview protocol.

\section{Section A : Participant background information and Purpose}

\section{Background information}

Name, Age, year of teaching experience at lower secondary school le' preferred pseudonym.

\section{Purpose}

1. What is the value of doing practical work?

2. What do students learn from it?

3. What should students learn from it?

4. Why do you find it is useful?

\section{Section B: Type}

1. What kind of activities do you use and/or prefer?

2. Do the different kinds of practical work have different purposes?

3. When and why do you choose a particular kind?

4. Can you give me some examples?

5. What is the purpose of doing this in this way?

6 . What are the challenges in implementing the practical work?

Adapted from (Pekmez et al., 2005)

\section{Appendix 5-9: Post-lesson follow-up interview (Teacher)}

1. What are the aims of this practical task?

2. Tell me what you think went well in the practical task?

3. Why do you think it worked/ did not work?

4. How do you think this approach helps your students to learn? 


\section{Appendix 5-10: Final interview protocol (Teacher)}

1. What are the aims of conducting practical work?

2. What makes you decide to use that particular practical work activity?

3. What criteria that you consider in choosing practical work?

4. What makes you think that the practical work that you choose may achieve your aims in teaching science?

\section{Appendix 5-11: Focus group interview (Students)}

1. What is the practical task do you remember doing?

2. Can you tell me how you conduct the activity?

3. Why you chose to do it that way rather than others?

4. What did the practical work task show you? 
Appendix 5-12: The observation protocol

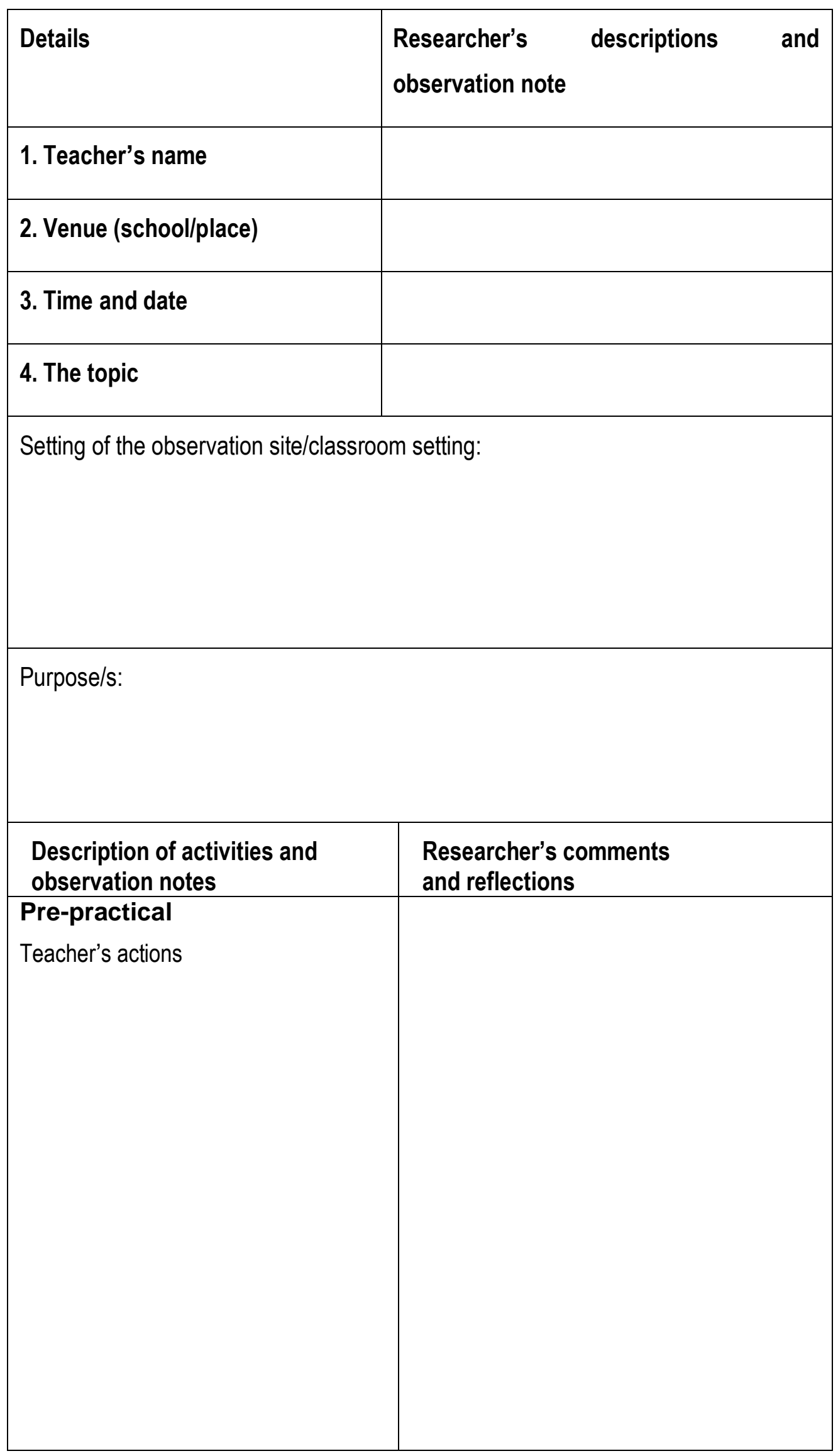




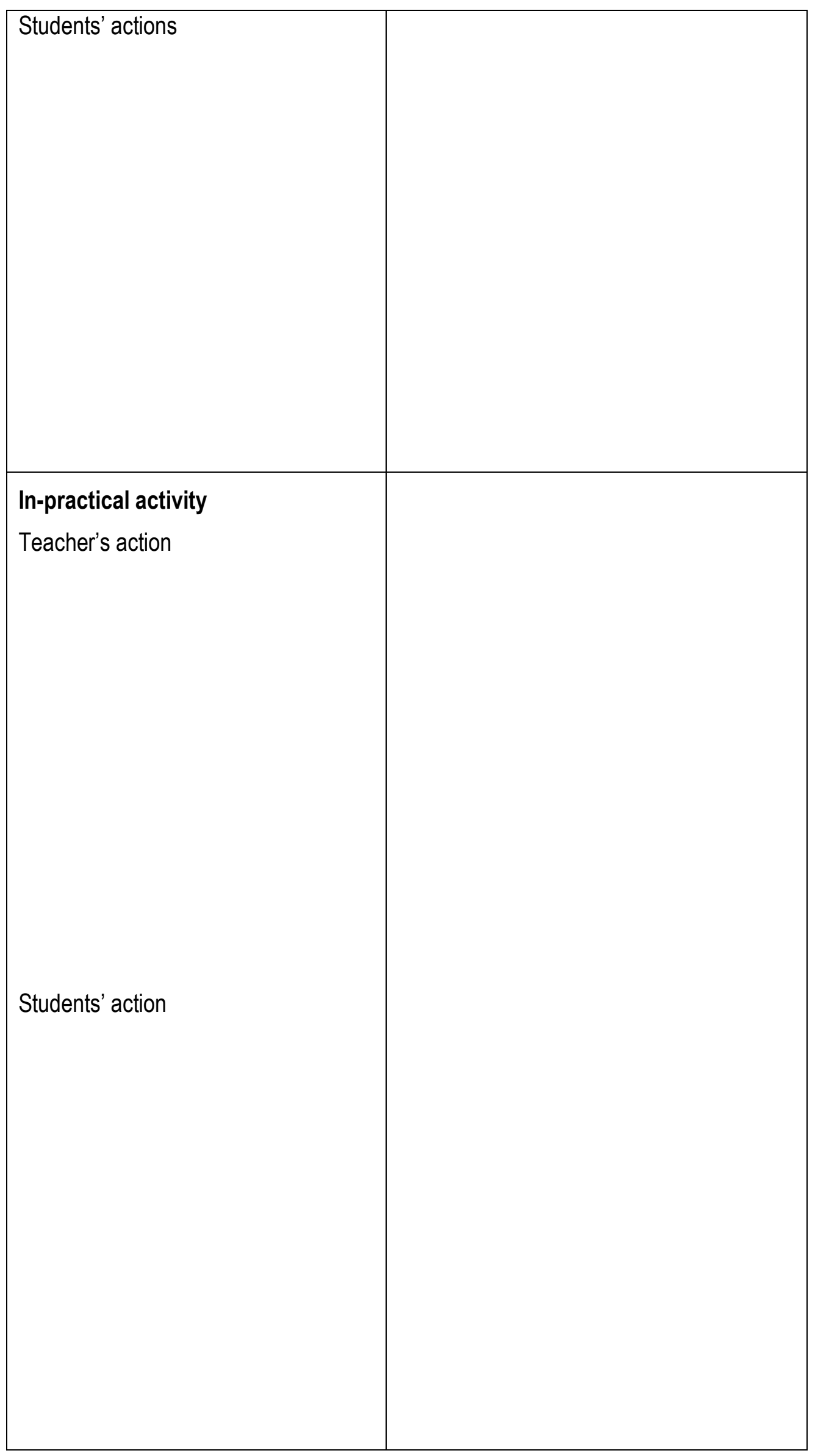




\section{Post-practical}

Teacher's action

Students' action 
Appendix 5-13: Practical Activity Analysis Inventory (Millar et al., 2002)

Lesson:

Teachers:

\section{Aspect B1: The cognitive structure of the task}

\begin{tabular}{|c|c|c|}
\hline \multicolumn{3}{|c|}{$\begin{array}{l}\text { B 1.1: What students are intended to do with objects and observable } \\
\text { (tick one or more boxes) }\end{array}$} \\
\hline \multirow[t]{3}{*}{ Use } & \multicolumn{2}{|l|}{ An observation or measuring instrument } \\
\hline & \multicolumn{2}{|l|}{ A laboratory device or arrangement } \\
\hline & \multicolumn{2}{|l|}{ A laboratory procedure } \\
\hline Present or display & \multicolumn{2}{|l|}{ An object } \\
\hline \multirow[t]{3}{*}{ Make } & \multicolumn{2}{|l|}{ An object } \\
\hline & \multicolumn{2}{|l|}{ A material } \\
\hline & \multicolumn{2}{|l|}{ An event occur } \\
\hline \multirow[t]{4}{*}{ Observe } & \multicolumn{2}{|l|}{ An object } \\
\hline & \multicolumn{2}{|l|}{ A material } \\
\hline & \multicolumn{2}{|l|}{ An event } \\
\hline & \multicolumn{2}{|l|}{ A physical quantity (a variable) } \\
\hline \multicolumn{3}{|c|}{ B 1.2: What students are intended to do with ideas $\quad$ (tick one or more boxes) } \\
\hline \multicolumn{3}{|l|}{ Report observation } \\
\hline \multicolumn{3}{|l|}{ Identify a pattern } \\
\hline \multirow{2}{*}{$\begin{array}{l}\text { Explore relationship } \\
\text { between }\end{array}$} & Objects & \\
\hline & Physical quantities (variables) & \\
\hline \multicolumn{3}{|c|}{ Invent (or discover) a new concept (a physical quantity or an entity) } \\
\hline \multicolumn{3}{|c|}{ Determine the value of a physical quantity which is not measured directly } \\
\hline \multirow{3}{*}{ Test a prediction } & From a guess & \\
\hline & From a law & \\
\hline & $\begin{array}{l}\text { From a theory (or model based on a theoretical } \\
\text { framework) }\end{array}$ & \\
\hline
\end{tabular}




\begin{tabular}{|l|l|l|}
\hline \multirow{3}{*}{$\begin{array}{l}\text { Account for } \\
\text { observations }\end{array}$} & In terms of a given law & \\
\cline { 2 - 3 } & In terms of a given theory (or model) & \\
\cline { 2 - 3 } & By proposing a law & \\
\cline { 2 - 3 } & By proposing a theory (a model) & \\
\hline Choose between two or more given explanations & (tick one box) \\
\hline B 1.3 object-or ideas-driven? & \\
\hline $\begin{array}{l}\text { What the students are intended to do with ideas arises from what they are } \\
\text { intended to do with objects }\end{array}$ & \\
\hline $\begin{array}{l}\text { What the students are intended to do with objects arises from what they are } \\
\text { intended to do with ideas }\end{array}$ & \\
\hline $\begin{array}{l}\text { There is no clear relationship between what the students are intended to do with } \\
\text { objects and with ideas }\end{array}$ & \\
\hline
\end{tabular}

\section{Aspect B 2: Level of nature of student involvement}

\begin{tabular}{|l|l|l|l|}
\hline \multicolumn{1}{|c|}{ B2.1: Degree openness and closure } & $\begin{array}{c}\text { Specified by } \\
\text { teacher }\end{array}$ & $\begin{array}{c}\text { Decided by } \\
\text { discussion }\end{array}$ & Chosen by student \\
\hline Question to be addressed & & & \\
\hline Equipment to be used & & & \\
\hline Procedure to be used & & & \\
\hline $\begin{array}{l}\text { Methods of handling data } \\
\text { collection }\end{array}$ & & & (tick one box) \\
\hline Interpretation of results & & & \\
\hline B 2.2 Nature of students involvement & & \\
\hline Demonstrated by teachers students observed & & \\
\hline Demonstrated by teachers students observe and assist as directed & \\
\hline Carried out by students in small groups & & \\
\hline Carried out by individual students & & & \\
\hline
\end{tabular}




\section{B3 Practical work context}

\begin{tabular}{|c|c|}
\hline B3.1 duration of task & (tick one box) \\
\hline \multicolumn{2}{|l|}{ Very short (less than 20 minutes) } \\
\hline \multicolumn{2}{|c|}{ Short (one science lesson, say up to 80 minutes) } \\
\hline \multicolumn{2}{|l|}{ Medium (2-3 science lessons) } \\
\hline \multicolumn{2}{|l|}{ Long (2 weeks or more) } \\
\hline B3.2 people with whom the students inte & (tick one or more boxes \\
\hline \multicolumn{2}{|c|}{ Other students carrying out the same labwork task } \\
\hline \multicolumn{2}{|c|}{ Other students who have already completed the task } \\
\hline \multicolumn{2}{|l|}{ Teachers } \\
\hline \multicolumn{2}{|l|}{ More advanced students (demostrators, etc) } \\
\hline \multicolumn{2}{|l|}{ Others (technician etc) } \\
\hline B3.4 type of apparatus involved & (tick one box) \\
\hline \multicolumn{2}{|l|}{ Standard laboratory equipment } \\
\hline \multicolumn{2}{|c|}{ Standard laboratory equipment+interface to computer } \\
\hline \multicolumn{2}{|c|}{ Everyday equipment (kitchen scale, domestic materials) } \\
\hline B3.5: Source of data & (tick one box) \\
\hline \multicolumn{2}{|l|}{ Real world: inside laboratory } \\
\hline \multicolumn{2}{|l|}{ Real world: outside laboratory } \\
\hline \multicolumn{2}{|l|}{ Simulation on computer or CD-ROM } \\
\hline \multicolumn{2}{|l|}{ Video recording } \\
\hline \multicolumn{2}{|l|}{ Text } \\
\hline B3.6: Tool available for processing data & (tick one or more boxes) \\
\hline \multicolumn{2}{|l|}{ Manual calculation } \\
\hline Computer & \\
\hline
\end{tabular}

(Adapted from Millar et al., 2002) 


\section{Appendix 7-1 : The worksheet that given by TM}

Aim : :To study the absorption of glucose by using a Visking tube

Materials : $1 \%$ starch solution, glucose solution, Visking tube, distilled water, iodine solution, Benedict solution, thread

Apparatus : boiling tube

Procedure :

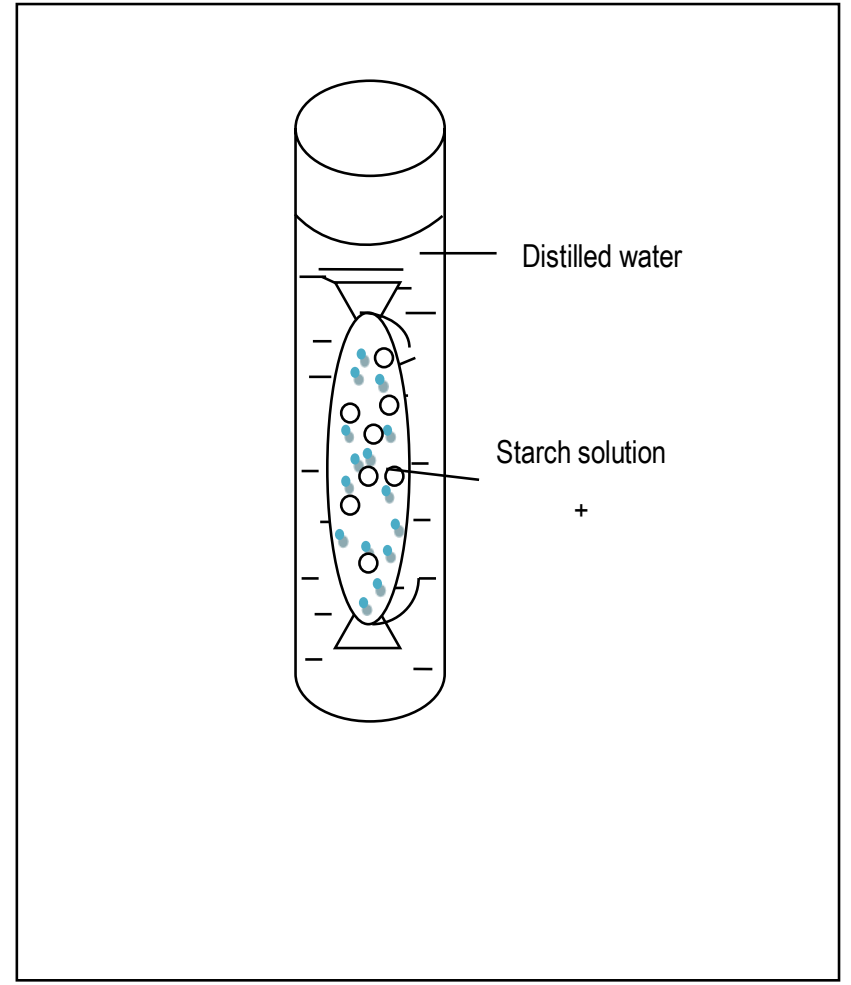

\section{Steps:}

1. The apparatus was set up as shown in the diagram above.

2. The distilled water in the boiling tube was tested for starch and glucose at the beginning of the experiment.

3. The apparatus was left to stand for 30 minutes.

4. The distilled water in the boiling tube was again tested for starch and glucose .

5. The results were recorded.

\section{Observation:}

\begin{tabular}{|l|l|l|}
\hline Type of food in distilled water & $\begin{array}{l}\text { Beginning of the } \\
\text { experiment }\end{array}$ & End of experiment \\
\hline Starch & & \\
\hline Glucose & & \\
\hline
\end{tabular}

Analysis: 
1. Make an analogy between the apparatus or material used in this activity and the parts of our digestive system

\begin{tabular}{|l|l|}
\hline Apparatus / Material & The part in the digestive system \\
\hline Visking tube & \\
\hline Water in the boiling tube & \\
\hline
\end{tabular}

2. Can glucose molecules move through the Visking tube? Give your reason. tube. . fine glucose molecules through the wall of the Visking

3. Can starch molecules move through the Visking tube? Give your reason. wall of the Visking tube. Strach molecules are and go through the

4. What happens to glucose in small intestine?

5. Glucose molecules are through the of the small intestine into the

\section{Conclusion:}

1. Can hypothesis be accepted?

2. What conclusion can be made from this experiment? diffuses through the wall of the bloodstream. into the 


\section{Appendix 7-2: Experiment on the absorption of glucose through the Visking tube (Tong \& Neo, 2003, pp. 51-52)}

Cinesing

1. Why is withecessary for our body to break oown the foed we eat?

2. What is peristalsis?

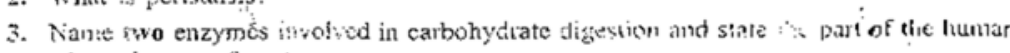
whare they are foum:

4. What are the functions of bilc?

5. What are the enc products of digestion fir cartolydtate.. prolems and fat:? :

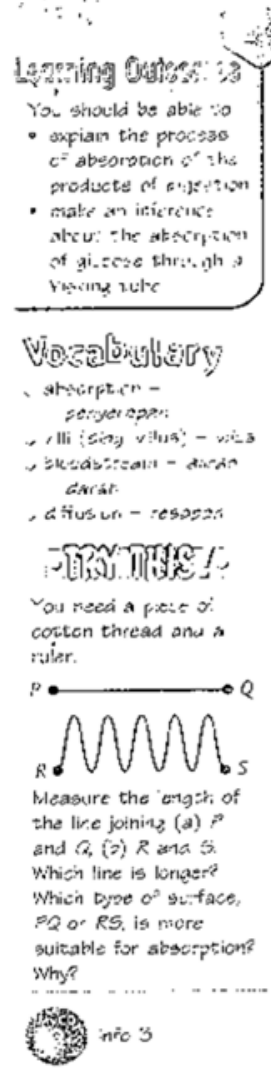

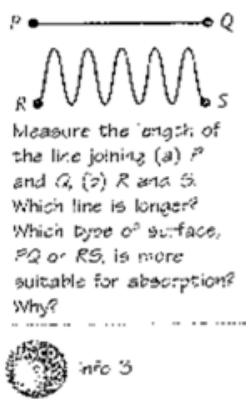$$
\text { Absorption of Digested Food }
$$

Resicts ination.

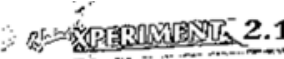

To slow the absorption of glucose through a Vikking tube

oblem How is digested food absorbed?

yputtesis Glucose can diffuse through a Visking tube

anipulated variahles: Types of food (starch and glucose)

espunding variable: Diffusion of foo

xcd variables: $\quad$ Visking tube, time, temperature

tecials: $1 \%$ staich solution, $10 \%$ glucose sotution, Benedict's solution, iop̣ine solution, Visking

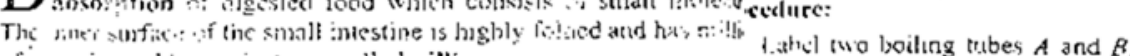

of tily inger-lit. projectrons called villi.

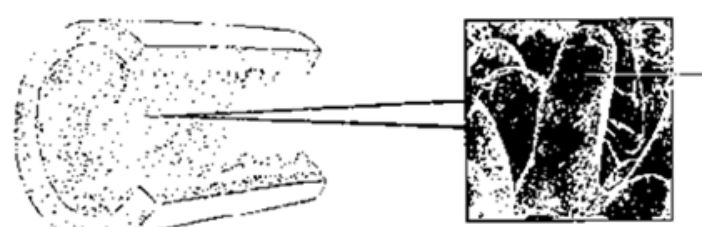

Aigure 2.4 ins

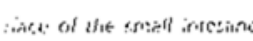

"is.s: two Visking tubes in water to softer (4).

11: itle end of a viskillig tube with cotton

Hitl the Visking tube wills 10 cin' of starch

(intion

II the other end of the Y'iskıng cube wilk

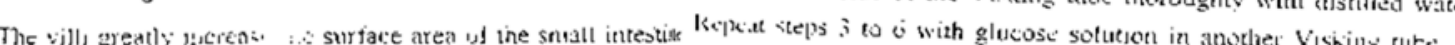

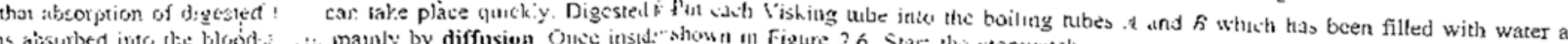
... manly by diffusion One trits.

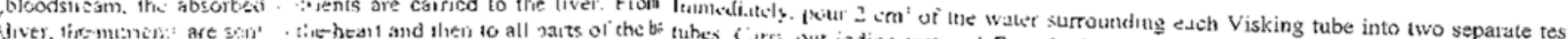

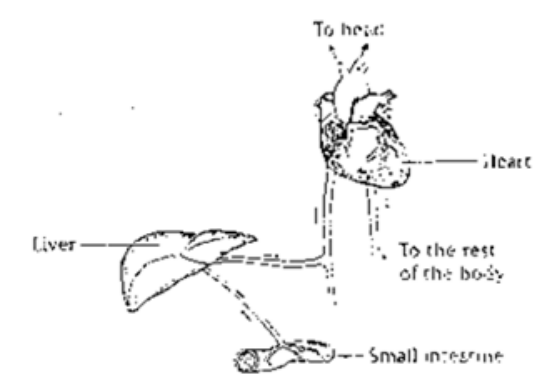

Alst is minutes, :ceseat slep y

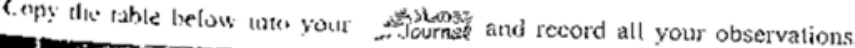

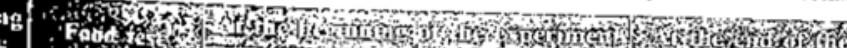

Fodills tes

ikendict's test

1 lixdinte test

Fsemestiet's test

Write a report on this experiment.

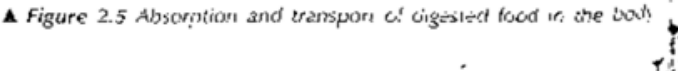


